\title{
Transcranial duplex scanning in parkinsonian disorders : comparison with SPECT
}

Citation for published version (APA):

Vlaar, A. M. (2009). Transcranial duplex scanning in parkinsonian disorders : comparison with SPECT. [Doctoral Thesis, Maastricht University]. Datawyse / Universitaire Pers Maastricht. https://doi.org/10.26481/dis.20090918av

Document status and date:

Published: 01/01/2009

DOI:

10.26481/dis.20090918av

Document Version:

Publisher's PDF, also known as Version of record

\section{Please check the document version of this publication:}

- A submitted manuscript is the version of the article upon submission and before peer-review. There can be important differences between the submitted version and the official published version of record.

People interested in the research are advised to contact the author for the final version of the publication, or visit the DOI to the publisher's website.

- The final author version and the galley proof are versions of the publication after peer review.

- The final published version features the final layout of the paper including the volume, issue and page numbers.

Link to publication

\footnotetext{
General rights rights.

- You may freely distribute the URL identifying the publication in the public portal. please follow below link for the End User Agreement:

www.umlib.nl/taverne-license

Take down policy

If you believe that this document breaches copyright please contact us at:

repository@maastrichtuniversity.nl

providing details and we will investigate your claim.
}

Copyright and moral rights for the publications made accessible in the public portal are retained by the authors and/or other copyright owners and it is a condition of accessing publications that users recognise and abide by the legal requirements associated with these

- Users may download and print one copy of any publication from the public portal for the purpose of private study or research.

- You may not further distribute the material or use it for any profit-making activity or commercial gain

If the publication is distributed under the terms of Article $25 \mathrm{fa}$ of the Dutch Copyright Act, indicated by the "Taverne" license above, 


\section{Transcranial duplex scanning in parkinsonian disorders Comparison with SPECT}


(C) 2009 AMM Vlaar, Maastricht, annemarievlaar@hotmail.com

Cover design: Danker-Jan Oreel

Layout: Tiny Wouters

Production: Datawyse | Universitaire Pers Maastricht

ISBN: 9789052788494

The research that founded this thesis, was carried out at the department of Neurology, Clinical Neurophysiology and Nuclear Medicine of the University hospital Maastricht, PO Box 5800, 6202 AZ Maastricht, The Netherlands.

Studies were funded by grants from the Internationaal Parkinson Fonds" foundation and the department of Neurology of the University hospital Maastricht.

Financial support for the printing of this thesis was kindly provided by:

Van Leersum Fonds, Stichting het Remmert Adriaan Laan fonds, TEVA Pharma Nederland, GE Healthcare, Solvay Pharma BV, UCB Pharma BV, Boehringer Ingelheim BV and Novartis Pharma BV.

All rights are reserved, whether the whole or part of the material is concerned. No part of this publication may be reproduced, stored in a retrieval system, or transmitted in any form or by any means, electronic, mechanical, photocopying, recording, or otherwise, without permission of the copyright owner. 


\title{
Transcranial duplex scanning in parkinsonian disorders Comparison with SPECT
}

\author{
PROEFSCHRIFT
}

ter verkrijging van de graad van doctor aan de Universiteit Maastricht, op gezag van de Rector Magnificus, Prof. mr. G.P.M.F. Mols

volgens het besluit van het College van Decanen in het openbaar te verdedigen op vrijdag 18 september 2009 om 14.00 uur

door

Anna Maria Margaretha Vlaar

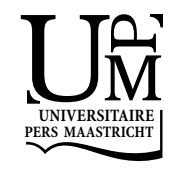




\section{Promotor}

Prof dr WH Mess

\section{Copromotores}

Dr WEJ Weber

Dr SC Tromp

Dr MJPG van Kroonenburgh

\section{Beoordelingscommissie}

Prof dr JSH Vles, voorzitter

Prof dr D Berg, Universiteit van Tübingen, Duitsland

Prof dr K van Laere, Universitair ziekenhuis Gasthuisberg en Katholieke Universiteit Leuven, België

Prof dr HWM Steinbusch

Prof dr FR Verhey 
Dit proefschrift wil ik graag opdragen aan de Zuid-Limburgse patiënten en hun families, die deelgenomen hebben deze studie. 


\section{Contents}

List of Abbreviations

Chapter 1 General introduction

Chapter 2 Meta-analysis of the literature on diagnostic accuracy of SPECT in parkinsonian syndromes

Chapter 3 Diagnostic value of FP-CIT and IBZM SPECT scans in 248 patients with parkinsonian syndromes

Chapter 4 Transcranial duplex scanning in the differential diagnostic of parkinsonian syndromes. A systematic review

Chapter 5 The reliability of transcranial duplex scanning in parkinsonian patients: comparison of different observers and ultrasound systems

Chapter 6 The predictive value of transcranial duplex scanning for the clinical diagnosis in undiagnosed parkinsonian syndromes: comparison with SPECT scans

Chapter 7 Protocol of a prospective study on the diagnostic value of transcranial duplex scanning of the substantia nigra in patients with parkinsonian symptoms 
Appendices A-clinical criteria 143

B - clinimetric scales $\quad 155$

C - practical guideline transcranial duplex $\quad 171$ scanning

D - additional files chapter $2 \quad 183$

E - additional file chapter $7 \quad 197$

$\begin{array}{ll}\text { Samenvatting } & 201\end{array}$

List of publications 213

$\begin{array}{ll}\text { Dankwoord } & 217\end{array}$

$\begin{array}{ll}\text { Curriculum Vitae } & 221\end{array}$ 



\section{List of abbreviations}

\begin{tabular}{|c|c|}
\hline CBD & corticobasal degeneration \\
\hline $\mathrm{Cl}$ & confidence interval \\
\hline DIP & drug induced parkinsonism \\
\hline DLBD & diffuse Lewy body disease \\
\hline ET & essential tremor \\
\hline FP-CIT & ${ }^{123}$ I-ioflupane \\
\hline IBZM & ${ }^{123}$ I-iodobenzamide \\
\hline IPD & idiopathic Parkinson's disease \\
\hline LN & lenticular nucleus \\
\hline MSA & multiple system atrophy \\
\hline NPV & negative predictive value \\
\hline OR & odds ratio \\
\hline PET & positron emission tomography \\
\hline PPV & positive predictive value \\
\hline PSP & progressive supranuclear palsy \\
\hline RN & Raphe nuclei \\
\hline SD & standard deviation \\
\hline SN & substantia nigra \\
\hline SPECT & single photon emission computer tomography \\
\hline TCD & transcranial duplex \\
\hline TRODAT & 99mCT-TRODAT-1 \\
\hline VP & vascular parkinsonism \\
\hline ZvP & ziekte van Parkinson \\
\hline
\end{tabular}


${ }_{10} \mid$ 


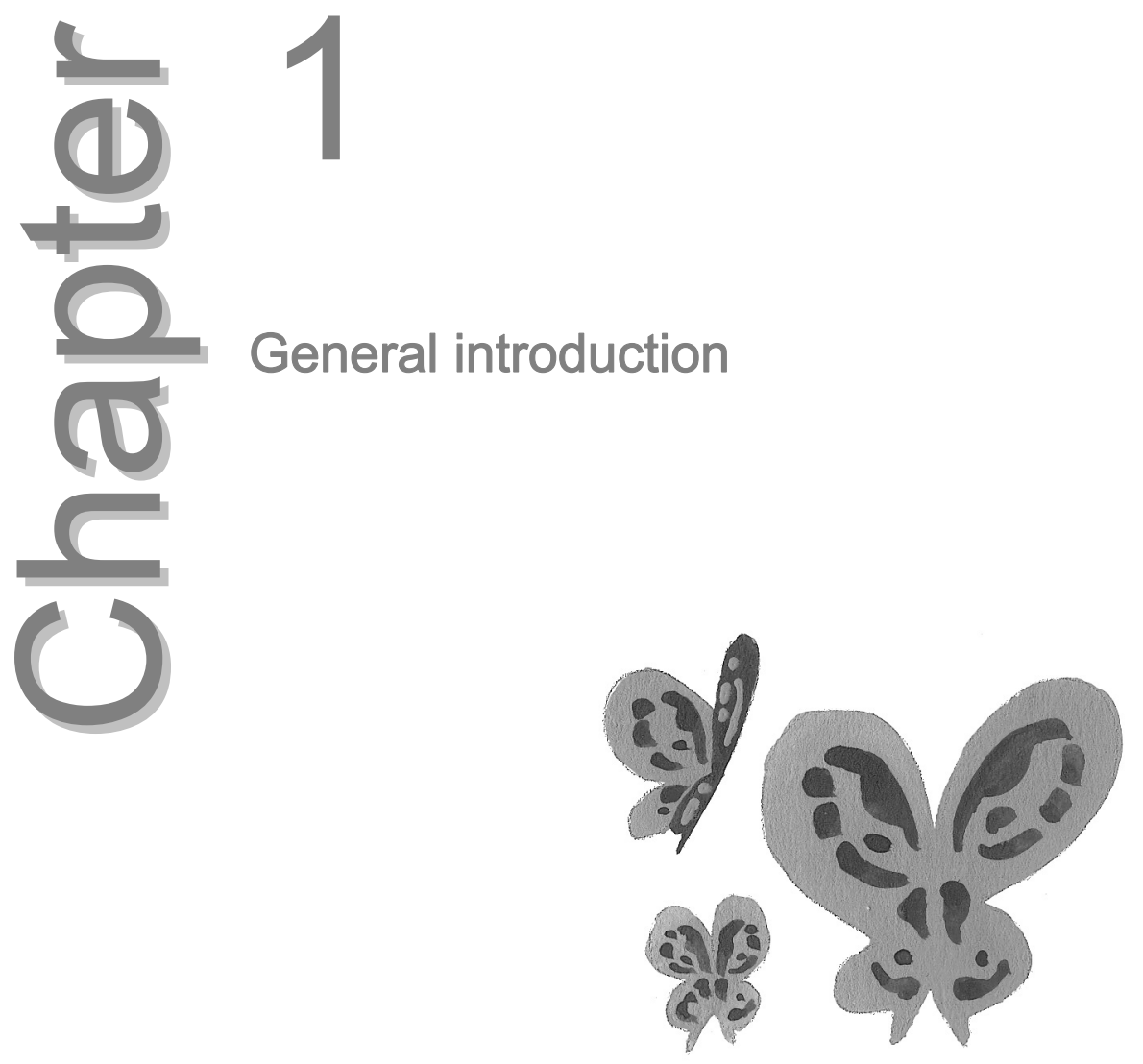




\section{General introduction}

\section{Parkinsonism}

Parkinsonism is a clinical rather than aetiologic entity, since it is associated with several pathological processes that damage the extrapyramidal system. Its many causes are divided into two categories: ${ }^{1}$

1. neurodegenerative parkinsonism:

A. primary Parkinson's disease: idiopathic Parkinson's disease (IPD) and familial Parkinson's disease

B. atypical parkinsonian syndromes (APS) also called parkinson-plus syndromes: multiple system atrophy (MSA), progressive supranuclear palsy (PSP), diffuse Lewy body disease (DLBD) and corticobasal degeneration (CBD)

C. hereditary degenerative diseases (e.g. Wilson's disease, Huntington's disease, Panthothenate kinase associated neurodegeneration)

2. secondary parkinsonism (associated with e.g. infectious agents, drugs, vascular disease, brain neoplasm, hydrocephalus, and psychogenic disorders)

IPD is the most prevalent type of parkinsonism and accounts for approximately $75-80 \%$ of all involved patients. ${ }^{2,3}$ In this introduction, therefore, the main focus is on parkinsonism caused by IPD. The other parkinsonian syndromes are discussed briefly. The clinical criteria of IPD, the APS and essential tremor are mentioned in the appendix A.

\section{Epidemiology of IPD}

The mean age of onset is 60; young onset IPD (onset $<40$ years) accounts for less than $5 \%$ of the cases. In the Netherlands IPD affects about 50.000 people and is therefore the second most common neurodegenerative disorder after Alzheimer's dementia. ${ }^{4}$ The prevalence of IPD in industrialised countries is generally estimated to be $0.3 \%$ within the entire population and approximately $0.5-1 \%$ among persons 65 to 69 years of age, rising to $1-3 \%$ among persons aged 80 years and older. $^{5}$ In comparison, the prevalence of probable Alzheimer's disease is $1-3 \%$ among patients between 65 to 69 year of age, $18 \%$ in those aged 75 to 84 years and up tot $47.2 \%$ in those over 85 years. ${ }^{5,6}$

Reported annual incidence rates of IPD range from 0.04-0.26 per 1000 personyears. The incidence of parkinsonism and IPD increases with age, with incidence rates for IPD increasing from 0.008 per 1000 person-years in the age group 0 to 29 years, 0.3 in subjects aged 55 to 65 years, to 4.4 per 1000 person-years for those aged 85 years and older. ${ }^{7,8}$ In comparison with IPD, the incidence of APS is significantly lower, for instance 0.05 per 1000 person-years for PSP and 0.03 for MSA for the age group 50 to 99 years. ${ }^{8}$ Some studies 
report a higher prevalence of IPD in men than in women with a ratio of up to $2: 1$, although other studies found no significant differences. ${ }^{7,9,10}$ IPD is expected to impose an increasing social and economic burden on societies as population ages.

\section{Aetiology and pathophysiology of IPD}

IPD was first described by James Parkinson in $1817 .^{11}$ Nowadays, almost two hundred years later, the exact cause of IPD is still unknown. The aetiology is probably multi-factorial, with contributions of variable significance from hereditary predisposition, environmental toxins, and ageing.

The main pathological features are the loss of neuromelanin containing dopaminergic neurons of the nigrostriatal pathway, particularly those in the pars compacta of the substantia nigra (SN) and the identification of Lewy bodies. Lewy bodies are inclusions within the cytoplasm of neurons that are composed of $\alpha$-synuclein, as well as other proteins including ubiquitin and neurofilament protein. ${ }^{12,13}$ Post-mortem studies of IPD patients have revealed three other major changes in the SN: 1) evidence of oxidative stress, 2) increased iron levels with reduced ferritin buffering and 3) mitochondrial injury. $^{14}$ Nevertheless, the intracellular cascade of events leading to accumulation of Lewy bodies and the dopaminergic cell death is still unknown.

\section{Clinical signs of IPD}

The classic tetrad consists of resting tremor, cogwheel rigidity, bradykinesia, and postural reflex impairment. ${ }^{3}$ However, early symptoms may be mild and aspecific and make a clinical diagnosis difficult. The onset of symptoms is usually so insidious, that patients can rarely pinpoint when the first symptoms appeared. Disease onset predates the expression of clinical manifestations of IPD, which by 18F-fluorodeoxyglucose with Positron Emission Tomography (PET) has been estimated to be about 4.5 years. By the time patients become symptomatic approximately $60 \%$ of the nigral dopaminergic neurons have been lost and the striatal dopamine content has been reduced by approximately $80 \%$. $^{15}$

Besides the well-known aforementioned motor symptoms, the IPD patient often experiences substantial non-motor symptoms like fatigue, hyposmia, pain, sleep disorders, neuropsychiatric disturbances and cognitive impairment.

\section{Diagnosis of IPD}

During life the diagnosis of IPD is based on clinical criteria (see appendix A). ${ }^{3}$ The main difficulty in the clinical diagnosis of IPD is to distinguish the disease from essential tremor or other parkinsonian syndromes that resemble specific 
features of IPD. The uncertainty of diagnoses based on clinical examination is evident in several studies. ${ }^{16-22}$ For example Meara and colleagues found that only $74 \%$ (298 of 402) of patients, who received anti-parkinsonian drugs, fulfilled the UK Parkinson's Disease Society brain bank clinical diagnostic criteria for IPD: $53 \%$ were diagnosed as having probable IPD, 21\% possible IPD and in $26 \%$ the diagnosis IPD could not be made at all. ${ }^{18}$

Clinical criteria at best lead to a diagnosis of probable IPD, while a definite diagnosis requires post-mortem confirmation. There are a few neuropathological studies which have shown that even in the final stages of the disease, the clinical diagnostic accuracy for IPD varies between $75-90 \%{ }^{16,19-22}$ Therefore, purely on clinical grounds, it can be difficult to differentiate IPD from other parkinsonian syndromes like vascular parkinsonism, drug induced parkinsonism and APS. This is especially true in the early stages of the disease when patients often do not yet fulfil the clinical criteria and physical findings can be subtle. In those cases the best clinical practice is to take time for follow-up to see if re-examining the patient then reveals features that may lead to a probable diagnosis.

\section{Treatment and prognosis of IPD}

Since the mechanisms that cause nigral dopaminergic neurons to degenerate are unknown, and the diagnosis always is made when the degenerative process is considered irreversible, there are no possible curative or preventive therapeutic options. The typical course of IPD is a gradual worsening over a decade or more, corresponding with ongoing neuronal loss. Therapy can exist of supportive treatment, drug treatment and neurosurgical interventions. Examples of supportive treatment are physiotherapy, occupational therapy and speech therapy. The drug treatment is dependent on the phase and severity of the disease. In early IPD most patients will be sufficiently treated with monotherapy of a dopaminergic agent (i.e., levodopa, dopamine receptor agonists, amantadine and MAO-B inhibitors). Of these dopaminergic drugs levodopa has an established role as the most efficacious antiparkinsonian agent, well documented after decades of clinical use. In a later phase of the disease most IPD patients will need a combination of various dopaminergic agents. If IPD is complicated by cognitive impairment, depression or hallucinations/psychosis cholinesterase inhibitors, antidepressive agents or antipsychotic drugs can be indicated, respectively. ${ }^{23}$

If oral therapy fails in advanced PD there are some additional options. For instance, the dopamine receptor agonist apomorfin can be given subcutaneously. ${ }^{24}$ Levodopa can also be given continuously by a tube in the duodenum or a continuous drip placed subcutaneously in selected patients with advanced IPD. ${ }^{25}$ Furthermore, deep brain stimulation of the subthalamic 
nucleus, pallidum, or thalamus by the neurosurgeon can be extremely helpful in carefully selected patients. ${ }^{26,27}$

Although the introduction of symptomatic treatment such as levodopa has prolonged survival, IPD patients still exhibit a higher mortality risk as compared to healthy controls. ${ }^{28}$

\section{Diagnostic tools}

Since the clinical diagnosis of IPD is often made late or even missed there is a clear need for an accurate diagnostic tool, ideally with presymptomatic detection qualities. Such a diagnostic tool could not only help to diagnose and treat patients in the early stages of the disease but also facilitate the development of preventive drugs.

Several diagnostic modalities have been proposed to diagnose IPD: functional imaging with PET or Single Photon Emission Computer Tomography (SPECT), transcranial duplex scanning (TCD), olfactory and neuropsychological tests, biomarkers and DNA tests. ${ }^{29-32}$

Especially neuro-imaging techniques like PET and SPECT scans can facilitate early diagnosis in patients with inconclusive parkinsonian symptoms in specialised settings. ${ }^{33-37}$ PET scans are at least as accurate as SPECT scans. However, the clinical use of PET is limited by the relative short half-life of its radioactive tracers (only hours), its high costs and its sporadic availability (in the Netherlands only 24 of the 140 hospitals) in comparison with SPECT. The PET technique is, therefore, not further discussed in this thesis.

Different radiotracers can be used in SPECT to visualise the nigrostriatal system. Presynaptic tracers are used to visualise the dopamine reuptake transporters, and postsynaptic radiotracers to assess dopamine receptor density. Although widely available, SPECT scans are only performed in a minority of patients suspected of having IPD. This is probably due to the fact that additional diagnostic tests such as SPECT are not part of the criteria to diagnose IPD. ${ }^{3}$ The rationale is an ongoing debate on the diagnostic accuracy of SPECT scans in differentiating IPD from other parkinsonian disorders. Especially its ability to discriminate between the various parkinsonian syndromes in which the dopaminergic system is involved, such as IPD, MSA, PSP and DLBD is under discussion. ${ }^{35}$

In 1995 an alternative method to visualise the alterations in the cerebral dopaminergic pathways has been proposed: transcranial duplex scanning (TCD) of the SN in the brainstem. ${ }^{32}$ The technical aspects of visualising the SN and other brain structures by TCD are explained in the appendix C.

Several publications consistently showed that up to $90 \%$ of IPD patients have an increased echointensity of the $\mathrm{SN}^{38-42}$ In healthy subjects and in patients with essential tremor this hyperechointensity of the $\mathrm{SN}$ is found in only 
$10 \%{ }^{43-46}$ It is noteworthy that healthy subjects with an increased echointensity can potentially be true positives since $60 \%$ of them also have decreased nigrostriatal function on PET scan. These results suggest that TCD as well as PET scans can be helpful in identifying patients potentially at risk to develop IPD. $^{40,43}$ Longitudinal follow-up studies are necessary to see if these asymptomatic subjects will develop IPD in the future.

Since TCD is widely available, less costly than SPECT and more comfortable for the patients its seems to be a promising technique. However, before TCD can be implemented in daily clinical practice it is desirable to investigate its reliability and attributive diagnostic value in comparison with already existing techniques like SPECT scintigraphy.

\section{Scope and aims of the study}

In this thesis we firstly investigated the diagnostic accuracy of SPECT in parkinsonian patients. Secondly, we studied the accuracy of TCD in the differential diagnosis of IPD. Finally, the combination of both techniques in the diagnostic work-up of patients with unclear clinical parkinsonism was assessed. The aim of chapter 2 and 3 was to analyse the accuracy of SPECT in the diagnostic work-up of parkinsonian patients. In chapter 2 we present a metaanalysis of all existing literature on the diagnostic accuracy of both pre- and post-synaptic dopaminergic SPECT imaging in the differential diagnosis of IPD. In chapter 3 we present the results of a study on the diagnostic accuracy of an initial pre-synaptic or post-synaptic SPECT scan in our own clinic. The study included 248 patients with an unclassified parkinsonian syndrome who underwent SPECT imaging between 2001 and 2006. The results of the SPECT imaging were compared with the clinical diagnosis after follow-up.

The aim of chapter 4 and 5 was to explore the diagnostic accuracy of TCD. In chapter 4 the existing literature on the use of TCD in parkinsonian patients is systematically reviewed. In chapter 5 we investigate the inter-observer as well as intra-observer variability of TCD.

The aim of chapter 6 and 7 was to analyse the diagnostic value of TCD in comparison with presynaptic SPECT scans. In chapter 6 we show the results of a study that took place between 2000 and 2006, in which 95 patients with clinical parkinsonism of unclear origin were investigated with TCD and presynaptic dopaminergic SPECT imaging. After a mean follow-up of fourteen months the patients were re-examined by an independent movement disorder specialist, whose clinical diagnosis was compared with the results of the additional tests. In chapter 7 we present the protocol of a prospective trial, which currently is in progress. In this study we will evaluate the diagnostic accuracy of TCD and SPECT, but also of motor tests, cognitive tests and smell 
tests in patients with parkinsonism of unclear origin. We have already enrolled 250 consecutive patients, who were referred to the neurology outpatient clinics of two teaching hospitals, for analysis of clinically unclear parkinsonism. The definitive clinical diagnosis will be made by two independent movement disorder specialists, after a follow-up of two years. The study started in 2006 and the follow-up will be completed in January 2010.

In chapter 8 a summary and implications of the findings presented in this thesis are argued and directions for future research are briefly discussed. 


\section{References}

1. Waters $\mathrm{CH}$. Diagnosis and management of Parkinson's disease. Third edition ed. New York, United States: Professional communications, Inc.; 2002.

2. Koller WC, Montgomery EB. Issues in the early diagnosis of Parkinson's disease. Neurology 1997;49(1 Suppl 1):S10-25.

3. Hughes AJ, Daniel SE, Kilford L, Lees AJ. Accuracy of clinical diagnosis of idiopathic Parkinson's disease: a clinico-pathological study of 100 cases. J Neurol Neurosurg Psychiatry 1992;55:181-4.

4. Hy LX, Keller DM. Prevalence of $A D$ among whites: a summary by levels of severity. Neurology 2000;55:198-204.

5. Tanner CM, Goldman SM. Epidemiology of Parkinson's disease. Neurol Clin 1996;14:317-35.

6. Hebert LE, Scherr PA, Bienias JL, Bennett DA, Evans DA. Alzheimer disease in the US population: prevalence estimates using the 2000 census. Arch Neurol 2003;60:1119-22.

7. de Lau LM, Giesbergen PC, de Rijk MC, Hofman A, Koudstaal PJ, Breteler MM. Incidence of parkinsonism and Parkinson disease in a general population: the Rotterdam Study. Neurology 2004;63:1240-4.

8. Bower JH, Maraganore DM, McDonnell SK, Rocca WA. Incidence and distribution of parkinsonism in Olmsted County, Minnesota, 1976-1990. Neurology 1999;52:1214-20.

9. Mayeux R, Marder K, Cote LJ, Denaro J, Hemenegildo N, Mejia H, Tang MX, Lantigua R, Wilder D, Gurland B, et al. The frequency of idiopathic Parkinson's disease by age, ethnic group, and sex in northern Manhattan, 1988-1993. Am J Epidemiol 1995;142:820-7.

10. Elbaz A, Bower JH, Maraganore DM, McDonnell SK, Peterson BJ, Ahlskog JE, Schaid DJ, Rocca WA. Risk tables for parkinsonism and Parkinson's disease. J Clin Epidemiol 2002;55:25-31.

11. Poewe WH, Wenning GK. The natural history of Parkinson's disease. Neurology 1996;47(6 Suppl 3):S146-52.

12. Price KS, Farley IJ, Hornykiewicz O. Neurochemistry of Parkinson's disease: relation between striatal and limbic dopamine. Adv Biochem Psychopharmacol 1978;19:293-300.

13. Dickson DW. What do we know about the pathology of akinetic rigid syndromes? American Academy of Neurology May 5-11 2001;53rd Annual Meeting Education Program Syllabus.

14. Jenner P, Olanow CW. Understanding cell death in Parkinson's disease. Ann Neurol 1998;44(3 Suppl 1):S72-84.

15. Moeller JR, Eidelberg D. Divergent expression of regional metabolic topographies in Parkinson's disease and normal ageing. Brain 1997;120 ( Pt 12):2197-206.

16. Watanabe H, Saito Y, Terao S, Ando T, Kachi T, Mukai E, Aiba I, Abe Y, Tamakoshi A, Doyu M, Hirayama M, Sobue G. Progression and prognosis in multiple system atrophy: an analysis of 230 Japanese patients. Brain 2002;125(Pt 5):1070-83.

17. Jankovic J, Rajput AH, McDermott MP, Perl DP. The evolution of diagnosis in early Parkinson disease. Parkinson Study Group. Arch Neurol 2000;57:369-72.

18. Meara J, Bhowmick BK, Hobson P. Accuracy of diagnosis in patients with presumed Parkinson's disease. Age Ageing 1999;28:99-102.

19. Hughes AJ, Daniel SE, Ben-Shlomo Y, Lees AJ. The accuracy of diagnosis of parkinsonian syndromes in a specialist movement disorder service. Brain 2002;125(Pt 4):861-70.

20. Rajput AH, Rozdilsky B, Rajput A. Accuracy of clinical diagnosis in parkinsonism--a prospective study. Can J Neurol Sci 1991;18:275-8.

21. Litvan I, Agid Y, Jankovic J, Goetz C, Brandel JP, Lai EC, Wenning G, D'Olhaberriague L, Verny M, Chaudhuri KR, McKee A, Jellinger K, Bartko JJ, Mangone CA, Pearce RK. Accuracy of clinical criteria for the diagnosis of progressive supranuclear palsy (SteeleRichardson-Olszewski syndrome). Neurology 1996;46:922-30.

22. Verny M, Jellinger KA, Hauw JJ, Bancher C, Litvan I, Agid Y. Progressive supranuclear palsy: a clinicopathological study of 21 cases. Acta Neuropathol (Berl) 1996;91:427-31.

23. Schapira AH, Olanow CW. Principles of treatment in Parkinson's disease. Philidelphia, PA: Butterworth Heinemann; 2008. 
24. Dewey RB, Jr., Hutton JT, LeWitt PA, Factor SA. A randomized, double-blind, placebocontrolled trial of subcutaneously injected apomorphine for parkinsonian off-state events. Arch Neurol 2001;58:1385-92.

25. Nyholm D. Enteral levodopa/carbidopa gel infusion for the treatment of motor fluctuations and dyskinesias in advanced Parkinson's disease. Expert Rev Neurother 2006;6:1403-11.

26. Guridi J, Luquin MR, Herrero MT, Obeso JA. The subthalamic nucleus: a possible target for stereotaxic surgery in Parkinson's disease. Mov Disord 1993;8:421-9.

27. Gillingham FJ, Watson WS, Donaldson AA, Naughton JA. The surgical treatment of parkinsonism. Br Med J 1960;2:1395-402.

28. Elbaz A, Bower JH, Peterson BJ, Maraganore DM, McDonnell SK, Ahlskog JE, Schaid DJ, Rocca WA. Survival study of Parkinson disease in Olmsted County, Minnesota. Arch Neurol 2003;60:91-6.

29. Dujardin K, Defebvre L, Duhamel A, Lecouffe P, Rogelet P, Steinling M, Destée A. Cognitive and SPECT characteristics predict progression of Parkinson's disease in newly diagnosed patients. J Neurol 2004;251:1383-92.

30. Ponsen MM, Stoffers D, Booij J, van Eck-Smit BLF, Wolters EC, Berendse HW. Idiopathic hyposmia as a preclinical sign of Parkinson's disease. Ann Neurol 2004;56:173-81.

31. Storch A, Hofer A, Kruger R, Schulz JB, Winkler J, Gerlach M. New developments in diagnosis and treatment of Parkinson's disease--from basic science to clinical applications. $J$ Neurol 2004;251 Suppl 6:VI/33-8.

32. Becker G, Seufert J, Bogdahn U, Reichmann H, Reiners K. Degeneration of substantia nigra in chronic Parkinson's disease visualized by transcranial color-coded real-time sonography. Neurology 1995;45:182-4.

33. Piccini P, Whone A. Functional brain imaging in the differential diagnosis of Parkinson's disease. Lancet Neurol 2004;3:284-90.

34. Antonini A, Leenders KL, Vontobel P, Maguire RP, Missimer J, Psylla M, Günther I. Complementary PET studies of striatal neuronal function in the differential diagnosis between multiple system atrophy and Parkinson's disease. Brain 1997;120 ( Pt 12):2187-95.

35. Scherfler C, Schwarz J, Antonini A, Grosset D, Valldeoriola F, Marek K, Oertel W, Tolosa E, Lees AJ, Poewe W. Role of DAT-SPECT in the diagnostic work up of Parkinsonism. Mov Disord 2007.

36. Jennings DL, Seibyl JP, Oakes D, Eberly S, Murphy J, Marek K. (123I) beta-CIT and singlephoton emission computed tomographic imaging vs clinical evaluation in Parkinsonian syndrome: unmasking an early diagnosis. Arch Neurol 2004;61:1224-9.

37. Catafau AM, Tolosa E. Impact of dopamine transporter SPECT using 123I-loflupane on diagnosis and management of patients with clinically uncertain Parkinsonian syndromes. Mov Disord 2004;19:1175-82.

38. Walter U, Niehaus L, Probst T, Benecke R, Meyer BU, Dressler D. Brain parenchyma sonography discriminates Parkinson's disease and atypical parkinsonian syndromes. Neurology 2003;60:74-7.

39. Behnke S, Berg D, Naumann M, Becker G. Differentiation of Parkinson's disease and atypical parkinsonian syndromes by transcranial ultrasound. J Neurol Neurosurg Psychiatry 2005;76:423-5.

40. Berg D, Roggendorf W, Schröder U, Klein R, Tatschner T, Benz P, Tucha O, Preier M, Lange KW, Reiners K, Gerlach M, Becker G. Echogenicity of the substantia nigra: association with increased iron content and marker for susceptibility to nigrostriatal injury. Arch Neurol 2002;59:999-1005.

41. Berg D, Siefker C, Becker G. Echogenicity of the substantia nigra in Parkinson's disease and its relation to clinical findings. J Neurol 2001;248:684-9.

42. Okawa M, Miwa H, Kajimoto Y, Hama K, Morita S, Nakanishi I, Kondo T. Transcranial sonography of the substantia nigra in Japanese patients with Parkinson's disease or atypical parkinsonism: clinical potential and limitations. Intern Med 2007;46:1527-31.

43. Berg D, Becker G, Zeiler B, Tucha O, Hofmann E, Preier M, Benz P, Jost W, Reiners K, Lange KW. Vulnerability of the nigrostriatal system as detected by transcranial ultrasound. Neurology 1999;53:1026-31. 
44. Schweitzer KJ, Behnke S, Liepelt I, Wolf B, Grosser C, Godau J, Gaenslen A, Bruessel T, Wendt A, Abel F, Müller A, Gasser T, Berg D. Cross-sectional study discloses a positive family history for Parkinson's disease and male gender as epidemiological risk factors for substantia nigra hyperechogenicity. J Neural Transm 2007;114:1167-71.

45. Huang YW, Jeng JS, Tsai CF, Chen LL, Wu RM. Transcranial imaging of substantia nigra hyperechogenicity in a Taiwanese cohort of Parkinson's disease. Mov Disord 2007;22:550-5.

46. Stockner H, Sojer M, K KS, Mueller J, Wenning GK, Schmidauer C, Poewe W. Midbrain sonography in patients with essential tremor. Mov Disord 2007;22:414-7. 

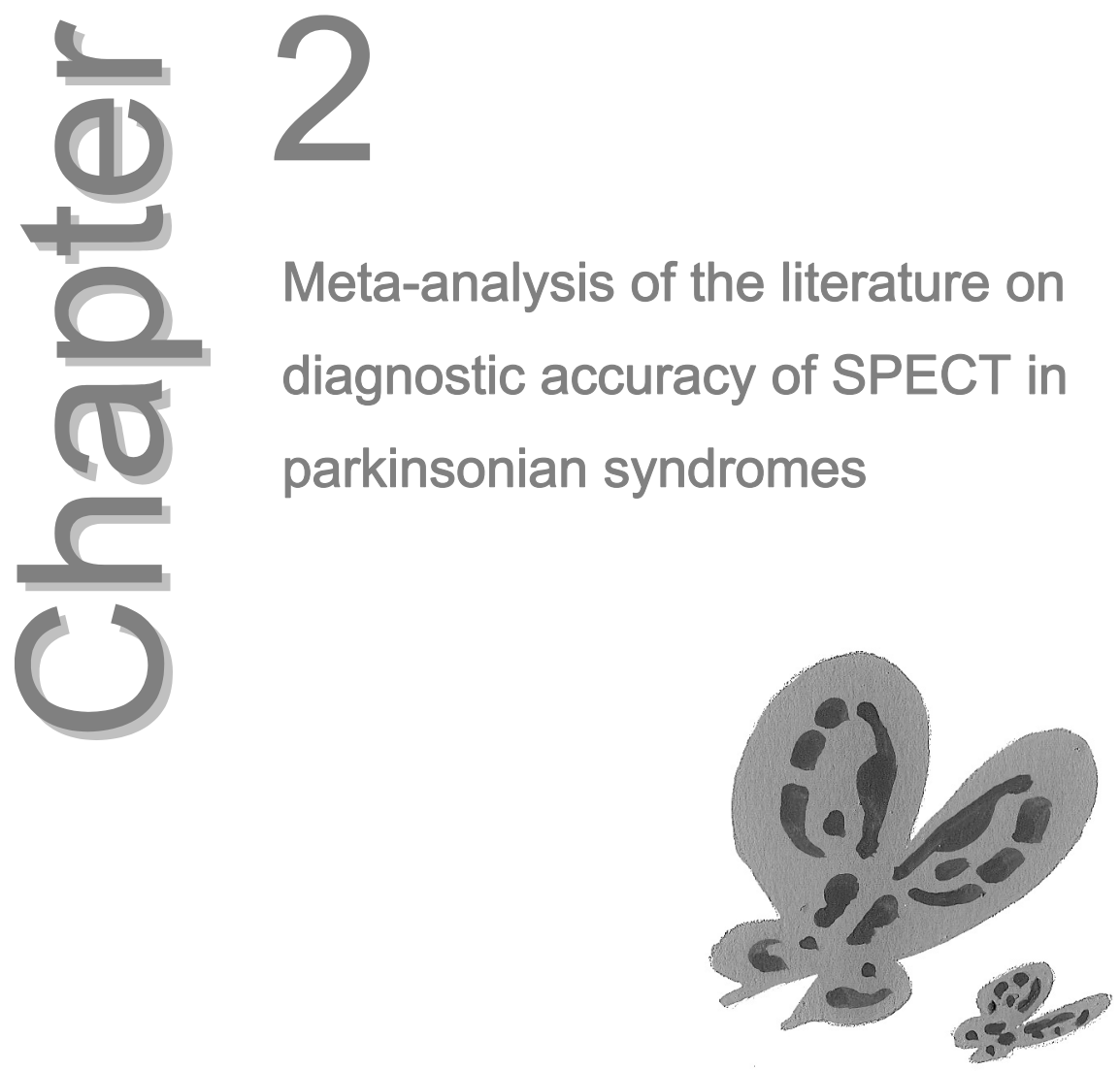

Annemarie M.M. Vlaar, Marinus J.P.G. van Kroonenburgh, Alfons G.H. Kessels, Wim E.J. Weber

BMC Neurology 2007;7:27 


\section{Abstract}

\section{Background}

Parkinson's disease (IPD) is the second most common neurodegenerative disorder. One of the most widely used techniques to diagnose IPD is a Single Photon Emission Computer Tomography (SPECT) scan to visualise the integrity of the dopaminergic pathways in the brain. Despite this there remains some discussion on the value of SPECT in the differential diagnosis of IPD. We did a meta-analysis of all the existing literature on the diagnostic accuracy of both pre- and post-synaptic SPECT imaging in the differential diagnosis of IPD.

\section{Methods}

Relevant studies were searched in Medline, EMBASE and Cochrane databases with backsearching of their reference lists. We limited our analysis to studies with a clinically relevant methodology: i.e. when they assessed the ability of SPECT to provide 1. diagnosis of IPD in an early phase vs. normalcy; 2 diagnostic differentiation between IPD and essential tremor (ET); 3 . distinguishing between IPD and vascular parkinsonism (VP); 4. delineation of IPD from atypical parkinsonian syndromes (APS). Gold standard was, dependent on the study type, clinical examination at initial visit or follow-up, and/or response to dopaminergic agents.

\section{Results}

The search gave 185 hits, of which we deemed 32 suitable for our analysis. From these we recalculated the diagnostic odds ratio of SPECT for the clinical questions above. The pooled odds ratio (with $95 \% \mathrm{Cl}$ ) for presynaptic SPECT scan's ability to distinguish between early IPD and normalcy was 60 (13-277). For the ability to differentiate between IPD and ET this ratio was 210 (78-563). The ratio for presynaptic SPECT's ability to delineate IPD from VP was 105 (32-348). The mean odds ratio for the presynaptic SPECT scans to differentiate between IPD and APS was 2 (1$4)$, and for the postsynaptic SPECT imaging this was 19 (10-36).

\section{Conclusions}

SPECT with presynaptic radiotracers is relatively accurate to differentiate patients with IPD in an early phase from normalcy, patients with IPD from those with ET, and IPD from VP.

The accuracy of SPECT with both presynaptic and postsynaptic tracers to differentiate between IPD and APS is relatively low. 


\section{Background}

Parkinson's disease (IPD) is the second most common neurodegenerative disorder with a life-time risk of $2 \%$ in males and $1.3 \%$ in females. ${ }^{1}$ In most cases the diagnosis of IPD is straightforward when cardinal clinical signs and symptoms as bradykinesia, rigidity, and resting tremor are present. ${ }^{2}$ However, these main features of IPD are shared, at least in part, by atypical parkinsonian syndromes (APS, i.e. multiple system atrophy [MSA] and progressive supranuclear palsy [PSP]) or secondary parkinsonism (i.e. vascular parkinsonism [VP], drugs induced parkinsonism [DIP]) and essential tremor (ET). Besides delineating IPD from the above parkinsonian disorders, distinguishing IPD from normality can also be difficult, especially in early stage of the disease. ${ }^{3}$

The gold standard for the diagnosis of IPD is post-mortem neuropathological examination. ${ }^{2,4}$ Neuropathological studies show that even at end-stage disease the clinical diagnostic accuracy for IPD varies between $75-90 \%$, with MSA and PSP accounting for most false positives. ${ }^{2,5-7}$ Diagnostic accuracy is certainly less than $90 \%$ in earlier disease, as Litvan et al. found that the median sensitivity for the diagnosis of IPD increased from $73 \%$ at the first visit to $80 \%$ to the last visit after a mean follow-up of nine years, and the median positive predictive value increased from 46 to $64 \%{ }^{8}$

A reliable test to diagnose IPD is important for two reasons. Prognosis and management of IPD and other parkinsonian disorders differ considerably, and an objective disease marker would facilitate the development of neuroprotective therapies. ${ }^{9,10}$ Several procedures have been proposed to diagnose IPD: functional imaging with Positron Emission Tomography (PET) or Single Photon Emission Computer Tomography (SPECT), transcranial sonography, olfactory- and neuropsychological tests, biomarkers and genetic tests. ${ }^{11-14}$

At the moment neuro-imaging techniques like PET and SPECT are the most widely used diagnostic tools. ${ }^{9} \mathrm{PET}$ is at least as reliable as SPECT, but its use in routine clinical practice is limited by high costs and a relative short half-life of its radioactive tracers. ${ }^{15-18}$ Different radiotracers can be used to visualise the nigrostriatal system. Presynaptic tracers are used to visualize the dopamine transporter, and postsynaptic radiotracers to assess dopamine receptor density. Examples of presynaptic radiotracers that can be used in SPECT are lodine-123-beta-CIT, lodine-123-loflupane (FP-CIT), lodine-123-IPT and 99mCT-TRODAT-1 (TRODAT). Examples of postsynaptic tracers are lodine123-iodobenzamide and lodine-123-lodobenzofuran. ${ }^{19}$

Despite its widespread use, there is no consensus about the value of SPECT in the differential diagnosis of IPD. First, comparisons between this functional dopaminergic imaging and the ultimate gold standard, autopsy-proven IPD, are almost non-existent. ${ }^{20,21}$ Second, using a surrogate gold standard in the form of 
a long-term clinical follow-up, the ability of SPECT to discriminate IPD from normality and/or other parkinsonian disorders and to distinguish one of the atypical parkinsonian syndromes from the other varies greatly among different studies. Comparing these studies is difficult, as they use different radiotracers and SPECT techniques, and, more importantly, involve different patient populations. A major issue here is that many studies use clearly-defined laterstage patients that are obviously not representative for the diagnostic problem that one wants to solve with a SPECT.

With this perspective of clinical relevance we did a meta-analysis of all the existing literature on the diagnostic accuracy of both pre- and post-synaptic SPECT in the differential diagnosis of IPD. We defined studies as clinically relevant when they dealt with the ability of SPECT to identify IPD in patients with diagnostic uncertainty, to delineate IPD from the other parkinsonian disorders and ET, and to provide an early diagnosis of IPD in patients with little signs and symptoms.

\section{Methods}

\section{Data sources}

Meta-analysis was done according to current methodological recommenddations. $^{22-24}$ We searched MEDLINE using the following terms: IPD, parkinsonian, MSA, PSP, VP and ET. We searched for MeSH terms and free text words. All in combination with SPECT and clinical trial. No beginning data limit was used. The search was updated until 9 January 2006. Only English-, Dutch- and German language studies were considered, because the investigators were familiar with these languages. The bibliographies of selected articles were screened for potentially suitable references which were then retrieved. We also searched the EMBASE and Cochrane database (Wiley InterScience) using the same search strategy.

\section{Study selection}

Two investigators (AV, WW) screened the full text of potential relevant articles using the inclusion criteria. For this we use a standard form combined with a modified QUADAS score, see Table 2.1 (form available upon request). ${ }^{25}$ In all cases the investigators reached consensus. Studies were selected if the subject of the study was in one of the following three areas: 
1. Patients who underwent SPECT because of diagnostic uncertainty.

2. Cross-sectional study of already diagnosed patient categories, in which SPECT was tested as a means to differentiate between various parkinsonian syndromes.

3. Cross-sectional studies with patients with known IPD in an early stage (Hoehn \& Yahr stage 2 or less) vs. normal healthy controls, in which SPECT was tested as a means to provide an early diagnosis.

\section{Exclusion criteria}

The following exclusion criteria were used: 1) whole article not available, 2) language different from English, German or Dutch, 3) studies including only advanced IPD patients vs. healthy controls, and studies with other main categories, e.g. dementia, 4) study population with less than 10 patients, 5) if the numbers of true positives, false negatives, true negatives and false positives with a cut-off point of two standard deviations (SD) from the mean of the control group were not available or could not be derived the study was excluded. When the study included more than 85 patients we contacted the corresponding author to ask for the raw data (see below).

We chose this approach, because we expected a substantial cut-off point effect in the included studies. We did not want to be dependent upon the assumption that the diagnostic odds ratio's in our study would not be affected by differences in the individual cut-off points. To reduce heterogeneity we decided to choose one common cut-off point for all studies. We took a cut-off point of two standard deviations (SD) after consulting with nuclear imaging experts in our hospital and the University Hospital of Amsterdam. Both departments use a cut-off point of 2 SD's below healthy controls. So we recalculated all results from all studies using the individual data from tables and figures in the published paper, using this new cut-off point. If recalculation was not possible (when data for individual patients were not traceable from the manuscript), we excluded the study. This exclusion leads to bias, of course. We feel, however, that, as these studies did not adhere to recommended guidelines by not providing the raw scan results to allow the construction of the diagnostic $2 \times 2$ table, we did not exclude the methodologically best studies. ${ }^{24}$ 


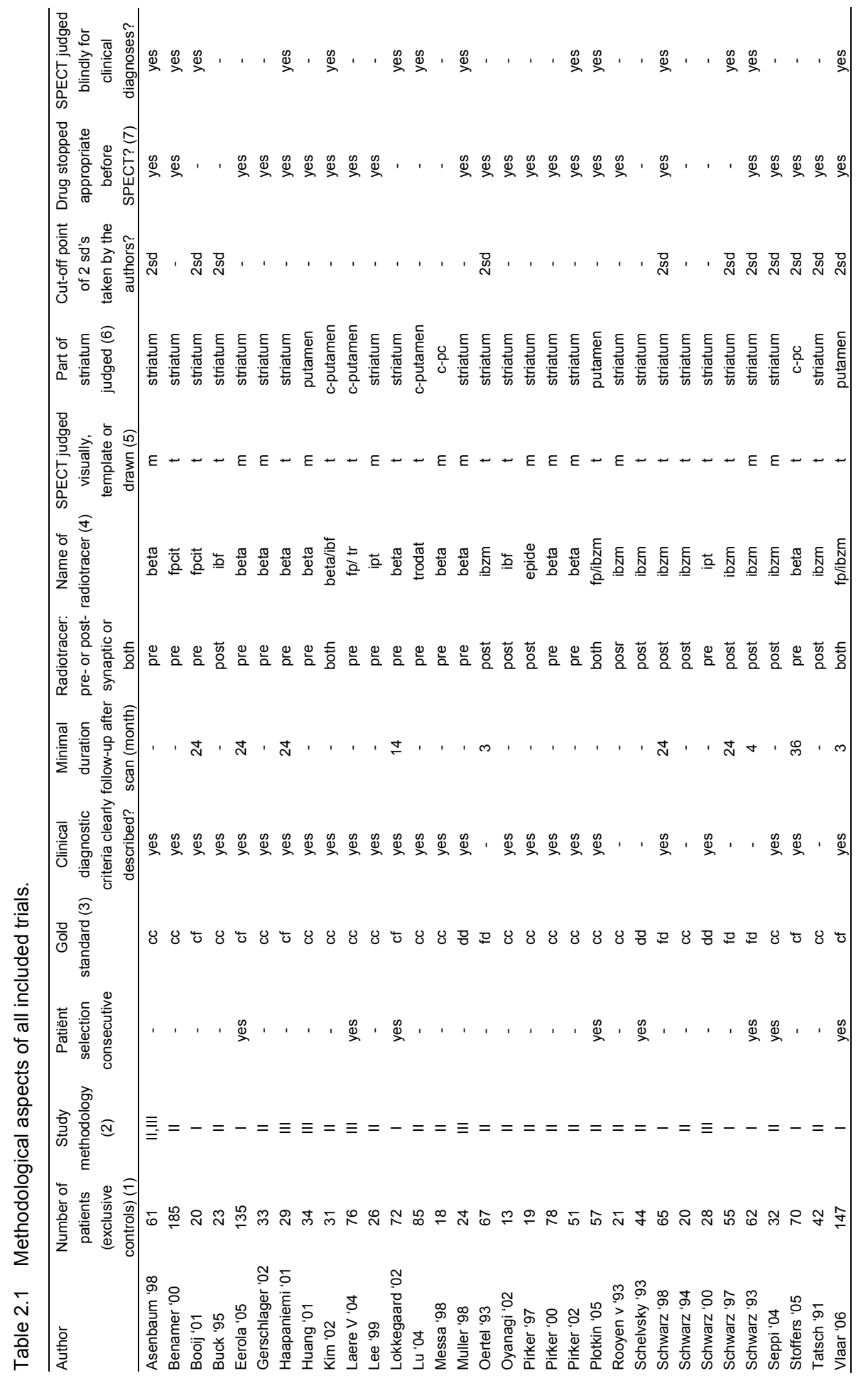


Legend to Table 2.1

(-) indicates a "no" or indicates that there was not sufficient information to make a proper assessment.

1) Number of patients of the particular study that were included in this meta-analysis. Healthy controls, patients without a relevant disease, or patients with an inconclusive diagnosis were not included.

2) Study methodology:

$\mathrm{I}=$ patients with an inconclusive diagnosis. Diagnostic accuracy of SPECT was determined with a surrogate gold standard

II = cross sectional study of already diagnosed patient categories

III = early IPD vs. normalcy

3) Gold standard:

$\mathrm{cf}=$ clinical criteria after follow-up

$\mathrm{cc}=$ clinical criteria without follow-up

$\mathrm{dd}=$ effect of dopaminergic drugs or apomorphine test

$\mathrm{fd}=$ clinical criteria after follow-up \& effect of dopaminergic drugs or apomorphine test

4) Radiotracers: beta $=$ lodine-123-beta-CIT, fpcit $=$ lodine-123-loflupane, $\operatorname{tr}=$ lodine-123-IPT and 99mCT-TRODAT-1, ibzm = 1231-iodobenzamide, ibf = lodine-123-lodobenzofuran, epide = lodine-123-epidepride.

5) $t=$ region of interest determined with a template

$\mathrm{m}=$ region of interest manually encircled

6) $\quad$ c-putamen $=$ contralateral putamen, $\mathrm{c}-\mathrm{pc}=$ contralateral putamen/caudate ratio

7) (yes) if the drugs that interfere with the radiotracers were stopped properly or if the subjects did not use dopaminergic drugs at the moment of the SPECT.

(-) if this information was not given or if dopaminergic drugs were not stopped properly.

\section{Data extraction and analyses}

Sensitivity, specificity and the odds ratio was calculated for each study separately, and the pooled odds ratio's (OR) for all studies together. Although we tried to reduce heterogeneity by recalculating study results using one common cut-off point, we still expected a threshold effect, because of differences in patients, SPECT machinery, radiotracers etc. Therefore, according to recommendations by Deekes and Egger we used diagnostic OR's. ${ }^{26}$

For studies with zeroes in one or more cells 0.5 was added to all four cells of the $2 \times 2$ table. Trials with a sensitivity of $100 \%$ and a specificity of $0 \%$ were not excluded, however the pooled OR's were also calculated without such studies (See \# in the legends of Figure 2.4, 2.5 and 2.6).

All results were put in software SPSS 11.0 for Windows and later converted to Stata/SE9.

The metan and metareg commands were built in Stata/SE9. Because of the heterogeneity of the selected studies we used a random model to calculate the diagnostic odds ratios. Heterogeneity was calculated with the $\mathrm{I}^{2}{ }^{27}$ 


\section{Results}

\section{Literature search}

The search on Medline (SPECT \& clinical trial) gave 1503 hits. When we added all parkinsonian disorders we limited the Medline search to 56 relevant hits.

In the Cochrane database we found 26 hits and in Embase 45 hits, but no additional clinical studies above the ones found in Medline. With crossreference searching we found an additional 128 relevant trials. See flowchart. Together with our own retrospective study of 248 patients with unclear parkinsonism who underwent SPECT in the period 2001 to 2006, this resulted in 185 possibly relevant studies. ${ }^{28}$

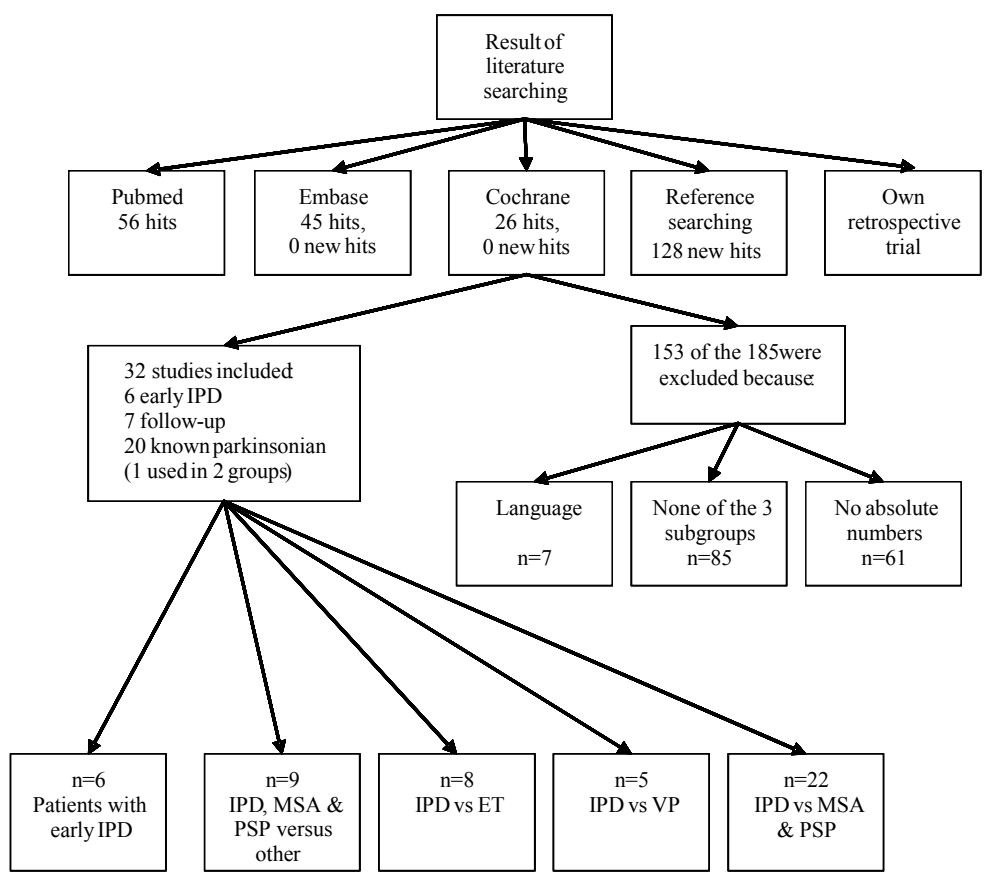

Flowchart

IPD idiopathic Parkinson's disease, MSA multiple system atrophy, PSP progressive supranuclear palsy, ET essential tremor, VP vascular parkinsonism, $n$ number of studies 
Of these 185 we excluded 153 studies (See appendix D). Seven were excluded because of the language criteria and 85 articles were excluded as they did not deal with one of our three designated areas of clinical relevancy: most of them were about techniques, dementia or drug efficacy. We excluded an additional 61, because the absolute numbers with a cut-off point of two standard deviations below the control group were not available or could not be derived. We mailed the authors of the four studies with more than 85 patients, to ask for missing data ${ }^{29-32}$, and received a response from one. ${ }^{30}$ We wanted to acquire raw data from relatively large studies that would have a substantial impact on our meta-analysis; there were four large studies with more than 85 patients, the rest involved smaller numbers in the 20-35 range. We thus sought to contact the authors of these four studies, as we felt that studies with less than 85 subjects would have a very limited impact on the overall scores.

Of the 32 trials left (See appendix D) seven dealt with diagnostic uncertainty including a clinical follow-up as surrogate gold standard, twenty studies were cross-sectional including subjects with known parkinsonian disorders, and six studies involved patients with early IPD. One clinical study fitted as well in the early IPD groups as in the study group of known parkinsonian disorders. ${ }^{33}$ Of the seven follow-up studies, five were prospective. Of these prospective analyses, two included untreated new patients with parkinsonism ${ }^{34,35}$, and three included patients with inconclusive parkinsonism or with a questionable effect of anti-parkinsonian medication. ${ }^{28,36,37}$ Two of the seven follow-up studies were retrospective: Lokkegaard and colleagues retrospectively investigated 90 consecutive patients referred for Beta-CIT SPECT for various reasons, and a non-treating neurologist obtained the final diagnosis from the clinical records of the patients. ${ }^{38}$ Stoffers et al. retrospectively analysed the SPECT scans of 72 patients with an initial diagnosis of IPD, who were then re-diagnosed after various intervals. ${ }^{39}$ The demographic and methodological characteristics of all included studies are visible in Table 2.1. The absolute numbers of the $2 \times 2$ tables of all included trials are shown in Table 2.2. 
Table 2.2 Two by two tables for all included trials.

\begin{tabular}{|c|c|c|c|c|}
\hline \multirow{2}{*}{\multicolumn{5}{|c|}{ Early IPD vs normalcy }} \\
\hline & & & & Presynaptic \\
\hline Asenbaum '98 & 23 & 6 & 30 & 0 \\
\hline Haapanimie '01 & 16 & 13 & 21 & 0 \\
\hline Huang '01 & 32 & 2 & 17 & 0 \\
\hline Muller '98 & 14 & 10 & 15 & 0 \\
\hline Schwarz '00 & 28 & 0 & 9 & 0 \\
\hline V. Laere (tracer FP-CIT) ‘04 & 15 & 24 & 10 & 0 \\
\hline V. Laere (tracer: TRODAT) ‘04 & 3 & 34 & 10 & 0 \\
\hline \multicolumn{5}{|l|}{ IPD vs ET } \\
\hline \multicolumn{5}{|l|}{ Presynaptic } \\
\hline Booij ‘00 & 7 & 1 & 5 & 0 \\
\hline Benamer '00 & 127 & 3 & 25 & 2 \\
\hline Plotkin '05 & 24 & 1 & 11 & 0 \\
\hline Eerola '05 & 92 & 0 & 16 & 0 \\
\hline Vlaar ‘06 & 90 & 22 & 20 & 1 \\
\hline Lokkegaard '02 & 44 & 1 & 8 & 0 \\
\hline Asenbaum '98 & 23 & 6 & 32 & 0 \\
\hline Lee "99 & 10 & 1 & 12 & 3 \\
\hline \multicolumn{5}{|l|}{ Postsynaptic } \\
\hline Vlaar '06 & 48 & 33 & 6 & 7 \\
\hline Plotkin ‘05 & 25 & 0 & 0 & 11 \\
\hline \multicolumn{5}{|l|}{ IPD vs VP } \\
\hline \multicolumn{5}{|l|}{ Presynaptic } \\
\hline Vlaar "06 & 90 & 22 & 14 & 0 \\
\hline Booij ‘00 & 7 & 1 & 4 & 0 \\
\hline Eerola '05 & 92 & 0 & 11 & 4 \\
\hline Lokkegaard '02 & 44 & 1 & 3 & 1 \\
\hline Gerschlager '02 & 18 & 2 & 12 & 1 \\
\hline \multicolumn{5}{|l|}{ Postsynaptic } \\
\hline Vlaar '06 & 65 & 16 & 8 & 4 \\
\hline \multicolumn{5}{|l|}{ IPD vs APS } \\
\hline \multicolumn{5}{|l|}{ Presynaptic } \\
\hline Booii “00 & 7 & 1 & 1 & 2 \\
\hline Benamer '00 & 127 & 3 & 1 & 27 \\
\hline Plotkin '05 & 24 & 1 & 3 & 18 \\
\hline Eerola '05 & 92 & 0 & 1 & 11 \\
\hline Stoffers '05 & 30 & 32 & 2 & 6 \\
\hline Lokkegaard '02 & 44 & 1 & 2 & 13 \\
\hline Kim ‘02 & 18 & 0 & 1 & 12 \\
\hline Lu ‘04 & 36 & 0 & 6 & 43 \\
\hline Messa '98 & 13 & 0 & 0 & 5 \\
\hline Pirker '02 & 26 & 10 & 3 & 7 \\
\hline Vlaar '06 & 90 & 22 & 4 & 13 \\
\hline
\end{tabular}




\begin{tabular}{|c|c|c|c|c|}
\hline & True positive & False negative & True negative & False positive \\
\hline \multicolumn{5}{|l|}{ Postsynaptic } \\
\hline Schwarz ‘93 & 45 & 2 & 9 & 6 \\
\hline Schwarz ‘97 & 30 & 4 & 8 & 1 \\
\hline Schwarz ‘98 & 53 & 5 & 5 & 2 \\
\hline Buck ‘95 & 17 & 0 & 3 & 3 \\
\hline Kim ‘02 & 18 & 0 & 5 & 8 \\
\hline Oertel ‘93 & 49 & 12 & 6 & 0 \\
\hline Oyanagu ‘02 & 7 & 0 & 2 & 4 \\
\hline Pirker ‘97 & 9 & 0 & 0 & 10 \\
\hline Plotkin ‘05 & 25 & 0 & 9 & 12 \\
\hline Schwarz ‘94 & 19 & 0 & 1 & 1 \\
\hline Seppi ‘04 & 12 & 5 & 13 & 2 \\
\hline Tatsch '91 & 18 & 0 & 20 & 4 \\
\hline Schelovsky ‘93 & 30 & 0 & 8 & 6 \\
\hline Vlaar ‘06 & 65 & 16 & 16 & 10 \\
\hline \multicolumn{5}{|l|}{ MSA vs PSP } \\
\hline \multicolumn{5}{|l|}{ Presynaptic } \\
\hline Vlaar ‘06 & 19 & 0 & 1 & 9 \\
\hline Plotkin ‘05 & 7 & 0 & 1 & 5 \\
\hline Pirker & 7 & 2 & 2 & 4 \\
\hline Pirker & 18 & 0 & 1 & 9 \\
\hline Kim ‘02 & 11 & 2 & 1 & 7 \\
\hline Benamer '00 & 4 & 1 & 0 & 2 \\
\hline \multicolumn{5}{|l|}{ Postsynaptic } \\
\hline Buck ‘95 & 5 & 2 & 6 & 0 \\
\hline Kim ‘02 & 1 & 1 & 2 & 2 \\
\hline Plotkin ‘05 & 7 & 6 & 6 & 2 \\
\hline Vlaar'06 & 10 & 4 & 3 & 6 \\
\hline v. Royen '93 & 13 & 4 & 1 & 3 \\
\hline
\end{tabular}

In the statistic analyses +0.5 was taken to be able to use zeroes in the calculations.

IPD idiopathic Parkinson's disease, APS atypical parkinsonian syndromes, MSA multiple system atrophy, PSP progressive supranuclear palsy, ET essential tremor, VP vascular parkinsonism, $n$ number of studies

\section{Results of the pooled study data analysis}

We recalculated the diagnostic power of SPECT for the following clinical problems: 1 . diagnosis of IPD in an early phase vs. normalcy; 2 diagnostic differentiation between IPD and ET; 3. diagnostic differentiation between IPD and vascular parkinsonism; 4. diagnostic differentiation between IPD and Atypical Parkinsonian Syndromes (APS) consisting of MSA and PSP.

\section{Diagnosis of IPD in an early phase vs. normalcy}

Pooled data from selected studies were used to calculate the diagnostic accuracy of SPECT to differentiate between IPD and normalcy. ${ }^{33,40-44}$ All six cross-sectionals (utilising presynaptic tracers) with patients with known IPD in an early stage (Hoehn \& Yahr score of 2 or lesser) had a specificity of $100 \%$. However sensitivity varied from 8 to $100 \%$. The pooled odds ratio with a $95 \% \mathrm{Cl}$ was 60 (13-277). See also Figure 2.1. 


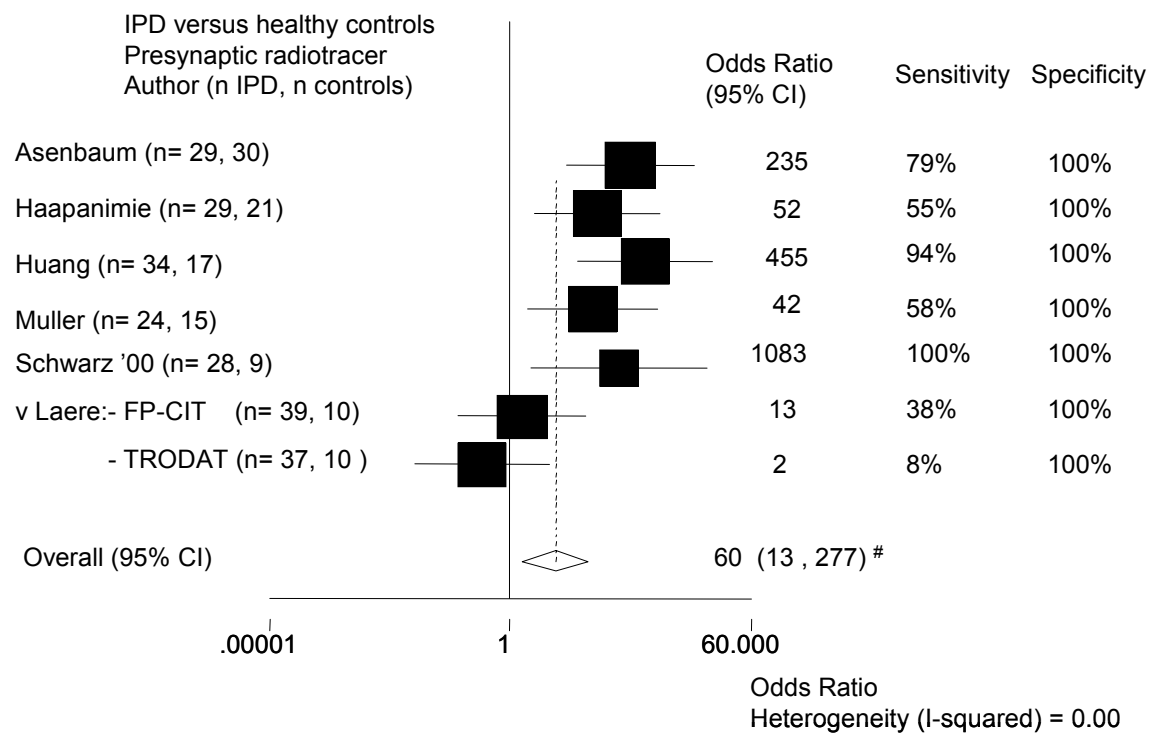

Figure 2.1 Diagnostic differentiation of patients with idiopathic Parkinson's disease (IPD) in an early phase versus healthy controls.

Presynaptic radiotracer. ${ }^{33.40-44}$

I.: surface of square represents the weight of the study.

FP-CIT: lodine-123-loflupane; TRODAT: 99mCT-TRODAT-1, n: number of subjects, $\mathrm{Cl}$ : confidence interval

\#: all of these studies have a specificity of $100 \%$ so the pooled odds ratio should therefore be infinite. The pooled odds ratio of 60 is caused by STATA software's procedure for handling zero cells in the $2 \times 2$ table.

Abnormal SPECT definition: $>2$ standard deviations below the bindings rate of healthy controls.

\section{Diagnostic differentiation between IPD and essential tremor (ET)}

Data from selected studies ${ }^{33,36,38,45-48}$ and our own clinical follow-up study ${ }^{28}$ were pooled and pooled odds ratios for diagnostic power of SPECT were calculated as described.

For presynaptic radiotracers the pooled odds ratio with $95 \% \mathrm{Cl}$ of the eight studies together was 210 (78-563). See also Figure 2.2. All studies scored high sensitivity and specificity. 


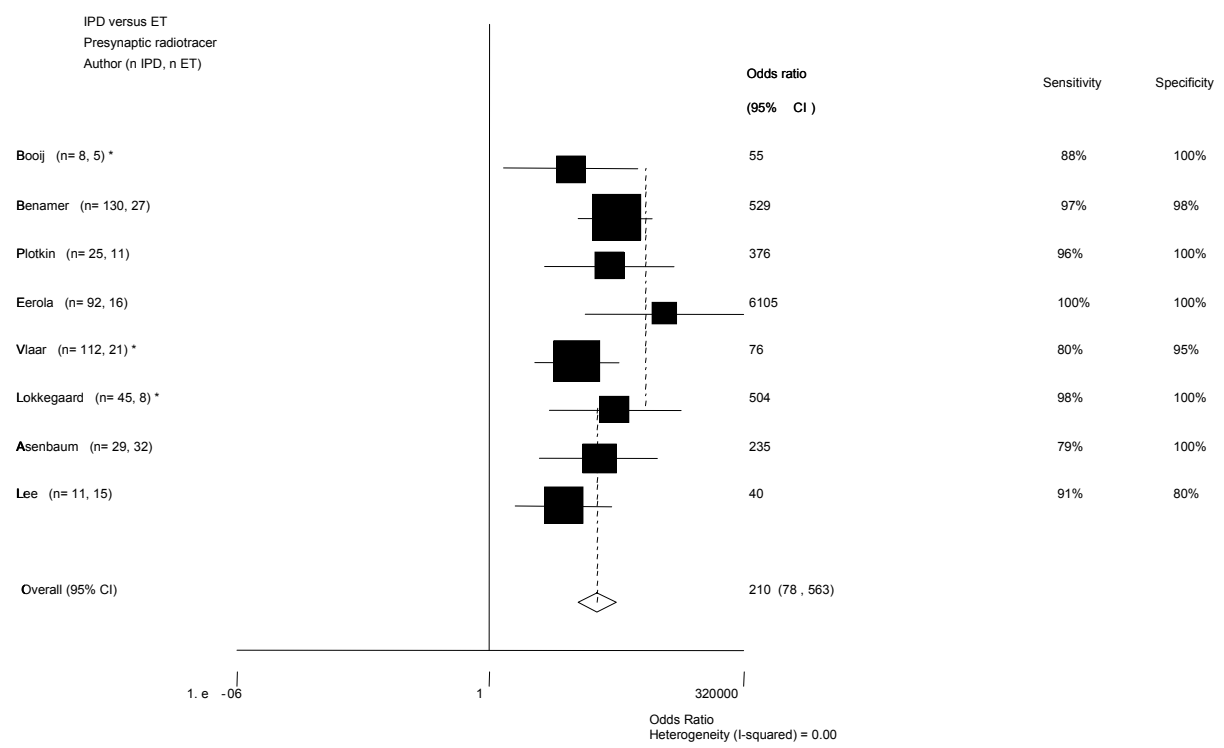

Figure 2.2 Patients with idiopathic Parkinson's disease (IPD) versus essential tremor (ET). Presynaptic radiotracer. ${ }^{36,38,45-48,84}$

* follow-up trial

For calculation of these odds ratios in studies with postsynaptic radiotracers we found two studies: one cross-sectional study (sensitivity $100 \%$, specificity of $0 \%$ ) and our own follow-up study (sensitivity 60\%, specificity $46 \%$ ). The pooled odds ratio with $95 \% \mathrm{Cl}$ was $2(0.4-5) .^{28,46}$

Two studies compared the diagnostic accuracy of the treating physician with SPECT in its capacity to delineate IPD from ET ${ }^{28,38}$ Clinical diagnosis in these trials reached a sensitivity of respectively $76 \%$ and $87 \%$ and a specificity of $50 \%$ and $80 \%$. The odds ratio with $95 \% \mathrm{Cl}$ of the two studies together is 9 (3-28).

\section{Diagnostic differentiation between IPD and vascular parkinsonism (VP)}

Pooled data from selected studies were used to calculate the diagnostic accuracy of SPECT to differentiate between IPD and VP. ${ }^{28,36,38,47,49}$

Using presynaptic radiotracers the five studies all scored high sensitivity and specificity for SPECT to differentiate between IPD and VP. The pooled odds ratio with $95 \% \mathrm{Cl}$ of all five studies together is 105 (32-348). See also Figure 2.3 . 


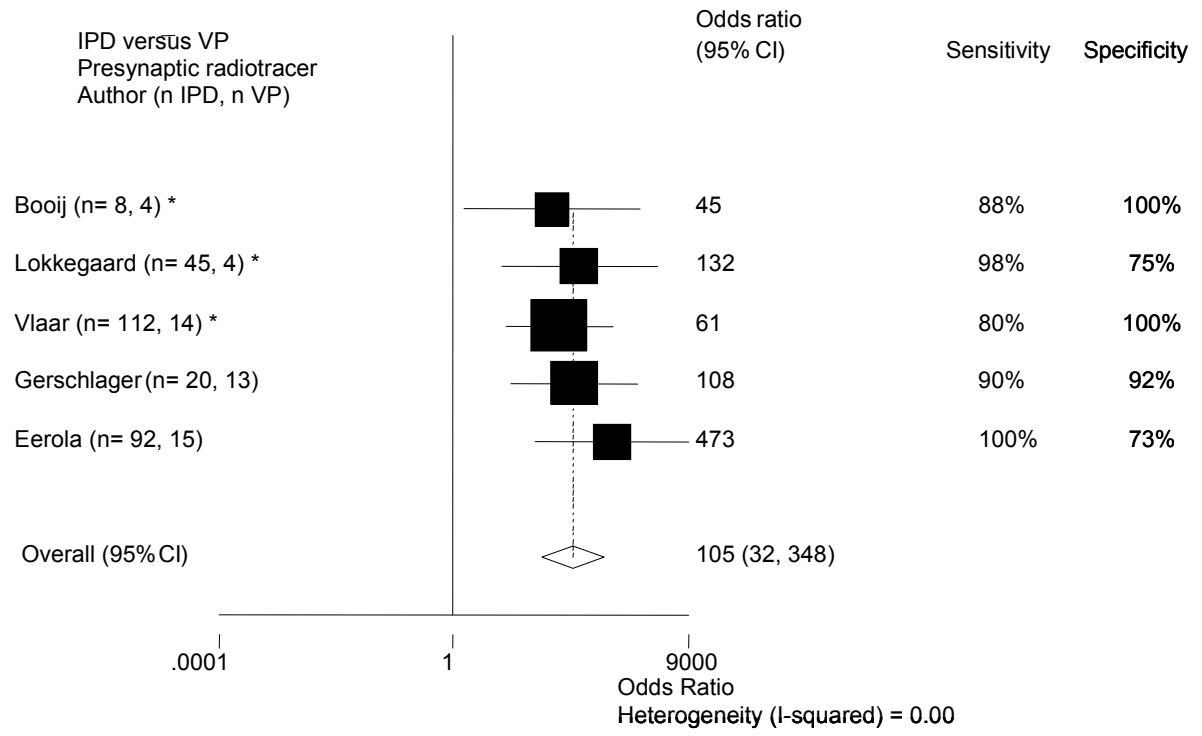

Figure 2.3 Diagnostic differentiation of patients with idiopathic Parkinson's disease (IPD) versus vascular parkinsonism (VP). Presynaptic tracer. ${ }^{28,36,38,47,49}$

* follow-up trial

We were not able to find any trials except our own trial with postsynaptic tracers aimed at this diagnostic problem. We found a sensitivity of $80 \%$, specificity of $67 \%$ and an odds ratio of $95 \% \mathrm{Cl}$ of $8(2-30)$.

Lokkegaard et al. and we mentioned the diagnostic accuracy of the clinician to differentiate IPD from VP and found a sensitivity of respectively $87 \%$ and $76 \%$ and a specificity of respectively $0 \%$ and $63 \%$ with a odds ratio $95 \% \mathrm{Cl}$ of 3 $(0.5-18){ }^{28,38}$

\section{Diagnostic differentiation between IPD and atypical parkinsonian syndromes (APS)}

Pooled data from selected studies were used to calculate the diagnostic accuracy of SPECT to differentiate between IPD and APS (MSA and PSP).

When using presynaptic tracers all trials scored moderate to high sensitivity, but with a low specificity. Combining all eleven trials the mean odds ratio with $95 \% \mathrm{Cl}$ for the presynaptic tracer to differentiate between IPD and the two APS was 2 (1-4). See Figure 2.4. 


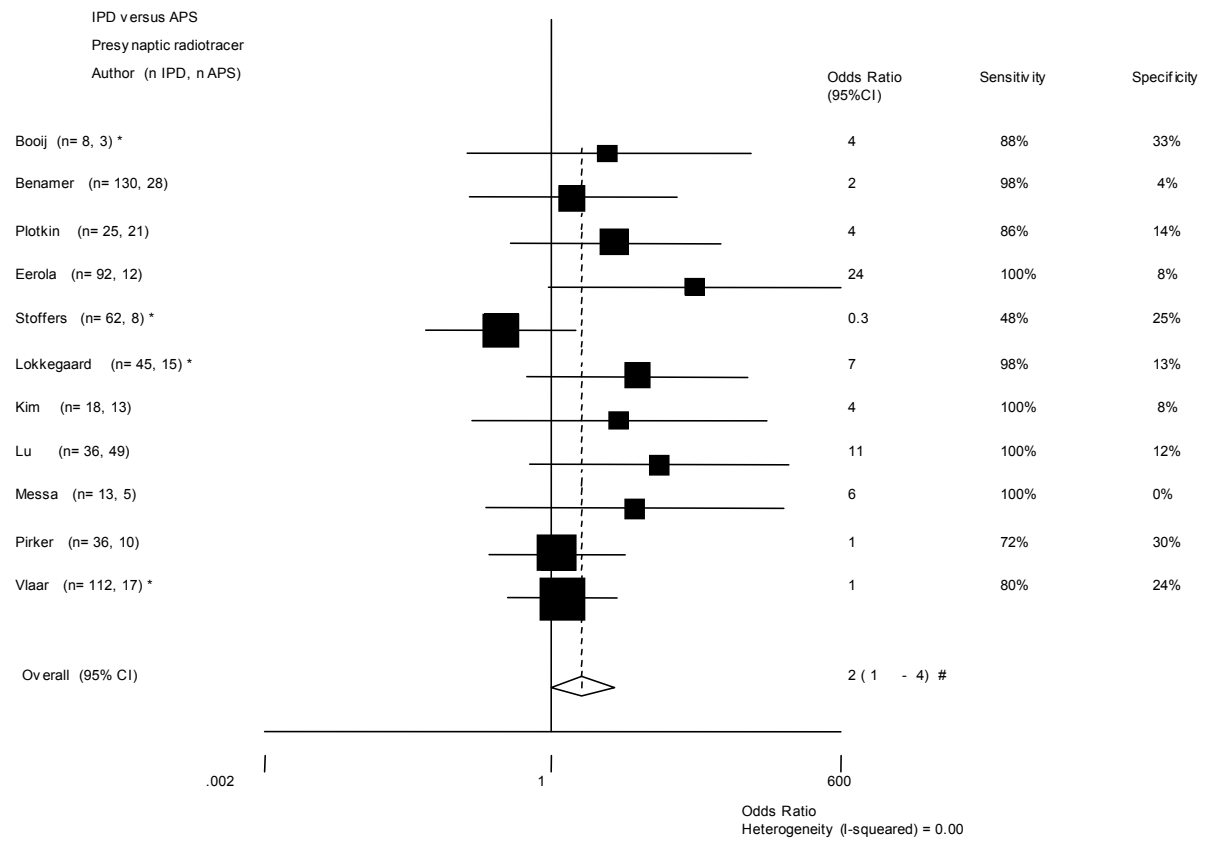

Figure 2.4 Diagnostic differentiation between idiopathic Parkinson's disease (IPD) and atypical parkinsonian syndromes (APS, i.e. MSA \& PSP). Presynaptic radiotracer. ${ }^{28,30,36,38,39,46-}$ 48,50-52

* follow-up trial

\# the pooled odds ratio remains unchanged after excluding the study of Messa '98 (sensitivity $100 \%$, specificity $0 \%$ ).

When using postsynaptic tracers the fourteen trials scored together a pooled odds ratio $95 \% \mathrm{Cl}$ of 19 (10-36). See Figure 2.5 .

Four follow-up studies compared the diagnostic accuracy of the treating physician with SPECT in its capacity to delineate IPD from the two APS. Clinical diagnosis in these trials reached a high sensitivity, but a low specificity. The pooled odds ratio $95 \% \mathrm{Cl}$ was 9 (2-34). See Figure 2.6.

The diagnostic accuracy of SPECT to differentiate MSA from PSP was low for both the presynaptic and postsynaptic radiotracers. With presynaptic racers sensitivity of the six trials was extremely high $(78-100 \%)$, however specificity was low $(0-33 \%)$. The five studies with postsynaptic tracers scored moderate sensitivity (50-71\%) and specificity $(25-100 \%)$.

The pooled odds ratio with $95 \% \mathrm{Cl}$ was 2 (0.6-7) for the presynaptic tracers and $2(0.8-6)$ for the postsynaptic tracers. ${ }^{28,46,48,50,52,56,60,61}$ 


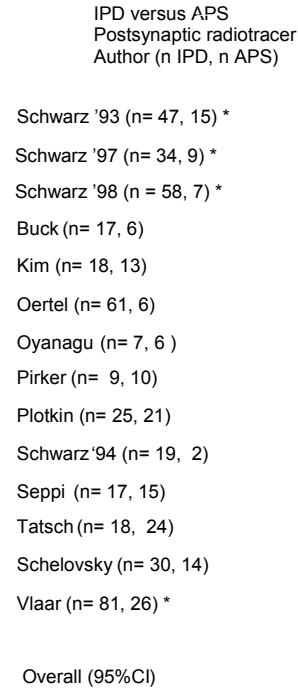

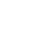




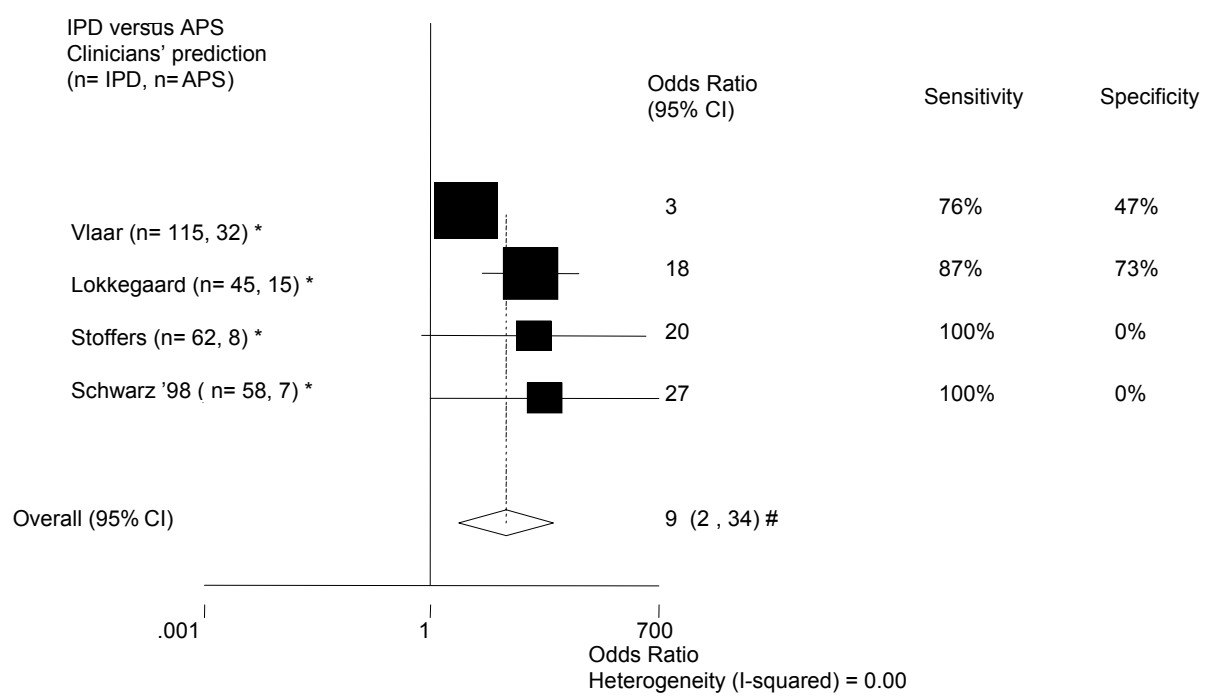

Figure 2.6 Diagnostic differentiation of patients with idiopathic Parkinson's disease (IPD) versus atypical parkinsonian syndromes (APS, i.e. MSA \& PSP) based on the clinicians' initial prediction. $^{28,34,38,39}$

${ }^{*}$ follow-up trial

\# after excluding the studies with a sensitivity of $100 \%$ and a specificity of $0 \%$ (Stoffers 2005 and Schwarz 1998) the pooled odds ratio $(95 \% \mathrm{Cl})$ did not change significantly: 6 (1-40). Both trials diagnosed all patients as having IPD at the beginning of the trial.

\section{Discussion}

To our knowledge this is the first meta-analysis of the literature on the diagnostic value of SPECT in patients with parkinsonian syndromes. Before discussing the actual results we would like to point out some methodological problems.

We were very strict in including studies. To compare the results from selected studies we defined positive tests as values equal with or exceeding two standard deviations below healthy controls. When authors defined their positive results otherwise, we recalculated these, where possible. However, as many studies did not include raw data, we had to reject these, as we were then not able to (re)calculate the absolute numbers of true positive, false negative, true negative, and false positives with a cut-off point of two standard deviations.

We dichotomised the radiotracers utilised into two groups: presynaptic and postsynaptic tracers. By doing this we assumed that all tracers in one group 
have a similar reliability. This seems to be reasonable for beta-CIT and FP-CIT, especially when the SPECT result of the parkinsonian patient is expressed as a percentage of the binding ratios found in healthy controls. ${ }^{62,63}$

Besides the use of different equipment, comparison between studies is also hampered by the different methods that investigators use to calculate the tracer binding. In some studies the striatum was encircled manually and others used predefined templates. The striatum was judged visually (compatible or not compatible with IPD) or fully automated quantitatively by others. Finally, and possibly the greatest confounding variable: in some studies the SPECT results are judged by investigators unaware of the clinical records, but in more than half of the studies blinding of the investigator is not mentioned.

Another methodological shortcoming in our meta-analysis is the great variability in clinical criteria used to classify patients; many authors do not even mention these. A major issue here is that most studies use clearly-defined later-stage patients that are obviously not representative for the diagnostic problem that one wants to solve with a SPECT. We thus limited our analysis to those studies that addressed the diagnostic accuracy in clinically relevant situations: early IPD, follow-up studies and studies with known parkinsonian diseases. All the measures mentioned above were taken to minimise heterogeneity, which was actually shown to be minimal as calculated by the $\mathrm{I}^{2}$ statistic. ${ }^{27}$ Despite this, interpreting of the results should be done with caution, as postsynaptic tracer binding in APS can be normal in an early stage of disease with a decrease later $\mathrm{on}^{64}$. Finally, strict age-matching is not done in all studies, but is mandatory as tracer binding in general decreases with age. ${ }^{65-67}$

These methodological problems do, however, allow one important conclusion to start with: as we derived only 32 papers suitable from a starting number of 185 , there is a paucity of methodologically sound and clinically relevant papers on this subject. Below we would like to discuss our results according to the predefined clinically relevant situations.

\section{Diagnosis of IPD in an early phase vs. normalcy}

Our meta-analysis confirms the general opinion that SPECT is relatively accurate to differentiate between patients with IPD in an early stage and healthy controls. The difference in sensitivity between trials can not be explained solely by different radiotracer usage. Especially the difference with the two studies using TRODAT is obvious. ${ }^{41,43}$ An explanation may be that the use of a template vs. hand-circling of the striatum leads to lower diagnostic specificities. ${ }^{40,42,43}$ Other possible explanations for the lower sensitivity scores in the study of van Laere et al. are their consecutive inclusion of patients and their clinic being a tertiary referral centre. ${ }^{43}$ 
Schwarz and Asenbaum were the only two authors who used two standard deviations below the normal controls as cut-off. ${ }^{33,42}$ In the other four studies we recalculated the absolute numbers of true positive, false negative etc. by ourselves, which led in all four studies to lower numbers for diagnostic accuracy. ${ }^{40,41,43,44}$ Apart from this different cut-off point, higher sensitivity figures in several large trials (normal SPECT scans in $5-10 \%$ of clinically definitive IPD patients) are probably explained by the disease stage of the patients. ${ }^{68-70}$

Asenbaum's, Haapaniemi's and Muller's were the only studies which mentioned blinding of the investigators. ${ }^{33,40,44}$ It is perhaps not surprising that these authors found lower numbers for diagnostic accuracy than Huang and Schwarz (See Figure 2.1). ${ }^{41,42}$

\section{Diagnosis of IPD versus essential tremor (ET)}

The results of our meta-analysis confirm the general opinion that SPECT with presynaptic tracers is highly accurate to differentiate between patients with IPD and ET. Lee et al. scored lowest specificity. A possible explanation is that they included not only patients with ET but as well patients with isolated postural tremor and postural in combination with resting tremor. ${ }^{45}$

\section{Diagnostic differentiation between patients with IPD versus vascular parkinsonism (VP)}

According to the results of the meta-analysis we conclude that presynaptic SPECT scans can accurately differentiate between patients with IPD and VP. The specificity, however, is only moderate in the studies of Lokkegaard and Eerola ${ }^{38,47}$ VP is a somewhat controversial clinical concept and the differences found in the studies we analysed probably reflect the variability in clinical definition. Whereas Lokkegaard et al., Gerschlager et al., and Eerola et al. ${ }^{38,49}$ used strict inclusion criteria, Booij et al. did not. ${ }^{36,47}$ This point is illustrated in the paper by Loberboym et al., who investigated twenty patients with VP with FP-CIT SPECT. Nine had a normal presynaptic SPECT scan but eleven had decreased striatal tracer binding. All nine patients with normal presynaptic SPECT scan had no reaction on levodopa treatment, however five of the eleven with decreased striatal FP-CIT binding did have. ${ }^{71}$ Although SPECT with presynaptic tracers scored high accuracy in differentiation between IPD and VP, conventional techniques like CT and MRI may still be necessary as additional diagnostic tools. 


\section{Diagnostic differentiation between patients with IPD versus atypical parkinsonian syndromes (APS)}

This meta-analysis confirmed the generally accepted view that presynaptic tracers cannot distinguish between IPD and APS. However, we also found that postsynaptic SPECT is not very good at this. A negative postsynaptic SPECT scan does not exclude APS. The positive predictive value of abnormal postsynaptic SPECT for the diagnosis of APS is high, making a reduced postsynaptic radiotracer binding likely to exclude a diagnosis of IPD. However, patients with IPD in our meta-analysis do show loss of dopamine-receptor binding. Studies which used IBZM scored higher accuracy than studies with lodine-123-lodobenzofuran or Epidepride..$^{50,53,56,59}$ If the trials are excluded which used other tracers than IBZM the mean $95 \% \mathrm{Cl}$ odds ratio only increased to 21 (11-44).

Some studies, excluded for this meta-analysis, found excellent accuracy for the postsynaptic tracer to differentiate between IPD and APS. ${ }^{19,64,72-77}$ Schulz et al., who investigated thirty-two MSA patients, found similar results as in our metaanalysis: only a significant loss in $63 \%$ of the patients using IBZM-SPECT with two standard deviations under controls (IPD patients) as cut-off point. ${ }^{78}$ Results of the studies by Berding and Bettin are in line with these. ${ }^{79,80}$

Possible explanations for the difference in results may be difference in cut-off points (many authors use only one SD below healthy controls), and the use of special techniques claimed by some to enhance diagnostic accuracy, e.g. asymmetric indices, caudate/ putamen ratio, presynaptic/postsynaptic ratio of tracer binding, speed of decline in follow-up. ${ }^{30,36,76,81,82}$ One other explanation of the low discriminating value of postsynaptic SPECT imaging is the reversible down regulation of dopamine receptors by dopaminergic drugs. ${ }^{83}$ If the drugs are not stopped appropriately, the scan result can be false positive. In our meta-analysis we found nine studies where potentially interfering medication was not discontinued appropriately or these did even not mention whether this medication was discontinued (and if, for how long) before the scan.

\section{Conclusion}

There is a paucity of methodologically sound and clinically relevant papers on the diagnostic accuracy of SPECT in parkinsonian syndromes. Our metaanalysis confirms the general opinion that SPECT is relatively accurate to differentiate between patients with IPD in an early stage and healthy controls. We were also able to confirm the general opinion that SPECT with presynaptic tracers is highly accurate to differentiate between patients with IPD and ET. Although SPECT with presynaptic tracers scored high accuracy in 
differentiation between IPD and VP, conventional techniques like CT and MRI may still be necessary as additional diagnostic tools. This meta-analysis confirmed the generally accepted view that presynaptic tracers cannot distinguish between IPD and APS. However, we also found that SPECT with postsynaptic tracers is not very good at this. 


\section{References}

1. Elbaz A, Bower JH, Maraganore DM, McDonnell SK, Peterson BJ, Ahlskog JE, Schaid DJ, Rocca WA. Risk tables for parkinsonism and Parkinson's disease. J Clin Epidemiol 2002; 55:25-31.

2. Hughes AJ, Daniel SE, Kilford L, Lees AJ. Accuracy of clinical diagnosis of idiopathic Parkinson's disease. A clinico-pathological study of 100 cases. J Neurol Neurosurg Psychiatry 1992;55:181-4.

3. Koller WC, Montgomery EB. Issues in the early diagnosis of Parkinson's disease. Neurology 1997;49:S10-25.

4. Hughes AJ, Daniel SE, Blankson S, Lees AJ. A clinicopathologic study of 100 cases of Parkinson's disease. Arch Neurol 1993;50:140-8.

5. Hughes AJ, Daniel SE, Lees AJ. Improved accuracy of clinical diagnosis of Lewy body Parkinson's disease. Neurology 2001;57:1497-9.

6. Rajput AH, Rozdilsky B, Rajput A. Accuracy of clinical diagnosis in parkinsonism--a prospective study. Can J Neurol Sci 1991;18:275-8.

7. Watanabe H, Saito Y, Terao S, Ando T, Kachi T, Mukai E, Aiba I, Abe Y, Tamakoshi A, Doyu M, Hirayama M, Sobue G. Progression and prognosis in multiple system atrophy: an analysis of 230 Japanese patients. Brain 2002;125:1070-83.

8. Litvan I, MacIntyre A, Goetz CG, Wenning GK, Jellinger K, Verny M, Bartko JJ, Jankovic J, McKee A, Brandel JP, Chaudhuri KR, Lai EC, D'Olhaberriague L, Pearce RK, Agid Y. Accuracy of the clinical diagnoses of Lewy body disease, Parkinson disease, and dementia with Lewy bodies: a clinicopathologic study. Arch Neurol 1998;55:969-78.

9. Piccini $\mathrm{P}$, Whone A. Functional brain imaging in the differential diagnosis of Parkinson's disease. Lancet Neurol 2004;3:284-90.

10. Clarke CE. Neuroprotection and pharmacotherapy for motor symptoms in Parkinson's disease. Lancet Neurol 2004;3:466-74.

11. Dujardin K, Defebvre L, Duhamel A, Lecouffe P, Rogelet P, Steinling M, Destee A. Cognitive and SPECT characteristics predict progression of Parkinson's disease in newly diagnosed patients. J Neurol 2004;251:1383-92.

12. Ponsen MM, Stoffers D, Booij J, van Eck-Smit BLF, Wolters EC, Berendse HW. Idiopathic hyposmia as a preclinical sign of Parkinson's disease. Ann Neurol 2004;56:173-81.

13. Storch A, Hofer A, Kruger R, Schulz JB, Winkler J, Gerlach M. New developments in diagnosis and treatment of Parkinson's disease--from basic science to clinical applications. J Neurol 2004;251 Suppl 6:VI/33-8.

14. Walter U, Klein C, Hilker R, Benecke R, Pramstaller PP, Dressler D. Brain parenchyma sonography detects preclinical parkinsonism. Mov Disord 2004;19:1445-9.

15. Fernandez HH, Friedman JH, Fischman AJ, Noto RB, Lannon MC. Is altropane SPECT more sensitive to fluoroDOPA PET for detecting early Parkinson's disease? Med Sci Monit 2001; 7:1339-43.

16. Huang WS, Chiang YH, Lin JC, Chou YH, Cheng CY, Liu RS. Crossover study of (99m)TCTRODAT-1 SPECT and (18)F-FDOPA PET in Parkinson's disease patients. J Nucl Med 2003;44:999-1005.

17. Ishikawa T, Dhawan V, Kazumata K, Chaly T, Mandel F, Neumeyer J, Margouleff C, Babchyck B, Zanzi I, Eidelberg D. Comparative nigrostriatal dopaminergic imaging with iodine-123-beta CIT-FP/SPECT and fluorine-18-FDOPA/PET. J Nucl Med 1996;37:1760-5.

18. Schwarz J, Antonini A, Tatsch K, Kirsch CM, Oertel WH, Leenders KL. Comparison of 123IIBZM SPECT and 11C-raclopride PET findings in patients with parkinsonism. Nucl Med Commun 1994;15:806-13.

19. Booij J, Tissingh G, Winogrodzka A, van Royen EA. Imaging of the dopaminergic neurotransmission system using single-photon emission tomography and positron emission tomography in patients with parkinsonism. Eur J Nucl Med 1999;26:171-82.

20. Jankovic J, Rajput AH, McDermott MP, Perl DP. The evolution of diagnosis in early Parkinson disease. Parkinson Study Group. Arch Neurol 2000;57:369-72. 
21. Walker Z, Costa DC, Walker RW, Shaw K, Gacinovic S, Stevens T, Livingston G, Ince P, McKeith IG, Katona CL. Differentiation of dementia with Lewy bodies from Alzheimer's disease using a dopaminergic presynaptic ligand. J Neurol Neurosurg Psychiatry 2002; 73:134-40.

22. Deville WL, Bossuyt PM, de Vet HC, Bezemer PD, Bouter LM, Assendelft WJ. Systematic reviews in practice. $X$. Searching, selecting and the methodological assessment of diagnostic evaluation research. Ned Tijdschr Geneeskd 2002;146:2281-4.

23. Assendelft WJ, van Tulder MW, Scholten RJ, Bouter LM. The practice of systematic reviews. II. Searching and selection of studies. Ned Tijdschr Geneeskd 1999;143:656-61.

24. Deville WL, Buntinx F, Bouter LM, Montori VM, de Vet HC, van der Windt DA, Bezemer PD. Conducting systematic reviews of diagnostic studies: didactic guidelines. BMC Med Res Methodol 2002; 2:9.

25. Whiting PF, Weswood ME, Rutjes AW, Reitsma JB, Bossuyt PN, Kleijnen J. Evaluation of QUADAS, a tool for the quality assessment of diagnostic accuracy studies. BMC Med Res Methodol 2006; 6:9.

26. Egger M, Smith GD, Altman DG. Systematic reviews in health care. BMJ Publishing Group, London 2005;271.

27. Higgins JP, Thompson SG, Deeks JJ, Altman DG. Measuring inconsistency in metaanalyses. BMJ 2003;327:557-60.

28. Vlaar AMM, Kessels AGH, Nijs de T, Winogrodzka A, Mess WH, Kroonenburgh MJPG, Weber WEJ. Additional value of SPECT imaging in comparance with clinical diagnosis in 248 patients with parkinsonism. Movement Disorders 2007;22 (supplement 16):S233.

29. Brucke T, Asenbaum S, Pirker W, Djamshidian S, Wenger S, Wober C, Muller C, Podreka I. Measurement of the dopaminergic degeneration in Parkinson's disease with [123I] beta-CIT and SPECT. Correlation with clinical findings and comparison with multiple system atrophy and progressive supranuclear palsy. J Neural Transm Suppl 1997;50:9-24.

30. Lu CS, Weng YH, Chen MC, Chen RS, Tzen KY, Wey SP, Ting G, Chang HC, TC Yen. 99mTC-TRODAT-1 imaging of multiple system atrophy. J Nucl Med 2004;45:49-55.

31. Popperl G, Radau P, Linke R, Hahn K, Tatsch K. Diagnostic performance of a 3-D automated quantification method of dopamine D2 receptor SPECT studies in the differential diagnosis of parkinsonism. Nucl Med Commun 2005;26:39-43.

32. Swanson RL, Newberg AB, Acton PD, Siderowf A, Wintering N, Alavi A, Mozley PD, Plossl K, Udeshi $M$, Hurtig $H$. Differences in [99mTc]TRODAT-1 SPECT binding to dopamine transporters in patients with multiple system atrophy and Parkinson's disease. Eur J Nucl Med Mol Imaging 2005;32:302-7.

33. Asenbaum S, Pirker W, Angelberger P, Bencsits G, Pruckmayer M, Brucke T. [123I]beta-CIT and SPECT in essential tremor and Parkinson's disease. J Neural Transm 1998;105:1213-28.

34. Schwarz J, Tatsch K, Gasser T, Arnold G, Pogarell O, Kunig G, Oertel WH. 123I-IBZM binding compared with long-term clinical follow up in patients with de novo parkinsonism. Mov Disord 1998;13:16-9.

35. Schwarz J, Tatsch K, Arnold G, Ott M, Trenkwalder C, Kirsch CM, Oertel WH. 123Iiodobenzamide-SPECT in 83 patients with de novo parkinsonism. Neurology 1993;43: S17-20.

36. Booij J, Speelman JD, Horstink MW, Wolters EC. The clinical benefit of imaging striatal dopamine transporters with [123I]FP-CIT SPET in differentiating patients with presynaptic parkinsonism from those with other forms of parkinsonism. Eur J Nucl Med 2001;28:266-72.

37. Schwarz J, Tatsch K, Gasser T, Arnold G, Oertel WH. [123]IBZM binding predicts dopaminergic responsiveness in patients with parkinsonism and previous dopaminomimetic therapy. Mov Disord 1997;12:898-902.

38. Lokkegaard A, Werdelin LM, Friberg L. Clinical impact of diagnostic SPET investigations with a dopamine re-uptake ligand. Eur J Nucl Med Mol Imaging 2002;29:1623-9.

39. Stoffers D, Booij J, Bosscher L, Winogrodzka A, Wolters EC, Berendse HW. Early-stage [(123)!]beta-CIT SPECT and long-term clinical follow-up in patients with an initial diagnosis of Parkinson's disease. Eur J Nucl Med Mol Imaging 2005. 
40. Haapaniemi TH, Ahonen A, Torniainen P, Sotaniemi KA, Myllyla VV. [123I]beta-CIT SPECT demonstrates decreased brain dopamine and serotonin transporter levels in untreated parkinsonian patients. Mov Disord 2001;16:124-30.

41. Huang WS, Lin SZ, Lin JC, Wey SP, Ting G, Liu RS. Evaluation of early-stage Parkinson's disease with 99mTc-TRODAT-1 imaging. J Nucl Med 2001;42:1303-8.

42. Schwarz J, Linke R, Kerner M, Mozley PD, Trenkwalder C, Gasser T, Tatsch K. Striatal dopamine transporter binding assessed by [I-123]IPT and single photon emission computed tomography in patients with early Parkinson's disease: implications for a preclinical diagnosis. Arch Neurol 2000;57:205-8.

43. van Laere K, de Ceuninck L, Dom R, van den Eynden J, Vanbilloen H, Cleynhens J, Dupont $P$, Bormans G, Verbruggen A, Mortelmans L. Dopamine transporter SPECT using fast kinetic ligands: 123I-FP-beta-CIT versus 99mTc-TRODAT-1. Eur J Nucl Med Mol Imaging 2004; 31:1119-27.

44. Muller T, Farahati J, Kuhn W, Eising EG, Przuntek H, Reiners C, Coenen HH. [123I]beta-CIT SPECT visualizes dopamine transporter loss in de novo parkinsonian patients. Eur Neurol 1998;39:44-8.

45. Lee MS, Kim YD, Im JH, Kim HJ, Rinne JO, Bhatia KP. 123I-IPT brain SPECT study in essential tremor and Parkinson's disease. Neurology 1999;52:1422-6.

46. Plotkin M, Amthauer H, Klaffke S, Kuhn A, Ludemann L, Arnold G, Wernecke KD, Kupsch A, Felix R, Venz S. Combined (123)I-FP-CIT and (123)I-IBZM SPECT for the diagnosis of parkinsonian syndromes: study on 72 patients. J Neural Transm 2005;112:677-92.

47. Eerola J, Tienari PJ, Kaakkola S, Nikkinen P, Launes J. How useful is [123l]beta-CIT SPECT in clinical practice? J Neurol Neurosurg Psychiatry 2005;76:1211-6.

48. Benamer TS, Patterson J, Grosset DG, Booij J, de Bruin K, van Royen E, Speelman JD, Horstink MH, Sips HJ, Dierckx RA, Versijpt J, Decoo D, Van Der Linden C, Hadley DM, Doder M, Lees AJ, Costa DC, Gacinovic S, Oertel WH, Pogarell O, Hoeffken H, Joseph K, Tatsch K, Schwarz J, Ries V. Accurate differentiation of parkinsonism and essential tremor using visual assessment of [123I]-FP-CIT SPECT imaging: the [123I]-FP-CIT study group. Mov Disord 2000;15:503-10.

49. Gerschlager W, Bencsits G, Pirker W, Bloem BR, Asenbaum S, Prayer D, Zijlmans JC, Hoffmann M, Brucke T. [123I]beta-CIT SPECT distinguishes vascular parkinsonism from Parkinson's disease. Mov Disord 2002;17:518-23.

50. Kim YJ, Ichise M, Ballinger JR, Vines D, Erami SS, Tatschida T, Lang AE. Combination of dopamine transporter and D2 receptor SPECT in the diagnostic evaluation of PD, MSA, and PSP. Mov Disord 2002;17:303-12.

51. Messa C, Volonte MA, Fazio F, Zito F, Carpinelli A, d'Amico A, Rizzo G, Moresco RM, Paulesu E, Franceschi M, Lucignani G. Differential distribution of striatal [123I]beta-CIT in Parkinson's disease and progressive supranuclear palsy, evaluated with single-photon emission tomography. Eur J Nucl Med 1998;25:1270-6.

52. Pirker W, Djamshidian S, Asenbaum S, Gerschlager W, Tribl G, Hoffmann M, Brucke T. Progression of dopaminergic degeneration in Parkinson's disease and atypical parkinsonism: a longitudinal beta-CIT SPECT study. Mov Disord 2002;17:45-53.

53. Oyanagi C, Katsumi Y, Hanakawa T, Hayashi T, Thuy DD, Hashikawa K, Nagahama $Y$, Fukuyama H, Shibasaki H. Comparison of striatal dopamine D2 receptors in Parkinson's disease and progressive supranuclear palsy patients using [123l] iodobenzofuran singlephoton emission computed tomography. J Neuroimaging 2002;12:316-24.

54. Oertel WH, Schwarz J, Tatsch K, Arnold G, Gasser T, Kirsch CM. IBZM-SPECT as predictor for dopamimetic responsiveness of patients with de novo parkinsonian syndrome. Adv Neurol 1993;60:519-24.

55. Tatsch K, Schwarz J, Oertel WH, Kirsch CM. SPECT imaging of dopamine D2 receptors with 123I-IBZM: initial experience in controls and patients with Parkinson's syndrome and Wilson's disease. Nucl Med Commun 1991;12:699-707.

56. Buck A, Westera G, Sutter M, Albani C, KungHF, vonSchulthess GK. lodine-123-IBF SPECT evaluation of extrapyramidal diseases. J Nucl Med 1995;36:1196-200. 
57. Seppi K, Schocke MF, Donnemiller E, Esterhammer R, Kremser C, Scherfler C, Diem A, Jaschke W, Wenning GK, Poewe W. Comparison of diffusion-weighted imaging and [123I]IBZM-SPECT for the differentiation of patients with the Parkinson variant of multiple system atrophy from those with Parkinson's disease. Mov Disord 2004;19:1438-45.

58. Schelosky L, Hierholzer J, Wissel J, Cordes M, Poewe W. Correlation of clinical response in apomorphine test with D2-receptor status as demonstrated by 123 I IBZM-SPECT. Mov Disord 1993;8:453-8.

59. Pirker W, Asenbaum S, Wenger S, Kornhuber J, Angelberger P, Deecke L, Podreka I, Brucke T. lodine-123-epidepride-SPECT: studies in Parkinson's disease, multiple system atrophy and Huntington's disease. J Nucl Med 1997;38:1711-7.

60. van Royen E, Verhoeff NF, Speelman JD, Wolters EC, Kuiper MA, Janssen AG. Multiple system atrophy and progressive supranuclear palsy. Diminished striatal D2 dopamine receptor activity demonstrated by $123 \mathrm{I}-\mathrm{IBZM}$ single photon emission computed tomography. Arch Neurol 1993;50:513-6.

61. Pirker W, Asenbaum S, Bencsits G, Prayer D, Gerschlager W, Deecke L, Brucke T. [123I]beta-CIT SPECT in multiple system atrophy, progressive supranuclear palsy, and corticobasal degeneration. Mov Disord 2000;15:1158-67.

62. Seibyl JP, Marek K, Sheff K, Zoghbi S, Baldwin RM, Charney DS, van Dyck CH, RB Innis RB. lodine-123-beta-CIT and iodine-123-FPCIT SPECT measurement of dopamine transporters in healthy subjects and Parkinson's patients. J Nucl Med 1998;39:1500-8.

63. Booij J, Tissingh G, Winogrodzka A, Boer GJ, Stoof JC, Wolters EC, van Royen EA. Practical benefit of [123l]FP-CIT SPET in the demonstration of the dopaminergic deficit in Parkinson's disease. Eur J Nucl Med 1997;24:68-71.

64. Hierholzer J, Cordes M, Venz S, Schelosky L, Harisch C, Richter W, Keske U, Hosten N, Maurer J, Poewe W, Felix R. Loss of dopamine-D2 receptor binding sites in Parkinsonian plus syndromes. J Nucl Med 1998;39:954-60.

65. Pirker W, Holler I, Gerschlager W, Asenbaum S, Zettinig G, Brucke T. Measuring the rate of progression of Parkinson's disease over a 5-year period with beta-CIT SPECT. Mov Disord 2003;18:1266-72.

66. Booij J, Bergmans P, Winogrodzka A, Speelman JD, Wolters EC. Imaging of dopamine transporters with [123I]FP-CIT SPECT does not suggest a significant effect of age on the symptomatic threshold of disease in Parkinson's disease. Synapse 2001;39:101-8.

67. van Dyck CH, Seibyl JP, Malison RT, Laruelle M, Zoghbi SS, Baldwin RM, Innis RB. Agerelated decline in dopamine transporters: analysis of striatal subregions, nonlinear effects, and hemispheric asymmetries. Am J Geriatr Psychiatry 2002;10:36-43.

68. Whone AL, Watts RL, Stoessl AJ, Davis M, Reske S, Nahmias C, Lang AE, Rascol O, Ribeiro MJ, Remy P, Poewe WH, Hauser RA, Brooks DJ; REAL-PET Study Group. Slower progression of Parkinson's disease with ropinirole versus levodopa: The REAL-PET study. Ann Neurol 2003;54:93-101.

69. Fahn S. Parkinson disease, the effect of levodopa, and the ELLDOPA trial. Earlier vs Later LDOPA. Arch Neurol 1999;56:529-35.

70. Benamer HT, Oertel WH, Patterson J, Hadley DM, Pogarell O, Hoffken H, Gerstner A, Grosset DG. Prospective study of presynaptic dopaminergic imaging in patients with mild parkinsonism and tremor disorders: part 1. Baseline and 3-month observations. Mov Disord 2003;18:977-84.

71. Lorberboym M, Djaldetti R, Melamed E, Sadeh M, Lampl Y. 123I-FP-CIT SPECT imaging of dopamine transporters in patients with cerebrovascular disease and clinical diagnosis of vascular parkinsonism. J Nucl Med 2004;45:1688-93.

72. Schwarz J, Kraft E, Vogl T, Arnold G, Tatsch K, Oertel WH. Relative quantification of signal on T2-weighted images in the basal ganglia: limited value in differential diagnosis of patients with parkinsonism. Neuroradiology 1999;41:124-8.

73. Pizzolato G, Cagnin A, Rossato A, Chierichetti F, Fabbri M, Dam M, Ferlin G, Battistin L. Striatal dopamine D2 receptor alterations and response to L-DOPA in Parkinson's disease. A [123I]IBZM SPET study. Adv Neurol 1996;69:467-73. 
74. Schwarz J, Tatsch K, Arnold G, Gasser T, Trenkwalder C, Kirsch CM, Oertel WH. 123Iiodobenzamide-SPECT predicts dopaminergic responsiveness in patients with de novo parkinsonism. Neurology 1992;42:556-61.

75. Hierholzer J, Cordes M, Schelosky L, Sander B, Bock JC, David I, Horowski R, Poewe W. The differential diagnosis of Parkinson diseases--123I-IBZM-SPECT vs. the apomorphine test. Rofo 1993;159:86-90.

76. Knudsen GM, Karlsborg M, Thomsen G, Krabbe K, Regeur L, Nygaard T, Videbaek C, Werdelin L. Imaging of dopamine transporters and D2 receptors in patients with Parkinson's disease and multiple system atrophy. Eur J Nucl Med Mol Imaging 2004;31:1631-8.

77. Prunier C, Tranquart F, Cottier JP, Giraudeau B, Chalon S, Guilloteau D, De Toffol B, Chossat F, Autret A, Besnard JC, Baulieu JL. Quantitative analysis of striatal dopamine D2 receptors with 123 I-iodolisuride SPECT in degenerative extrapyramidal diseases. Nucl Med Commun 2001;22:1207-14.

78. Schulz JB, Klockgether T, Petersen D, Jauch M, Muller-Schauenburg W, Spieker S, Voigt K, Dichgans J. Multiple system atrophy: natural history, MRI morphology, and dopamine receptor imaging with 123IBZM-SPECT. J Neurol Neurosurg Psychiatry 1994;57:1047-56.

79. Berding G, Gratz KF, Kolbe H, Meyer GJ, Dengler R, Knoop BO, Hundeshagen H. 123I-IBZM SPECT. reconstruction methodology and results in parkinsonism and dystonia. Nuklearmedizin 1994;33:194-9.

80. Bettin S, Kampfer I, Seese A, Schafer A, Reuter M, Lossner J, Dietrich J, Wagner A, Knapp WH. Striatal uptake of I-123-beta-CIT and I-123-IBZM in patients with extrapyramidal symptoms. Nuklearmedizin 1997;36:167-72.

81. Scherfler C, Seppi K, Donnemiller E, Goebel G, Brenneis C, Virgolini I, Wenning GK, Poewe W. Voxel-wise analysis of [123I] beta-CIT SPECT differentiates the Parkinson variant of multiple system atrophy from idiopathic Parkinson's disease. Brain 2005.

82. Staffen W, Mair A, Unterrainer J, Trinka E, Ladurner G. Measuring the progression of idiopathic Parkinson's disease with [123l] beta-CIT SPECT. J Neural Transm 2000;107: 543-52.

83. Thobois S, Jahanshahi M, Pinto S, Frackowiak R, Limousin-Dowsey P. PET and SPECT functional imaging studies in Parkinsonian syndromes: from the lesion to its consequences. Neuroimage 2004;23:1-16.

84. Parkinson Study Group. A multicenter assessment of dopamine transporter imaging with DOPASCAN/SPECT in parkinsonism. Neurology 2000;55:1540-7. 

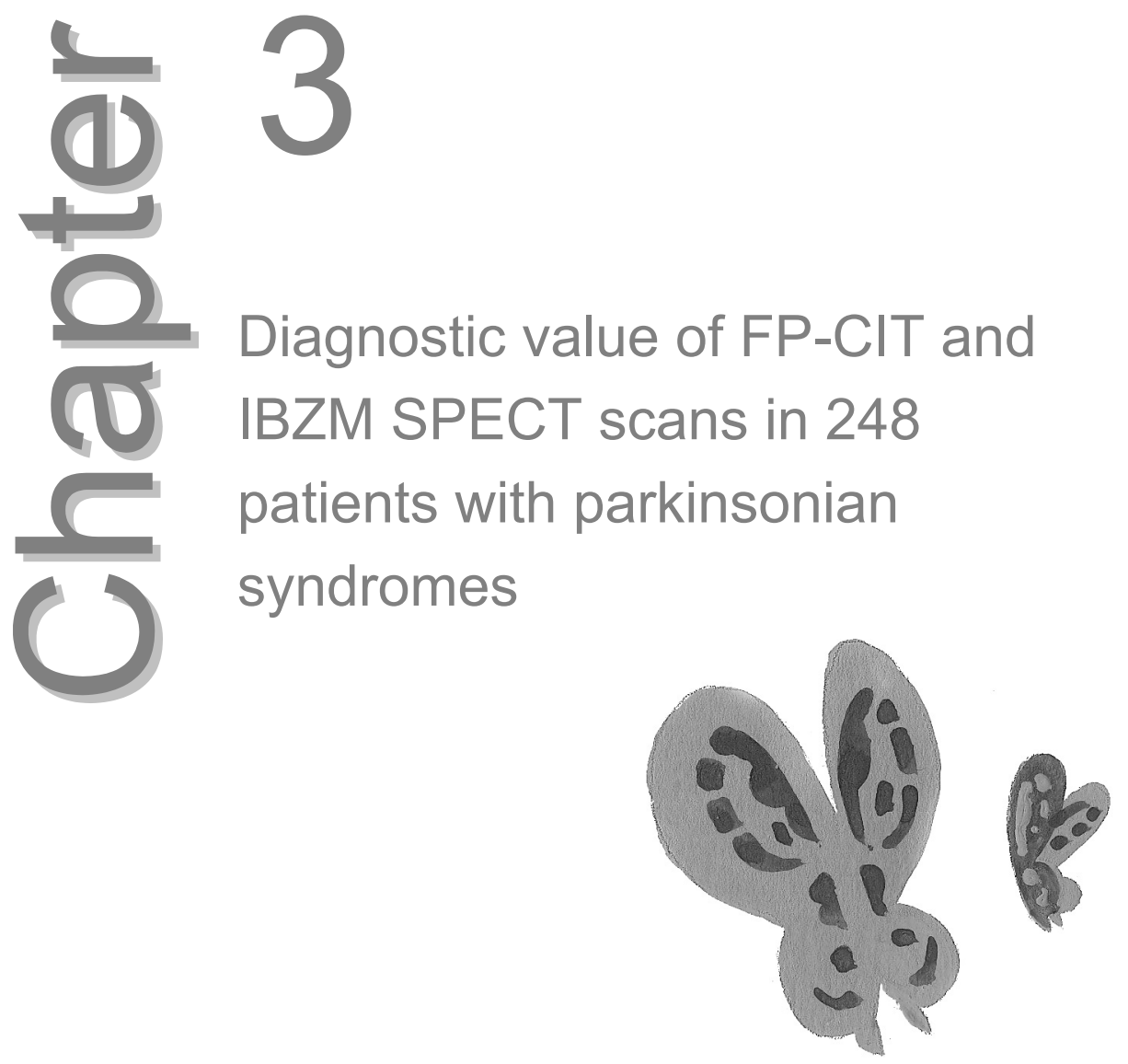

Annemarie M.M. Vlaar, Tjerk de Nijs, Alfons G.H. Kessels, Fred W. Vreeling, Ania Winogrodzka, Werner H. Mess, Selma C. Tromp, Marinus J.P.G. van Kroonenburgh, Wim E.J. Weber 


\section{Abstract}

\section{Background}

Single Photon Emission Computer Tomography (SPECT) is one of the most employed techniques in the diagnostic work-up of idiopathic Parkinson's disease (IPD). Despite of its widespread use, the exact diagnostic accuracy of this technique in parkinsonian syndromes remains controversial.

\section{Methods}

In this study we investigated the diagnostic accuracy of an initial ${ }^{123}$ I-ioflupane (FP-CIT) and/or ${ }^{123}$ Iiodobenzamide (IBZM) SPECT to differentiate between IPD and other parkinsonian disorders. 248 patients underwent a SPECT scan because of an as yet unclassified parkinsonian syndrome in our clinic between 2001 and 2006. Gold standard was the clinical diagnosis derived from the latest available clinical record, or, when this was not possible, a new complete physical and neurological examination by a blinded movement disorder specialist neurologist. Mean follow-up between SPECT and the latest clinical information was 18 months (range 3 months- 5 years).

\section{Results}

223 of the 248 patients were clinically definitely diagnosed after follow-up: IPD 127, atypical parkinsonian syndromes (APS) 27, essential tremor (ET) 22, vascular parkinsonism (VP) 16, druginduced parkinsonism (DIP) 5, doubt between IPD and APS 2, other diseases without dopaminergic involvement 24.

The mean odds ratio $(\mathrm{OR}, 95 \% \mathrm{Cl})$ for FP-CIT SPECT's ability to distinguish between IPD and ET was 82 (11-674); between IPD and VP 61 (8-490); between IPD and DIP 33 (2-697) and between IPD and APS was $1(0-4)$. The odds ratio for the IBZM SPECT tracer to differentiate between IPD and APS was $7(2-17)$.

\section{Conclusions}

FP-CIT SPECT is accurate to differentiate patients with IPD from those with ET, and IPD from VP and DIP. The accuracy of both FP-CIT and IBZM SPECT scans to differentiate between IPD and APS is low. 


\section{Introduction}

Idiopathic Parkinson's disease (IPD) is the second most common neurodegenerative disorder with a prevalence in industrialised countries of $0.3 \%$ in the entire population and about $1 \%$ in people over 60 years of age. ${ }^{1}$ The exact cause of IPD is still unknown, but the main pathological hallmark of the disease is the loss of dopaminergic neurons in the basal ganglia. ${ }^{2}$ Diagnosis is based on clinical criteria. ${ }^{3}$ In most cases the diagnosis of IPD is straightforward when cardinal clinical signs and symptoms as bradykinesia, rigidity, resting tremor and postural instability are present. ${ }^{3}$ However, solely on clinical grounds it is, especially in the early stages, often difficult to differentiate IPD from other parkinsonian syndromes. Diseases resembling IPD in an early stage are diseases which might resemble early-stage IPD are atypical parkinsonian syndromes (APS, i.e. multiple system atrophy [MSA] and progressive supranuclear palsy [PSP]) or secondary parkinsonism (i.e. vascular parkinsonism [VP], drugs induced parkinsonism [DIP]) and essential tremor $(\mathrm{ET}))^{4-9}$ Since the prognosis and medical treatment are different in the various parkinsonian syndromes, an accurate and early diagnosis is essential for optimal counselling.

Single Photon Emission Computer Tomography (SPECT) is widely used to visualise the integrity of the nigrostriatal dopaminergic system. SPECT with various tracers labelling presynaptic dopamine transporters (such as ${ }^{123}$ I-ioflupane (FP-CIT)) has been shown to correlate with clinical severity and disease progression of IPD. ${ }^{10-14}$ The uptake of these radiotracers, however, has also to been shown to be decreased in the atypical parkinsonian syndromes (APS: i.e. MSA, PSP and DLBD). ${ }^{15-18}$ SPECT with tracers labelling postsynaptic dopamine receptors (such as ${ }^{123}$ I-iodobenzamide (IBZM)) have been used to differentiate IPD from APS. ${ }^{17,19,20}$ Some have suggested even that the combination of presynaptic SPECT and postsynaptic SPECT scan gives better discrimination between IPD and APS. ${ }^{17,21}$ Despite its widespread use, the exact diagnostic accuracy of these techniques in parkinsonian syndromes remains controversial. ${ }^{22-24}$

In the present study we investigated the diagnostic accuracy in 248 patients in whom FP-CIT and/or IBZM SPECT scans were performed because of uncertainty on the diagnosis of their parkinsonian syndrome. 


\section{Patients and methods}

\section{Subjects}

We see an estimated 250 new patients (primary and secondary referrals and requests for second opinions) with parkinsonism in our Neurology outpatient clinic each year, of which about $20 \%$ are referred for SPECT scintigraphy. Patients who did not undergo SPECT scanning were mainly patients presenting with a clear unequivocal diagnosis of their parkinsonism, and referrals who already had SPECT scintigraphy elsewhere.

From February 2001 tot February 2006301 patients with parkinsonism were subjected to a SPECT scan in our hospital. Fifty-three patients were excluded because they already had a clear diagnosis and underwent SPECT as part of a diagnostic work-up for a Deep Brain Stimulation procedure, where one wants to exclude diagnoses other than IPD. The included 248 patients all suffered an as yet unclassified parkinsonian syndrome.

Depending on the clinical differential diagnosis of the neurologist a FP-CIT $(n=80)$, an IBZM SPECT $(n=38)$ or both scans $(n=130)$ were performed.

The study was approved by the University Hospital Maastricht Institutional Review Board and all patients who were re-examined clinically to reach a definite diagnosis gave informed consent.

Fifty-nine percent of the 248 patients were male. The mean age was 65 years with a range from 21 to 96 years (standard deviation (SD) 11 years). The initial probable diagnosis of the neurologist before SPECT imaging was IPD in 125 patients, APS (MSA, PSP or DLBD) in 41 patients, VP 9, ET 10 and DIP in 2 patients. In 61 cases the initial probable diagnosis was solely defined as parkinsonism. For the clinical diagnosis after follow-up see Table 3.1.

The mean Hoehn and Yahr score was 2.4 (range 1 to 5; sd 1.2). Of all patients $37 \%$ were on dopaminergic drugs before they were referred for SPECT scanning.

The mean duration of the complaints before SPECT imaging was 45 months (range 2 to 250; sd 45) and the clinical follow-up after the SPECT scan was at least 3 months with a mean (SD) of 18 (15) months. If a patient underwent both scans, the mean elapsed time between the FP-CIT and IBZM SPECT was 40 days (range 1-1460; median 5; sd 178 days).

\section{Acquisition of clinical data and final clinical diagnosis}

Two investigators (AV, TN) checked each patient record and filled in a standard form. The investigators established a clinical diagnosis according to generally accepted clinical criteria. ${ }^{3,8,25-28}$ If the investigators did not reach consensus, or if the patient did not fulfil the accepted criteria for a final diagnosis, a movement disorder specialist neurologist (AW, WW) was asked for advice. In case of 
persistent discussion, the movement disorder specialist could decide to contact the referring neurologist, to phone the patient or to ask the patient to visit the clinic for re-examination by a movement disorder specialist neurologist (AW, FV, WW).

Table 3.1 Demographic and clinical variables for each patient subgroup.

\begin{tabular}{|c|c|c|c|c|c|c|}
\hline $\begin{array}{l}\text { Final clinical } \\
\text { diagnosis } \\
n=\end{array}$ & $\begin{array}{c}\text { Age } \\
\text { Median } \\
(25-75 \% \text { IR })\end{array}$ & $\begin{array}{c}\text { Sex } \\
n=\end{array}$ & $\begin{array}{l}\text { H\&Y score* } \\
\text { Median } \\
(25-75 \% \text { IR) }\end{array}$ & $\begin{array}{l}\text { Duration before } \\
\text { SPECT in } \\
\text { months } \\
\text { Median } \\
(25-75 \% \text { IR })\end{array}$ & $\begin{array}{c}\text { Follow up after } \\
\text { SPECT } \\
\text { in months } \\
\text { Median } \\
(25-75 \% \text { IR) }\end{array}$ & $\begin{array}{c}\text { Dead at the } \\
\text { moment of } \\
\text { data analyses } \\
n=\end{array}$ \\
\hline $\begin{array}{l}\mathrm{IPD} \\
\mathrm{n}=127\end{array}$ & $64(56-72)$ & $44 \uparrow, 83 \bigcirc^{\wedge}$ & $2(1-3)$ & $30(12-60)$ & $16(8-36)$ & 7 \\
\hline $\begin{array}{l}\text { APS } \\
n=27\end{array}$ & $67(67-73)$ & 14 ․, $13 \widehat{\diamond}$ & $3(2-4)$ & $23(12-39)$ & $13(4-24)$ & 8 \\
\hline $\begin{array}{l}\text { IPD or APS } \\
n=2\end{array}$ & $59(40-75)$ & 2 우, $0 \curvearrowright$ & $1.5(1-2)$ & $48(36-60)$ & $20(12-28)$ & - \\
\hline $\begin{array}{l}E T \\
n=22\end{array}$ & $68(62-74)$ & 11 ㅇ, $11 \overbrace{}^{\lambda}$ & $2(1-2)$ & $48(27-114)$ & $20(9-39)$ & 2 \\
\hline $\begin{array}{l}\text { VP } \\
n=16\end{array}$ & $73(66-78)$ & $3+13 \AA$ & $3(2-4)$ & $24(12-42)$ & $7(4-29)$ & 4 \\
\hline $\begin{array}{l}\text { DIP } \\
n=5\end{array}$ & $60(58-68)$ & 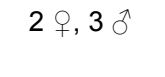 & $3(2-4)$ & $48(19-72)$ & $12(4-33)$ & 1 \\
\hline $\begin{array}{l}\text { other } \\
n=24\end{array}$ & $65(53-78)$ & 13 \%, $11 \mathrm{o}^{\lambda}$ & $3(2.5-3)$ & $36(11-63)$ & $7(4-24)$ & 2 \\
\hline $\begin{array}{l}\text { inconclusive } \\
\mathrm{n}=25\end{array}$ & $68(57-77)$ & 12 ㅇ, 13 ๙ & $2(2-4)$ & $36(13-72)$ & $3(1-20)$ & 6 \\
\hline $\begin{array}{l}\text { total } \\
n=248\end{array}$ & $67(58-74)$ & 100 ㅇ, $148 \overbrace{}^{\pi}$ & $2(2-3)$ & $36(12-60)$ & $13(5-27)$ & 30 \\
\hline
\end{tabular}

IPD: idiopathic Parkinson's disease; APS: atypical parkinsonian syndromes; ET: essential tremor; VP: vascular parkinsonism; DIP drug induced parkinsonism; n: number of subjects; IR: interquartile range; H\&Y: Hoehn and Yahr.

* Hoehn and Yahr scores are formally restricted to IPD, but we have assessed these also in the other patient groups to facilitate comparison between these groups.

\section{SPECT}

In this study FP-CIT (General Electrics Health, Eindhoven, The Netherlands) was used to visualise the integrity of the presynaptic dopaminergic system and IBZM (General Electrics Health, Eindhoven, The Netherlands) to visualise the postsynaptic dopamine receptors. Medication which could interfere with the radiotracer was stopped at least five half-life times before the SPECT scan was made. SPECT scans were performed with a triple head camera (MultiSPECT3, Siemens, Ohio, USA) equipped with high-resolution collimators. A semiautomatic template model programme was used to calculate the ratios between left striatal and right striatal and occipital regions, respectively. Total time of acquisition was 30 minutes ( 45 seconds per frame for 40 views per detector), 
zoom factor: 1.00 and the matrix size: $128 \times 128$. Filtered back-projection acquisition was performed. ${ }^{29}$

Images were filtered using a Butterworth filter with a cut-off value of 0.4-0.5 and an order of 5 . The ratios were corrected using Alderson's brain phantom with known activities in the caudate nucleus and putamen. A binding of two standard deviations (sd) below or above healthy controls was considered as abnormal (FP CIT 8.25, sd 1.85 for putamen and 7.76, sd 1.77 for caudate nucleus. IBZM for striatum 3.58 , sd 0.18 ). The scans were analysed by a nuclear specialist blinded for the clinical diagnosis.

\section{Data analysis}

Descriptives are presented as median and inter-quartile ranges, unless otherwise specified. To determine the accuracy to differentiate between IPD, ET and other parkinsonian syndromes sensitivity, specificity, positive predictive value (PPV), negative predictive value (NPV) and diagnostic odd's ratio (OR) with its $95 \%$ confidence intervals $(95 \% \mathrm{Cl})$ were calculated. This was determined for the initial probable diagnosis of the neurologist, FP-CIT- and IBZM SPECT results and the combination of both. Finally, we calculated the additional value of judging the caudate nucleus FP-CIT binding ratios in comparison with only putamen FP-CIT binding.

All descriptive analyses were made with software SPSS 11.0 for Windows (SPSS, Chicago, IL) and the accuracy parameters were determined with Stata/SE9.

\section{Results}

In 154 of the 248 cases the investigators reached consensus and were certain enough to make a final diagnosis from the clinical records alone, according to generally accepted criteria. ${ }^{3,8,25-28}$ Of the remaining ninety-two patients five patients had died, two could not be traced and two lived outside the district.

In twenty-seven of the eighty-five patients still without final diagnosis the referring neurologist was phoned and in five cases the patient, to obtain information about the follow-up period. Finally fifty-three patients were asked to visit for re-examination. Forty-five of these gave informed consent. Most important reasons for refusing consent for re-examination were decreased mobility, living in a nursing home and anxiety. Figure 3.1 presents a flowchart of patients in- and excluded from the analysis. 


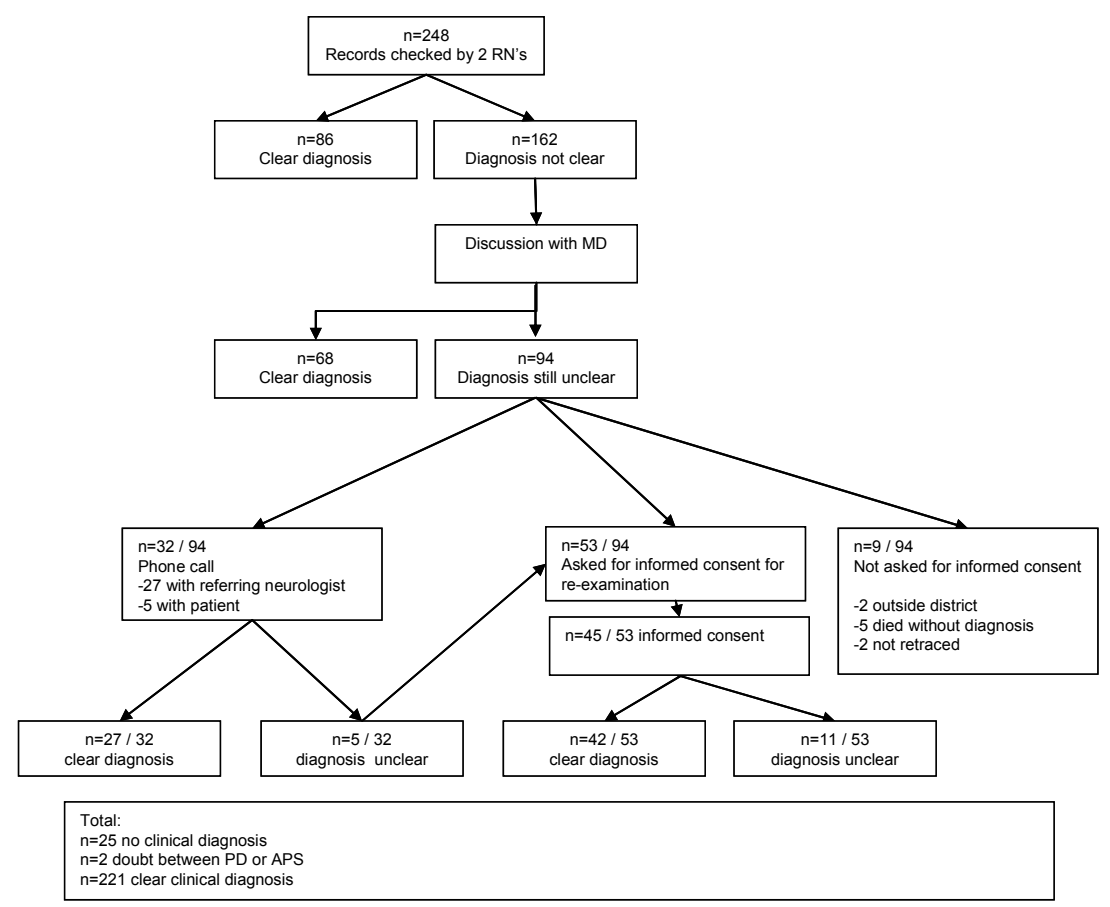

Figure 3.1 Flowchart

$\mathrm{n}$ : number of patients; RN: resident in neurology; MD: movement disorder specialist.

In 223 of the 248 patients the final clinical diagnosis after follow-up was known: IPD in 127 patients, APS in 27 ( $n=17$ MSA, n=8 PSP, $n=2$ DLBD), unclear but IPD or APS in 2, ET in 22, DIP in 5 and VP in 16 patients. Of the sixteen patients diagnosed with VP six underwent MRI-scan and ten underwent CTscan. In ten of the sixteen patients vascular lesions were visible in typical places according the criteria formulated by Zijlmans et al. ${ }^{26}$ All the other patients had suffered at least one stroke, but their vascular lesions on CT or MRI-cerebrum were at non-typical places like capsula interna, parietal or occipital lobe. However, all patients had parkinsonism and a time relationship (acute or delayed) between stroke and parkinsonism or in case of multiple subcortical white matter lesions an insidious onset of parkinsonism and no exclusion criteria for VP.

Twenty-four patients were diagnosed with another diagnosis without dopaminergic involvement (i.e. no clear indication of parkinsonism [ $\mathrm{n}=8]$, psychogenic parkinsonism [ $n=1]$, normal pressure hydrocephalus [ $n=2]$, Alzheimer's disease [n=4], autonomic failure [n=1], corticobasal degeneration $[n=1]$, frontotemporal dementia [n=1], alcohol abuse $[n=1]$, Meige syndrome 
[n=1], Niemann-Pick syndrome [n=1], familiar dominant tremor [n=1], dystonia $[n=1]$, inconclusive but no dopaminergic involvement $[n=1]$ ).

The absolute tracer binding rates of FP-CIT and IBZM SPECT scans for each parkinsonian subgroup are shown in Figure 3.2A and 3.2B. From these figures one sees that the median of the absolute putamen FP-tracer binding ratios in the IPD group as well as in the APS group is decreased compared with for example ET patients.

A

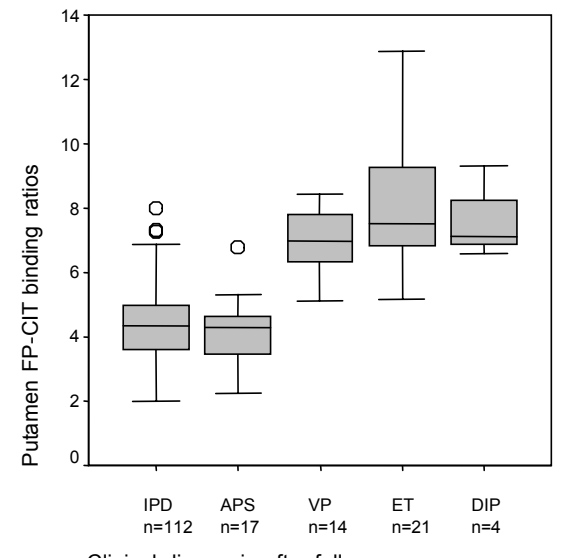

Clinical diagnosis after follow-up
B

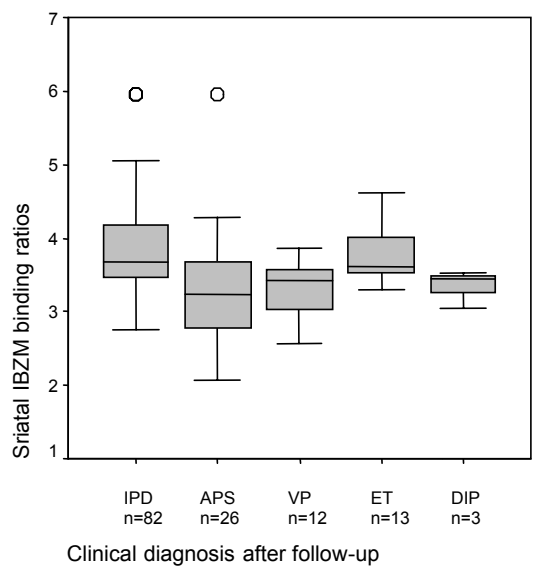

Figure 3.2 A. Box plot of the median FP-CIT binding ratios and interquartile ranges for each subgroup

B. Box plot of the median IBZM binding ratios and interquartile ranges for each subgroup

IPD: idiopathic Parkinson's disease, APS: atypical parkinsonian syndromes, VP: vascular parkinsonism, ET: essential tremor, DIP: drug induced parkinsonism.

The striatal IBZM binding ratios in the APS group for example are decreased in comparison with the IPD group. However, discrimination between the groups is difficult, because of a large overlap in ranges.

Besides the diagnostic accuracy for the different subgroups of patients we also determined the accuracy of SPECT and the initial probable diagnosis of the clinician for each individual patient separately. A summary of the results of presynaptic and postsynaptic SPECT scanning for all patients in the different subgroups of the final diagnoses (IPD, ET, VP and APS) is given in Table 3.2. From this table the numbers of true positives, true negatives, false positives and false negatives are derived to calculate the sensitivity, specificity, PPV, NPV and mean odd's ratio (OR) for the differentiation between IPD versus ET, IPD versus VP, IPD versus DIP and IPD versus APS. An overview is given in Figure 3.3. 
As shown in Figure 3.3, FP-CIT SPECT's ability to distinguish between patients with IPD and patients with ET is high. FP-CIT scans are also relatively accurate to differentiate patients with IPD from those with VP or DIP. In these three situations sensitivity is $80 \%$ and specificity $95-100 \%$. With a positive predictive value (PPV) of above $95 \%$ an abnormal FP-CIT SPECT scan is highly predictive for IPD. However, the negative predictive value (NPV) of a normal SPECT for ET, VP or DIP is low (15-48\%). This is a consequence of the fact that not only twenty of the twenty-one ET patients and all fourteen VP and four DIP patients had a normal FP-CIT SPECT scan, but also twenty-two of the 112 IPD patients.

The addition of IBZM SPECT only leads to a small (not statistically significant) increase in accuracy in the discrimination between patients with IPD from VP and patients with IPD from DIP. See also Figure 3.3 and Table 3.2.

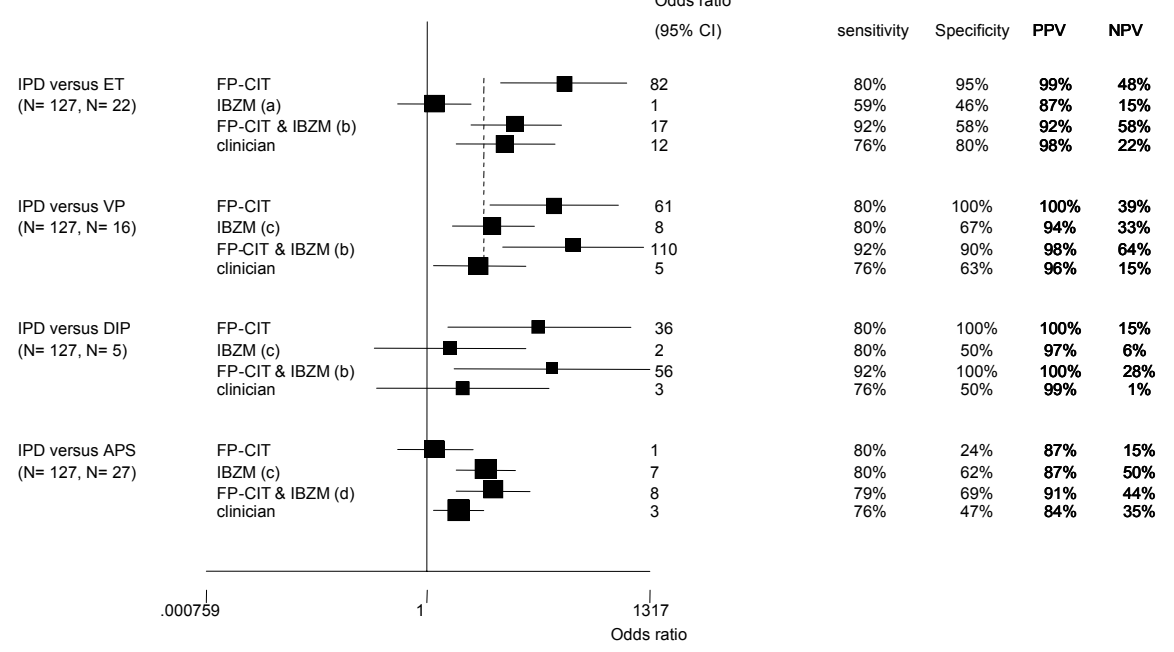

Figure 3.3 Accuracy of FP-CIT SPECT, IBZM SPECT, the combination of FP-CIT \& IBZM SPECT, and the initial diagnosis of the clinician to predict clinical diagnosis after follow-up.

IPD: idiopathic Parkinson's disease, ET: essential tremor, VP: vascular parkinsonism, DIP: drug induced parkinsonism, APS: atypical parkinsonian syndromes (i.e. MSA, PSP, DLBD), PPV: positive predictive value, NPV: negative predictive value, clinician: initial diagnosis of the clinician, $\mathrm{n}$ : number of subjects.

$a=$ True positives: IPD patients with decreased or increased IBZM binding ratios.

True negatives: ET patients with normal IBZM SPECT.

$b=$ True positives: ET, VP and DIP patients with normal FP-CIT and normal (or decreased) IBZM binding ratios.

True negatives: IPD patients with all other SPECT combinations.

$c=$ True positives: IPD patients with normal or increased IBZM binding ratios.

True negatives: VP, DIP and APS patients with decreased IBZM binding ratios.

$\mathrm{d}=$ True positives: APS patients with the combination normal FP-CIT and decreased IBZM binding or a combination of decreased FP-CIT as well as decreased IBZM binding ratios.

True negatives: IPD patients with all other combinations. 
Table 3.2 SPECT results for each patient subgroup.

\begin{tabular}{|c|c|c|c|c|c|c|c|}
\hline \multirow{2}{*}{\multicolumn{2}{|c|}{ Final clinical diagnosis }} & \multirow{2}{*}{\multicolumn{2}{|c|}{ FP-CIT }} & \multicolumn{4}{|c|}{ IBZM } \\
\hline & & & & $=$ & $\uparrow$ & $\downarrow$ & None \\
\hline \multirow[t]{3}{*}{ IPD } & $n=127$ & $=$ & 22 & 4 & 9 & 1 & 8 \\
\hline & & $\downarrow$ & 90 & 21 & 19 & 13 & 37 \\
\hline & & None & 15 & 8 & 5 & 2 & - \\
\hline \multirow[t]{3}{*}{$\overline{\mathrm{APS}^{*}}$} & $\mathrm{n}=27$ & $=$ & 4 & - & - & 4 & - \\
\hline & & $\downarrow$ & 13 & 2 & 3 & 7 & 1 \\
\hline & & None & 10 & 3 & 2 & 5 & - \\
\hline IPD/APS & $\mathrm{n}=2$ & $\downarrow$ & 2 & - & 1 & - & 1 \\
\hline \multirow[t]{3}{*}{ ET } & $\mathrm{n}=22$ & $=$ & 20 & 5 & 5 & 2 & 8 \\
\hline & & $\downarrow$ & 1 & - & - & - & 1 \\
\hline & & None & 1 & 1 & - & - & - \\
\hline \multirow[t]{2}{*}{$\overline{\mathrm{VP}}$} & $\mathrm{n}=16$ & $=$ & 14 & 2 & 1 & 7 & 4 \\
\hline & & None & 2 & 1 & - & 1 & - \\
\hline \multirow[t]{2}{*}{$\overline{D I P}$} & $n=5$ & $=$ & 4 & 1 & - & 1 & 2 \\
\hline & & None & 1 & 1 & - & - & - \\
\hline \multirow[t]{3}{*}{ Other } & $\mathrm{n}=24$ & $=$ & 16 & 5 & - & 1 & 10 \\
\hline & & $\downarrow$ & 4 & 2 & - & 1 & 1 \\
\hline & & None & 4 & 1 & 3 & - & - \\
\hline
\end{tabular}

IPD: idiopathic Parkinson's disease, APS: atypical parkinsonian syndromes, ET: essential tremor, VP: vascular parkinsonism, DIP: drug induced parkinsonism; = : normal FP-CIT or IBZM tracer binding ratios; $\downarrow$ : tracer binding of 2 sd below healthy controls; $\uparrow$ : tracer binding of 2 sd above healthy controls; none = SPECT was not performed; $n$ : number of subjects.

* APS: atypical parkinsonian syndromes (i.e. multiple system atrophy, progressive supranuclear palsy and diffuse Lewy body disease).

FP-CIT tracer binding was decreased in 7 of the 9 MSA, 4 of the 6 PSP and both DLBD patients; IBZM striatal tracer binding was decreased in 10 of the 14 MSA, 6 of the 9 PSP and none of the 3 DLBD patients.

The differentiation between IPD and APS (PSP, MSA and DLBD) by both FPCIT and IBZM SPECT scored relatively low accuracy. Specificity and NPV are low, as $62 \%$ of the APS patients and $20 \%$ of the IPD patients have lowered striatal IBZM tracer binding. The combination of FP-CIT and IBZM SPECT scored only minimally increased accuracy. See Figure 3.3.

We expected APS patients to have a more diffusely decreased striatal FP-CIT binding rate in comparison to patients with IPD, showing mainly a selective loss of tracer binding in the putamen: we calculated the additional value of judging the FP-CIT uptake in the caudate nucleus in comparison with only the uptake in the putamen. The FP-CIT binding of the caudate nucleus was decreased (>2 sd below the mean of the healthy controls) in fourteen of the 127 IPD patients with IPD, one of the fifteen MSA patients and in two of the nine PSP patients and in none of the three patients with DLBD. All patients with low caudate FP-CIT binding ratios also had decreased putamen FP-CIT binding. So with an odd's ratio $(95 \% \mathrm{Cl})$ of $1(0.3-4)$ judging of the FP-CIT tracer binding 
in the caudate nucleus does not lead to an increase of accuracy to differentiate between IPD and APS.

In the present study differentiation among the different atypical parkinsonian syndromes MSA, PSP and DLBD was not accurate with FP-CIT SPECT: seven of the nine MSA patients, as well as four of the six PSP patients and two of the three DLBD patients had abnormal FP-CIT SPECT scan results. IBZM SPECT could not discriminate between patients with MSA and PSP: IBZM binding ratios were decreased in ten of the fourteen MSA and in six of the nine patients with PSP. All three patients with DLBD had a normal to high striatal IBZM binding.

Finally, the diagnostic accuracy of FP-CIT and/or IBZM SPECT in this study was always higher than the initial probable diagnosis by the clinician before the SPECT. See also Figure 3.3.

\section{Discussion}

To our knowledge this is the largest retrospective study on the diagnostic value of the FP-CIT and IBZM SPECT scan in patients with parkinsonian symptoms of unknown origin. In our study we focused on the diagnostic delineation of IPD vs. ET, VP, DIP and APS.

Using FP-CIT SPECT to differentiate IPD from ET we found a high odd's ratio of 82 for overall diagnostic accuracy. In this diagnostic situation the positive predictive value was $99 \%$, and the negative predictive value $48 \%$, so we conclude that FP-CIT SPECT scans are sensitive in detecting IPD, but not capable in excluding IPD when negative. This is partly inherent to our study design: the low number of patients with other diseases than IPD obviously leads to a low negative predictive value. These results are in accordance with data from a recent meta-analysis. ${ }^{30}$

A possible explanation of the finding that twenty-two of 112 IPD had normal FP-CIT scans is that SPECT can be normal in early stages of disease. ${ }^{10-14}$ In our study population twelve of the 248 patients underwent a second FP-CIT SPECT at various time points; in these cases accordance with the ultimate clinical diagnosis rose from four to ten patients (data not shown).

Another explanation for the relatively high number of false negative IPD patients is the quantitative analysis of the SPECT scans. We recalculated the accuracy to differentiate patients with IPD from those with ET for visual qualitative judgement: sensitivity increased from 80 to $94 \%$, NPV from 48 to $71 \%$, specificity and PPV stayed unchanged. This is in accordance with recent data from Marshall et al. ${ }^{31}$

All patients with VP had a normal FP-CIT SPECT binding. IBZM SPECT scan was normal to high in four and decreased in eight patients with VP. Our results 
accord with the study by Tzen et al. ${ }^{32}$, who found normal presynaptic radiotracer binding in VP. However, Plotkin and Lorberboym found VP patients with decreased both presynaptic and postsynaptic radiotracer bindings. ${ }^{33-35}$ These conflicting results probably reflect the controversy surrounding the diagnostic criteria of VP. ${ }^{26}$ Future studies in this field should include welldefined patient populations and a brain MRI scan to give additional information about vascular lesions in the basal ganglia and within basal ganglia-cortical projections. Theoretically FP-CIT and IBZM binding is expected to be normal in VP patients, when clear vascular lesions in the basal ganglia have been excluded. Moreover, SPECT scans in these cases should be interpreted visually, to appreciate the abnormal pattern of receptor uptake that is probable typical for VP.

Our five DIP patients had normal FP-CIT scans. This accords with the studies by Burn and Lavalaye. ${ }^{36,37}$ Hypothesizing that DIP is primarily a post-synaptic problem, one would expect IBZM SPECT to yield lower binding ratios. We could not confirm this as we found two normal and one abnormal IBZM SPECT in this population. ${ }^{38}$ As we could not retrieve information on the medication at the moment of the scan, we do not feel comfortable to draw firm conclusions from this small sample.

Using SPECT scans to delineate IPD from APS gave disappointing results in our study for FP-CIT, IBZM as well as the combination of both SPECT scans. With only $62 \%$ of the APS patients having decreased striatal postsynaptic tracer binding, but also $20 \%$ of the IPD patients, the specificity and negative predictive value of IBZM are relatively low.

The literature on this is somewhat conflicting. There are eight studies in which postsynaptic SPECT is fairly accurate, and these found postsynaptic receptors mainly affected in APS and normal or up-regulated in IPD. ${ }^{39-46}$ Schulz, who investigated thirty-two MSA patients, found similar results as in our metaanalysis: only a significant loss in $63 \%$ of the patients with IBZM. ${ }^{19}$ However, a problem is that IPD, especially in later stages, can give low striatal postsynaptic radiotracer binding too. A study by Schwarz et al. confirmed our finding that reduced postsynaptic tracer binding makes IPD unlikely but does not completely exclude IPD. ${ }^{47}$

A major shortcoming of our study is that we did not re-examine all patients, blinded for the SPECT results. We only invited patients of whom the clinical diagnosis could not be derived from the clinical records or the referring specialist. We tried to reduce bias by having two independent observers read the clinical records critically, to check if the patient fulfilled the accepted clinical criteria of one of the parkinsonian disorders. In any case of doubt the patient was invited for re-examination. Nevertheless, all diagnoses that were not checked by an independent, blinded physician may still be biased in favour of 
accurate prediction by the SPECT, as these data were known by the treating physician.

Finally, a clinical follow-up is still only a surrogate gold standard. $^{23}$ Clinicopathological studies show that $2-25 \%$ of the patients with IPD are classified incorrectly in the final stage of their disease, even by specialists in movement disorders. ${ }^{4-6}$ Comparisons between functional dopaminergic imaging and the ultimate gold standard, autopsy-proven IPD, are almost nonexistent. $^{48,49}$ Although practically and ethically difficult, only post-mortem analysis will conclusively prove whether or not the clinical diagnosis of IPD was correct in those cases.

In summary, in these 248 patients with initially unclassified parkinsonism, roughly $76 \%$ of the ordered FP-CIT scans accurately predicted the final clinical diagnosis after follow-up. In $10 \%$ of the patients a clinical diagnosis after followup could not be made.

To differentiate patients with IPD from ET, VP and DIP the FP-CIT SPECT has an additional value above the initial clinical diagnosis. However, because the relative high number of false negative FP-CIT SPECT scans in IPD patients a normal FP-CIT scan does not exclude IPD.

To differentiate patients with IPD from those with APS, both FP-CIT and IBZM SPECT scan have no additional value above the initial probable diagnosis of the clinician who ordered the SPECT scan. 


\section{References}

1. De Lau LM, Breteler MM. Epidemiology of Parkinson's disease. Lancet Neurol 2006;5: 525-35.

2. Braak H, Bohl JR, Muller CM, Rub U, De Vos RA, Del Tredici K. Stanley Fahn Lecture 2005: The staging procedure for the inclusion body pathology associated with sporadic Parkinson's disease reconsidered. Mov Disord 2006;21:2042-51.

3. Hughes AJ, Daniel SE, Kilford L, Lees AJ. Accuracy of clinical diagnosis of idiopathic Parkinson's disease: a clinico-pathological study of 100 cases. J Neurol Neurosurg Psychiatry 1992;55:181-4

4. Hughes AJ, Daniel SE, Ben-Shlomo Y, Lees AJ. The accuracy of diagnosis of parkinsonian syndromes in a specialist movement disorder service. Brain 2002;125:861-70.

5. Watanabe H, Saito Y, Terao S, Ando T, Kachi T, Mukai E, Aiba I, Abe Y, Tamakoshi A, Doyu M, Hirayama M, Sobue G. Progression and prognosis in multiple system atrophy: an analysis of 230 Japanese patients. Brain 2002;125:1070-83.

6. Rajput $\mathrm{AH}$, Rozdilsky B, Rajput A. Accuracy of clinical diagnosis in parkinsonism--a prospective study. Can J Neurol Sci 1991;18:275-8.

7. Litvan I, Goetz CG, Jankovic J, Wenning GK, Booth V, Bartko JJ, McKee A, Jellinger K, Lai EC, Brandel JP, Verny M, Chaudhuri KR, Pearce RK, Agid Y. What is the accuracy of the clinical diagnosis of multiple system atrophy? A clinicopathologic study. Arch Neurol 1997;54:937-44.

8. Litvan I, Agid Y, Jankovic J, Goetz C, Brandel JP, Lai EC, Wenning G, D'Olhaberriague L, Verny M, Chaudhuri KR, McKee A, Jellinger K, Bartko JJ, Mangone CA, Pearce RK. Accuracy of clinical criteria for the diagnosis of progressive supranuclear palsy (SteeleRichardson-Olszewski syndrome). Neurology 1996;46:922-30.

9. Verny M, Jellinger KA, Hauw JJ, Bancher C, Litvan I, Agid Y. Progressive supranuclear palsy: a clinicopathological study of 21 cases. Acta Neuropathol (Berl) 1996;91:427-31.

10. Winogrodzka A, Bergmans P, Booij J, Van Royen EA, Janssen AG, Wolters EC. [123I]FP-CIT SPECT is a useful method to monitor the rate of dopaminergic degeneration in early-stage Parkinson's disease. J Neural Transm 2001;108:1011-9.

11. Pirker W, Djamshidian S, Asenbaum S, Gerschlager W, Tribl G, Hoffmann M, Brucke T. Progression of dopaminergic degeneration in Parkinson's disease and atypical parkinsonism: a longitudinal beta-CIT SPECT study. Mov Disord 2002;17:45-53.

12. Marek K, Innis R, Van Dyck C, Fussell B, Early M, Eberly S, Oakes D, Seibyl J. [123l]betaCIT SPECT imaging assessment of the rate of Parkinson's disease progression. Neurology 2001;57:2089-94.

13. Seibyl JP, Marek KL, Quinlan D, Sheff K, Zoghbi S, Zea-Ponce Y, Baldwin RM, Fussell B, Smith EO, Charney DS, et al. Decreased single-photon emission computed tomographic [123I]beta-CIT striatal uptake correlates with symptom severity in Parkinson's disease. Ann Neurol 1995;38:589-98.

14. Booij J, Tissingh G, Boer GJ, Speelman JD, Stoof JC, Janssen AG, Wolters EC, Van Royen EA. [123I]FP-CIT SPECT shows a pronounced decline of striatal dopamine transporter labelling in early and advanced Parkinson's disease. J Neurol Neurosurg Psychiatry 1997; 62:133-40.

15. Brucke T, Asenbaum S, Pirker W, Djamshidian S, Wenger S, Wober C, Muller C, Podreka I. Measurement of the dopaminergic degeneration in Parkinson's disease with [123I] beta-CIT and SPECT. Correlation with clinical findings and comparison with multiple system atrophy and progressive supranuclear palsy. J Neural Transm Suppl 1997;50:9-24.

16. Varrone A, Marek KL, Jennings D, Innis RB, Seibyl JP. [(123)I]beta-CIT SPECT imaging demonstrates reduced density of striatal dopamine transporters in Parkinson's disease and multiple system atrophy. Mov Disord 2001;16:1023-32.

17. Kim YJ, Ichise M, Ballinger JR, Vines D, Erami SS, Tatschida T, Lang AE. Combination of dopamine transporter and D2 receptor SPECT in the diagnostic evaluation of PD, MSA, and PSP. Mov Disord 2002;17:303-12. 
18. Pirker W, Asenbaum S, Bencsits G, Prayer D, Gerschlager W, Deecke L, Brucke T. [123I]beta-CIT SPECT in multiple system atrophy, progressive supranuclear palsy, and corticobasal degeneration. Mov Disord 2000;15:1158-67.

19. Schulz JB, Klockgether T, Petersen D, Jauch M, Muller-Schauenburg W, Spieker S, Voigt K, Dichgans J. Multiple system atrophy: natural history, MRI morphology, and dopamine receptor imaging with 123IBZM-SPECT. J Neurol Neurosurg Psychiatry 1994;57:1047-56.

20. Tatsch K, Schwarz J, Oertel WH, Kirsch CM. SPECT imaging of dopamine D2 receptors with 123I-IBZM: initial experience in controls and patients with Parkinson's syndrome and Wilson's disease. Nucl Med Commun 1991;12:699-707.

21. Dresel SH, Kung MP, Huang XF, PlossI K, Hou C, Meegalla SK, Patselas G, Mu M, Saffer JR, Kung HF. Simultaneous SPECT studies of pre- and postsynaptic dopamine binding sites in baboons. J Nucl Med 1999;40:660-6.

22. Piccini $\mathrm{P}$, Whone A. Functional brain imaging in the differential diagnosis of Parkinson's disease. Lancet Neurol 2004;3:284-90.

23. Morrish P. The meaning of negative DAT SPECT and F-Dopa PET scans in patients with clinical Parkinson's disease. Mov Disord 2005;20:117.

24. Morrish PK. How valid is dopamine transporter imaging as a surrogate marker in research trials in Parkinson's disease? Mov Disord 2003;18 Suppl 7:S63-70.

25. Bain, Brin M, Deuschl G, Elble R, Jankovic J, Findley L, Koller WC, Pahwa R. Criteria for the diagnosis of essential tremor. Neurology 2000;54:S7.

26. Zijlmans JC, Daniel SE, Hughes AJ, Revesz T, Lees AJ. Clinicopathological investigation of vascular parkinsonism, including clinical criteria for diagnosis. Mov Disord 2004;19:630-40.

27. Gilman S, Low PA, Quinn N, Albanese A, Ben-Shlomo Y, Fowler CJ, Kaufmann H, Klockgether T, Lang AE, Lantos PL, Litvan I, Mathias CJ, Oliver E, Robertson D, Schatz I, Wenning GK. Consensus statement on the diagnosis of multiple system atrophy. J Neurol Sci 1999;163:94-8.

28. McKeith IG, Galasko D, Kosaka K, Perry EK, Dickson DW, Hansen LA, Salmon DP, Lowe J, Mirra SS, Byrne EJ, Lennox G, Quinn NP, Edwardson JA, Ince PG, Bergeron C, Burns A, Miller BL, Lovestone S, Collerton D, Jansen EN, Ballard C, de Vos RA, Wilcock GK, Jellinger $\mathrm{KA}$, Perry RH. Consensus guidelines for the clinical and pathologic diagnosis of dementia with Lewy bodies (DLB): report of the consortium on DLB international workshop. Neurology 1996;47:1113-24.

29. Vles JS, Feron FJ, Hendriksen JG, Jolles J, Van Kroonenburgh MJ, Weber WE. Methylphenidate down-regulates the dopamine receptor and transporter system in children with attention deficit hyperkinetic disorder (ADHD). Neuropediatrics 2003;34:77-80.

30. Vlaar AM, Van Kroonenburgh MJ, Kessels AG, Weber WE. Meta-analysis of the literature on diagnostic accuracy of SPECT in parkinsonian syndromes. BMC Neurol 2007;7:27.

31. Marshall VL, Patterson J, Hadley DM, Grosset KA, Grosset DG. Two-year follow-up in 150 consecutive cases with normal dopamine transporter imaging. Nucl Med Commun 2006; 27:933-7.

32. Tzen KY, Lu CS, Yen TC, Wey SP, Ting G. Differential diagnosis of Parkinson's disease and vascular parkinsonism by (99m)Tc-TRODAT-1. J Nucl Med 2001;42:408-13.

33. Lorberboym M, Djaldetti R, Melamed E, Sadeh M, Lampl Y. 123I-FP-CIT SPECT imaging of dopamine transporters in patients with cerebrovascular disease and clinical diagnosis of vascular parkinsonism. J Nucl Med 2004;45:1688-93.

34. Korten AGGC, Al Younis IHA, Kroonenburgh MJPG, Weber WEJ, Vreeling FW, Kessels F, Lodder J. Dopamine availability in vascular parkinsonism and idiopathic Parkinson's disease: a comparion with 123I FP CIT and 123I IBZM SPECT. Thesis 2005:93-105.

35. Plotkin M, Amthauer H, Quill S, Marzinzik F, Klostermann F, Klaffke S, Kivi A, Gutberlet M, Felix R, Kupsch A. Imaging of dopamine transporters and D2 receptors in vascular parkinsonism: a report of four cases. J Neural Transm 2005;112:1355-61.

36. Burn DJ, Brooks DJ. Nigral dysfunction in drug-induced parkinsonism: an 18F-dopa PET study. Neurology 1993;43:552-6. 
37. Lavalaye J, Linszen DH, Booij J, Dingemans PM, Reneman L, Habraken JB, Gersons BP, Van Royen EA. Dopamine transporter density in young patients with schizophrenia assessed with [123]FP-CIT SPECT. Schizophr Res 2001;47:59-67.

38. Farde L, Nordstrom AL, Wiesel FA, Pauli S, Halldin C, Sedvall G. Positron emission tomographic analysis of central D1 and D2 dopamine receptor occupancy in patients treated with classical neuroleptics and clozapine. Relation to extrapyramidal side effects. Arch Gen Psychiatry 1992;49:538-44.

39. Schwarz J, Kraft E, Vogl T, Arnold G, Tatsch K, Oertel WH. Relative quantification of signal on T2-weighted images in the basal ganglia: limited value in differential diagnosis of patients with parkinsonism. Neuroradiology 1999;41:124-8.

40. Pizzolato G, Cagnin A, Rossato A, Chierichetti F, Fabbri M, Dam M, Ferlin G, Battistin L. Striatal dopamine D2 receptor alterations and response to L-DOPA in Parkinson's disease. A [123I]IBZM SPET study. Adv Neurol 1996;69:467-73.

41. Schwarz J, Tatsch K, Arnold G, Gasser T, Trenkwalder C, Kirsch CM, Oertel WH. 123Iiodobenzamide-SPECT predicts dopaminergic responsiveness in patients with de novo parkinsonism. Neurology 1992;42:556-61.

42. Hierholzer J, Cordes M, Schelosky L, Sander B, Bock JC, David I, Horowski R, Poewe W. The differential diagnosis of Parkinson diseases--123I-IBZM-SPECT vs. the apomorphine test. Rofo 1993;159:86-90.

43. Hierholzer J, Cordes M, Venz S, Schelosky L, Harisch C, Richter W, Keske U, Hosten N, Mäurer J, Poewe W, Felix R. Loss of dopamine-D2 receptor binding sites in Parkinsonian plus syndromes. J Nucl Med 1998;39:954-60.

44. Booij J, Tissingh G, Winogrodzka A, Van Royen EA. Imaging of the dopaminergic neurotransmission system using single-photon emission tomography and positron emission tomography in patients with parkinsonism. Eur J Nucl Med 1999;26:171-82.

45. Prunier C, Tranquart F, Cottier JP, Giraudeau B, Chalon S, Guilloteau D, De Toffol B, Chossat F, Autret A, Besnard JC, Baulieu JL. Quantitative analysis of striatal dopamine D2 receptors with 123 l-iodolisuride SPECT in degenerative extrapyramidal diseases. Nucl Med Commun 2001;22:1207-14.

46. Knudsen GM, Karlsborg M, Thomsen G, Krabbe K, Regeur L, Nygaard T, Videbaek C, Werdelin L. Imaging of dopamine transporters and D2 receptors in patients with Parkinson's disease and multiple system atrophy. Eur J Nucl Med Mol Imaging 2004, 31:1631-8.

47. Schwarz J, Tatsch K, Gasser T, Arnold G, Oertel WH. [123]IBZM binding predicts dopaminergic responsiveness in patients with parkinsonism and previous dopaminomimetic therapy. Mov Disord 1997;12:898-902.

48. Walker Z, Costa DC, Walker RW, Shaw K, Gacinovic S, Stevens T, Livingston G, Ince P, McKeith IG, Katona CL. Differentiation of dementia with Lewy bodies from Alzheimer's disease using a dopaminergic presynaptic ligand. J Neurol Neurosurg Psychiatry 2002; 73:134-40.

49. Jankovic J, Rajput AH, McDermott MP, Perl DP. The evolution of diagnosis in early Parkinson disease. Parkinson Study Group. Arch Neurol 2000;57:369-72. 

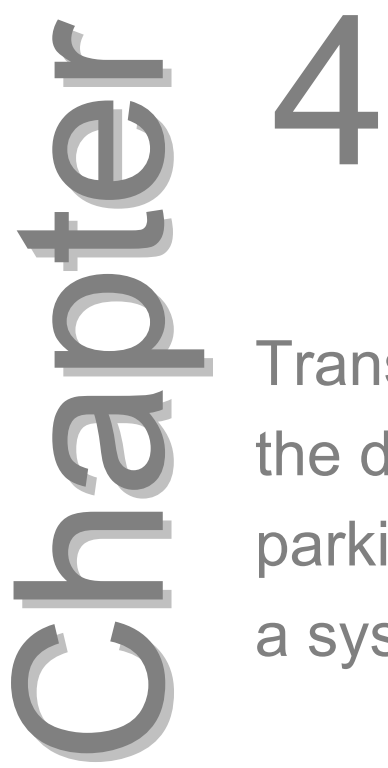

Transcranial duplex scanning in the differential diagnosis of parkinsonian syndromes: a systematic review

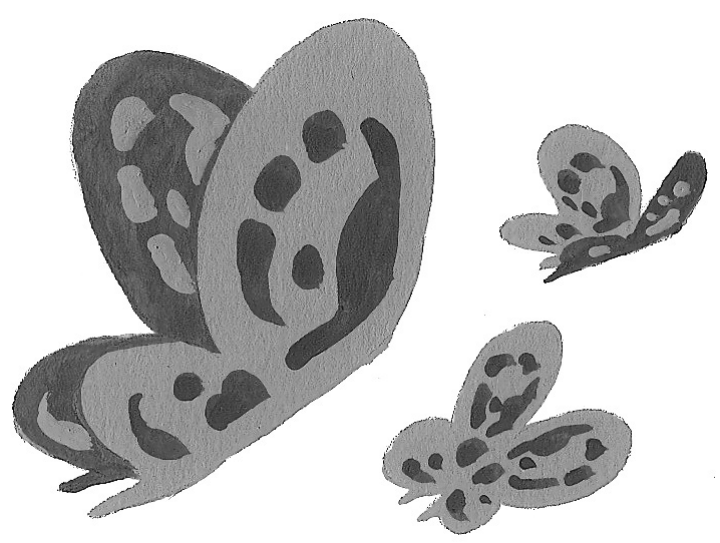

Annemarie M.M. Vlaar, Angela Bouwmans, Werner H. Mess, Selma C. Tromp, Wim E.J. Weber

Journal of Neurology 2009: 256:530-8 


\section{Abstract}

\section{Background}

Transcranial duplex scanning (TCD) of the substantia nigra (SN) is increasingly used to diagnose idiopathic Parkinson's Disease (IPD). Up till now 70 diagnostic studies have been published, not only on investigation of the SN, but also of the lenticular nucleus (LN) and the Raphe nuclei (RN).

\section{Methods}

We systematically reviewed all diagnostic TCD studies in parkinsonian patients up to June 2008 .

\section{Results}

We found 35 eligible studies. Of the 1534 IPD patients investigated in the 35 studies $200(13 \%)$ had an inconclusive SN-TCD. An increased echointensity of the SN was seen in $1167(87 \%)$ of the 1334 IPD patients, $276(12 \%)$ of the 2340 healthy controls and in $41(30 \%)$ of the 138 patients with an atypical parkinsonian syndrome (APS).

On the contrary, a pathological LN-TCD was found more often in APS patients (79\%) than in IPD patients $(23 \%)$ and healthy controls $(6 \%)$. A decreased echointensity of the RN was found more often in depressed (46\%) than in non-depressed IPD patients (16\%).

\section{Conclusions}

SN-TCD accurately differentiates between patients with IPD and healthy controls, but not between patients with IPD and APS. LN-TCD is only moderate accurate to delineate IPD from APS, but combinations of SN- and LN-TCD may be more promising. RN-TCD has only marginal diagnostic accuracy in diagnosing depression in IPD and non-IPD patients. Before TCD can be implicated more research is needed to standardise the TCD technique, to investigate TCD in non-research settings and to determine the additional value of TCD in comparance with already clinical implicated techniques like SPECT imaging. 


\section{Introduction}

The diagnosis of idiopathic Parkinson's disease (IPD) and other parkinsonian disorders, such as multiple system atrophy (MSA), progressive supranuclear palsy (PSP) or vascular parkinsonism (VP), is based on clinical criteria. ${ }^{1-5}$ In patients with the essential clinical symptoms such as bradykinesia, rigidity, and resting tremor, diagnosis of IPD is usually straightforward, however early in the disease it can be difficult to differentiate among the various parkinsonian disorders purely on clinical grounds. In the early stages of the disease it can also be difficult to differentiate a parkinsonian tremor from an essential tremor (ET). The gold standard for the diagnosis of IPD is post-mortem neuropathological examination. Neuropathological studies have shown that even at end-stage disease the clinical diagnostic accuracy for IPD varies between $75-90 \%$, with MSA and PSP accounting for most false positives. ${ }^{3,6,7}$ As prognosis and management differ considerably among the various parkinsonian syndromes an early correct diagnosis is of cardinal importance.

Several procedures and combinations of different techniques have been proposed to diagnose IPD: olfactory- and neuropsychological tests, biomarkers, DNA tests and functional imaging with MIBG scintigraphy, Positron Emission Tomography (PET) or Single Photon Emission Computer Tomography (SPECT). ${ }^{8-12}$

The SPECT scan is presently the most widely used diagnostic test for parkinsonian syndromes. Nevertheless, its diagnostic accuracy is still debated. $^{13}$

A recently developed diagnostic tool is transcranial duplex scanning (TCD). Using this technique Becker and colleagues were the first to report hyperechointensity of the substantia nigra (SN) in patients with Parkinson's disease. ${ }^{14}$ Several studies found that $90 \%$ of IPD patients show this SN hyperechointensity, which is presumably caused by an increased iron content. $^{14-19}$ Only in about $9 \%$ of healthy individuals this increased echointensity is found. TCD can also visualise the Raphe Nuclei (RN) and the Lenticular Nucleus (LN). The echointensity of the $L N$ is postulated to differentiate between IPD and other parkinsonian syndromes. Differences in echointensity of the RN are reported to be associated with depression in patients with or without parkinsonism.

Since the first report, numerous studies on the diagnostic accuracy of TCD in parkinsonian syndromes have been published, including a systematic review, which considered all papers published before $2003 .{ }^{20}$ Since several more research groups started TCD and the majority of the papers on this subject is published after 2003 we did an updated systematic review. 


\section{Technical aspect}

TCD is a non-invasive, fast, and patient-friendly technique, which is employable at the bedside. Mostly, the technique is applied for the examination of the intracranial vessels. ${ }^{21}$

Since 15 years TCD is also used to visualise other brain structures, such as the mesencephalon. ${ }^{22}$ With TCD the echointensity of various brain structures can be studied. Changes in echointensity seem to reflect changes in tissue impedance due to glial reaction, alterations in cell density and iron content. ${ }^{14,16}$ TCD is performed by placing the ultrasound transducer on the temporal bone in front of the ear. In most patients (approximately $80-90 \%{ }^{23}$ ) the temporal bone window is appropriate to acquire a 2-dimensional image of the intracranial structures. Typically, a low-frequency phased array transducer is used with a frequency range of $1-4 \mathrm{MHz}$ being focussed at a depth of $6-8 \mathrm{~cm}$. The depth range ideally is chosen to allow for the visualisation of the contralateral side of the skull. The mesencephalon becomes visible as an echolucent, butterflyshaped structure, surrounded by the basal cisterns characterised by a higher echointensity. Normally, the mesencephalon has a predominantly homogeneous aspect; in most cases a small hyperechogenic stripe can be discerned within the area of the substantia nigra (SN). However, in up to $90 \%$ of the IPD patients the $\mathrm{SN}$ is clearly visible due to its large hyperechointense area as compared to the surrounding brainstem tissue.

Other brain structures like the lenticular nucleus $(L N)$ and the Raphe Nuclei $(\mathrm{RN})$ can be visualised by TCD as well. The $L N$ are visible in an axial section at the level of the thalamus. The $L N$ is only discernable when its echointensity is abnormally increased compared with the surrounding brain parenchyma. An increase in echointensity of one or both of the LN might differentiate between APS and IPD. ${ }^{20,24,25}$

Finally, the RN are visible in the same axial section as the SN. Normally the RN are visible because they are hyperechointense in comparance with the adjacent brainstem parenchyma. A decrease in the echointensity of the RN is reported to be associated with depression in both patients with and without parkinsonism. $^{23,26}$

Different scorings systems are used by different research groups, however the various methods agree on the main points. Generally the echointensity of the $\mathrm{SN}$ is evaluated by ipsilateral TCD examination. The SN-TCD is scored abnormal if the $\mathrm{SN}$ is pathological at least at one side (uni- or bilateral).

The echointensity of the $\mathrm{SN}$ can be judged qualitatively or quantitatively. In the qualitative way the $\mathrm{SN}$ can be scored by judging whether or not a typical hyperechointensity in the area of the $\mathrm{SN}$ is present. Most investigators, however, did use the quantitative method: measuring the area of hyperechointensity by encircling the hyperintense area. Normal values depend 
on the ultrasound device which is used, but approximately an area of $<0.2 \mathrm{~cm}^{2}$ is defined as normal and an area of $>0.25 \mathrm{~cm}^{2}$ as pathological. ${ }^{17,18,27}$ For the quantitative method excellent intra- and inter-observer agreement has been reported with kappa values of $0.80-0.85 .^{16,18,28-30}$ The $L N$ as well the RN are always scored qualitatively (hyper-, iso-, or hypoechointense).

\section{Systematic review of the literature}

We systematically reviewed the literature by searching Ovid Medline databases and cross-referenced clinical trials published in this field until June 152008. Both, medical subjects headings (MESH) terms and text words were used: 1) ultrasound, sonography or duplex scanning, 2) substantia nigra (SN), Raphe nuclei (RN), lenticular or lentiform nucleus (LN) and 3) parkinsonian, parkinsonism, IPD, MSA, PSP, ET or APS.

Two investigators $(A V, A B)$ screened the full text of potentially relevant articles. Papers were only included into the review if information on the following items was supplied: 1) patient population, 2) ultrasound system applied, 3) TCD procedures of assessment and quantification of echointensity, 4) number of true positive, false positive, true negative and false negative TCD results with the clinical diagnosis as the gold standard.

Additionally, we mentioned the number of sonographers, if the sonographers were blinded for the clinical diagnosis and if the included patients were diagnosed or yet undiagnosed.

Papers were excluded if: 1) the full article was not available, 2) the language was other than English or German, 3) brain structures other than the SN, LN or RN were studied, 4) and if studies did not include patients with neurodegeneratieve parkinsonism (IPD, APS i.e. MSA, PSP, diffuse Lewy body disease, corticobasal degeneration), patients with secondary parkinsonism (ET, VP, drug-induced parkinsonism [DIP]) or patients with ET, healthy controls and patients with depression.

\section{Data extraction and analysis}

The studies were sorted into three categories, either studying the SN, LN or the RN. The number of patients with a normal and abnormal echointensity of, respectively, the $\mathrm{SN}, \mathrm{LN}$ and $\mathrm{RN}$ are given in Tables 4.1-4.3. We used cut-off points defined by the original authors. A TCD was considered inconclusive if either there was an inappropriate temporal bone window or the sonographer judged the target structure as borderline hyperechointense. Sensitivity and specificity were calculated for each brain structure and patient category separately. The following patient categories were studies: 1) neurodegenerative parkinsonism A) IPD and B) APS (MSA, PSP, diffuse Lewy body 
disease, corticobasal degeneration), 2) patients with non-degenerative forms of parkinsonism i.e. vascular, drug-induced, infectious, 3) patients without parkinsonism (ET, healthy controls).

\section{Results}

\section{Overview}

The Medline search resulted in 68 hits. We found no additional clinical studies searching the Cochrane and Embase databases. Cross-reference searching added another four relevant trials. Of these 72 studies we excluded 37 . The reasons for exclusion for as follows: of eighteen studies only an abstract existed, two articles did not fulfil the language criteria, ten papers did not deal with the diseases mentioned above, and in seven articles we were not able to derive the number of true positive, false positive, true negative and false negative findings.

In the 35 trials left, either one or several brain structures (SN, LN and RN) were investigated. In total, thirty-one dealt with the $\mathrm{SN}$, ten with the $\mathrm{LN}$ and seven with the RN (See Tables 4.1, 4.2 and 4.3).

\section{TCD of the substantia nigra}

Results are given in Table 4.1. Only twenty-three of the thirty-one studies mentioned the percentage of patients in which the authors experienced difficulties judging the SN-TCD, either because of an inappropriate temporal bone window or an atypical form of the hyperechointensity. The percentages in which the SN-TCD was inconclusive ranged from 0 to $64 \%$.

In the majority of cases the SN-TCD was regarded as abnormal if the SN showed a pathological signal at least at one side. However, some authors calculated the mean of both sides. ${ }^{31-33}$ Mostly, the area of increased signal intensity was measured to estimate whether the SN was normal or not.

The incidence of a pathological SN-TCD varied remarkably between the different parkinsonian syndromes as shown in Table 4.1. Of the 1334 IPD patients 1167 (87\%, range 48-100\%) had an increased echointensity of the SN. In patients with APS this hyperechointensity was seen less frequently, namely in forty-one of the 138 (30\%; range 0-100\%). In ET, VP and DIP the prevalence of a hyperechointense SN was even lower: thirteen of the $112(12 \%)$ ET patients, six of the thirty (20\%) VP patients and in none of the three DIP patients. In healthy controls SN hyperechointensity was found in only 276 of the $2340(12 \%$, range $0-20 \%)$ individuals. 


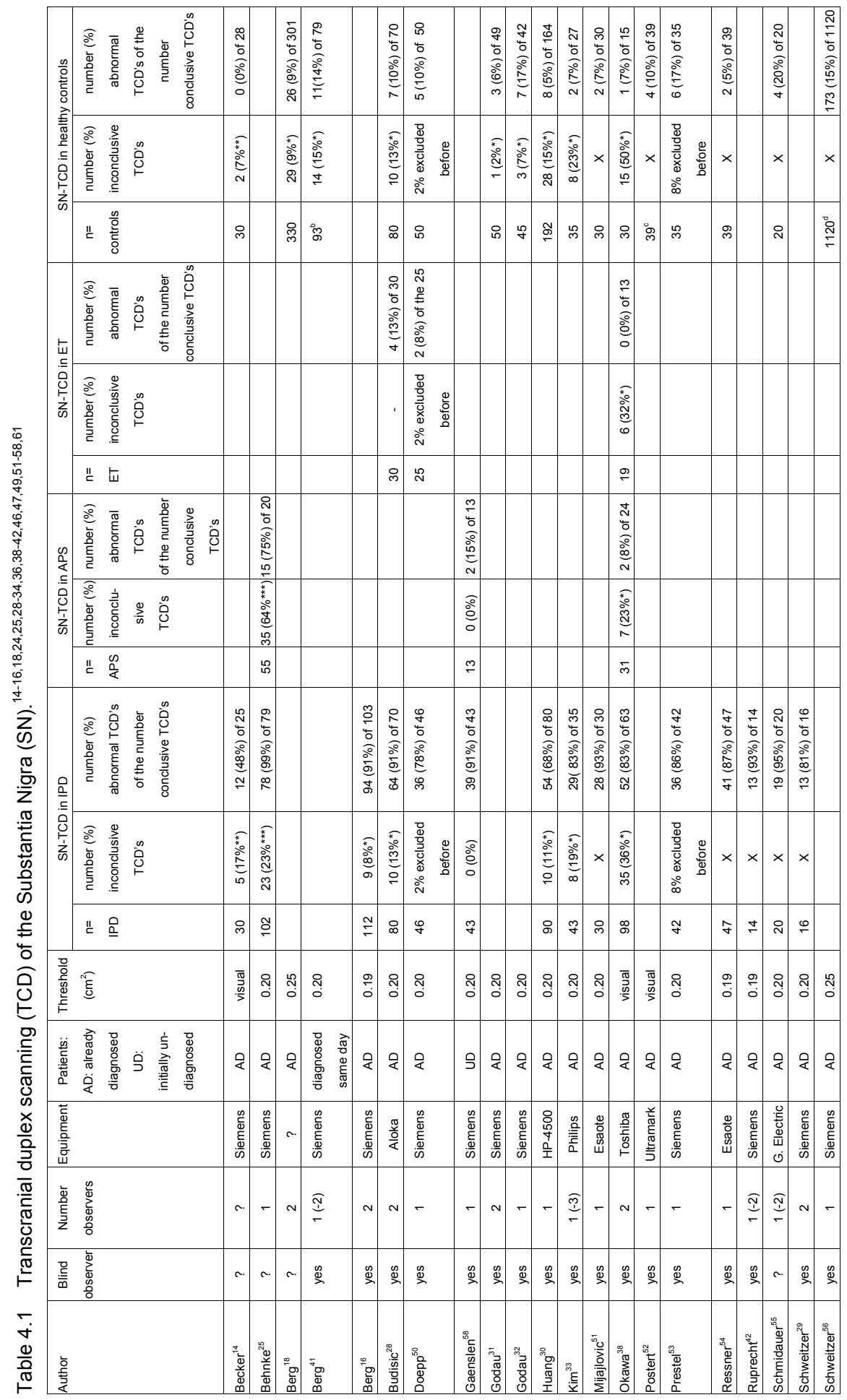


\begin{tabular}{l|l}
70 & Chapter 4
\end{tabular}

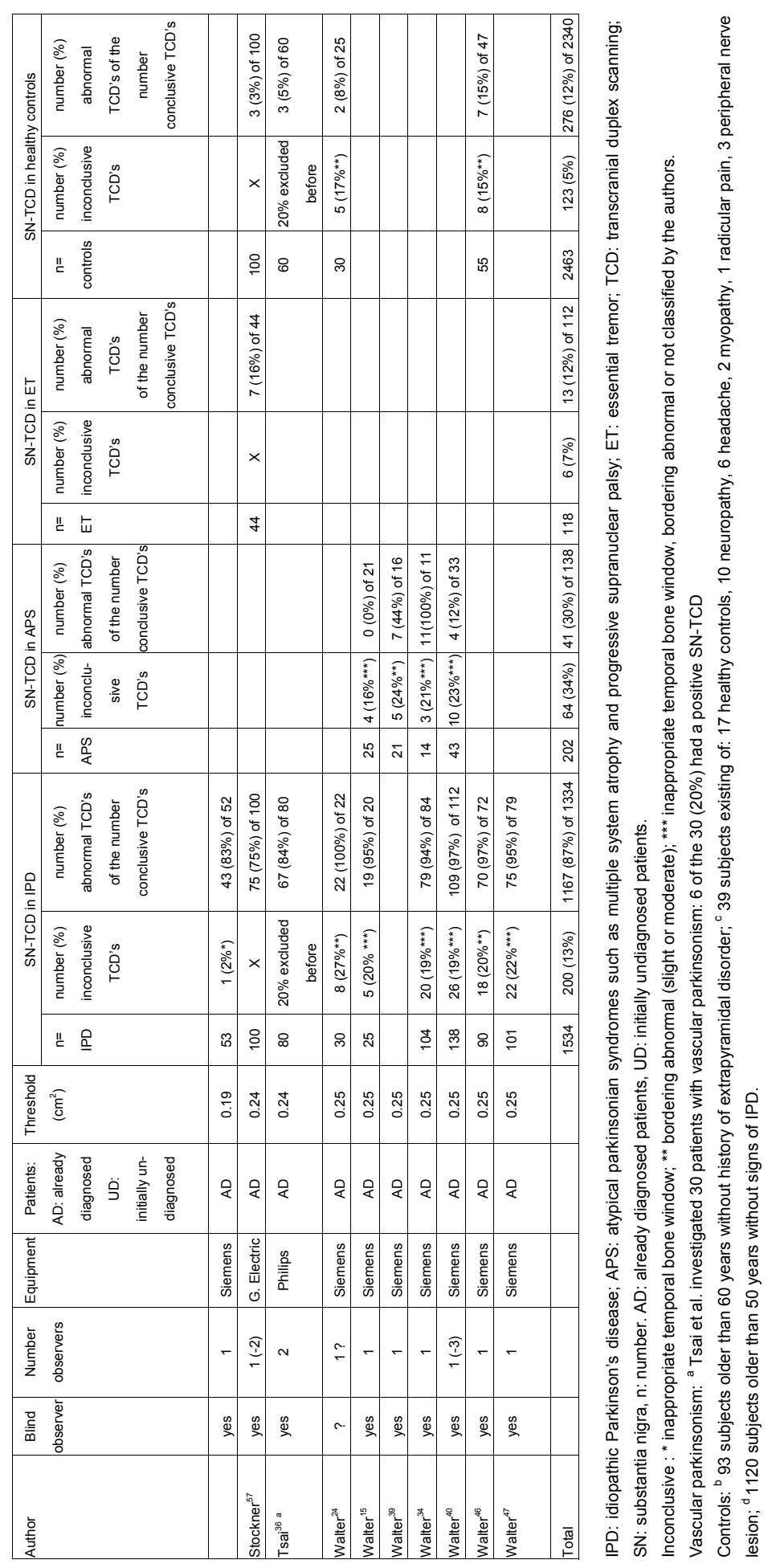




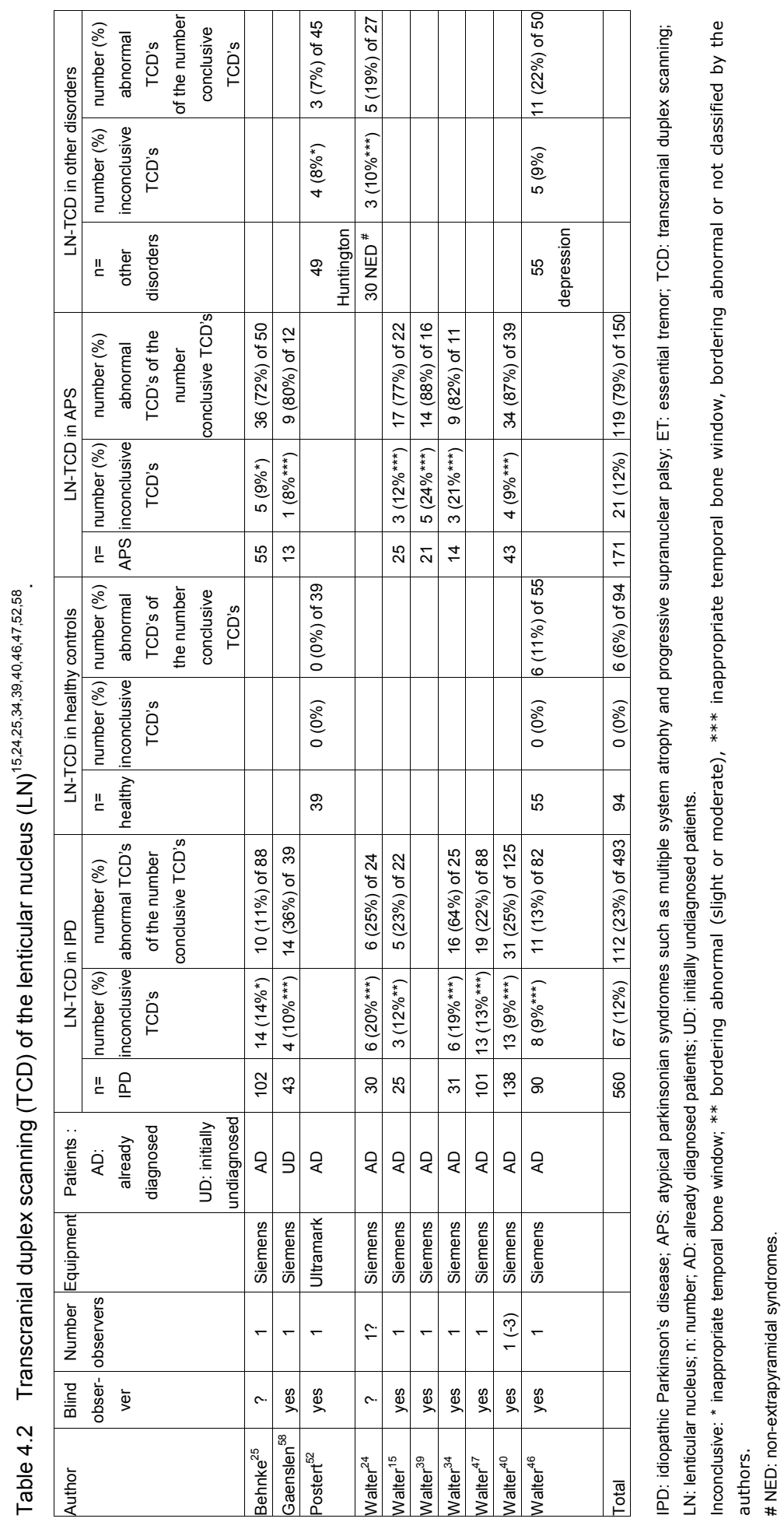




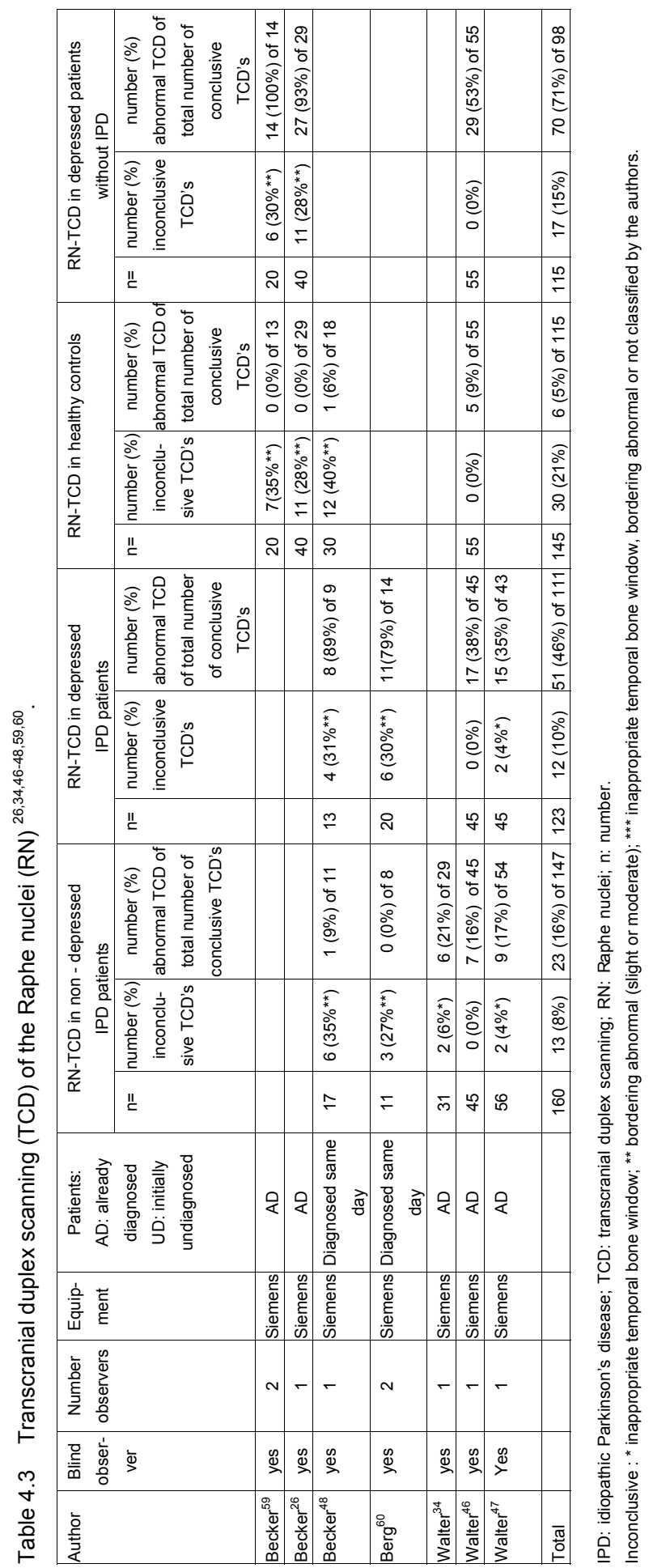




\section{TCD of the lenticular nucleus}

Results are given in Table 4.2. The investigators of all ten studies mentioned the percentage of patients in which they had difficulties to judge the echointensity of the LN. The percentages in which the LN-TCD was inconclusive ranged from 0 to $24 \%$. Of the 150 APS patients 119 (79\%; range $72-88 \%$ ) had an increased echointensity of the LN. In IPD patients this hyperechointensity was seen less often, namely in 112 of the $493(23 \%$, range $11-64 \%)$ patients, with the remarkable exception of demented IPD patients: $64 \%$ of these had a pathological LN-TCD. ${ }^{34}$ In healthy controls this finding was seen in only six of 94 subjects $(6 \%$, range $0-11 \%)$.

\section{TCD of the Raphe nuclei}

Results are given in Table 4.3. In all seven studies the percentage of patients with an inconclusive RN-TCD was mentioned and ranged from 0 to $40 \%$. Fiftyone of the 111 depressed IPD patients (46\%, range $35-89 \%)$ had a decreased echointensity of the RN in contrast to twenty-three of the 147 non-depressed IPD patients $(16 \%$, range $0-21 \%)$. In patients without IPD this difference was more pronounced: in depressed patients without IPD a decreased echointensity of the RN was much more common than in non-depressed healthy controls: $71 \%$ (range $53-100 \%$ ) versus $5 \%$ (range $0-9 \%$ ), respectively.

\section{Discussion}

In this review we included thirty-five papers on the diagnostic use of TCD in parkinsonian syndromes. The results are discussed separately for: A) the TCD technique in general, B) TCD of the substantia nigra, C) the lenticular nucleus, D) the Raphe nuclei.

\section{A. The TCD technique in general}

Studying the literature we found the following differences in TCD technique:

1) Different research groups use different transducers, different measuring methods and cut-off points of normal values, causing variety in sensitivity and specificity. To compare the results of these different studies, we applied a simplified semi-quantitative scoring system to the original data: abnormal, normal, or inconclusive. Consequently, lower sensitivity and higher specificity values were obtained than compared to the ones originally reported.

2) We can not rule out that the same patient(s) that were used in one particular study were included in other studies of the same research group, i.e. that there is an overlap in patients. 


\section{B. TCD of the substantia nigra}

Of the 1167 IPD patients examined in thirty-one different clinical studies, approximately $90 \%$ had an increased echointensity of the SN. The sensitivity as compared with the final clinical diagnosis varied from 48 to $100 \%$. The wide range can be explained by the different patient population under study, the use of various transducers and scorings methods by the different investigators.

The incidence of a pathological SN-TCD in patients with APS was considerably lower than in patients with IPD. Yet, the range was very large between studies and also depended on the subtype of APS. All eleven patients with diffuse Lewy body disease and seven of the eight patients with corticobasal degeneration had a positive SN-TCD. ${ }^{34-39}$ A positive SN-TCD seemed to be more common in $\mathrm{PSP}(30 \%$, range $8-47 \%)$ than in $\mathrm{MSA}(17 \%$, range $6-25 \%) .^{15,25,38-40}$

In all patients with APS, the number of inconclusive TCD examinations was higher than in patients with IPD. This finding was mostly attributable to difficulties in the interpretation of the ultrasound image and rarely due to an inappropriate bone window.

In $12 \%$ of 2340 healthy controls SN hyperechointensity was found, suggesting a rather large number of false-positive findings. However, there is some evidence that the $\mathrm{SN}$ hyperechointensity in healthy controls is related to a slight motor impairment. ${ }^{41}$ Additionally, earlier studies showed that PET or SPECT scans are also abnormal in up to $60 \%$ of the asymptomatic patients with an abnormal TCD. 17,18,42,43,44 Long-term follow-up studies are currently underway to evaluate if these asymptomatic subjects with an abnormal SN-TCD will develop IPD. Furthermore, from literature there is indeed some evidence to suggest that a subset of ET patients is predisposed to developing IPD, possible explaining the fact that $12 \%$ of the ET patients had an abnormal SN-TCD. ${ }^{45}$

\section{TCD of the lenticular nucleus}

It appears that hyperechointensity of the LN is found quite often in APS (79\%), but considerably less often in IPD (23\%) and healthy controls $(6 \%)$. These findings suggest that TCD of the LN solely will not allow for the discrimination between IPD and APS in an individual patient, given the relatively low positive and negative predictive values. However, when combining the results of different insonated brain structures, the diagnostic accuracy could be improved considerably. An increased echointensity of the SN and a normal echointensity of the LN is strongly suggestive for the diagnosis of IPD. ${ }^{23,25,46,47}$ On the contrary, a normal SN echointensity and an increased intensity of the LN indicates MSA or PSP. Furthermore, a dilation of the third ventricle or the frontal horn is postulated to be a predictor of PSP. ${ }^{40}$ However, these results were obtained with post-hoc analyses and their definitive diagnostic value 
remains to be determined in a long-term follow-up study with an 'intention-todiagnose' principle.

\section{TCD of the Raphe nuclei}

Seven retrospective studies have been published about the difference of RN echointensity between IPD patients and controls with and without depression. Decreased RN echointensity was found more often in depressed patients $(71 \%)$ than in healthy controls without depression $(5 \%)$. Similarly, decreased RN echointensity was more common in IPD patients with a depression $(46 \%)$ than in IPD patients without depression (16\%).

Although the diagnostic accuracy of RN-TCD seems to be fairly high in nonIPD patients, RN-TCD is considerably less accurate in patients with IPD. Furthermore, the percentage of patients with doubtful findings or slightly decreased echointensity in the latter group is surprisingly high, with a maximum of $40 \%$ in one study. ${ }^{48}$

\section{Conclusion}

Compared to an earlier review considering the literature available until 2003, our present up-to-date review confirms the high diagnostic accuracy of SNTCD to differentiate patients with IPD from patients with ET and healthy controls. This accuracy is less for differentiating patients with IPD from those with APS. ${ }^{23}$ The diagnostic value of LN-TCD and RN-TCD appears to be lower than previously assumed.

We identified several methodological issues: lack of standardized TCD techniques, normal values and scoring systems, and the high percentage of subjects with an inconclusive TCD. More research is needed, especially in patients with as yet undefined parkinsonism. Moreover, these studies should ideally include neuropathological post-mortem investigation, or at least comparison with follow-up examinations and accepted techniques as SPECT or PET. ${ }^{49,50}$ Without these issues, the clinical significance of SN-TCD would not be established. 


\section{References}

1. Litvan I, Agid Y, Jankovic J, Goetz C, Brandel JP, Lai EC, Wenning G, D'Olhaberriague L, Verny M, Chaudhuri KR, McKee A, Jellinger K, Bartko JJ, Mangone CA, Pearce RK. Accuracy of clinical criteria for the diagnosis of progressive supranuclear palsy (SteeleRichardson-Olszewski syndrome). Neurology 1996;46:922-30.

2. Gilman S, Low PA, Quinn N, Albanese A, Ben-Shlomo $Y$, Fowler CJ, Kaufmann H, Klockgether T, Lang AE, Lantos PL, Litvan I, Mathias CJ, Oliver E, Robertson D, Schatz I, Wenning GK. Consensus statement on the diagnosis of multiple system atrophy. J Neurol Sci 1999;163:94-8.

3. Hughes AJ, Daniel SE, Kilford L, Lees AJ. Accuracy of clinical diagnosis of idiopathic Parkinson's disease: a clinico-pathological study of 100 cases. J Neurol Neurosurg Psychiatry 1992;55:181-4.

4. Bain P, Brin M, Deuschl G, Elble R, Jankovic J, Findley L, Koller WC, Pahwa R. Criteria for the diagnosis of essential tremor. Neurology 2000;54(11 Suppl 4):S7.

5. Zijlmans JC, Daniel SE, Hughes AJ, Revesz T, Lees AJ. Clinicopathological investigation of vascular parkinsonism, including clinical criteria for diagnosis. Mov Disord 2004;19:630-40.

6. Watanabe H, Saito Y, Terao S, Ando T, Kachi T, Mukai E, Aiba I, Abe Y, Tamakoshi A, Doyu M, Hirayama M, Sobue G. Progression and prognosis in multiple system atrophy: an analysis of 230 Japanese patients. Brain 2002;125: 1070-83.

7. Rajput $\mathrm{AH}$, Rozdilsky B, Rajput A. Accuracy of clinical diagnosis in parkinsonism--a prospective study. Can J Neurol Sci 1991;18:275-8.

8. Dujardin K, Duhamel A, Becquet E, Grunberg C, Defebvre L, Destee A. Neuropsychological abnormalities in first degree relatives of patients with familial Parkinson's disease. J Neurol Neurosurg Psychiatry 1999;67:323-8.

9. Ponsen MM, Stoffers D, Booij J, van Eck-Smit BLF, Wolters EC, Berendse HW. Idiopathic hyposmia as a preclinical sign of Parkinson's disease. Ann Neurol 2004;56:173-81.

10. Storch A, Hofer A, Kruger R, Schulz JB, Winkler J, Gerlach M. New developments in diagnosis and treatment of Parkinson's disease--from basic science to clinical applications. J Neurol 2004;251 S6:VI/33-8.

11. Lee PH, Yeo SH, Kim HJ, Youm HY. Correlation between cardiac 123I-MIBG and odor identification in patients with Parkinson's disease and multiple system atrophy. Mov Disord. 2006;21:1975-7.

12. Spiegel J, Möllers MO, Jost WH, Fuss G, Samnick S, Dillmann U, Becker G, Kirsch CM. FPCIT and MIBG scintigraphy in early Parkinson's disease. Mov Disord. 2005;20:552-61.

13. Vlaar AM, van Kroonenburgh MJ, Kessels AG, Weber WE. Meta-analysis of the literature on diagnostic accuracy of SPECT in parkinsonian syndromes. BMC Neurol. 2007;7:27.

14. Becker G, Seufert J, Bogdahn U, Reichmann H, Reiners K. Degeneration of substantia nigra in chronic Parkinson's disease visualized by transcranial color-coded real-time sonography. Neurology 1995;45:182-4.

15. Walter U, Niehaus L, Probst T, Benecke R, Meyer BU, Dressler D. Brain parenchyma sonography discriminates Parkinson's disease and atypical parkinsonian syndromes. Neurology 2003;60:74-7.

16. Berg D, Siefker C, Becker G. Echogenicity of the substantia nigra in Parkinson's disease and its relation to clinical findings. J Neurol. 2001;248:684-9.

17. Berg D, Roggendorf W, Schröder U, Klein R, Tatschner T, Benz P, Tucha O, Preier M, Lange KW, Reiners K, Gerlach M, Becker G. Echogenicity of the substantia nigra: association with increased iron content and marker for susceptibility to nigrostriatal injury. Arch Neurol. 2002; 59:999-1005.

18. Berg D, Becker G, Zeiler B, Tucha O, Hofmann E, Preier M, Benz P, Jost W, Reiners K, Lange KW. Vulnerability of the nigrostriatal system as detected by transcranial ultrasound. Neurology 1999;53:1026-31. 
19. Berg D. Disturbance of iron metabolism as a contributing factor to $\mathrm{SN}$ hyperechogenicity in Parkinson's disease: implications for idiopathic and monogenetic forms. Neurochem Res. 2007;32:1646-54.

20. Walter U, Behnke S, Eyding J, Niehaus L, Postert T, Seidel G, Berg D. Transcranial brain parenchyma sonogrpahy in movement disorders: state of the art. Ultrasound Med Biol. 2007;33:15-25.

21. Hennerici MG, Meairs SP. Cerebrovascular Ultrasound: Theory, Practice and Future Developments. First edition ed. Cambridge, U.K.: Cambridge University Press. 2001

22. Schoning M, Grunert D, Stier B. Transcranial duplex sonography through intact bone: a new diagnostic procedure. Ultraschall Med. 1989;10:66-71.

23. Walter U, Behnke S, Eyding J, Niehaus L, Postert T, Seidel G, Berg D. Transcranial brain parenchyma sonography in movement disorders: state of the art. Ultrasound Med Biol. 2007;33:15-25.

24. Walter $U$, Wittstock $M$, Benecke R, Dressler D. Substantia nigra echogenicity is normal in non-extrapyramidal cerebral disorders but increased in Parkinson's disease. J Neural Transm. 2002;109:191-6.

25. Behnke S, Berg D, Naumann M, Becker G. Differentiation of Parkinson's disease and atypical parkinsonian syndromes by transcranial ultrasound. J Neurol Neurosurg Psychiatry 2005;76:423-5.

26. Becker G, Becker T, Struck M, Lindner A, Burzer K, Retz W, Bogdahn U, Beckmann H. Reduced echogenicity of brainstem raphe specific to unipolar depression: a transcranial color-coded real-time sonography study. Biol Psychiatry 1995;38:180-4.

27. Glaser M, Weber $U$, Hinrichs $\mathrm{H}$, Niehaus L. Neuroimaging of midbrain structures with different phased array ultrasound systems. Klin Neurophysiol. 2006;37:165-8.

28. Budisic M, Trkanjec Z, Bosnjak J, Lovrencic-Huzjan A, Vukovic V, Demarin V. Distinguishing Parkinson's disease and essential tremor with transcranial sonography. Acta Neurol Scand. 2008, June 10 [Epub ahead of print]

29. Schweitzer KJ, Hilker R, Walter U, Burghaus L, Berg D. Substantia nigra hyperechogenicity as a marker of predisposition and slower progression in Parkinson's disease. Mov Disord. 2006;21:94-8.

30. Huang YW, Jeng JS, Tsai CF, Chen LL, Wu RM. Transcranial imaging of substantia nigra hyperechogenicity in a Taiwanese cohort of Parkinson's disease. Mov Disord. 2007;22:550-5.

31. Godau J, Schweitzer KJ, Liepelt I, Gerloff C, Berg D. Substantia nigra hypoechogenicity: definition and findings in restless legs syndrome. Mov Disord. 2007;22:187-92.

32. Godau J, Wevers AK, Gaenslen A, Di Santo A, Liepelt I, Gasser T, Berg D. Sonographic abnormalities of brainstem structures in restless legs syndrome. Sleep Med. 2008;9:782-9.

33. Kim JY, Kim ST, Jeon SH, Lee WY. Midbrain transcranial sonography in Korean patients with Parkinson's disease. Mov Disord. 2007;22:1922-6.

34. Walter U, Dressler D, Wolters A, Wittstock M, Greim B, Benecke R. Sonographic discrimination of dementia with Lewy bodies and Parkinson's disease with dementia. J Neurol. 2006;253:448-54.

35. Tromp SC, Vlaar AMM, Kroonenburgh MJPG, Mess WH, Nijs de T, Winogrodzka A, et al. The diagnostic value of transcranial duplex scanning and SPECT imaging versus clinical diagnosis (clinical prospective study). Movement Disorders 2007;22(S16):S220.

36. Tsai CF, Wu RM, Huang YW, Chen LL, Yip PK, Jeng JS (2007) Transcranial color-coded sonography helps differentiation between idiopathic Parkinson's disease and vascular parkinsonism. J Neurol 2007;254:501-7.

37. Stockner H, Seppi K, Kiechl S, Schmidauer C, Sojer M, Schwaiger M, et al. Midbrain transcranial sonography finding in a population based study. Movement Disorders 2006;21(S15):S634.

38. Okawa M, Miwa H, Kajimoto Y, Hama K, Morita S, Nakanishi I, Kondo T. Transcranial sonography of the substantia nigra in Japanese patients with Parkinson's disease or atypical parkinsonism: clinical potential and limitations. Intern Med 2007;46:1527-31. 
39. Walter U, Dressler D, Wolters A, Probst T, Grossmann A, Benecke R. Sonographic discrimination of corticobasal degeneration vs progressive supranuclear palsy. Neurology 2004;63:504-9.

40. Walter U, Dressler D, Probst T, Wolters A, Abu-Mugheisib M, Wittstock M, Beneke R. Transcranial brain sonography findings in discriminating between parkinsonism and idiopathic Parkinson disease. Arch Neurol. 2007;64:1635-40.

41. Berg D, Siefker C, Ruprecht-Dorfler P, Becker G. Relationship of substantia nigra echogenicity and motor function in elderly subjects. Neurology 2001;56:13-7.

42. Ruprecht-Dorfler P, Berg D, Tucha O, Benz P, Meier-Meitinger M, Alders GL, Lange KW, Becker G. Echogenicity of the substantia nigra in relatives of patients with sporadic Parkinson's disease. Neuroimage 2003;18:416-22.

43. Walter U, Klein C, Hilker R, Benecke R, Pramstaller PP, Dressler D. Brain parenchyma sonography detects preclinical parkinsonism. Mov Disord. 2004;19:1445-9.

44. Sommer U, Hummel T, Cormann K, Mueller A, Frasnelli J, Kropp J, Reichmann H. Detection of presymptomatic Parkinson's disease: combining smell tests, transcranial sonography, and SPECT. Mov Disord. 2004;19:1196-202.

45. Shahed J, Jankovic J. Exploring the relationship between essential tremor and Parkinson's disease. Parkinsonism Relat Disord. 2007;13:67-76.

46. Walter U, Hoeppner J, Prudente-Morrissey L, Horowski S, Herpertz SC, Benecke R. Parkinson's disease-like midbrain sonography abnormalities are frequent in depressive disorders. Brain 2007;130:1799-807.

47. Walter U, Dressler D, Wolters A, Wittstock M, Benecke R. Transcranial brain sonography findings in clinical subgroups of idiopathic Parkinson's disease. Mov Disord. 2007;22:48-54.

48. Becker T, Becker G, Seufert J, Hofmann E, Lange KW, Naumann M, Lindner A, Reichmann $\mathrm{H}$, Riederer P, Beckmann H, Reiners K. Parkinson's disease and depression: evidence for an alteration of the basal limbic system detected by transcranial sonography. J Neurol Neurosurg Psychiatry 1997;63:590-6.

49. Spiegel J, Hellwig D, Möllers MO, Behnke S, Jost W, Fassbender K, Samnick S, Dillmann U, Becker G, Kirsch CM. Transcranial sonography and [123l]FP-CIT SPECT disclose complementary aspects of Parkinson's disease. Brain 2006;129:1188-93.

50. Doepp F, Plotkin M, Siegel L, Kivi A, Gruber D, Lobsien E, Kupsch A, Schreiber SJ. Brain parenchyma sonography and 123I-FP-CIT SPECT in Parkinson's disease and essential tremor. Mov Disord 2008;23:405-10.

51. Mijajlovic M, Dragasevic N, Stefanova E, Petrovic I, Svetel M, Kostic VS. Transcranial sonography in spinocerebellar ataxia type 2. J Neurol 2008;255:1164-7.

52. Postert T, Lack B, Kuhn W, Jergas M, Andrich J, Braun B, Przuntek H, Sprengelmeyer R, Agelink M, Büttner T. Basal ganglia alterations and brain atrophy in Huntington's disease depicted by transcranial real time sonography. J Neurol Neurosurg Psychiatry 1999;67: 457-62.

53. Prestel J, Schweitzer KJ, Hofer A, Gasser T, Berg D. Predictive value of transcranial sonography in the diagnosis of Parkinson's disease. Mov Disord. 2006;21:1763-5.

54. Ressner $P$, Skoloudik D, Hlustik $P$, Kanovsky P. Hyperechogenicity of the substantia nigra in Parkinson's disease. J Neuroimaging 2007;17:164-7.

55. Schmidauer C, Sojer M, Seppi K, Stockner H, Högl B, Biedermann B, Brandauer E, Peralta $\mathrm{CM}$, Wenning GK, Poewe W. Transcranial ultrasound shows nigral hypoechogenicity in restless legs syndrome. Ann Neurol. 2005;58:630-4.

56. Schweitzer KJ, Behnke S, Liepelt I, Wolf B, Grosser C, Godau J, Gaenslen A, Bruessel T, Wendt A, Abel F, Müller A, Gasser T, Berg D. Cross-sectional study discloses a positive family history for Parkinson's disease and male gender as epidemiological risk factors for substantia nigra hyperechogenicity. J Neural Transm. 2007;114:1167-71.

57. Stockner H, Sojer M, K KS, Mueller J, Wenning GK, Schmidauer C, Poewe W. Midbrain sonography in patients with essential tremor. Mov Disord. 2007;22:414-7. 
58. Gaenslen A, Unmuth B, Godau J, Liepelt I, Di Santo A, Schweitzer KJ, Gasser T, Machulla $\mathrm{HJ}$, Reimold M, Marek K, Berg D. The specificity and sensitivity of transcranial ultrasound in the differential diagnosis of Parkinson's disease: a prospective blinded study. Lancet Neurol. 2008;7:417-24.

59. Becker G, Struck M, Bogdahn U, Becker T. Echogenicity of the brainstem raphe in patients with major depression. Psychiatry Res 1994;55:75-84.

60. Berg D, Supprian T, Hofmann E, Zeiler B, Jäger A, Lange KW, Reiners K, Becker T, Becker G. Depression in Parkinson's disease: brainstem midline alteration on transcranial sonography and magnetic resonance imaging. J Neurol 1999;246:1186-93. 
${ }_{80} \mid$ 


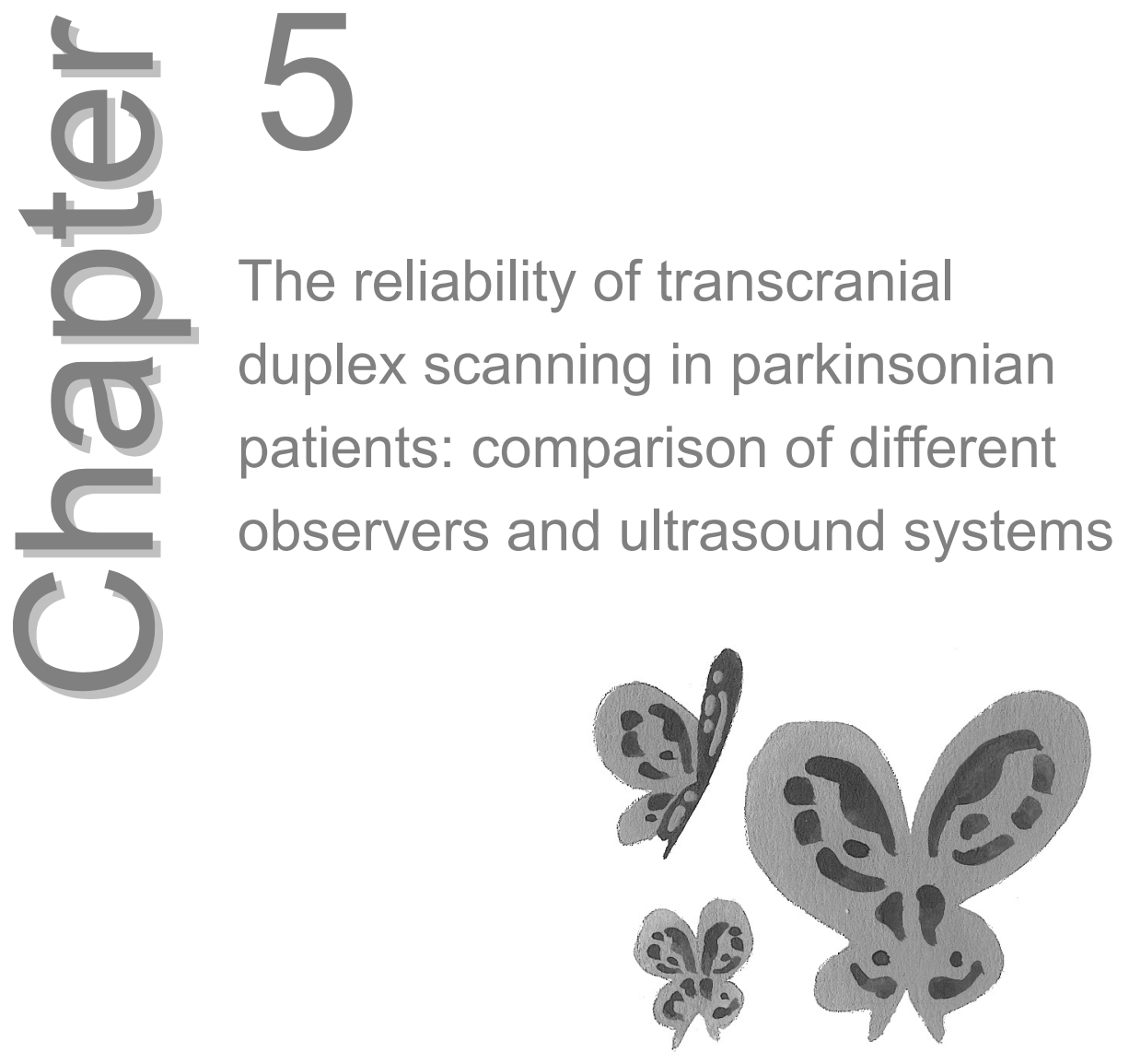

Annemarie M.M. Vlaar, Selma C. Tromp, Wim E.J. Weber, Rosie M.H.J. Hubens-Hustinx, Werner $\mathrm{H}$. Mess 


\section{Abstract}

\section{Objectives}

To establish the inter-observer and intra-transducer reliability of "on-line" and "off-line" assessment of substantia nigra (SN) and Raphe nuclei (RN) by transcranial duplex scanning (TCD) in a mixed study population.

\section{Setting}

Out-patient neurology department of the University Hospital Maastricht

\section{Subjects}

In total 24 subjects were investigated: 9 patients with idiopathic Parkinson's disease, 10 with parkinsonism from yet unclear origin, 1 with essential tremor and 4 healthy volunteers.

\section{Design}

Each patient was assessed four times by two independent experienced sonographers using two different ultrasound devices: SONOS 5500 and iU22; both Philips, Eindhoven, The Netherlands. The echointensity of the $\mathrm{SN}$ is evaluated qualitatively and quantitatively and the RN only qualitatively.

1) In the "on-line" assessment we determined:

A) the inter-observer agreement of the four possible combinations

B) the intra-observer agreement of both sonographers using two different ultrasound systems.

2) In the "off-line" assessment a third sonographer re-examined the stored images. We determined the inter-observer agreement of the third sonographer with the "on-line" assessment of the other 2 sonographers. Cohen's $\mathrm{k}$ value was calculated for the agreement.

\section{Results}

1A. The "on-line" inter-observer agreement of the four possible combinations of sonographer and transducer was: kappa 0.23-0.39 for the qualitative evaluation of the SN, kappa 0.31-0.56 for the quantitative evaluation of the SN and kappa $0.03-0.15$ for the evaluation of the RN.

1B. The "on-line" intra-observer agreement was: kappa $0.53-0.67$ for the qualitative evaluation of the SN, kappa $0.55-0.76$ for the quantitative evaluation of the $\mathrm{SN}$ and kappa $0.45-0.47$ for the evaluation of the RN

2. The "off-line" inter-observer agreement was: kappa $0.32-0.67$ for the qualitative evaluation of the $\mathrm{SN}$, kappa $0.53-0.61$ for the quantitative evaluation of the $\mathrm{SN}$ and kappa 0.08-0.33 for the evaluation of the RN.

\section{Conclusions}

For the SN we found mediocre accordance comparing both observers "on-line" with each other as well as comparing an "off-line" observer with both "on-line" observers. Comparing the "on-line" observers with themselves, the intra-observer agreement appeared to be moderate to substantial. For evaluation of the RN, the concordance between the different observers was apparently low, whereas the consistency for a single "on-line" observer using two different ultrasound systems was comparable to evaluation of the SN. 


\section{Introduction}

Transcranial duplex scanning (TCD) of the brainstem is increasingly used in the diagnostic work-up of patients who are suspected to suffer from idiopathic Parkinson's disease (IPD). In healthy individuals, the substantia nigra (SN) is hardly discernable from the surrounding mesencephalon since the B-mode ultrasound image has a predominantly homogeneous aspect. In most cases only a small hyperechogenic band can be visualised within the anatomical area of the SN. However, in up to $90 \%$ of the IPD patients the SN is clearly distinguishable due to its large hyperechogenic area as compared to the surrounding brainstem tissue. ${ }^{1-4}$ Contrary to the $\mathrm{SN}$, in healthy individuals the Raphe nuclei (RN) can be easily depicted as a hyperechogenic band located in the midline of the brainstem extending in an anterior-posterior direction. A decreased echogenicity of the RN has been related to depression, which holds also true for patients with IPD.,

Since the first report on the use of TCD in IPD patients by Becker and colleagues $^{2}$ in 1995 more than 70 diagnostic trials have been published showing that TCD is a useful diagnostic tool for differentiating patients with IPD from healthy controls and other parkinsonian syndromes.

A well-known limitation of TCD can be attributed to an inappropriate temporal bone window, which will make intracranial ultrasound examination impossible in approximately $10-20 \% .^{7}$ Furthermore, in up to $10 \%$ of the patients the Bmode image might be inconclusive since an increased echogenicity does not match with the anatomical area of the $\mathrm{SN} .^{8}$

Additionally, the widespread use of TCD in clinical practice might be questioned if the results obtained vary when different examiners perform the test or when using different ultrasound systems. This might especially be the case when the sonographers had their ultrasound training at different institutions. Previously, excellent values for the inter-observer agreement of SN duplex scanning have been reported (intra class correlation coefficients and kappa values between $0.80-0.98) \cdot{ }^{3,4,9-11}$ Yet, in these studies, the evaluation of the inter-observer agreement was not the primary objective. So, it was not reported how the inter-observer agreement was determined. Furthermore, to our knowledge, no data exist on the intra-observer agreement.

Therefore, the purpose of the present study is to determine the inter-observer agreement for the assessment of the echointensity of the $\mathrm{SN}$ and $\mathrm{RN}$, but also the intra-observer agreement when the same patient is examined by the same ultrasonographer, but with different ultrasound systems. 


\section{Methods}

\section{Subjects}

A mixed population was studied in order to decrease the 'a priori chance' of a positive finding. Twenty-four volunteers (15 males) were studied. The mean age was 60 years (SD: 13; range 28-78). Nine individuals suffered from IPD, ten from parkinsonism of unspecified origin, one had an essential tremor and four were healthy volunteers. All subjects gave informed consent. The study was approved by the local medical ethics committee.

\section{TCD technique}

Both ultrasonographers used two ultrasound systems to perform TCD (SONOS 5500 and iU22; both Philips, Eindhoven, The Netherlands). Both devices were supplied with a low-frequency phased array transducer with a frequency range of 1-4 $\mathrm{MHz}$ and 1-3 MHz, respectively, for insonation through the transtemporal bone window bilaterally. The focus was set at a depth of 6-8 $\mathrm{cm}$ and the depth range was chosen to allow for the visualisation of the contralateral side of the skull. Overall gain and the degree of compression were visually adapted to optimally depict an increased echogenicity of the $\mathrm{SN}$, if present. In practice, a relatively high gain setting was used in combination with relatively little compression. This combination resulted in an almost homogeneously echolucent brainstem in those areas where no increase of the echointensity can be expected. The RN, the nucleus ruber and the SN (in case of a positive finding) on the other hand were easily distinguishable due to their increased echointensity. All other parameters, such as time gain compensation, postprocessing and power settings were kept constant throughout the study. The quality of the B-mode images was scored as sufficient or insufficient depending on the visibility of the afore mentioned anatomical structures and, hence, the possibility to evaluate their echointensity.

A loop of 64 images was acquired by scanning the brainstem cranio-caudally and all images were stored digitally to allow for off-line analysis.

The echogenicity of the $\mathrm{SN}$ was determined following ipsilateral insonation. Firstly, the $\mathrm{SN}$ echogenicity was quantitatively estimated by manually encircling the area of hyperechogenicity, if present. The surface was automatically calculated. A hyperechogenic area of at least $0.23 \mathrm{~cm}^{2}$ at one side was classified as abnormal and a smaller area at both sides as normal. ${ }^{4,12,13}$

Since in our experience it is often difficult to accurately delineate the area of the SN hyperechogenicity, we also performed a simplified method using the following qualitative scores: "positive", "negative", and "inconclusive". Comparable qualitative scoring systems have also been used by other investigator groups. ${ }^{11,14,15}$ The SN-TCD was scored "positive", when, at least on 
one side, the $\mathrm{SN}$ was clearly visible due to its increased echointensity as compared to the surrounding brainstem tissue. Additionally, the hyperechogenic area had to correspond with the anatomical site of the SN; only if the hyperechogenic area extended as an oblique and continuous band in the medial-anterior to lateral-posterior direction, we scored this as a "positive" finding.

If the image quality was sufficient to evaluate the echointensity of the $\mathrm{SN}$, but the afore mentioned criteria were not met, the SN-TCD was scored "negative". All other examinations were regarded as "inconclusive". Firstly, this could be either due to an atypical anatomical distribution or only a small area of hyperechointensity not extending throughout the whole brainstem in the horizontal plane as described above. Secondly, all patients with insufficient bone window were scored as "inconclusive".

The echointensity of the RN was scored only qualitatively as being either "normal" (hyperechogenic from one or both insonation sides), "abnormal" (the hyperechogenic line is interrupted or not visible, i.e., hypoechogenic, from both insonation sides) or "inconclusive" (when equivocal results from both insonation sides were obtained or when the image quality was insufficient.

\section{Setting}

"On-line" assessment: each individual was scanned by two sonographers (1 \& 2) both using two different ultrasound systems. So, in total each individual underwent four examinations. Several individuals were evaluated at the same session, and the examination schedule was set up to avoid that a given individual was scanned consecutively by the same sonographer. The sonographers were blinded for the clinical diagnosis of the subjects and the TCD results of the other sonographer.

Altogether, four different combinations for the inter-observer agreement analysis were possible. Furthermore, the intra-observer agreement of both ultrasonographers using two different ultrasound systems was evaluated.

"Off-line" assessment: two months after data acquisition, a third independent observer re-evaluated the ultrasound images that observer 1 and 2 had acquired with the SONOS 5500 system, allowing us to calculate an "off-line" inter-observer agreement.

\section{Data analysis}

Cohen's kappa values were calculated for all inter- and intra-observer comparisons of the $\mathrm{SN}$ and $\mathrm{RN}$ echogenicity. At first, the agreement in evaluating the $\mathrm{SN}$ was calculated based on the three categories (positive, negative, and inconclusive). Previously, we have shown that the presence of a pathologically increased echointensity of the $\mathrm{SN}$ was highly correlated with an 
abnormal presynaptic dopaminergic SPECT examination, whereas the absence of a positive SN-TCD finding had only little predictive power for the SPECT.$^{16}$ This implies that a positive finding has more impact in daily practice. Therefore, in a second step the negative and inconclusive scores were pooled and compared with the positive findings. In other words, we evaluated the agreement dichotomically, i.e., for the presence of a positive SN-TCD or not. We evaluated the data of the RN-TCD likewise. All statistical analyses were performed with SPSS 11.0 for Windows.

\section{Results}

For reasons of clarity, for all studies only the proportion of matching results is given as well as the kappa value. Only for the inter-observer agreement study on the qualitative analysis of the $\mathrm{SN}$, the detailed scores are presented in order to elucidate their distribution.

\section{"On-line" inter-observer agreement}

Qualitative evaluation of SN-TCD: both observers agreed in approximately $2 / 3$ of the 24 subjects. The agreement slightly improved if the negative and inconclusive TCD's were pooled, in other words, when the positive findings were compared with all other ones. The investigators then agreed in approximately $70 \%$, corresponding to kappa values between 0.3 and 0.4 . See Table 5.1 for all comparisons and results of statistics. The detailed distribution of the scores is given in Table 5.2. It appears that the number of positive findings for observer 1 is slightly higher when using the SONOS 5500 as compared to the iU22, but for the remainder the positive and negative scores are evenly distributed. Quantitative evaluation of $S N-T C D$ : with this approach results were comparable to those achieved with the qualitative evaluation. The agreement also improved when the inconclusive TCD's were pooled with the negative ones. See Table 5.1 for detailed results and the kappa statistics.

$R N-T C D$ : In approximately half of the patients both sonographers agreed that the RN-TCD was normal, abnormal or inconclusive, resulting in very low kappa values. On the contrary, if the inconclusive RN-TCD's were pooled with the normal ones, the investigators agreed very well (maximally 22/24; 92\%). 
Table 5.1 "On-line" inter-observer agreement of two different observers on the echointensity of the substantia nigra and Raphe nuclei, when scanning each with two different ultrasound systems.

\begin{tabular}{|c|c|c|c|}
\hline & $\begin{array}{l}\text { Observer and ultrasound } \\
\text { system used }\end{array}$ & $\begin{array}{c}\text { Agreement } \\
\text { (n/24 subjects, } \%, \text { kappa) }\end{array}$ & $\begin{array}{c}\text { Agreement on } \\
\text { pooled data (see below) } \\
\text { (n/24 subjects, } \% \text {, kappa) }\end{array}$ \\
\hline $\mathrm{SN}$ & $1+$ SONOS / 2 + SONOS & $15 / 24(63 \%), 0.23$ & $16 / 24(67 \%), 0.26$ \\
\hline qualitative & $1+i U 22 / 2+i U 22$ & $15 / 24(63 \%), 0.31$ & $16 / 24(67 \%), 0.31$ \\
\hline \multirow[t]{2}{*}{ evaluation } & $1+\mathrm{iU} 22$ / 2 + SONOS & $16 / 24(67 \%), 0.39$ & $17 / 24(71 \%), 0.39$ \\
\hline & $1+$ SONOS / 2 + iU22 & $15 / 24$ (63\%), 0.24 & $17 / 24(71 \%), 0.37$ \\
\hline SN; & $1+$ SONOS / $2+$ SONOS & $16 / 24(67 \%), 0.38$ & $17 / 24(71 \%), 0.40$ \\
\hline quantitative & $1+i U 22 / 2+i U 22$ & $15 / 24(63 \%), 0.31$ & $16 / 24(67 \%), 0.31$ \\
\hline \multirow[t]{2}{*}{ evaluation } & $1+i U 22 / 2+$ SONOS & 18/24 (75\%), 0.56 & 19/24 (79\%), 0.58 \\
\hline & $1+$ SONOS / 2 + iU22 & $16 / 24(67 \%), 0.33$ & $18 / 24(75 \%), 0.47$ \\
\hline $\mathrm{RN}$ & $1+$ SONOS / $2+$ SONOS & $11 / 24(46 \%), 0.03$ & 19/24 (79\%), 0.06 \\
\hline qualitative & $1+i U 22 / 2+i U 22$ & $13 / 24(54 \%), 0.15$ & $21 / 24(88 \%), 0.19$ \\
\hline \multirow[t]{2}{*}{ evaluation } & $1+i U 22 / 2+$ SONOS & $11 / 24(46 \%), 0.04$ & 18/24 (75\%), 0.08 \\
\hline & 1+ SONOS / 2 + iU22 & $13 / 24(54 \%), 0.15$ & $22 / 24(92 \%), 0.46$ \\
\hline
\end{tabular}

SN: substantia nigra, RN: Raphe nuclei, n: number of subjects. Pooled data: when evaluating the $\mathrm{SN}$, negative and inconclusive findings were pooled, when evaluating the RN, normal and inconclusive findings were pooled.

Table 5.2 "On-line" inter-observer agreement. The scores for both observers on the qualitative evaluation of the echointensity of the substantia nigra, when scanning with two different ultrasound systems.

a) Observer 1 and 2 both using SONOS 5500

Obs. 2

SN-TCD pos. SN-TCD neg. SN-TCD inconcl. Total

\begin{tabular}{llrrrr}
\hline Obs.1 & SN-TCD pos. & 12 & 4 & 1 & 17 \\
& SN-TCD neg. & 3 & 2 & 1 & 6 \\
& SN-TCD inconcl. & 0 & 0 & 1 & 1 \\
\hline Total & 15 & 6 & 3 & 24
\end{tabular}

b) Observer 1 and 2 both using iU22

Obs.2

SN-TCD pos. SN-TCD neg. SN-TCD inconcl. Total

\begin{tabular}{llrrrr}
\hline Obs.1 & SN-TCD pos. & $\mathbf{1 0}$ & 4 & 0 & 14 \\
& SN-TCD neg. & 3 & $\mathbf{4}$ & 0 & 7 \\
& SN-TCD inconcl. & 1 & 1 & $\mathbf{1}$ & 3 \\
\hline Total & 14 & 9 & 1 & 24
\end{tabular}


c) Observer 1 using iU22 and observer 2 using SONOS 5500

Obs.2

\begin{tabular}{|c|c|c|c|c|c|}
\hline & & $\begin{array}{c}\text { Obs.2 } \\
\text { SN-TCD pos. }\end{array}$ & SN-TCD neg. & SN-TCD inconcl. & Total \\
\hline \multirow{4}{*}{$\overline{O b s .1}$} & SN-TCD pos. & 11 & 2 & 1 & 14 \\
\hline & SN-TCD neg. & 4 & 3 & 0 & 7 \\
\hline & SN-TCD inconcl. & 0 & 1 & 2 & 3 \\
\hline & Total & 15 & 6 & 3 & 24 \\
\hline
\end{tabular}

d) Observer 1 using SONOS 5500 and observer 2 using iU22

Obs. 2

\begin{tabular}{llcccc} 
& & SN-TCD pos. & SN-TCD neg. & SN-TCD inconcl. & Total \\
\hline Obs.1 & SN-TCD pos. & $\mathbf{1 2}$ & 5 & 0 & 17 \\
& SN-TCD neg. & 2 & $\mathbf{3}$ & 1 & 6 \\
& SN-TCD inconcl. & 0 & 1 & $\mathbf{0}$ & 1 \\
\hline \multicolumn{2}{c}{ Total } & 14 & 9 & 1 & 24
\end{tabular}

SN: substantia nigra; Obs: observer; pos: positive; neg: negative; inconcl: inconclusive; SN-TCD: transcranial duplex scanning of the substantia nigra.

\section{"On-line" intra-observer agreement}

Qualitative evaluation of SN-TCD: when comparing the results of a single observer using both ultrasound systems, observer 1 came to the same conclusion in 20 out of the 24 subjects (83\%). Observer 2 agreed 18 times (75\%).

Quantitative evaluation of SN-TCD: similar results were obtained for both observers as compared to the qualitative method.

$R N-T C D$ : the intra-observer agreement for the evaluation of the RN was slightly less than for the evaluation of the substantia nigra.

For detailed results and kappa values also after pooling the normal scores with the inconclusive scores, see Table 5.3.

Table 5.3 Online intra-observer agreement of two different observers on the echointensity of the substantia nigra and Raphe nuclei, when scanning with two ultrasound systems.

\begin{tabular}{|c|c|c|c|}
\hline & Observer & $\begin{array}{c}\text { Agreement } \\
\text { (n/24 subjects, } \%, \text { kappa) }\end{array}$ & $\begin{array}{c}\text { Agreement on } \\
\text { pooled data (see below) } \\
\text { (n/24 subjects, } \% \text {, kappa) }\end{array}$ \\
\hline SN; qualitative & observer 1 & 20/24 (83\%), kappa 0.67 & 21/24 (88\%), kappa 0.73 \\
\hline evaluation & observer 2 & 18/24 (75\%), карра 0.53 & 19/24 (79\%), kарра 0.57 \\
\hline SN; quantitative & observer 1 & 21/24 (88\%), kappa 0.76 & 22/24 (92\%), kappa 0.82 \\
\hline evaluation & observer 2 & 18/24 (75\%), kappa 0.55 & 19/24 (79\%), карра 0.58 \\
\hline $\mathrm{RN}$; qualitative & observer 1 & 17/24 (71\%), kappa 0.47 & 23/24 (96\%), kappa 0.65 \\
\hline evaluation & observer 2 & $16 / 24(67 \%)$, карра 0.45 & 21/24 (88\%), kappa 0.51 \\
\hline
\end{tabular}

SN: substantia nigra, RN: Raphe nuclei, pooled data: when evaluating the SN, negative and inconclusive findings were pooled, when evaluating the $\mathrm{RN}$, normal and inconclusive findings were pooled. 


\section{"Off-line" inter-observer agreement}

Qualitative evaluation of SN-TCD: when evaluating the data "off-line", observer 3 fairly agreed with the scores that observer 1 had given during the "on-line" sessions and to a lesser degree with those from observer 2. Pooling the negative and inconclusive findings, the results were identical. For detailed results, see Table 5.4 .

Quantitative evaluation of $S N-T C D$ : in contrast to the qualitative analysis, the agreement between observer 3 and observers 1 and 2 did not differ.

$R N-T C D$ : The inter-observer agreement was fair for the comparison between observer 3 and 1 . Pooling the normal and inconclusive findings resulted in a considerable increase of agreement. There was almost no agreement between observer 3 and 2.

Table 5.4 Agreement of the "off-line" observer with the "on-line" observers on the echointensity of the substantia nigra and Raphe nuclei.

\begin{tabular}{|c|c|c|c|}
\hline & $\begin{array}{l}\text { Observer } 3 \\
\text { ("off-line") } \\
\text { versus: }\end{array}$ & $\begin{array}{c}\text { Agreement } \\
\text { (n/24 subjects, } \%, \text { kappa) }\end{array}$ & $\begin{array}{c}\text { Agreement on } \\
\text { pooled data (see below) } \\
\text { (n/24 subjects, } \%, \text { kappa) }\end{array}$ \\
\hline$\overline{\mathrm{SN} \text {; qualitative }}$ & observer 1 & 20/24 (83\%), kappa 0.67 & 20/24 (83\%), kappa 0.66 \\
\hline evaluation & observer 2 & 16/24 (67\%), kappa 0.32 & 16/24 (67\%), карра 0.26 \\
\hline SN; quantitative & observer 1 & 18/24 (75\%), kappa 0.53 & $18 / 24$ (75\%), карра 0.50 \\
\hline evaluation & observer 2 & 19/24 (79\%), kappa 0.61 & 19/24 (79\%), карра 0.66 \\
\hline $\mathrm{RN}$; qualitative & observer 1 & 15/24 (63\%), kappa 0.33 & 23/24 (96\%), kappa 0.65 \\
\hline evaluation & observer 2 & 11/24 (46\%), kappa 0.08 & $18 / 24(75 \%)$, карра -0.08 \\
\hline
\end{tabular}

SN: substantia nigra, RN: Raphe nuclei, Pooled data: when evaluating the $\mathrm{SN}$, negative and inconclusive findings were pooled, when evaluating the $\mathrm{RN}$, normal and inconclusive findings were pooled.

\section{Discussion and conclusions}

In the present study we determined the inter-observer and intra-observer agreement for the evaluation of brainstem nuclei with the help of TCD. For the evaluation of the $\mathrm{SN}$ mediocre accordance was found, when comparing the results of two observers "on-line" as well as when comparing the results of an "off-line" observer with both "on-line" observers. Comparing the "on-line" observers with themselves when using an other ultrasound device, the intraobserver agreement appeared to be moderate to substantial. For the evaluation of the RN, the concordance between the different observers was apparently low, whereas the consistency for a single "on-line" observer using two different ultrasound systems was comparable to the evaluation of the SN.

Previously, considerably higher values for the inter-observer agreement evaluating the $\mathrm{SN}$ quantitatively have been reported: intra class correlation 
coefficients and kappa values of $0.80-0.98$ were reached instead of kappa values ranging between 0.26 and 0.58 in the present study. ${ }^{3,4,9-11}$ Those investigators, however, studied patients already diagnosed with IPD, restless legs syndrome or vascular parkinsonism. In contrast, we studied a mixed population, including not only patients with IPD and patients with parkinsonism of unspecified origin but also healthy volunteers in order to decrease the 'a priori chance' of a positive finding. Furthermore, our sonographers were completely blinded for the clinical diagnoses. Additionally, the sonographers had had their training at different institutions and did never work together before.

One might expect that quantitatively evaluating the area of enhanced echointensity might be more accurate than qualitatively judging whether the SN appears hyperechogenic or not. Hence, the inter-observer agreement might be better using the first approach. Our data can not confirm this assumption, indicating that measuring the area of increased echointensity does not introduce more diagnostic reliability as compared to a more simple, qualitative approach.

The results of the "off-line" assessment were in line with those of the "on-line" assessments, which means that reliably estimating the ultrasound properties of the $\mathrm{SN}$ is not restricted to the "on-line" examination situation. This is important with regard to future studies on the inter-observer agreement as well as quality control. One should take into account that the "off-line" assessment in the present study was performed on a loop of images, and not on one static image, allowing a broader view on the surrounding structures and borders of the SN.

We could previously show that only the presence of a positive SN-TCD was highly correlated with an abnormal presynaptic dopaminergic SPECT. ${ }^{12,16}$ This implies that the latter examination might be omitted in those patients with an increased echogenicity of the $\mathrm{SN}$, resulting in a considerable reduction of costs and patient burden. A negative SN-TCD, on the contrary, was of low predictive value. So, for the analysis of the $\mathrm{SN}$, pooling the inconclusive and negative findings appears to be clinically warranted. The agreement only slightly improved after reducing the findings to two categories, reflecting the low proportion of patients with inconclusive TCD findings. Hence, the latter does not explain the relatively low kappa values as compared to the data reported by others. ${ }^{3,4,9-11}$

The highest agreement in our study was achieved when the "on-line" observers were compared with themselves using an other ultrasound device, albeit that observer 1 showed more consistency than observer 2 (substantial and fair agreement, respectively). Evaluating the same patient with two different systems did not substantially affect the scores of the intra-observer agreement study. However, observer 1 had slightly more positive findings using the SONOS 5500 system and observer 2 marginally less negative and more 
inconclusive findings. This might be explained by the fact that in every day practice observer 1 uses the SONOS 5500 system whereas observer 2 is more familiar with the iU22 system. Also, for the inter-observer study, the degree of agreement between both observers was not affected by the use of a specific ultrasound system.

The inter and intra-observer agreement for the evaluation of the RN using TCD have not been studied before. We found a very low inter-observer agreement, practically not different from chance for the "on-line" comparison and the "offline" comparison between observer 3 and 2. On the contrary, the "off-line" agreement between observer 3 and 1 was considerably better than the intraobserver agreement. So, obviously, there was a mismatch between observer 1 and 2 for the evaluation of the ultrasound properties of the RN despite the pre-defined criteria. The meaningfulness of the agreement analysis is, however, limited in our study due to the fact that at most two subjects were scored "on-line" as abnormal with regard to the RN-TCD.

It is conceivable that the better the quality of the ultrasound images obtained the better the intra-and inter-observer agreement will be. Yet the number of the included subjects was too small to allow for evaluation of this aspect. It is likely that more recent ultrasound devices deliver higher resolution. Technical developments like second harmonic imaging possible will possibly influence the inter-observer agreement. This has to be tested in further studies. Additionally, one has to realise that the image quality cannot be enhanced in a given patient for example by the use of contrast agents, which means that a relatively poor image quality will occur regularly in daily practice.

Kappa statistics are frequently used for estimating the agreement between two observers, for example when evaluating the echogenicity of the SN by means of ultrasound. ${ }^{14}$ Mostly, the strength of agreement is expressed according to a classification as proposed by Landis and Koch. ${ }^{17} \mathrm{~A}$ kappa value of 0-0.2 is commonly interpreted as slight, $0.21-0.4$ as fair, $0.41-0.60$ as moderate, $0.61-0.8$ as substantial and more than 0.81 as almost perfect. Hence, the "on-line" and "off-line" inter-observer agreement for the SN-TCD in this study for example can be regarded more or less as moderate, which might be interpreted as relatively low for a medical test. Nevertheless, the inter-observer agreement for the determination of the vascular territory in patients with a recent minor stroke or transient ischemic attack was in the same order of magnitude (kappa 0.48-0.54). ${ }^{18}$

However, it has to be kept in mind, that several methodological concerns have been raised limiting the practical value of this statistic approach. ${ }^{19,20}$ For example, an uneven distribution of the contingency table might affect the kappa 
statistics, probably being relevant for the part of our study in which the RN were evaluated, since the proportion of the pathological findings was very low. But also the comparability of kappa values across different studies and the use of the aforementioned classification are not unanimously accepted.

The present study has some limitations. Firstly, the total number of subjects studied was limited, restricting the significance of our findings especially if the distribution between pathological and normal findings was quite asymmetric, which was the case for the evaluation of the RN. Secondly, the subjects underwent their four TCD examinations on the same day. Although a subject was not scanned consecutively by the same sonographer using the two different ultrasound systems some memory bias in the intra-observer study can not be ruled out. Furthermore, for a true intra-observer agreement study the same subject should have been scanned with the same ultrasound system twice. Since the subjects were already scanned four times, we decided not to perform this test modality.

The relatively mediocre agreement in our study might be partly explained by a lack of generally accepted criteria for the evaluation of the echointensity of the $\mathrm{SN}$ and the RN. Possibly, a standardised quantitative measurement of the echointensity of the SN and the surrounding tissue might aid in improving the uniformity of the results. Additionally, standard settings for the ultrasound system used are required.

In this study two observers from different institutions each used two different ultrasound systems for the evaluation of the $\mathrm{SN}$ and the $\mathrm{RN}$ of a mixed population. On the whole, the inter-observer and intra-observer agreement were moderate to substantial for the evaluation of the SN. "On-line" and "offline" comparisons yielded comparable results. The agreement for the evaluation of the RN, on the contrary, was considerably lower. TCD of the brainstem is a patient friendly and reasonably reliable technique. Unambiguously defined and commonly accepted criteria for its evaluation might facilitate its clinical implementation. 


\section{References}

1. Walter U, Niehaus L, Probst T, Benecke R, Meyer BU, Dressler D. Brain parenchyma sonography discriminates Parkinson's disease and atypical parkinsonian syndromes. Neurology 2003;60:74-7.

2. Becker G, Seufert J, Bogdahn U, Reichmann H, Reiners K. Degeneration of substantia nigra in chronic Parkinson's disease visualized by transcranial color-coded real-time sonography. Neurology 1995;45:182-4.

3. Berg D, Siefker C, Becker G. Echogenicity of the substantia nigra in Parkinson's disease and its relation to clinical findings. J Neurol 2001;248:684-9.

4. Berg D, Becker G, Zeiler B, Tucha O, Hofmann E, Preier M, Benz P, Jost W, Reiners K, Lange KW. Vulnerability of the nigrostriatal system as detected by transcranial ultrasound. Neurology 1999;53:1026-31.

5. Becker G, Becker T, Struck M, Lindner A, Burzer K, Retz W, Bogdahn U, Beckmann H. Reduced echogenicity of brainstem raphe specific to unipolar depression: a transcranial color-coded real-time sonography study. Biol Psychiatry 1995;38:180-4.

6. Berg D, Supprian T, Hofmann E, Zeiler B, Jäger A, Lange KW, Reiners K, Becker T, Becker G. Depression in Parkinson's disease: brainstem midline alteration on transcranial sonography and magnetic resonance imaging. J Neurol 1999;246:1186-93.

7. Walter U, Behnke S, Eyding J, Niehaus L, Postert T, Seidel G, Berg D. Transcranial brain parenchyma sonography in movement disorders: state of the art. Ultrasound Med Biol 2007;33:15-25.

8. Vlaar AMM, Bouwmans A, Mess WH, Tromp SC, Weber WEJ. Transcranial duplex in the differential diagnosis of parkinsonian syndromes: a systematic review. Journal of Neurology 2009; 256:530-8.

9. Godau J, Schweitzer KJ, Liepelt I, Gerloff C, Berg D. Substantia nigra hypoechogenicity: definition and findings in restless legs syndrome. Mov Disord 2007;22:187-92.

10. Huang YW, Jeng JS, Tsai CF, Chen LL, Wu RM. Transcranial imaging of substantia nigra hyperechogenicity in a Taiwanese cohort of Parkinson's disease. Mov Disord 2007;22:550-5.

11. Tsai CF, Wu RM, Huang YW, Chen LL, Yip PK, Jeng JS. Transcranial color-coded sonography helps differentiation between idiopathic Parkinson's disease and vascular parkinsonism. J Neurol 2007;254:501-7.

12. Tromp SC, Vlaar AMM, Weber WEJ, Mess WH. Can ultrasonography of the substantia nigra replace FP-CIT-SPECT? Parkinsonism Relat Disord 2005;11(supplement 2):S221.

13. Berg D, Roggendorf W, Schröder U, Klein R, Tatschner T, Benz P, Tucha O, Preier M, Lange KW, Reiners K, Gerlach M, Becker G. Echogenicity of the substantia nigra: association with increased iron content and marker for susceptibility to nigrostriatal injury. Arch Neurol 2002; 59:999-1005.

14. Okawa M, Miwa H, Kajimoto Y, Hama K, Morita S, Nakanishi I, Kondo T. Transcranial sonography of the substantia nigra in Japanese patients with Parkinson's disease or atypical parkinsonism: clinical potential and limitations. Intern Med 2007;46:1527-31.

15. Iova A, Garmashov A, Androuchtchenko N, Kehrer M, Berg D, Becker G, Garmashov Y. Postnatal decrease in substantia nigra echogenicity Implications for the pathogenesis of Parkinson's disease. J Neurol 2004;251:1451-4.

16. Vlaar A, de Nijs T, van Kroonenburgh M, Mess W, Winogrodzka A, Tromp S, Weber W. The predictive value of transcranial duplex sonography for the clinical diagnosis in undiagnosed parkinsonian syndromes: comparison with SPECT scans. BMC Neurology 2008;8:42.

17. Landis JR, Koch GG. The measurement of observer agreement for categorical data. Biometrics 1977;1:159-74.

18. Flossmann E, Redgrave JN, Briley D, Rothwell P. Reliability of clinical diagnosis of the symptomatic vascular territory in patients with recent transient ischemic attack or minor stroke. Stroke 2008;39:2457-60.

19. Uebersax JS. Kappa coefficients. Web citation 2008: http://ourworld.compuserve.com/ homepages/jsuebersax/kappa.htm 
94 Chapter 5

20. Altman DG. Practical statistics for medical research. 1991 Chapman \& Hall/ CRC, New York, USA. 

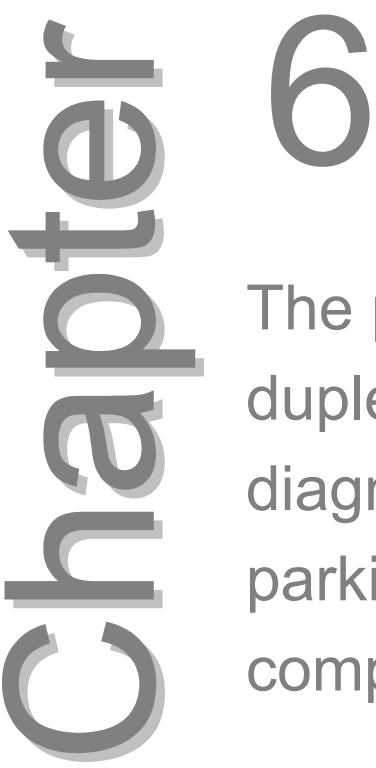

The predictive value of transcranial duplex scanning for the clinical diagnosis in undiagnosed parkinsonian syndromes: comparison with SPECT scans

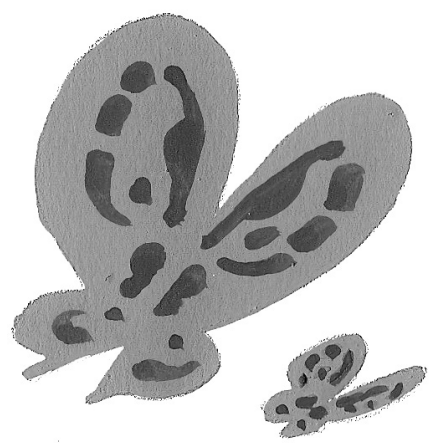

Annemarie M.M. Vlaar, Tjerk de Nijs, Marinus J.P.G. van Kroonenburgh, Werner H. Mess, Ania Winogrodzka, Selma C. Tromp, Wim E.J. Weber BMC Neurology 2008;8:42 


\section{Abstract}

\section{Background}

Transcranial duplex sonography (TCD) of the substantia nigra has emerged as a promising, noninvasive tool to diagnose idiopathic Parkinson's disease (IPD). However, its diagnostic accuracy in patients with undefined parkinsonism remains to be determined.

\section{Objective}

To determine the predictive value of TCD for the clinical diagnosis in undiagnosed parkinsonian syndromes. To compare the predictive value of TCD with that of presynaptic and postsynaptic SPECT scans.

\section{Methods}

We studied 82 patients with an unclassified parkinsonian syndrome. All 82 patients were subjected to a TCD, 59 of them underwent a presynaptic SPECT scans and 32 underwent a postsynaptic SPECT scan.

We determined the diagnostic accuracy of TCD and SPECT scans in differentiating:1) IPD patients from patients without nigrostriatal degeneration and 2) IPD patients from patients with atypical parkinsonian syndromes (APS). To compare the diagnostic accuracy of TCD and SPECT scans, we used the clinical diagnosis after follow-up according to generally accepted clinical criteria as the gold standard. This clinical diagnosis was determined by a movement disorder specialist. 3) Finally, we ascertained the predictive value of TCD for the SPECT result.

\section{Results}

The clinical diagnoses after follow-up resulted in 51 cases of IPD, 7 patients with APS and 17 patients without nigrostriatal degeneration. In total 7 patients remained undiagnosed.

1) The accuracy of TCD, measured by sensitivity and specificity, to differentiate IPD patients from patients without nigrostriatal degeneration was $50 \%$ and $82 \%$ respectively. For the presynaptic SPECT scans sensitivity was $97 \%$ and specificity $100 \%$.

2) In differentiating IPD patients from APS patients, the sensitivity and specificity of TCD was $50 \%$ and $43 \%$ respectively. For presynaptic SPECT scans this was $97 \%$ and $0 \%$. For the postsynaptic SPECT scans the sensitivity was $75 \%$ and the specificity $81 \%$.

3) The positive predictive value (PPV) of an abnormal TCD for an abnormal presynaptic SPECT scan was $88 \%$.

\section{Conclusions}

Presynaptic SPECT scanning has a higher predictive value for the clinical diagnosis than TCD. However, since the PPV of an abnormal TCD for parkinsonism with nigrostriatal degeneration is high, TCD might be used as screening tool, before ordering a presynaptic SPECT. 


\section{Introduction}

The diagnosis of idiopathic Parkinson's disease (IPD) is based on clinical criteria. When cardinal clinical signs and symptoms as bradykinesia, rigidity, and resting tremor are present, the diagnosis of IPD is straightforward. ${ }^{1}$ However, the differentiation between IPD and other parkinsonian syndromes can be difficult, especially in the early stages of the disease.

Diseases which might resemble early-stage IPD are atypical parkinsonian syndromes (APS, i.e. multiple system atrophy [MSA], progressive supranuclear palsy [PSP], diffuse Lewy body disease [DLBD], and corticobasal degeneration [CBD]), but also vascular parkinsonism (VP), drug induced parkinsonism (DIP) and essential tremor (ET). Clinico-pathological studies show that $2-25 \%$ of the patients with IPD are classified incorrectly in the final stage of their disease, even by specialists in movement disorders. ${ }^{2-6}$ Because the prognosis and medical treatment differ between various parkinsonian syndromes, an accurate and early diagnosis is essential for optimal treatment and counselling.

Single Photon Emission Computer Tomography (SPECT), with presynaptic and postsynaptic radiotracers, is widely used in the diagnostic work-up of patients with parkinsonian syndromes. Despite its widespread use, the exact diagnostic accuracy of this technique in parkinsonian syndromes remains somewhat controversial. ${ }^{7,8}$

Becker and colleagues were first to report hyperechointensity of the substantia nigra (SN) in patients with IPD by using transcranial duplex sonography (TCD). ${ }^{9}$ Several studies found that this increased SN echointensity is present in $90 \%$ of IPD patients ${ }^{9-12}$, presumably caused by a local increased iron content. ${ }^{13,14}$ In healthy individuals this increased SN echointensity is found in only $9 \% .{ }^{15}$ Since Becker's first report, roughly 70 studies on the diagnostic accuracy of TCD in parkinsonian syndromes have been published. Most studies on TCD and IPD have been done on later-stage, well-diagnosed patients. However, this does not resemble the situation in clinical practice, where the neurologist would want to use TCD to reach a diagnosis in patients with a clinically unclear parkinsonism.

In the present study we assessed the diagnostic accuracy of SN-TCD with that of SPECT scan, which was performed simultaneously in most of these patients. We also calculated the predictive value of the SN-TCD for the results of the SPECT scans. 


\section{Patients and methods}

\section{Patients}

We retrospectively studied 82 consecutive patients with a parkinsonism of yet unknown origin. All of these patients were subjected to a SN-TCD between 2004 - 2006 after giving their informed consent. The study was approved by the Institutional Review Board (committee for Medical Ethics) of the University Hospital Maastricht. We initially studied 95 patients, of whom we had to exclude $13(15 \%)$ with inconclusive SN-TCD's because of an inappropriate temporal bone window (i.e. insufficient to acquire a 2-dimensional image of the intracranial structures). This percentage of inconclusive results is within the normal range. ${ }^{15-17}$

Of the 82 patients, fifty-nine underwent presynaptic-SPECT imaging and thirtytwo postsynaptic SPECT imaging depending on the personal judgement of the treating specialist (Figure 6.1).

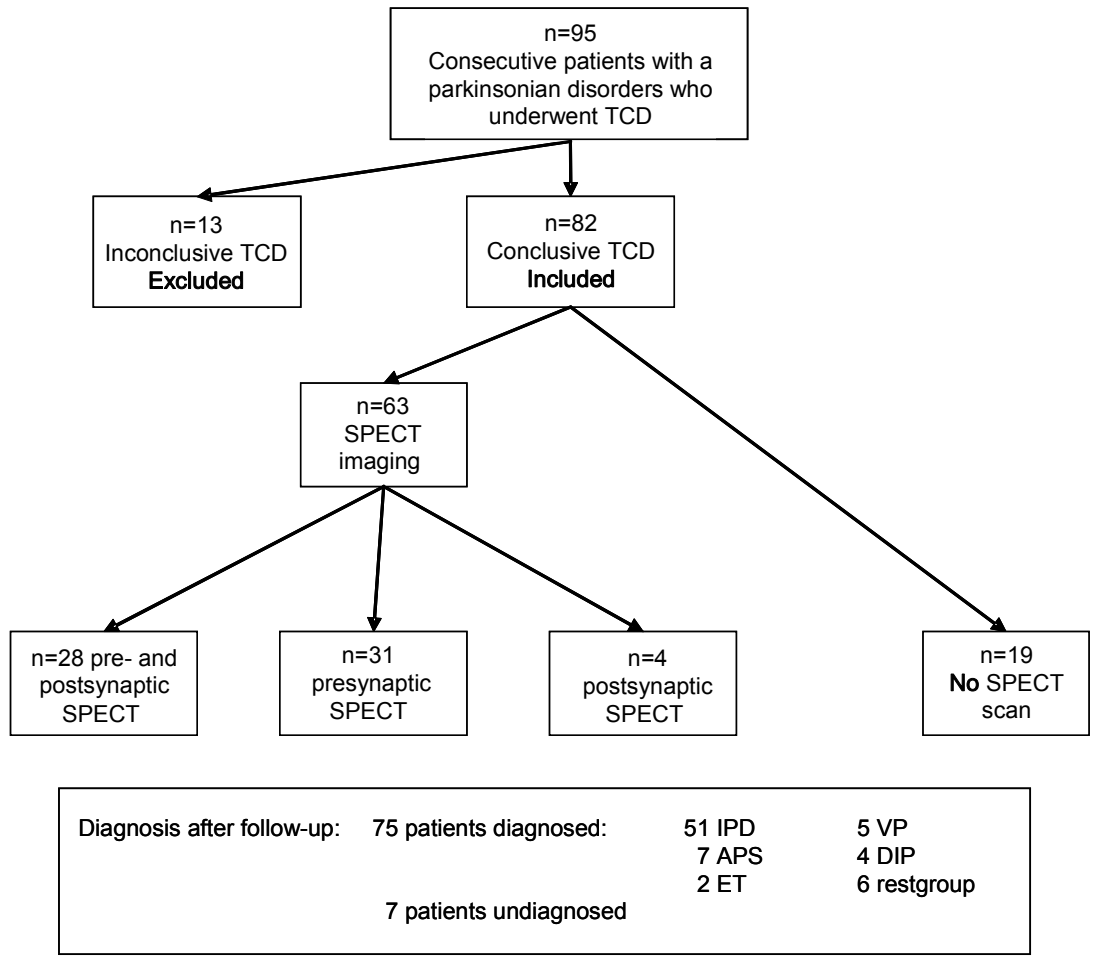

Figure 6.1 Flowchart

$\mathrm{n}=$ number of subjects, TCD transcranial duplex scanning, SPECT single photon emission computer tomography, IPD idiopathic Parkinson's disease, APS atypical parkinsonian syndromes, ET essential tremor, VP vascular parkinsonism, DIP drug induced parkinsonism. 
To come to a clinical diagnosis (the surrogate gold standard in this study) the patients were re-examined by an independent neurologist specialized in movement disorders. This happened after a follow-up interval of at least six months.

A total of 52 patients (63\%) gave consent to be re-examined (twenty-one refused re-examination, five patients died, and four were lost to follow-up). However, the clinical records of the 30 patients that were not re-examined, were studied by the experts (WW, AW) to see if it was possible draw a conclusion on the final diagnosis of these patients, according to generally accepted clinical criteria. ${ }^{1,3,18-21}$ If there was clinical doubt between different parkinsonian disorders a patient was called "undiagnosed".

\section{SN-TCD}

We used a 2-4 MHz phased array transducer on a commercially available ultrasound system (SONOS 5500; Philips, Eindhoven, the Netherlands). The transducer was placed over the transtemporal bone window and focussed at a depth of $6-8 \mathrm{~cm}$ to allow for optimal image quality of the brainstem. Overall gain and the degree of compression were visually adapted to optimally depict an increased echointensity of the $\mathrm{SN}$, if present. In practice a relatively high gain setting was used in combination with relatively little compression. This combination resulted in an almost homogeneously echolucent brainstem for the areas where no increase of the echointensity can be expected. The Raphe nuclei, the nucleus ruber and the SN (in case of a positive finding) on the other hand were easily distinguishable due to their increased echointensity. All other parameters like time gain compensation, post processing and power settings were kept constant throughout the study.

Initially were performed also second harmonic imaging (insonation frequency 1.8 MHz). Yet it appeared, that with our ultrasound system we were able to visualize the brainstem only in a minority of patients. Since it is also well-known (personal conversation with Prof. D. Berg, Tübingen), that second harmonic imaging will lead to an increase of the hyperechointense area of the $\mathrm{SN}$ if compared to images based on the basal frequency content, we decided to use only primary images in this study.

A loop of 64 images was acquired by scanning the brainstem cranio-caudally through the pre-auricular bone window on the both sides. The images were stored digitally to allow for off-line analysis by a second sonographer. Both sonographers were blinded for the SPECT results and the clinical diagnoses. The echointensity of the SN was evaluated by ipsilateral insonation.

The SN echointensity can be estimated semi-quantitatively by manually encircling the area of hyperechointensity and having the ultrasound system 
measuring the area. ${ }^{10,15}$ in our experience it is often difficult to accurately delineate the area of the SN hyperechointensity (if present), which would lead to inconsistent results. Therefore, we used a simplified and more practical method using the following qualitative scores: "positive", "negative", "inconclusive". Comparable qualitative scoring systems have also been used by other investigator groups. ${ }^{22-24}$

The SN-TCD is scored "positive", when, at least on one side, the SN is clearly visible due to its large hyperechointense area as compared to the surrounding brainstem tissue. Additionally, the hyperechointense area has to correspond with the anatomy of the SN. Only if the hyperechointense area extends as an oblique and continuous band in the medial-anterior to lateral-posterior direction, we scored this as a "positive" finding. We could show that such an echo intensity increase always corresponded to an area larger than $0.2 \mathrm{~cm}^{2}$ (unpublished data; currently under review).

If the image quality is sufficient to evaluate the echointensity of the SN, but the above mentioned criteria are not met, then the SN-TCD is scored "negative". This implies, that an SN-TCD is also called "negative" if there is a doubtful hyperechointensity. This could be either due to an atypical anatomical distribution or only a small area of hyperechointensity not extending throughout the whole brainstem in the horizontal plane as described above.

An "inconclusive" SN-TCD is a measurement where visualization of the intracranial structures is not or only partly possible due to insufficient temporal bone windows on both sides.

\section{SPECT}

In this study we used the presynaptic radiotracer FP-CIT (123I-loflupane, General Electrics Health, Eindhoven, The Netherlands) and the postsynaptic tracer IBZM (123I-iodobenzamide, General Electrics Health, Eindhoven, The Netherlands). Medication which could interfere with the radiotracer was stopped at least 5 half-life times before the SPECT scan was made. SPECT scans were performed with a triple head camera (MultiSPECT3, Siemens, Ohio, USA) equipped with high-resolution collimators. A semi-automatic template model programme was used to calculate the ratios between left striatal and right striatal and occipital regions, respectively. Total time of acquisition was 30 minutes (45 seconds per frame for 40 views per detector), zoom factor: 1.00 and the matrix size: 128x128. Filtered back-projection acquisition was performed. Images were filtered using a Butterworth filter with a cut-off value of 0.4-0.5 and an order of 5 . The ratios were corrected using Alderson's brain phantom with known activities in the caudate nucleus and putamen. 
A binding of two standard deviations below healthy controls was considered as abnormal (FP CIT 8.25, sd 1.85 for putamen and 7.76, sd 1.77 for caudate nucleus. IBZM for striatum 3.58, sd 0.18). The scans were analysed by a nuclear medicine specialist who was blinded for the clinical diagnosis and the SN-TCD results.

\section{Statistics}

The diagnostic accuracy of SN-TCD, presynaptic and postsynaptic SPECT scintigraphy was determined by comparing their results to the surrogate gold standard: the clinical diagnosis after follow-up. Diagnostic accuracy is defined as the sensitivity, specificity, positive predictive value (PPV) and negative predictive value (NPV).

The accuracy was determined for: 1) IPD patients and patients without nigrostriatal degeneration (ET, DIP, VP, restgroup) and 2) IPD and APS patients.

And finally, we calculated the predictive value of SN-TCD for the presynaptic and postsynaptic SPECT result. SPSS (SPSS, Chicago, IL) was used for statistical analysis.

\section{Results}

\section{Descriptives}

The mean (SD) age of the eighty-two patients was 69 (10) years, and the majority (65\%) was male. The mean (SD) Hoehn and Yahr score was 2.4 (1.1). The follow-up duration after the SN-TCD was on average 17 (10) months.

In seventy-five (91\%) of the eighty-two cases, it was possible for the MDspecialist to come to a definite clinical diagnosis. In total seven cases stayed undiagnosed after follow-up, because they did not fulfil the generally accepted clinical criteria. ${ }^{1,3,18-21}$ For an overview of all the clinical diagnoses after followup see Table 6.1.

\section{Accuracy of SN-TCD and pre- and post-synaptic SPECT in predicting the clinical diagnosis after follow-up}

For the complete overview of the results of the SN-TCD, presynaptic and postsynaptic SPECT in each subgroup of patients, see Table 6.1.

The first thing we looked at was the sensitivity of the SN-TCD in differentiating patients with IPD $(n=51)$ from patients with ET, VP, DIP or the rest group $(n=17)$. This sensitivity was $50 \%$, while the specificity was $82 \%$, the PPV $89 \%$ 
and the NPV 35\%. For the presynaptic SPECT scans these values were respectively $97 \%, 100 \%, 100 \%$ and $92 \%$.

SN-TCD could differentiate IPD patients $(n=51)$ from patients with APS $(n=7)$ with a sensitivity of $50 \%$ and a specificity of $43 \%$; the PPV and NPV were $86 \%$ and $10 \%$ respectively. For the presynaptic SPECT scans, these values were $97 \%, 0 \%, 86 \%$ and $0 \%$ respectively, while for the postsynaptic SPECT the were $75 \%, 81 \%, 43 \%$ and $94 \%$.

Of the seven APS patients, four had a positive SN-TCD, while all seven had an abnormal presynaptic SPECT scan. Further all seven IPD and APS patients with an abnormal postsynaptic SPECT also had a significantly lowered presynaptic SPECT scan.

When the second sonographer (ST) assessed the SN-TCD, she obtained similar results in the vast majority of the patients $(92 \%)$.

Table 6.1 Results of SN-TCD and presynaptic and postsynaptic SPECT imaging for each patient subgroup.

\begin{tabular}{lccc}
\hline $\begin{array}{l}\text { Clinical diagnosis after } \\
\text { follow-up }\end{array}$ & $\begin{array}{c}\text { SN- TCD } \\
\text { number positive } \\
\text { (=abnormal) of total }\end{array}$ & $\begin{array}{c}\text { Presynaptic SPECT } \\
\text { number abnormal } \\
\text { of total }\end{array}$ & $\begin{array}{c}\text { Postsynaptic SPECT } \\
\text { number abnormal } \\
\text { of total }\end{array}$ \\
\hline IPD $n=51$ & 25 of 51 & 37 of 38 & 4 of the 21 \\
APS $n=7$ & 4 of 7 & 6 of 6 & 3 of 4 \\
$M S A n=2$ & 2 of 2 & 1 of 1 & 1 of 1 \\
$P S P n=2$ & 1 of 2 & 2 of 2 & 1 of 1 \\
$C B D n=2$ & o of 2 & 2 of 2 & 1 of 1 \\
$D L B D n=1$ & 1 of 1 & 1 of 1 & 0 of 1 \\
ET $n=2$ & 0 of 2 & 0 of 2 & - \\
VP $n=5$ & 2 of 5 & 0 of 4 & 2 (visually 0 ) of 3 \\
DIP $n=4$ & 0 of 4 & 0 of 1 & - \\
rest group $n=6$ & 1 of 6 & 0 of 4 & 0 of 1 \\
undiagnosed $n=7^{\text {b }}$ & 3 of 7 & 3 of 4 & 1 of 3 \\
\hline$n=82$ & $n=82$ & $n=59$ & $n=32$ \\
\hline
\end{tabular}

$\mathrm{n}$ : number of patients, SN-TCD: transcranial duplex of the substantia nigra, SPECT: Single Photon Emission Computer Tomography, IPD: idiopathic Parkinson's disease, APS: atypical parkinsonian syndromes, MSA: multiple system atrophy, PSP: progressive supranuclear paralysis, CBD: cortical basal degeneration, DLBD: diffuse Lewy body disease, ET: essential tremor, VP vascular parkinsonism, DIP: drug induced parkinsonism,

a restgroup: 4 patients had spontaneous disappeared parkinsonism, 1 normal pressure hydrocephalus, 1 frontotemporal dementia.

b undiagnosed: a patient was called undiagnosed if it was not possible draw a conclusion on the final diagnosis from these, according to generally accepted clinical criteria the patient. ${ }^{1,3,18-21}$

\section{Predictive value of SN-TCD for the results of the SPECT scan}

Fifty-nine patients underwent presynaptic SPECT imaging (see Table 6.2). In 33 patients $(56 \%)$, the result of the SN-TCD was in line with the result of the presynaptic SPECT scan. The PPV of a positive SN-TCD for an abnormal 
SPECT was high: $88 \%$. However, the NPV of a negative SN-TCD for a normal presynaptic SPECT was only $30 \%$.

Thirty-two patients underwent postsynaptic SPECT imaging (see Table 6.3). In fourteen (44\%) of the thirty-two cases, the result of the SN-TCD was in line with the result of the postsynaptic SPECT scan. The PPV of a positive SN-TCD for an abnormal postsynaptic SPECT was $29 \%$ and the NPV $73 \%$.

Table 6.2 Contingency of the 59 patients who underwent both SN-TCD and presynaptic SPECT imaging.

\begin{tabular}{lcc}
\hline $\mathrm{n}=59$ & $\begin{array}{c}\text { Presynaptic SPECT } \\
\text { abnormal }\end{array}$ & $\begin{array}{c}\text { Presynaptic SPECT } \\
\text { normal }\end{array}$ \\
\hline SN -TCD positive (= abnormal) & $23^{\mathrm{a}}$ & $3^{\mathrm{c}}$ \\
SN -TCD negative (= normal) & $23^{\mathrm{b}}$ & $10^{\mathrm{d}}$ \\
\hline
\end{tabular}

SN: substantia nigra, TCD: transcranial duplex, SPECT: Single Photon Emission Computer Tomography, n: number of subjects

${ }^{a} n=23$ (19 IPD, 3 APS, 1 undiagnosed); ${ }^{b} n=23$ (18 IPD, 3 APS [2 CBD, 1 PSP], 2 undiagnosed);

${ }^{c} \mathrm{n}=3$ (2 VP, 1 spontaneous disappeared parkinsonism); ${ }^{\mathrm{d}} \mathrm{n}=10$ (1 IPD, 2 VP, 2 ET, 1 DIP, 3 rest group, 1 undiagnosed).

Table 6.3 Contingency of the 32 patients who underwent both SN-TCD and postsynaptic SPECT imaging.

\begin{tabular}{lcc}
\hline & $\begin{array}{c}\text { Postsynaptic SPECT } \\
\text { Abnormal }\end{array}$ & $\begin{array}{c}\text { Postsynaptic SPECT } \\
\text { normal }\end{array}$ \\
\hline SN-TCD positive (= abnormal) & $6^{\text {a }}$ & $15^{\mathrm{c}}$ \\
SN-TCD negative (= normal) & $3^{\mathrm{b}}$ & $8^{\mathrm{d}}$ \\
\hline
\end{tabular}

SN: substantia nigra, TCD: transcranial duplex, SPECT: Single Photon Emission Computer Tomography, n: number of subjects

${ }^{a} n=6$ (IPD 2, APS 2, inconclusive 2); ${ }^{b} n=3$ (2 IPD, 1 APS); ${ }^{c} n=15$ (13 IPD, 1 APS, inconclusive 1);

${ }^{d} \mathrm{n}=8$ (4 IPD, 3 VP, 1 restgroup)

\section{Discussion}

Since the first report by Becker et al. in 1995, SN hyperechogenicity in patients with IPD has been confirmed by many researchers. ${ }^{9,16,25-28}$ These investigators have suggested that SN-TCD is an accurate instrument in discriminating IPD patients from normal healthy subjects, and from patients with other types of parkinsonism. However, most studies on TCD of the SN involve groups of welldiagnosed IPD patients, in the latter stages of the disease. The diagnostic accuracy of SN-TCD in early-stage patient populations, with less well-defined clinical syndromes, thus remains to be determined. In an effort to investigate the diagnostic accuracy of SN-TCD in early-stage patients we performed an SN-TCD in 82 undiagnosed parkinsonian patients. As the gold standard for the 
patient's final diagnosis, we chose the clinical diagnosis after follow-up. This is, of course, not as good as post-mortem neuropathological analysis, but the best possible alternative at present.

In our study, the diagnostic accuracy of presynaptic SPECT imaging is superior to that of SN-TCD. Especially the sensitivity and NPV in differentiating patients with parkinsonism with nigrostriatal degeneration (IPD, MSA, PSP, DLBD, $\mathrm{CBD}$ ), from other causes of parkinsonism, are remarkably higher in presynaptic SPECT than in SN-TCD. However, the PPV of a positive SN-TCD for parkinsonism with nigrostriatal degeneration is high. This means that, although not all patients with nigrostriatal degeneration have a positive SN-TCD, a positive SN-TCD is a good predictor in diagnosing parkinsonism with nigrostriatal degeneration.

In our study, we also investigated the similarity in results between SN-TCD and presynaptic SPECT. We found a high PPV (88\%) of a positive SN-TCD for an abnormal SPECT result, confirming other reports. ${ }^{29}$ For clinical practice, this would imply that a positive SN-TCD in a patient with an early-stage, recently diagnosed parkinsonian syndrome, would reduce the added diagnostic value of a presynaptic SPECT scan.

A striking difference between ours and other studies, is the percentage of falsenegative IPD patients diagnosed by SN-TCD. Our $50 \%$ is much higher than the $0-20 \%$ reported by other investigators. ${ }^{9,16,25-28}$ There are several explanations for our lower sensitivity rate. Firstly, we used a broad spectrum of parkinsonian patients, which is representative for the diagnostic problem that one wants to solve. Other studies with similarly mixed patient groups also found a lower accuracy of the SN-TCD. ${ }^{22,23,30}$ Secondly, our sonographers were blinded to the results of the clinical diagnosis. This might also have led to a decreased sensitivity of the SN-TCD, since we considered the SN-TCD negative in cases where we had doubts about the level of hyperechointensity. Thirdly, our patient population had a relatively large number of patients in the early stages of their disease. Although Berg et al. reported SN echointensity to be stable during follow-up, the question remains whether this is also the case in early-stage patient populations. ${ }^{31}$ Fourthly, the quality of the ultrasound system is a nonneglectable variable, since in our pilot experiments, we found that the newest ultrasound systems will reveal hyperechointensity of the $\mathrm{SN}$ in more patients. ${ }^{32}$ Finally, the TCD technique itself can provide an explanation. One needs considerable personal expertise to perform and interpret a TCD correctly. Since the pioneering research group in Tübingen has built up an enormous amount of expertise, it will be difficult for other groups to reproduce their excellent diagnostic results. ${ }^{25,32-37}$

In summary, our study with early-stage parkinsonian patients, shows that the specificity and the PPV of SN-TCD for the final clinical diagnosis is just as high 
as it is for the SPECT scans. The sensitivity of the SN-TCD in our patient population is significantly lower than that of presynaptic SPECT scans. So in this population, the SN-TCD might be used as screening instrument: one could argue that in patients where the SN-TCD is compatible with parkinsonism with nigrostriatal degeneration, a presynaptic SPECT is no longer necessary in the diagnostic work-up. Applying this strategy, in our group of patients, 35\% SPECT scans could have been omitted, resulting in a significant reduction in costs. Besides this, SN-TCD is also a more patient-friendly technique than SPECT scans.

\section{Conclusion}

Our study with early-stage parkinsonian patients shows that the diagnostic accuracy of presynaptic SPECT scans is higher than that of SN-TCD. However, the specificity and the PPV of SN-TCD for the final clinical diagnosis, are almost as high as for presynaptic SPECT scans. So in this population, the SN-TCD might be used as screening instrument: patients with a SN-TCD compatible with parkinsonism with nigrostriatal degeneration would not need a presynaptic SPECT. 


\section{References}

1. Hughes AJ, Daniel SE, Kilford L, Lees AJ. Accuracy of clinical diagnosis of idiopathic Parkinson's disease: a clinico-pathological study of 100 cases. J Neurol Neurosurg Psychiatry 1992;55:181-4.

2. Hughes AJ, Daniel SE, Ben-Shlomo Y, Lees AJ. The accuracy of diagnosis of parkinsonian syndromes in a specialist movement disorder service. Brain 2002;125:861-70.

3. Litvan I, Agid Y, Jankovic J, Goetz C, Brandel JP, Lai EC, Wenning G, D'Olhaberriague L, Verny M, Chaudhuri KR, McKee A, Jellinger K, Bartko JJ, Mangone CA, Pearce RK. Accuracy of clinical criteria for the diagnosis of progressive supranuclear palsy (SteeleRichardson-Olszewski syndrome). Neurology 1996;46:922-30.

4. Litvan I, Goetz CG, Jankovic J, Wenning GK, Booth V, Bartko JJ, McKee A, Jellinger K, Lai EC, Brandel JP, Verny M, Chaudhuri KR, Pearce RK, Agid Y. What is the accuracy of the clinical diagnosis of multiple system atrophy? A clinicopathologic study. Arch Neurol 1997;54:937-44.

5. Watanabe H, Saito Y, Terao S, Ando T, Kachi T, Mukai E, Aiba I, Abe Y, Tamakoshi A, Doyu M, Hirayama M, Sobue G. Progression and prognosis in multiple system atrophy: an analysis of 230 Japanese patients. Brain 2002;125:1070-83.

6. Rajput AH, Rozdilsky B, Rajput A. Accuracy of clinical diagnosis in parkinsonism--a prospective study. Can J Neurol Sci 1991;18:275-8.

7. Vlaar AM, de Nijs T, Kessels AG, Vreeling FW, Winogrodzka A, Mess WH, Tromp SC, van Kroonenburgh MJ, Weber WE. Diagnostic Value of I-loflupane and (123)I-lodobenzamide SPECT Scans in 248 Patients with Parkinsonian Syndromes. Eur Neurol 2008;59:258-66.

8. Vlaar AM, van Kroonenburgh MJ, Kessels AG, Weber WE. Meta-analysis of the literature on diagnostic accuracy of SPECT in parkinsonian syndromes. BMC Neurol 2007;7:27.

9. Becker G, Seufert J, Bogdahn U, Reichmann H, Reiners K. Degeneration of substantia nigra in chronic Parkinson's disease visualized by transcranial color-coded real-time sonography. Neurology 1995;45:182-4.

10. Walter U, Niehaus L, Probst T, Benecke R, Meyer BU, Dressler D. Brain parenchyma sonography discriminates Parkinson's disease and atypical parkinsonian syndromes. Neurology 2003;60:74-7.

11. Becker G, Becker T, Struck M, Lindner A, Burzer K, Retz W, Bogdahn U, Beckmann H. Reduced echogenicity of brainstem raphe specific to unipolar depression: a transcranial color-coded real-time sonography study. Biol Psychiatry 1995;38:180-4.

12. Berg D, Roggendorf W, Schröder U, Klein R, Tatschner T, Benz P, Tucha O, Preier M, Lange KW, Reiners K, Gerlach M, Becker G. Echogenicity of the substantia nigra: association with increased iron content and marker for susceptibility to nigrostriatal injury. Arch Neurol 2002;59:999-1005.

13. Zecca L, Berg D, Arzberger T, Ruprecht $P$, Rausch WD, Musicco M, Tampellini D, Riederer $P$, Gerlach M, Becker $G$. In vivo detection of iron and neuromelanin by transcranial sonography: a new approach for early detection of substantia nigra damage. Mov Disord 2005;20:1278-85.

14. Berg D, Grote C, Rausch WD, Maurer M, Wesemann W, Riederer P, Becker G. Iron accumulation in the substantia nigra in rats visualized by ultrasound. Ultrasound Med Biol 1999;25:901-4.

15. Berg D, Becker G, Zeiler B, Tucha P, Hofmann E, Preier M, Benz P, Jost W, Reiners K, Lange KW. Vulnerability of the nigrostriatal system as detected by transcranial ultrasound. Neurology 1999;53:1026-31.

16. Walter U, Hoeppner J, Prudente-Morrissey L, Horowski S, Herpertz SC, Benecke R. Parkinson's disease-like midbrain sonography abnormalities are frequent in depressive disorders. Brain 2007;130:1799-807.

17. Huang YW, Jeng JS, Tsai CF, Chen LL, Wu RM. Transcranial imaging of substantia nigra hyperechogenicity in a Taiwanese cohort of Parkinson's disease. Mov Disord 2007;22:550-5. 
18. Zijlmans JC, Daniel SE, Hughes AJ, Revesz T, Lees AJ. Clinicopathological investigation of vascular parkinsonism, including clinical criteria for diagnosis. Mov Disord 2004;19:630-40.

19. Gilman S, Low PA, Quinn N, Albanese A, Ben-Shlomo Y, Fowler CJ, Kaufmann H, Klockgether T, Lang AE, Lantos PL, Litvan I, Mathias CJ, Oliver E, Robertson D, Schatz I, Wenning GK. Consensus statement on the diagnosis of multiple system atrophy. J Neurol Sci 1999;163:94-8.

20. McKeith IG, Galasko D, Kosaka K, Perry EK, Dickson DW, Hansen LA, Salmon DP, Lowe J, Mirra SS, Byrne EJ, Lennox G, Quinn NP, Edwardson JA, Ince PG, Bergeron C, Burns A, Miller BL, Lovestone S, Collerton D, Jansen EN, Ballard C, de Vos RA, Wilcock GK, Jellinger $\mathrm{KA}$, Perry RH. Consensus guidelines for the clinical and pathologic diagnosis of dementia with Lewy bodies (DLB): report of the consortium on DLB international workshop. Neurology 1996;47:1113-24.

21. Bain P, Brin M, Deuschl G, Elble R, Jankovic J, Findley L, Koller WC, Pahwa R. Criteria for the diagnosis of essential tremor. Neurology 2000;54:S7.

22. Okawa M, Miwa H, Kajimoto Y, Hama K, Morita S, Nakanishi I, Kondo T. Transcranial sonography of the substantia nigra in Japanese patients with Parkinson's disease or atypical parkinsonism: clinical potential and limitations. Intern Med 2007;46:1527-31.

23. Tsai CF, Wu RM, Huang YW, Chen LL, Yip PK, Jeng JS. Transcranial color-coded sonography helps differentiation between idiopathic Parkinson's disease and vascular parkinsonism. J Neurol 2007;254:501-7.

24. Lova A, Garmashov A, Androuchtchenko N, Kehrer M, Berg D, Becker G, Garmashov Y. Postnatal decrease in substantia nigra echogenicity Implications for the pathogenesis of Parkinson's disease. J Neurol 2004;251:1451-4.

25. Behnke S, Berg D, Naumann M, Becker G. Differentiation of Parkinson's disease and atypical parkinsonian syndromes by transcranial ultrasound. J Neurol Neurosurg Psychiatry 2005; 76:423-5.

26. Berg D, Siefker C, Ruprecht-Dorfler P, Becker G. Relationship of substantia nigra echogenicity and motor function in elderly subjects. Neurology 2001;56:13-7.

27. Prestel J, Schweitzer KJ, Hofer A, Gasser T, Berg D. Predictive value of transcranial sonography in the diagnosis of Parkinson's disease. Mov Disord 2006;21:1763-5.

28. Schweitzer KJ, Hilker R, Walter U, Burghaus L, Berg D. Substantia nigra hyperechogenicity as a marker of predisposition and slower progression in Parkinson's disease. Mov Disord 2006;21:94-8.

29. Spiegel J, Hellwig D, Mollers MO, Behnke S, Jost W, Fassbender K, Samnick S, Dillmann U, Becker G, Kirsch CM. Transcranial sonography and [123l]FP-CIT SPECT disclose complementary aspects of Parkinson's disease. Brain 2006;129:1188-93.

30. Stockner H, Sojer M, K KS, Mueller J, Wenning GK, Schmidauer C, Poewe W. Midbrain sonography in patients with essential tremor. Mov Disord 2007;22:414-7.

31. Berg D, Merz B, Reiners K, Naumann M, Becker G. Five-year follow-up study of hyperechogenicity of the substantia nigra in Parkinson's disease. Mov Disord 2004;20:383-5.

32. Becker G, Berg D. Neuroimaging in basal ganglia disorders: perspectives for transcranial ultrasound. Mov Disord 2001;16:23-32.

33. Gaenslen A, Unmuth B, Godau J, Liepelt I, Di Santo A, Schweitzer KJ, Gasser T, Machulla HJ, Reimold M, Marek K, et al. The specificity and sensitivity of transcranial ultrasound in the differential diagnosis of Parkinson's disease: a prospective blinded study. Lancet Neurol 2008;7:417-24.

34. Berg D, Siefker C, Becker G. Echogenicity of the substantia nigra in Parkinson's disease and its relation to clinical findings. J Neurol 2001;248:684-9.

35. Godau J, Wevers AK, Gaenslen A, Di Santo A, Liepelt I, Gasser T, Berg D. Sonographic abnormalities of brainstem structures in restless legs syndrome. Sleep Med 2008;7:782-9..

36. Schweitzer KJ, Behnke S, Liepelt I, Wolf B, Grosser C, Godau J, Gaenslen A, Bruessel T, Wendt A, Abel F, Müller A, Gasser T, Berg D. Cross-sectional study discloses a positive family history for Parkinson's disease and male gender as epidemiological risk factors for substantia nigra hyperechogenicity. J Neural Transm 2007;114:1167-71. 
37. Walter U, Behnke S, Eyding J, Niehaus L, Postert T, Seidel G, Berg D. Transcranial brain parenchyma sonography in movement disorders: state of the art. Ultrasound Med Biol 2007; 33:15-25. 


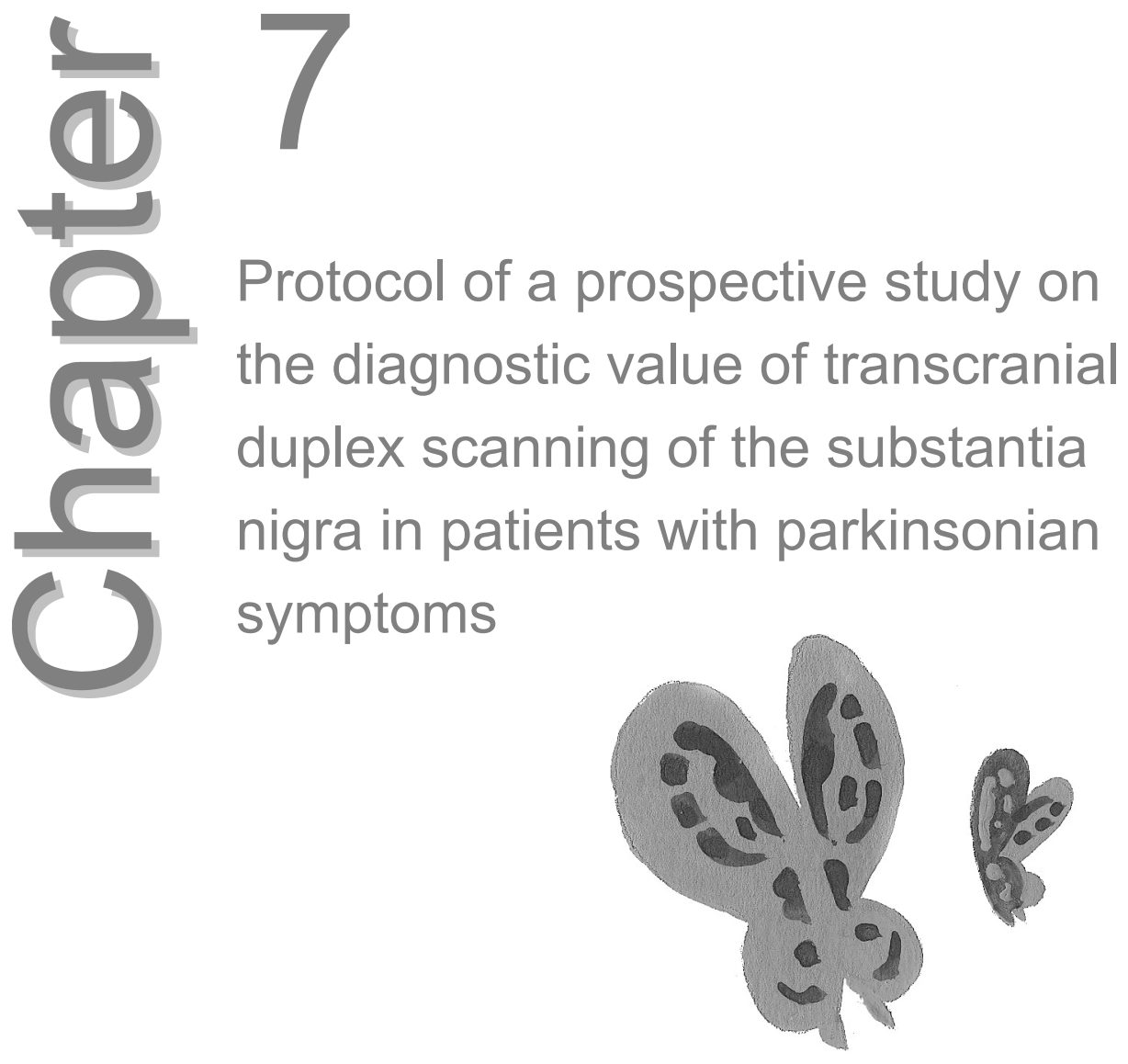

Annemarie M.M. Vlaar, Angela E.P. Bouwmans, Marinus J.P.G. van Kroonenburgh, Werner H. Mess, Selma C. Tromp, Piet G.W.M. Wuisman Alfons G.H. Kessels, Ania Winogrodzka, Wim E.J. Weber BMC Neurology 2007 sept 4;7:28 


\section{Abstract}

\section{Background}

Parkinson's disease (IPD) is the second most common neurodegenerative disorder. As there is no definitive diagnostic test, its diagnosis is based on clinical criteria. Recently transcranial duplex scanning (TCD) of the substantia nigra in the brainstem has been proposed as an instrument to diagnose IPD. We and others have found that TCD scanning of substantia nigra duplex is a relatively accurate diagnostic instrument in patients with parkinsonian symptoms. However, all studies on TCD so far have involved well-defined, later-stage IPD patients, which will obviously lead to an overestimate of the diagnostic accuracy of TCD.

We have therefore set out to conduct a prospective study testing the diagnostic accuracy of TCD in patients with a parkinsonism of unclear origin.

\section{Methods/Design}

We will enrol 250 consecutive patients, who are referred to neurology outpatient clinics of two teaching hospitals, for analysis of clinically unclear parkinsonism. Patients, whose parkinsonism is clearly diagnosable at the first visit, will be excluded from the study. All patients will undergo a TCD of the substantia nigra. As a surrogate gold standard we will use the consensus clinical diagnosis reached by two independent, blinded, movement disorder specialist neurologists after two years follow-up. At the time of TCD, patients will also undergo a SPECT scan of the brain.

\section{Discussion}

As this prospective trial enrols only patients with an early-stage parkinsonism, it will yield data on the diagnostic accuracy of TCD that is relevant to daily clinical practice: The neurologist needs a diagnostic tool that provides additional information in patients with a clinically indefinable parkinsonian syndrome. The above described observational longitudinal study was designed to explicitly study this aspect in the diagnostic process. 


\section{Introduction}

Parkinson's disease (IPD) is the second most common neurodegenerative disorder with a life-time risk of 2 percent in males and 1.3 percent in females. ${ }^{1}$ Diagnosis is based on clinical criteria. In most cases the diagnosis of IPD is straightforward when cardinal clinical signs and symptoms as bradykinesia, rigidity, and resting tremor are present. ${ }^{2}$ However, these main features of IPD are shared, at least in part, by atypical parkinsonian syndromes (APS i.e. multiple system atrophy [MSA], progressive supranuclear palsy [PSP], corticobasal degeneration and dementia with Lewy bodies), secondary parkinsonisms like vascular parkinsonism (VP) and drug induced parkinsonism (DIP). Besides delineating IPD from the above parkinsonian syndromes, distinguishing IPD from normality and essential trermor (ET) can also be difficult, especially in early stage of the disease. ${ }^{3}$

The gold standard for the diagnosis of IPD is post-mortem neuropathological examination. Clinicopathological studies show that $2-25 \%$ of the patients with IPD are classified incorrectly in the final stage of their disease, even by specialists in movement disorders, with MSA and PSP accounting for most false positives. ${ }^{2,4,5}$ Diagnostic accuracy is certainly less than $90 \%$ in earlier disease, as Litvan et al. found that the median sensitivity for the diagnosis of IPD increased from $73 \%$ at the first visit to $80 \%$ to the last visit after a mean follow-up of 9 years, and the median positive predictive value increased from 46 to $64 \%{ }^{6}$

A reliable test to diagnose IPD is important for two reasons. Prognosis and medical treatment in the various parkinsonian syndromes differ considerably and an objective disease marker would facilitate the development of neuroprotective therapies. ${ }^{7,8}$ Several procedures have been proposed to diagnose IPD: functional imaging with Positron Emission Tomography (PET)scan or Single Photon Emission Computer Tomography (SPECT), olfactoryand neuropsychological tests, and DNA tests. ${ }^{9-12}$

At the moment neuro-imaging techniques like PET and SPECT are the most widely used diagnostic tools. ${ }^{8}$ PET is at least as reliable as SPECT, but its use in routine clinical practice is limited by high costs and a relative short half-life of its radioactive tracers. ${ }^{13-16}$ Despite its widespread use, there is no consensus about the value of SPECT scintigraphy in the differential diagnosis of IPD., ${ }^{8,17-19}$ The ability of SPECT scanning to discriminate IPD from normality and other parkinsonian syndromes varies greatly among different studies. A major issue here is that many studies use well-defined later-stage patients that are obviously not representative for the diagnostic problem that one wants to solve with a SPECT. 
A more recent addition to the diagnostic armamentarium of the neurologist is transcranial duplex scanning (TCD) of the substantia nigra (SN) in the brainstem. In 1994 Becker discovered that patients with IPD had bilateral hyperechogenicity of the SN, probably caused by iron deposition. ${ }^{12,20,21}$ Several publications confirmed this observation that up to $90 \%$ of IPD patients have increased echo-intensity of the SN. In healthy subjects and in patients with ET or VP this hyperintensity of the SN is only found in $10-25 \% .^{20,22-29}$

This technique has high inter-observer reliability. ${ }^{22,25,29}$ In a pilot study with 45 patients with IPD or APS who underwent SPECT and TCD we found a positive predictive value of $95 \%$ of an abnormal TCD for an abnormal FP-CIT SPECT scan. $^{30}$

Based on this study we hypothesized that TCD of SN is a tool deserving a place in the diagnostic work-up of parkinsonian patients. TCD is less costly and less invasive than SPECT. ${ }^{31}$ Since a diagnostic test for parkinsonian syndromes is especially valuable in the early stage of disease(s), we devised a prospective diagnostic study with a clinical follow-up after two years as surrogate gold standard. As SPECT is currently the most widely used diagnostic tool in parkinsonian syndromes we included this in the study to directly compare the two techniques as to their diagnostic capacities in this field.

\section{Methods and design}

\section{Design}

Observational, prospective, longitudinal study.

\section{Setting}

Consecutive patients will be recruited from the Neurology Outpatient Clinic of two hospitals: the University Hospital Maastricht in Maastricht and the Maasland Hospital in Sittard, The Netherlands. TCD will be done in the departments of Clinical Neurophysiology of the two above mentioned hospitals. SPECT scanning will be done in the departments of Nuclear Medicine of the two hospitals

\section{Ethical approval}

The Institutional Review Board (IRB) of the University Hospital Maastricht has approved the study (MEC 05-228, 4 April 2006). (This IRB also functions as IRB for the Maasland Hospital in Sittard, The Netherlands). All patients will be 
asked for informed consent through a standardised information form that is also approved by the Institutional Review Board.

\section{Participants}

250 consecutive patients with new parkinsonian signs and symptoms (of unclear origin at the time of visit) referred to the Neurology Outpatient Clinics of the University Hospital Maastricht $(n=150)$ and the Maasland Hospital Sittard, $(n=100)$.

\section{Inclusion criteria}

1. Patients with parkinsonian signs and symptoms of unclear origin at the time of visit at the Neurology Outpatient Clinic. In his/her differential diagnosis the treating neurologist should be considering one of the following conditions: IPD, MSA, PSP, VP or DIP.

2. Age older than 18 years.

\section{Exclusion criteria}

1. Patients presenting with a clear unequivocal diagnosis of their parkinsonism.

2. Patients whose life expectancy is less than the required follow-up of two years.

\section{Methods}

After informed consent all subjects will undergo a structured interview, neurological examination, TCD and SPECT within six weeks of the initial visit at the Outpatient Clinic. After two years all patients are re-examined by two movement disorder specialist neurologists for a final clinical diagnosis. This diagnosis serves as a surrogate gold standard to calculate the accuracy of SPECT and TCD to differentiate between IPD and other types of parkinsonism.

\section{A. Interview and neurological examination}

After informed consent the patient is seen on the outpatient clinic for the inclusion interview and neurological examination by a third party physician (i.e. a physician not treating the patient, and blinded for information in the routine clinical records). In the structured interview a standard form with the following items are discussed: medical history, used drugs and effect, intoxications, duration of complaints, and most affected body- side (See appendix E). The following clinimetric scales are scored: UPDRS (parts I, III and IV), Hoehn and Yahr score, Hamilton Rating Scale for depression and the SCOPA cognition 
scale. $^{32-35}$ The Sniffin Sticks smell test is done according to a standardised protocol. $^{36,37}$

Finally, the including physician will try to reach a probable diagnosis, strictly applying the UK Parkinson's Disease Society Brain Bank criteria and the generally accepted criteria for the other parkinsonian disorders. ${ }^{2,38-44}$ For the used clinimetric scales and clinical criteria see appendix A en B.

\section{B. SPECT}

All subjects will undergo SPECT scanning within six weeks of inclusion in the study. In this study FP-CIT ( ${ }^{123}$ I-ioflupane, Nycomed, Amersham, U.K.) is used as presynaptic radiotracer. Medication (amphetamine, citalopram, fentanyl, cocaine, fluoxetine, fluvoxamine, paroxetine, sertraline, venlafaxine) which could interfere with the radiotracer is discontinued at least 5 half life times. After intravenous injection of the tracer, SPECT measures baseline dopamine transporter integrity in the brain. SPECT is performed with a triple head camera (MultiSPECT3, Siemens, Ohio, USA) equipped with high-resolution collimators. A semi-automatic template model programme is used to calculate the ratios between left striatal and right striatal and occipital regions respectively. Total time of acquisition is thirty minutes (45 seconds per frame for 40 views per detector). Zoom factor: 1.00 and the matrix size: 128x128. Filtered backprojection acquisition is performed. Images are filtered using a Butterworth filter with a cut-off value of: 0.4-0.5 and an order of 5. A division between the caudate nucleus and putamen is made. The ratios are corrected using Alderson's brain phantom, with known activities in the caudate nucleus and putamen. A binding of two standard deviations below healthy controls is considered as abnormal (FP-CIT $8.25+-1.85$ for putamen and $7.76+-1.77$ for caudate nucleus). Beside quantitative the scans will be also judged visually by the same nuclear specialist blinded for the final clinical diagnosis. If quantitative and visual judgments do not agree the conclusion of visual judgment is taken (unpublished data).

\section{Transcranial Duplex Scanning (TCD)}

TCD investigation is performed bilaterally through the pre-auricular bone window with a 2-4 MHz phased array transducer (SONOS 5500; Philips, Eindhoven, the Netherlands) by an experienced sonographer, blinded for the clinical data and SPECT results. The quality of the temporal bone window, the $\mathrm{SN}$ and Raphe nuclei (RN) of all subjects are scored directly by the sonographer blinded for the final clinical diagnosis and SPECT result. The quality of the bone window is scored as good, moderate or inconclusive.

Two different methods are applied for the evaluation of the echointensity of the SN. Firstly, the presence or absence of an obviously visible bilateral 
hyperechogenic $\mathrm{SN}$ is scored (qualitative method). The $\mathrm{SN}$ are scored as hyperechointens, not hyperechointens or inconclusive (=no typical configuration of hyperechointensity or low quality of the temporal bone window). Secondly, the area of an eventually hyperechogenic SN will be measured quantitatively (quantitative method). Both the right and left SN are measured from both sides, i.e. both temporal bone windows. After encircling, the area is automatically calculated. A hyperechogenic area of at least $0.2 \mathrm{~cm}^{2}$ is classified as characteristic for IPD. The RN are scored as: invisible (=isointense), just visible, visible (=hyper-intense) or inconclusive (=doubtful echointensity or low quality temporal bone window).

To determine inter-observer variability and to increase the power of the study a second sonographer will also judge the acquired echo data. A loop of 64 images of each patient will be acquired scanning the brainstem cranio-caudally and will be stored in order to allow for off-line analysis. Off-line the quality of the temporal bone window, $\mathrm{SN}$ and $\mathrm{RN}$ will scored by the second sonographer.

\section{Regular outpatient follow-up}

The initial treating neurologist will remain responsible for the regular outpatient management of the patient included in the study. He or she will discuss the test results with the patient, and base his/her treatment plan on these. All further clinical decisions will be made by the treating neurologist.

\section{E. Re-examination at two-year follow-up}

Two years after inclusion, all patients will be re-examined separately by two independent movement disorder specialist neurologists blinded for the tests results. They will also be blinded for the clinical records of the treating neurologist. The same standard form as in the first visit is filled in (See appendix E) and the clinimetric tests are repeated. The neurologists will be asked to reach a clinical diagnosis, independently from each other, according to generally accepted clinical criteria. ${ }^{38-44}$ If these two diagnoses are not identical, the final diagnosis of this patient will be coded as inconclusive.

\section{Data analysis}

Our main hypothesis is that TCD is as sensitive as SPECT to differentiate IPD from other parkinsonian disorders. For the power analyses we assumed a sensitivity of SPECT of $90 \%$, based on the analysis of our own data on 248 consecutive patients. ${ }^{19}$ Assuming this $90 \%$ for TCD sensitivity we can accept as lowest border of the $95 \%$ confidence interval, $86 \%$ or higher:

$S D=(\sqrt{ }(\mathrm{p} 1(1-\mathrm{p} 1)) / \mathrm{n} \rightarrow \mathrm{p} 1=0.9$, sd 0.02, implying $\mathrm{n}=190$ patients, needed who have the hyperintensity of SN with TCD scanning. 
In our pilot study $15 \%$ of the patients had an insufficient temporal bone window, so 224 patients are needed to compensate for the amount of inconclusive TCDs. $^{28}$ Based on this study we expect that $90 \%$ of all patients with inconclusive parkinsonism will ultimately have IPD, so we set a target of initial 250 patients with unclear parkinsonism needed for this trial.

We will calculate the sensitivity and specificity, positive predictive value, negative predictive value and diagnostic odd's ratio (OR) with its 95\% confidence intervals $(95 \% \mathrm{Cl})$ of the first clinical judgment, TCD, FP-CIT SPECT scan and smell tests to predict the clinical diagnosis after two year follow-up. Accuracy is determined for all parkinsonian subgroups separately (IPD versus APS, IPD versus ET, and IPD versus VP, IPD versus DIP, and IPD versus all other types of parkinsonism). For expected SPECT, TCD and smell tests scores for each parkinsonian disorder, see Table 7.1.

Additionally we will determine the predictive value of TCD compatible with IPD for an abnormal FP-CIT SPECT scan. Finally the inter-observer reliability for SN and RN judgement by TCD will be determined (Cohen's kappa test). SPSS 11.0 for windows (SPSS, Chicago, IL, USA) and StataSE9 (Stata corporation, Texas, USA) will be used for statistical analysis.

Table 7.1 Expected TCD, FP-CIT SPECT and odour recognition results for all parkinsonian disorders based on our systematic reviews and retrospective studies. ${ }^{19,28,46,49}$

\begin{tabular}{|c|c|c|c|c|}
\hline Disorder & $\begin{array}{c}\text { Abnormal } \\
\text { FP-CIT SPECT }^{19,46}\end{array}$ & $\begin{array}{c}\text { Abnormal SN } \\
\text { TCD }^{47}\end{array}$ & $\begin{array}{c}\text { Odour recognition } \\
\text { deficit }\end{array}$ & Cognition deficit \\
\hline IPD & + & + & + & \pm \\
\hline ET & normal & normal & normal & normal \\
\hline VP & normal $^{a}$ & normal & normal & \pm \\
\hline $\mathrm{DIP}^{\mathrm{b}}$ & normal $( \pm)$ & normal ( \pm ) & normal $( \pm)$ & normal $( \pm)$ \\
\hline MSA & $+{ }^{\mathrm{C}}$ & \pm & + & \pm \\
\hline PSP & $+^{\mathrm{C}}$ & \pm & normal $( \pm)$ & + \\
\hline DLBD & + & + & + & + \\
\hline CBD & + & + & \pm & + \\
\hline
\end{tabular}

Frequency of abnormal findings: $+=$ frequently found, $\pm=$ sparsely found, normal $=$ rarely or not found.

IPD idiopathic Parkinson's disease; ET essential tremor; VP vascular parkinsonism; DIP drug induced parkinsonism; MSA multiple system atrophy; PSP progressive supranuclear palsy

${ }^{a}$ Especially visual judgement together with CT or MRI.

${ }^{b}$ At least $10 \%$ percent of the patients with DIP will develop IPD. ${ }^{48}$ Berg et al. investigated the correlation between the echointensity of the SN on TCD and DIP after starting the patients on antipsychotic drugs. Patients with serious parkinsonism showed higher echointensity than patients with mild or no parkinsonism. ${ }^{47}$

${ }^{c}$ In our retrospective trial, $76 \%$ of the 27 patients with APS had FP-CIT binding lower than two standard deviations below healthy controls. In the eleven studies included in our meta-analysis, this percentage varies from 67 to $100 \% .{ }^{19,46}$ 


\section{Discussion}

The hitherto published literature on TCD in parkinsonian syndromes are crosssectional studies on clinically well-defined patient populations. ${ }^{20-30,45}$ Although one has to start with these to study the diagnostic potential of a new technique, these kind of studies are obviously not representative of the clinical problem that one wants to solve with a TCD in parkinsonian syndromes. The treating neurologist wants a diagnostic tool that provides additional information in patients with a clinically indefinable parkinsonian syndrome.

The above described observational longitudinal study was designed to explicitly study this aspect in the diagnostic process. We arbitrarily choose the clinical diagnosis after two years as the surrogate gold standard. This is, of course, not ideal, as there will always remain a small proportion of patients that is not definitely diagnosable after two years, and misdiagnoses (as opposed to the ultimate gold standard the post-mortem pathological analysis) are still possible. In an effort to tackle this last obstacle we require the final diagnosis to be shared by two independent, blinded, experienced movement disorders specialist neurologists.

We included SPECT scans in the study to enable us to make a direct comparison between SPECT and TCD as to their diagnostic accuracy. Although the use of SPECT scans in the diagnostic work-up of parkinsonian patients is still debated, it is widely used. ${ }^{8,19,46}$ We feel that this will add to the clinical relevancy of our study results. Additionally, we also included tests on smell, depression and cognition, in the diagnostic process. 


\section{References}

1. Elbaz A, Bower JH, Maraganore DM, McDonnell SK, Peterson BJ, Ahlskog JE, Schaid DJ, Rocca WA. Risk tables for parkinsonism and Parkinson's disease. J Clin Epidemiol 2002; 55:25-31.

2. Hughes AJ, Daniel SE, LKilford L, Lees AJ. Accuracy of clinical diagnosis of idiopathic Parkinson's disease. A clinico-pathological study of 100 cases. J Neurol Neurosurg Psychiatry 1992;55:181-4.

3. Koller WC, Montgomery. EB Issues in the early diagnosis of Parkinson's disease. Neurology 1997;49:S10-25.

4. Watanabe H, Saito Y, Terao S, Ando T, Kachi T, Mukai E, Aiba I, Abe Y, Tamakoshi A, Doyu M, Hirayama M, Sobue G. Progression and prognosis in multiple system atrophy: an analysis of 230 Japanese patients. Brain 2002;125:1070-83.

5. Rajput AH, Rozdilsky B, Rajput A. Accuracy of clinical diagnosis in parkinsonism--a prospective study. Can J Neurol Sci 1991;18:275-8.

6. Litvan I, MacIntyre A, Goetz CG, Wenning GK, Jellinger K, Verny M, Bartko JJ, Jankovic J, McKee A, Brandel JP, Chaudhuri KR, Lai EC, D'Olhaberriague L, Pearce RK, Agid Y. Accuracy of the clinical diagnoses of Lewy body disease, Parkinson disease, and dementia with Lewy bodies: a clinicopathologic study. Arch Neurol 1998;55:969-78.

7. Clarke CE. Neuroprotection and pharmacotherapy for motor symptoms in Parkinson's disease. Lancet Neurol 2004;3:466-74.

8. Piccini $\mathrm{P}$, Whone A. Functional brain imaging in the differential diagnosis of Parkinson's disease. Lancet Neurol 2004;3:284-90.

9. Dujardin K, Defebvre L, Duhamel A, Lecouffe P, Rogelet P, Steinling M, Destee A. Cognitive and SPECT characteristics predict progression of Parkinson's disease in newly diagnosed patients. J Neurol 2004;251:1383-92.

10. Ponsen MM, Stoffers D, Booij J, van Eck-Smit BLF, Wolters EC, Berendse HW. Idiopathic hyposmia as a preclinical sign of Parkinson's disease. Ann Neurol 2004;56:173-181.

11. Storch A, Hofer A, Kruger R, Schulz JB, Winkler J, Gerlach M. New developments in diagnosis and treatment of Parkinson's disease--from basic science to clinical applications. J Neurol 2004;251 Suppl 6:VI/33-8.

12. Becker $G$, Struck M, Bogdahn U, Becker T. Echogenicity of the brainstem raphe in patients with major depression. Psychiatry Res 1994;55:75-84.

13. Fernandez HH, Friedman JH, Fischman AJ, Noto RB, Lannon MC. Is altropane SPECT more sensitive to fluoroDOPA PET for detecting early Parkinson's disease? Med Sci Monit 2001; 7:1339-43.

14. Huang WS, Chiang YH, Lin JC, Chou YH, Cheng CY, Liu RS. Crossover study of (99m)TCTRODAT-1 SPECT and (18)F-FDOPA PET in Parkinson's disease patients. J Nucl Med 2003;44:999-1005.

15. Ishikawa T, Dhawan V, Kazumata K, Chaly T, Mandel F, Neumeyer J, Margouleff C, Babchyck B, Zanzi I, Eidelberg D. Comparative nigrostriatal dopaminergic imaging with iodine-123-beta CIT-FP/SPECT and fluorine-18-FDOPA/PET. J Nucl Med 1996;37:1760-5.

16. Schwarz J, Antonini A, Tatsch K, Kirsch CM, Oertel WH, Leenders KL. Comparison of 123IIBZM SPECT and 11C-raclopride PET findings in patients with parkinsonism. Nucl Med Commun 1994;15:806-13.

17. Morrish PK. How valid is dopamine transporter imaging as a surrogate marker in research trials in Parkinson's disease? Mov Disord 2003;18 Suppl 7:S63-70.

18. Morrish P. The meaning of negative DAT SPECT and F-Dopa PET scans in patients with clinical Parkinson's disease. Mov Disord 2005;20:117; author reply 117-8.

19. Vlaar AMM, Kessels AGH, Nijs de T, Winogrodzka A, Mess WH, Kroonenburgh MJPG, Weber WEJ. Additional value of SPECT imaging in comparance with clinical diagnosis in 248 patients with parkinsonism. Movement Disorders 2007;22 (supplement 16):S233. 
20. Berg D, Roggendorf W, Schröder U, Klein R, Tatschner T, Benz P, Tucha O, Preier M, Lange KW, Reiners K, Gerlach M, Becker G. Echogenicity of the substantia nigra: association with increased iron content and marker for susceptibility to nigrostriatal injury. Arch Neurol 2002;59:999-1005.

21. Berg D, Grote C, Rausch WD, Maurer M, Wesemann W, Riederer P, Becker G. Iron accumulation in the substantia nigra in rats visualized by ultrasound. Ultrasound Med Biol 1999;25:901-4.

22. Berg D, Becker G, Zeiler B, Tucha O, Hofmann E, Preier M, Benz P, Jost W, Reiners K, Lange KW. Vulnerability of the nigrostriatal system as detected by transcranial ultrasound. Neurology 1999;53:1026-31.

23. Becker G, Seufert J, Bogdahn U, Reichmann H, Reiners K. Degeneration of substantia nigra in chronic Parkinson's disease visualized by transcranial color-coded real-time sonography. Neurology 1995;45:182-4.

24. Walter U, Niehaus L, Probst T, Benecke R, Meyer BU, Dressler D. Brain parenchyma sonography discriminates Parkinson's disease and atypical parkinsonian syndromes. Neurology 2003;60:74-7.

25. Berg D, Siefker C, Becker G. Echogenicity of the substantia nigra in Parkinson's disease and its relation to clinical findings. J Neurol 2001;248:684-9.

26. Seppi K, Stockner S, Kiechl S, Schwaiger M, Sawires M, Willeit J, Poewe W. Hyposmia, midbrain hyperechogenity and Parkinson's disease: findings in a population-based study. Movement Disorders 2007;22:S10.

27. Bartova $P$, Skoloudik D, Fadma $T$, Ressner $P$, Kanovsky $P$, Herzig R. Substantia nigra evaluation in atypical parkinsonian syndromes and Parkinson's disease. Movement Disorders 2007;22:S142.

28. Tromp SC, Vlaar AMM, Kroonenburgh MJPG, Mess WH, Nijs de T, Winogrodzka A, Kessels AGH, Weber WEJ. The diagnostic value of transcranial duplex scanning and SPECT imaging versus clinical diagnosis (clinical prospective study). Movement Disorders 2007; 22(supplement 16):S220.

29. Schweitzer KJ, Hilker R, Walter U, Burghaus L, Berg D. Substantia nigra hyperechogenicity as a marker of predisposition and slower progression in Parkinson's disease. Mov Disord 2006;21:94-8.

30. Tromp SC, Vlaar AMM, Weber WEJ, MessWH. Can ultrasonography of the substantia nigra replace FP-CIT-SPECT? Parkinsonism Relat Disord 2005;11(supplement 2):S221.

31. Stockner H, Seppi K, Kiechl S, Schmidauer C, Schwaiger M, Sawires M, Willeit J, Poewe W. Assessment of the feasibility of midbrain sonography in a population-based study. Movement Disorders 2007;22:S146.

32. Fahn S, Elton RL. The Unified Parkinson's Disease Rating Scale. In: Recent developments in Parkinson's disease. Edited by M Goldstein. pp. 153-64. Florham Park, NJ: Marcmillan Health Care Information. 1987;153-64.

33. Brandt T, Caplan LR, Dichgans J, Diener C, Kennard C. Neurological disorders. Course and treatment. In. San Diego, California: Academic press; 1996.

34. Hamilton M. A rating scale for depression. J Neurol Neurosurg Psychiatry 1960;23:56-62.

35. Marinus J, Visser M, Verwey NA, Verhey FR, Middelkoop HA, Stiggelbout AM, Hilten van JJ. Assessment of cognition in Parkinson's disease. Neurology 2003;61:1222-8.

36. Hummel T, Sekinger B, Wolf SR, Pauli E, Kobal G. 'Sniffin' sticks': olfactory performance assessed by the combined testing of odor identification, odor discrimination and olfactory threshold. Chem Senses 1997;22:39-52.

37. Kobal G, Hummel T, Sekinger B, Barz S, Roscher S, Wolf S. "Sniffin' sticks": screening of olfactory performance. Rhinology 1996;34:222-6.

38. Litvan I, Agid Y, Jankovic J, Goetz C, Brandel JP, Lai EC, Wenning G, D'Olhaberriague L, Verny M, Chaudhuri KR, McKee A, Jellinger K, Bartko JJ, Mangone CA, Pearce RK. Accuracy of clinical criteria for the diagnosis of progressive supranuclear palsy (SteeleRichardson-Olszewski syndrome). Neurology 1996;46:922-30.

39. Daniel SE, Lees AJ. Parkinson's Disease Society Brain Bank, London: overview and research. J Neural Transm Suppl 1993;39:165-72. 
40. Bain P, Brin M, Deuschl G, Elble R, Jankovic J, Findley L, Koller WC, Pahwa R. Criteria for the diagnosis of essential tremor. Neurology 2000;54:S7.

41. Zijlmans JC, Daniel SE, Hughes AJ, Revesz T, Lees AJ. Clinicopathological investigation of vascular parkinsonism, including clinical criteria for diagnosis. Mov Disord 2004;19:630-40.

42. Gilman S, Low PA, Quinn N, Albanese A, Ben-Shlomo Y, Fowler CJ, Kaufmann H, Klockgether T, Lang AE, Lantos PL, Litvan I, Mathias CJ, Oliver E, Robertson D, Schatz I, Wenning GK. Consensus statement on the diagnosis of multiple system atrophy. J Neurol Sci 1999;163:94-8.

43. McKeith IG, Galasko D, Kosaka K, Perry EK, Dickson DW, Hansen LA, Salmon DP, Lowe J, Mirra SS, Byrne EJ, Lennox G, Quinn NP, Edwardson JA, Ince PG, Bergeron C, Burns A, Miller BL, Lovestone S, Collerton D, Jansen EN, Ballard C, de Vos RA, Wilcock GK, Jellinger $\mathrm{KA}$, Perry RH. Consensus guidelines for the clinical and pathologic diagnosis of dementia with Lewy bodies (DLB): report of the consortium on DLB international workshop. Neurology 1996;47:1113-24.

44. Wolters EC, Laar van T. Bewegingsstoornissen. Amsterdam, The Netherlands.: VU uitgeverij; 2002.

45. Weise D, Lorenz R, Schliesser M, Reiners K, Classen J. Transcranial sonography (TCS) of the substantia nigra (SN)-biological and clinical significance in patients with parkinsonian syndromes (PS). Movement Disorders 2007;22(supplement 16):S194.

46. Vlaar AMM, Kroonenburgh MJPG, Kessels AGH, Tromp SC, Weber WEJ. Diagnostic accuracy of SPECT in parkinsonian syndromes: a meta-analysis. Movement Disorders 2007; 22(supplement 16):S174.

47. Berg D, Jabs B, Merschdorf U, Beckmann H, Becker G. Echogenicity of substantia nigra determined by transcranial ultrasound correlates with severity of parkinsonian symptoms induced by neuroleptic therapy. Biol Psychiatry 2001;50:463-7.

48. Mena MA, de Yebenes JG. Drug-induced parkinsonism. Expert Opin Drug Saf 2006;5: 759-71.

49. Vlaar AMM, Bouwmans A, Mess WH, Tromp SC, Weber WEJ. Transcranial duplex in the differential diagnosis of parkinsonian syndromes: a systematic review. Journal of Neurology 2009 Feb 17 [Epub ahead of print]. 
General discussion

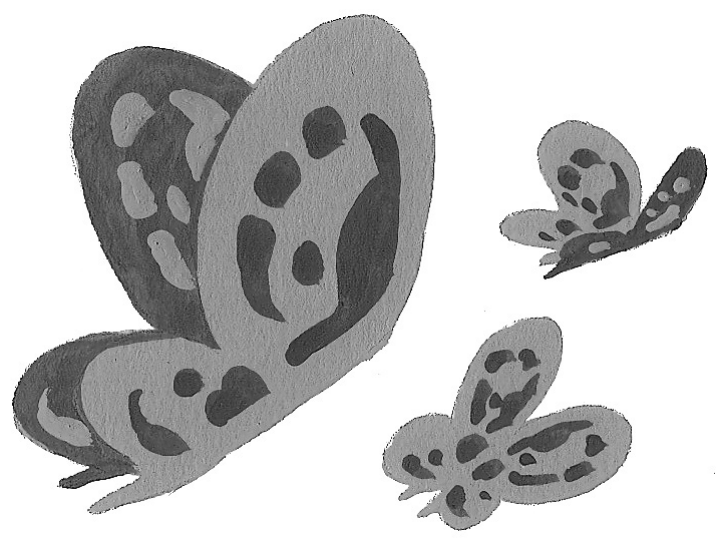


122 


\section{General discussion}

The diagnosis Idiopathic Parkinson's disease (IPD) is based on the clinical finding of bradykinesia combined with rigidity, resting tremor and postural instability. ${ }^{1}$ Yet, it can be difficult to diagnose the disease in a considerable proportion of patients. Two major problems are responsible for this dilemma. Firstly, in the early stages of the disease, the typical symptoms may only partly be present or to a very subtle degree. Secondly, IPD's main symptoms are nonspecific meaning that they do occur in other movement disorders as well. These disorders are characterised by tremor (particularly essential tremor [ET]) or bradykinesia and rigidity, such as atypical parkinsonian syndromes (APS, i.e. multiple system atrophy [MSA], progressive supranuclear palsy [PSP], diffuse Lewy body disease and corticobasal degeneration) and secondary parkinsonism (i.e. vascular parkinsonism [VP] and drug induced parkinsonism [DIP]).

An accurate diagnosis in early stages of the disease is essential for optimal treatment and counselling since the prognosis and medical treatment differ between various parkinsonian syndromes. Hence, to enable early diagnosis, the development of objective diagnostic markers to aid in the differentiation between these syndromes has gained considerable research interest.

Currently, there is no test available that reliably allows for diagnosing IPD. The available diagnostic tools are not included in the internationally accepted diagnostic criteria for IPD. Therefore, although frequently used, these tests do not belong to the regular diagnostic work-up of a patient suspected of IPD. ${ }^{1}$

What should be the requirements for the ideal clinical diagnostic test for IPD? Along with the obvious need for a high sensitivity in diagnosing IPD, it also should be able to separate IPD from the other parkinsonian disorders. The tool should, therefore, display a high sensitivity, specificity and positive predictive value (PPV). The values for sensitivity and specificity should be at least $85 \%$ and that for the PPV at least $80 \%{ }^{2}$ Further requirements would be the ability to monitor disease progression as well as to detect presymptomatic changes, which in case of IPD might in the future offer fascinating possibilities for neuroprotective intervention. Furthermore, a clinical diagnostic test should be minimally invasive, of low costs and widely available, which would all favour its use in everyday clinical practice.

Despite the shortcomings mentioned above, various tests are currently employed in the diagnostic work-up of the parkinsonian patient: Single Photon Emission Computer Tomography (SPECT), Positron Emission Tomography $(\mathrm{PET})$, magnetic resonance imaging, biochemical tests, genetic analyses, neuropsychological and depression scales, smell tests, autonomic function 
tests and sleep disorder analyses. ${ }^{3-5}$ SPECT is the most commonly used technique. It visualises the integrity of the dopaminergic pathways in the brain. Despite of its widespread use, the exact diagnostic accuracy of this technique in parkinsonian syndromes remains controversial. A relatively new method to visualise alterations in structures involved in the cerebral dopaminergic pathways is transcranial duplex scanning (TCD). ${ }^{6}$

In this thesis, two of the aforementioned imaging techniques are discussed with regard to their value in the diagnostic work-up of undiagnosed parkinsonian patients: the widely available and frequently used SPECT and the promising TCD, which has only lately been added to the armamentarium of the neurologist. Although PET is at least comparable with SPECT in terms of diagnostic accuracy we have chosen not to include this modality in our study due to its inherent practical disadvantages. ${ }^{7}$ The relatively short half-life of its radioactive tracers, its high costs and its sporadic availability are very likely to prevent this technique from widespread clinical use.

\section{Single Photon Emission Computer Tomography}

By using SPECT, the uptake of a radiotracer can be measured quantitatively, and the absolute and percentual difference from the normal uptake can be determined. Different tracers can be used to visualise the function of the dopaminergic system: presynaptic tracers are used to visualise the dopamine transporter density, and postsynaptic radiotracers to assess the dopamine receptor density. The highest tracer uptake in both pre- and postsynaptic SPECT scans takes place in the striatum, an area representing the terminal projections of nigral dopaminergic neurons.

It has consistently been shown by several research groups, as well as in our retrospective study, that presynaptic SPECT imaging is very accurate in discriminating patients with IPD from patients suffering from disorders without nigrostriatal degeneration, such as ET, DIP and VP.

However, accurately differentiating IPD from APS is not possible. Especially the specificity $(24 \%)$ and predictive value $(15 \%)$ of a normal presynaptic SPECT scan for APS is relatively low, since the majority of both IPD and APS patients show a decreased presynaptic striatal tracer binding. ${ }^{8}$

It is a matter of debate whether a normal presynaptic SPECT scan completely excludes a diagnosis of IPD. ${ }^{9-11}$ Recent clinical trials using presynaptic SPECT scans and PET as surrogate markers for disease progression have found that a proportion of patients diagnosed as early IPD have normal presynaptic 
SPECT scans. These have been termed subjects with "scans without evidence of dopaminergic deficit (SWEDD)" and represented from 5.7 to $14.7 \%$ of all patients clinically diagnosed as having early IPD in different studies. ${ }^{9,10,12}$

In our study even $19.6 \%$ of the 112 IPD patients had a normal initial presynaptic SPECT scan.

Possible explanations for a discrepancy between clinical diagnosis and SPECT findings are, firstly, that the patient is wrongly diagnosed as having IPD, or, secondly, that the reduction in striatal radioactive tracer uptake is so low that is escapes detection. Of course, the latter is dependent on the evaluation method (cut-off values, quantitative or visual analysis) used.

Since the tracer-uptake in both healthy and parkinsonian patients declines during follow-up the presynaptic SPECT result theoretically can change from normal to abnormal during follow-up. ${ }^{13}$ In our sample of 12 IPD patients who underwent a second SPECT scan during follow-up, accordance with the ultimate clinical diagnosis rose from $4(33 \%)$ to $10(83 \%)$ patients. According to our results, a normal initial presynaptic SPECT scan makes IPD highly unlikely, but not completely excludes the diagnosis of IPD.

There is also discussion about the diagnostic value of postsynaptic SPECT scintigraphy. In our meta-analysis as well as in our retrospective trial, it appeared that the ability to discriminate patients with IPD from those with APS patients is relatively low. Although a normal postsynaptic SPECT scan is found in $80 \%$ of the IPD patients, the sensitivity $(62 \%)$ and positive predictive value $(50 \%)$ of an abnormal scan for APS is relatively low, mainly since (especially advanced) IPD patients can also have an abnormal postsynaptic scan.

In conclusion, presynaptic SPECT scans can provide valuable support in the diagnosis of dopamine deficiency related parkinsonian syndromes like IPD and APS. So, albeit the result of a SPECT scan is not part of the internationally accepted criteria for IPD, a presynaptic SPECT scan has an additional diagnostic value if there is a certain level of clinical uncertainty. ${ }^{1}$ However, accurate differentiation between IPD and APS is not possible with presynaptic nor with postsynaptic SPECT scans. As a consequence we no longer use postsynaptic SPECT scans in our clinic.

\section{Transcranial duplex scanning}

In 1995, Becker and colleagues reported for the first time that IPD patients have a characteristic finding on intracranial B-mode imaging. The area of the substantia nigra (SN) can show a hyperechointensity as compared to the adjacent brainstem tissue. ${ }^{6}$ Up to $90 \%$ of the IPD patients have such an SN 
hyperechointensity. ${ }^{14-17}$ On the contrary, we found that only $50 \%$ of the IPD patients had an abnormal SN-TCD despite the fact that $97 \%$ of the IPD patients in our study had an abnormal presynaptic SPECT scan. However, our study confirmed the finding of other investigators of a high PPV (88\%) of an abnormal SN-TCD for an abnormal presynaptic SPECT scan. ${ }^{18,19}$

Some studies reported that the area of SN-hyperechointensity in IPD patients was larger as compared to APS patients. Yet, in other studies both patient groups had a similar SN hyperechointensity area. Therefore, it remains indefinite, whether or not it is not possible to differentiate between both groups by solely using SN-TCD. ${ }^{16,17,20,21}$

The echointensity of the SN can be judged qualitatively (i.e. whether or not a typical hyperechointensity is present) as well as quantitatively (i.e. encircling the hyperechogenic area). In addition to the SN, TCD can also be used to visualise other brain structures such as the lenticular nucleus (LN) and the Raphe nuclei (RN).

Visualisation of the LN has been described to differentiate IPD from APS. The LN is only discernable when its echointensity is abnormally increased compared to the surrounding brain parenchyma. Finding a marked $\mathrm{SN}$ hyperechogenicity in combination with a normal aspect of the LN might discriminate IPD from APS (especially MSA, PSP and CBD). By combining SNand LN-TCD, a PPV of more than $90 \%$ can be achieved. ${ }^{22,16,17,23}$ However, the reliability of sonographic visualisation of the $L N$ appeared in our hands to be technically more challenging than the insonation of the $\mathrm{SN}$, which might partly be due to the use of different equipment. Consequently, we do not expect that in the short term insonation of the LN will be implemented into the routine clinical work-up of the patient with suspected IPD or APS.

A diminished echointensity of the $\mathrm{RN}$ has been reported to be associated with depression in subjects with and without parkinsonism. ${ }^{24,25}$ However, according to our systematic review, the RN-TCD has only marginal diagnostic accuracy in diagnosing depression in IPD patients. ${ }^{21}$

Other research groups described excellent inter-observer agreement for SN$\mathrm{TCD}^{14,26,27}$, in our hands mediocre accordance was found for the inter-observer agreement. The agreement of the quantitative evaluation of the SN-TCD was comparable to the qualitative judgement. The results of the "off-line" assessment were in line with those of the "on-line" assessments, which means that reliably estimating the ultrasound properties of the $\mathrm{SN}$ is not restricted to the "on-line" situation. The intra-observer agreement appeared to be 
considerably better, namely moderate to substantial according the commonly used classification by Landis and Koch. ${ }^{28}$

Furthermore, we found the inter-observer agreement of the RN-TCD (which was not studied by other investigators before) to be rather low, whereas the intra-observer agreement of the RN-TCD was comparable to the sonographic evaluation of the SN. The impact of these findings for further TCD research will be discussed later.

The relatively mediocre inter-observer agreement in our study might be partly explained by a lack of generally accepted criteria for the evaluation of the echointensity of the $\mathrm{SN}$ and the RN. A more standardised method of qualitatively and quantitatively measuring the echointensity of the respective anatomical areas is needed to improve the uniformity of the results.

Several reasons might account for the relatively low diagnostic accuracy of TCD in our studies. Firstly, we used a broad spectrum of undiagnosed parkinsonian patients. In most of the studies included in our systematic review the involved patients were already diagnosed. Secondly, our patient population to a considerable degree comprised patients in early stages of their disease. Although Berg and colleagues reported $\mathrm{SN}$ echointensity to be stable during follow-up, the question remains whether this is also the case in early-stage patient populations. ${ }^{29}$ Thirdly, the type and quality of the ultrasound system might be a non-neglectable variable. So far, no systematic comparison between different ultrasound systems used in the same patient has been done except for our intra-observer agreement study. Finally, it is commonly agreed upon that considerable experience both in terms of performance and interpretation of TCD is needed to obtain optimal results. The latter might partly explain why we were not able to reproduce the excellent results that were obtained for example by the research group in Tübingen with a more than 10 year history of ultrasound examination of the brainstem.

Nevertheless, in our opinion TCD might be used in the diagnostic work-up of the undiagnosed parkinsonian patient.

Firstly, although diagnostic tools such as SPECT and SN-TCD are not completely accurate, they definitely do have additional diagnostic value supporting the initial clinical opinion of the clinician. Cost effectiveness studies showed that it is economically worth considering to include presynaptic SPECT scans in the regular diagnostic work-up of patients with uncertain parkinsonism. ${ }^{30-32}$ By estimation, in roughly $30 \%$ of the 13.000 new patients with parkinsonism in the Netherlands a SPECT scan is performed, leading to about 4.000 presynaptic SPECT scans every year. This number of presynaptic SPECT scans can be decreased if SN-TCD is used as a screening tool. Since 
its high PPV (88\%) for an abnormal presynaptic SPECT, a presynaptic SPECT scan can be considered unnecessary in case the SN-TCD is compatible with IPD. In our study $78 \%$ of the patients referred for a presynaptic SPECT had an abnormal scan, $14 \%$ of all patients had an inconclusive SN-TCD and $50 \%$ of the patients with an abnormal presynaptic SPECT had an abnormal SN-TCD. Applying this strategy, at least $35 \%$ of the presynaptic SPECT scans could have been omitted. This will mean a reduction of 800 SPECT scans in the current situation and more than 4.000 presynaptic scans if presynaptic SPECT scans will become part of the regular diagnostic work-up. The policy outlined above could lead to a considerable reduction of health care costs if the huge difference of the price tag for TCD (about 80 Euros) and SPECT (about 900 Euros) is considered.

Secondly, TCD is far more patient-friendly. The examination can be performed within ten minutes, with the patient sitting in a comfortable chair, while a presynaptic SPECT scan requires an injection of a radioactive tracer, then three hours of waiting and thereafter twenty minutes lying on a stretcher in the scanner.

\section{Ongoing TCD research in our clinic}

Two years ago, we started a prospective trial with undiagnosed parkinsonian patients. ${ }^{33}$ We planned to include 250 patients and currently these 250 patients have all been included in the trial. All patients underwent TCD and presynaptic SPECT scintigraphy. Additionally, their olfactory function, cognition, motor function and emotional state were tested. All patients will be re-examined by two independent movement disorder specialists after a follow-up of two years in order to make the final clinical diagnosis. At this moment the first 60 patients are re-examined. This study will provide information on the additional value of the aforementioned examinations with respect to their capability of predicting the natural course of the patient with parkinsonism of unclear origin. Another ongoing study is aimed to find out whether the $\mathrm{SN}$ echointensity will remain stable in 100 early stage patients during the follow-up period of two years.

\section{TCD in the future}

Although TCD is an attractive diagnostic tool there are also shortcomings that we need to consider and for which improvements or further research are needed. 
1) TCD has to be tested against a reference standard by truly blinded investigators to accurately establish its value. In all studies TCD was compared against clinical criteria or functional neuro-imaging. As outlined in the introduction, the definite diagnosis is still made neuropathologically. Therefore, in order to determine the true meaning of the ultrasound examination of the $\mathrm{SN}$, a comparison with post-mortem studies is definitely needed.

2) To determine if SN-TCD can be applied on a large scale, the reliability must be assessed more extensively, especially in an environment outside the expert use in a clinical research setting.

The relatively mediocre inter-observer agreement in our study might be partly explained by a lack of generally accepted criteria for the evaluation of the echointensity of the SN and the RN. Possibly, a standardised quantitative and qualitative measurement of the echointensity of the SN and the surrounding tissue might aid in improving the uniformity of the results. Additionally, standard settings for the ultrasound system used might be required.

3) Widespread application of TCD is hindered by the fact that the investigator needs extensive experience with ultrasound and has to be trained by an expert. Possibly, a training course might be a good starting point, whereas later on a discussion on the acquired data would be feasible via the internet.

4) In our systematic review we could confirm that in approximately $10 \%$ of the patients the temporal bone window is inappropriate to visualise the intracranial brain structures. Contrary to the evaluation of the intracranial vasculature, which has been established as a clinically relevant method that is applied on a large scale, the visibility of the brainstem can not be enhanced by the use of ultrasound contrast agents. Hence, in 1 out of 10 patients, the temporal bone window will be inappropriate to visualise the SN and other brain structures. This failure rate has to be taken into account when implementing TCD in daily clinical practice. Whether this percentage can be lowered, for instance by applying a lower insonation frequency has to be determined.

5) If healthy people are subjected to TCD, approximately ten percent will show a SN hyperechointensity. Despite being apparently healthy, Berg and colleagues found that $60 \%$ of the asymptomatic subjects with SN hyperechointensity also had decreased nigrostriatal dopaminergic function when PET scans were performed. Longitudinal follow-up studies on these 
asymptomatic subjects are currently under way to investigate whether they will develop IPD. ${ }^{34}$ These findings may suggest that TCD as well as PET and SPECT scans might be helpful in identifying individuals potentially at risk to develop IPD. ${ }^{35,15}$

If in the future imaging techniques will allow for diagnosing IPD presymptomatically, this will not only enable the neurologist to advise the patient much earlier in the course of the disease but the targeted use of preventive drugs will also be feasible. TCD would be the preferred screening technique for large scale studies and not SPECT and PET scans, since it is more patient-friendly, less costly and readily available. Due to recent technical developments, it is now even possible to carry a duplex system in a briefcase to almost any location.

\section{Conclusion}

Diagnosing IPD is most challenging in the early stages of the disease. If there is a need for a diagnostic tool in an individual patient the first choice is still a presynaptic SPECT scan since this technique is well investigated and still more accurate than TCD. With a presynaptic SPECT the diagnostic accuracy of differentiating neurodegenerative parkinsonian syndromes from healthy controls, patients with ET, DIP and VP is excellent. However, differentiation of IPD from APS is relatively inaccurate with presynaptic as well as with postsynaptic SPECT scans.

The SPECT scans display higher diagnostic accuracy than TCD. However, the PPV of an abnormal TCD for an abnormal SPECT finding as well as for the clinical diagnosis of IPD is high, implying that TCD can be used as a screening tool. If the TCD results are indicative for IPD, a SPECT scan can be considered unnecessary.

Longitudinal studies are under way to show if TCD has the ability to diagnose IPD in a presymptomatic stage, leading to exciting possibilities to develop neuroprotective, or even curative drugs. 


\section{References}

1. Hughes AJ, Daniel SE, Kilford L, Lees AJ. Accuracy of clinical diagnosis of idiopathic Parkinson's disease: a clinico-pathological study of 100 cases. J Neurol Neurosurg Psychiatry 1992;55:181-4.

2. Shaw LM, Korecka M, Clark CM, Lee VM, Trojanowski JQ. Biomarkers of neurodegeneration for diagnosis and monitoring therapeutics. Nat Rev Drug Discov 2007;6:295-303.

3. Dujardin K, Defebvre L, Duhamel A, Lecouffe P, Rogelet P, Steinling M, Destee A. Cognitive and SPECT characteristics predict progression of Parkinson's disease in newly diagnosed patients. J Neurol 2004;251:1383-92.

4. Ponsen MM, Stoffers D, Booij J, van Eck-Smit BL, Wolters E, Berendse HW. Idiopathic hyposmia as a preclinical sign of Parkinson's disease. Ann Neurol 2004;56:173-81.

5. Storch A, Hofer A, Kruger R, Schulz JB, Winkler J, Gerlach M. New developments in diagnosis and treatment of Parkinson's disease--from basic science to clinical applications. $\mathrm{J}$ Neurol 2004;251 Suppl 6:VI/33-8.

6. Becker G, Seufert J, Bogdahn U, Reichmann H, Reiners K. Degeneration of substantia nigra in chronic Parkinson's disease visualized by transcranial color-coded real-time sonography. Neurology 1995;45:182-4.

7. Eshuis SA, Jager PL, Maguire RP, Jonkman S, Dierckx RA, Leenders KL. Direct comparison of FP-CIT SPECT and F-DOPA PET in patients with Parkinson's disease and healthy controls. Eur J Nucl Med Mol Imaging 2008.

8. Vlaar AMM, van Kroonenburgh MJ, Kessels AG, Weber WE. Meta-analysis of the literature on diagnostic accuracy of SPECT in parkinsonian syndromes. BMC Neurol 2007;7:27.

9. Dopamine transporter brain imaging to assess the effects of pramipexole vs levodopa on Parkinson disease progression. Jama 2002;287:1653-61.

10. Whone AL, Watts RL, Stoessl AJ, Davis M, Reske S, Nahmias C, Lang AE, Rascol O, Ribeiro MJ, Remy P, Poewe WH, Hauser RA, Brooks DJ; REAL-PET Study Group. Slower progression of Parkinson's disease with ropinirole versus levodopa: The REAL-PET study. Ann Neurol 2003;54:93-101.

11. Seibyl JP. Single-photon emission computed tomography and positron emission tomography evaluations of patients with central motor disorders. Semin Nucl Med 2008;38:274-86.

12. Fahn S, Oakes D, Shoulson I, Kieburtz K, Rudolph A, Lang A, Olanow CW, Tanner C, Marek K. Levodopa and the progression of Parkinson's disease. N Engl J Med 2004;351:2498-508.

13. Schwarz J, Storch A, Koch W, Pogarell O, Radau PE, Tatsch K. Loss of dopamine transporter binding in Parkinson's disease follows a single exponential rather than linear decline. J Nucl Med 2004;45:1694-7.

14. Berg D, Siefker C, Becker G. Echogenicity of the substantia nigra in Parkinson's disease and its relation to clinical findings. J Neurol 2001;248:684-9.

15. Berg D, Roggendorf W, Schröder U, Klein R, Tatschner T, Benz P, Tucha O, Preier M, Lange KW, Reiners K, Gerlach M, Becker G. Echogenicity of the substantia nigra: association with increased iron content and marker for susceptibility to nigrostriatal injury. Arch Neurol 2002; 59:999-1005.

16. Walter U, Niehaus L, Probst T, Benecke R, Meyer BU, Dressler D. Brain parenchyma sonography discriminates Parkinson's disease and atypical parkinsonian syndromes. Neurology 2003;60:74-7.

17. Behnke S, Berg D, Naumann M, Becker G. Differentiation of Parkinson's disease and atypical parkinsonian syndromes by transcranial ultrasound. J Neurol Neurosurg Psychiatry 2005; 76:423-5.

18. Spiegel J, Hellwig D, Mollers MO, Behnke S, Jost W, Fassbender K, Samnick S, Dillmann U, Becker G, Kirsch CM. Transcranial sonography and [123l]FP-CIT SPECT disclose complementary aspects of Parkinson's disease. Brain 2006;129:1188-93.

19. Doepp F, Plotkin M, Siegel L, Kivi A, Gruber D, Lobsien E, Kupsch A, Schreiber SJ. Brain parenchyma sonography and 123I-FP-CIT SPECT in Parkinson's disease and essential tremor. Mov Disord 2008;23:405-10. 
20. Walter U, Behnke S, Eyding J, Niehaus L, Postert T, Seidel G, Berg D. Transcranial brain parenchyma sonography in movement disorders: state of the art. Ultrasound Med Biol 2007; 33:15-25

21. Vlaar AMM, Bouwmans A, Mess WH, Tromp SC, Weber WEJ. Transcranial duplex in the differential diagnosis of parkinsonian syndromes: a systematic review. Journal of Neurology 2009 256:530-8.

22. Walter $U$, Wittstock $M$, Benecke R, Dressler D. Substantia nigra echogenicity is normal in non-extrapyramidal cerebral disorders but increased in Parkinson's disease. J Neural Transm 2002;109:191-6.

23. Walter U, Behnke S, Eyding J, Niehaus L, Postert T, Seidel G, Berg D. Transcranial brain parenchyma sonogrpahy in movement disorders: state of the art. Ultrasound Med Biol 2007; 33:15-25.

24. Becker G, Struck M, Bogdahn U, Becker T. Echogenicity of the brainstem raphe in patients with major depression. Psychiatry Res 1994;55:75-84.

25. Becker T, Becker G, Seufert J, Hofmann E, Lange KW, Naumann M, Lindner A, Reichmann $\mathrm{H}$, Riederer P, Beckmann H, Reiners K. Parkinson's disease and depression: evidence for an alteration of the basal limbic system detected by transcranial sonography. J Neurol Neurosurg Psychiatry 1997;63:590-6.

26. Godau J, Schweitzer KJ, Liepelt I, Gerloff C, Berg D. Substantia nigra hypoechogenicity: definition and findings in restless legs syndrome. Mov Disord 2007;22:187-92.

27. Huang YW, Jeng JS, Tsai CF, Chen LL, Wu RM. Transcranial imaging of substantia nigra hyperechogenicity in a Taiwanese cohort of Parkinson's disease. Mov Disord 2007;22:550-5.

28. Landis JR, Koch GG. The measurement of observer agreement for categorical data. Biometrics 1977;33:159-74.

29. Berg D, Merz B, Reiners K, Naumann M, Becker G.: Five-year follow-up study of hyperechogenicity of the substantia nigra in Parkinson's disease. Mov Disord 2004; 20:383-5.

30. Dodel RC, Hoffken H, Moller JC, Bornschein B, Klockgether T, Behr T, Oertel WH, Siebert Y. Dopamine transporter imaging and SPECT in diagnostic work-up of Parkinson's disease: a decision-analytic approach. Mov Disord 2003;18 Suppl 7:S52-62.

31. Antonini A, Berto P, Lopatriello S, Tamma F, Annemans L, Chambers M. Cost-effectiveness of (123)I-FP-CIT SPECT in the differential diagnosis of essential tremor and Parkinson's disease in Italy. Mov Disord 2008.

32. Van Laere K, Everaert L, Annemans L, Gonce M, Vandenberghe W, Vander Borght T. The cost effectiveness of (123)I-FP-CIT SPECT imaging in patients with an uncertain clinical diagnosis of parkinsonism. Eur J Nucl Med Mol Imaging 2008;35:1367-76.

33. Vlaar AMM, Bouwmans AE, van Kroonenburgh MJ, Mess WH, Tromp SC, Wuisman PG, Kessels AG, Winogrodzka A, Weber WE. Protocol of a prospective study on the diagnostic value of transcranial duplex scanning of the substantia nigra in patients with parkinsonian symptoms. BMC Neurol 2007;7:28.

34. Schweitzer KJ, Behnke S, Liepelt I, Wolf B, Grosser C, Godau J, Gaenslen A, Bruessel T, Wendt A, Abel F, Müller A, Gasser T, Berg D. Cross-sectional study discloses a positive family history for Parkinson's disease and male gender as epidemiological risk factors for substantia nigra hyperechogenicity. J Neural Transm 2007; 114:1167-71.

35. Berg D, Becker G, Zeiler B, Tucha O, Hofmann E, Preier M, Benz P, Jost W, Reiners K, Lange KW. Vulnerability of the nigrostriatal system as detected by transcranial ultrasound. Neurology 1999;53:1026-31. 


\section{Summary}

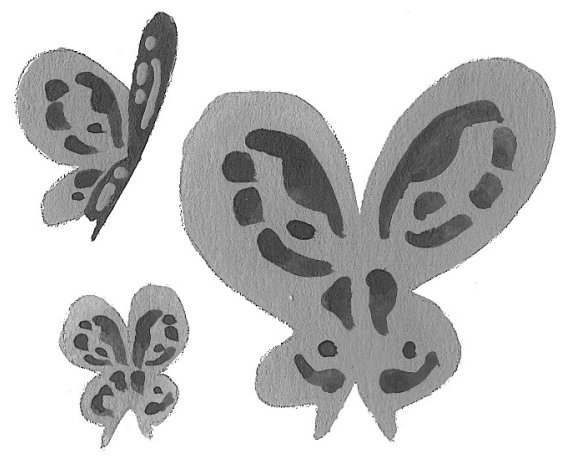




\section{Summary}

Idiopathic Parkinson's disease (IPD) is the second most common neurodegenerative disorder. Since there is no definitive diagnostic test, the diagnosis of IPD is based on clinical criteria. When cardinal clinical signs and symptoms, such as bradykinesia, rigidity, and resting tremor are present, the diagnosis of IPD is straightforward. However, in the early stages of the disease, when symptoms are mild and non-specific, differentiation between IPD and other parkinsonian syndromes can be difficult. Diseases which might resemble early-stage IPD are the atypical parkinsonian syndromes (APS, e.g. multiple system atrophy [MSA] and progressive supranuclear palsy [PSP]) or secondary parkinsonisms (e.g. vascular parkinsonism [VP] and drug induced parkinsonism [DIP]) and essential tremor (ET). Clinical criteria at best lead to a diagnosis of probable IPD, while a definite diagnosis requires post-mortem confirmation. Neuropathological studies have shown that even in the final stages of the disease, the clinical diagnostic accuracy for IPD varies between $75-90 \%$. $^{1-5}$

An accurate diagnosis in the early stages of the disease is essential for giving patients optimal treatment and counselling, since the prognosis and treatment differ between various parkinsonian syndromes. Hence, to enable early diagnosis, the development of diagnostic tools is an important research topic. Examples of techniques widely studied, but not yet incorporated in the regular diagnostic work-up of the parkinsonian patient, are single photon emission computer tomography (SPECT), positron emission tomography (PET), magnetic resonance imaging (MRI), transcranial duplex scanning (TCD), smell tests, neuropsychological tests and genetic analyses.

Of the above mentioned techniques, SPECT scans are most frequently employed when diagnosing patients with parkinsonism of unclear origin. SPECT scans are used to visualise the integrity of the dopaminergic pathways in the brain. There are several SPECT radiotracers available to be used to investigate different parts of the dopaminergic systems. A SPECT scan with radioactive isotopes binding to presynaptic dopamine transporters has been shown to be a good predictor of the existence of IPD as underlying mechanism of the parkinsonism. The most widely used presynaptic radiotracers are ${ }^{123} \mathrm{I}-$ ioflupane and 99mCT-TRODAT-1.

A SPECT scan with tracers binding to postsynaptic dopamine receptors provides information on the postsynaptic level of the nigro-striatal circuitry. Postsynaptic SPECT scans seem to be helpful to discriminate patients with IPD from those with APS. The most used postsynaptic radiotracer is ${ }^{123}$ I-iodobenzamide.

Despite its widespread use, the exact diagnostic accuracy of this technique in parkinsonian syndromes remains controversial. 
A relatively new diagnostic method in parkinsonian patients is transcranial duplex scanning (TCD). ${ }^{6}$ This technique is different from SPECT, since it visualises structural changes while SPECT visualises the function of a particular system. A TCD can reveal increased echointensity of the substantia nigra (SN). It is still a research tool, but since TCD is widely available and a simple and non-expensive method, it seems to be a promising technique. However, before TCD can be implemented in daily clinical practice, it is desirable to investigate its reliability and attributive diagnostic value in comparison with already existing techniques like SPECT scintigraphy.

In this thesis we started with exploring and investigating the diagnostic accuracy of SPECT in parkinsonian patients. Secondly, we assessed the accuracy of TCD in the differential diagnosis of IPD. Finally, we studied the combination of both techniques in the diagnostic work-up of patients with clinical parkinsonism of unclear origin.

In chapter 2 the existing literature regarding the diagnostic accuracy of both pre- and post-synaptic SPECT imaging in the differential diagnosis of IPD is reviewed and presented in a meta-analysis. Relevant studies were searched in Medline, EMBASE and Cochrane databases with back-searching of their reference lists. The search resulted in 185 articles, of which we deemed 32 suitable for our analysis. From these we recalculated the diagnostic odds ratio (OR) with $95 \%$ confidence interval of SPECT for the clinical questions above. We found a high diagnostic accuracy for the presynaptic SPECT scan to distinguish patients with IPD in an early stage from normalcy (OR 60 [13-277]), patients with IPD from those with ET (OR 210 [78-563]) and patients with IPD from those with VP (OR 105 [32-348]). The accuracy to differentiate between patients with IPD and those with APS was low for the presynaptic (OR 2 [1-4]) as well as the postsynaptic (OR 19 [10-36]) SPECT scans.

In conclusion, SPECT with presynaptic radiotracers is relatively accurate to differentiate patients with IPD in an early phase from normalcy, or from patients with ET or VP. This meta-analysis also confirmed that presynaptic tracers cannot accurately differentiate between patients with IPD and those with APS. Neither is the SPECT with postsynaptic tracers highly accurate in distinguishing patients with IPD from those with APS.

Until now, most studies have been performed using late-stage, well-diagnosed patients. However, this does not resemble the situation in clinical practice, where one seeks to find the cause of the parkinsonian disorder in a given patient in a rather early stage by using a diagnostic tool such as SPECT.

In chapter 3 we retrospectively determined the predictive value of presynaptic and postsynaptic SPECT scans for the clinical diagnosis after follow-up in 248 
parkinsonian patients with initially unclassified parkinsonism. Gold standard in this study was the clinical diagnosis derived from the latest available clinical record, or, when this was not possible, a new complete physical and neurological examination by a blinded neurologist specialised in movement disorders. We found a relatively high diagnostic OR for presynaptic SPECT scans to differentiate patients with IPD from patients with ET (OR 82 [11-674]), from those with VP (OR 61 [8-490]) and from those with DIP (OR 33 [2-697]). The accuracy to discriminate between patients with IPD and those with APS was relatively low for both presynaptic (OR 1 [0-4]) and postsynaptic (OR 7 [2-17]) SPECT scans. This study is the largest diagnostic retrospective study which included as yet undiagnosed parkinsonian patients. The conclusions of this study were similar to the results of our meta-analysis discussed in chapter 2.

Chapter 4 reviews the literature regarding transcranial duplex scanning (TCD) in parkinsonian disorders. TCD is a non-invasive, fast, and patient-friendly technique, which is employable at the bedside. With TCD several brain structures like the substantia nigra (SN) can be visualised. TCD is performed by placing the ultrasound transducer on the temporal bone in front of the ear. Usually, the mesencephalon has a predominantly homogeneous aspect; in most cases a small hyperechogenic zone can be discerned within the area of the SN. However, in the majority of patients with IPD the SN is clearly visible due to its large hyperechointense area, which is presumably caused by an increased iron content. Also other brain structures like the lenticular nucleus $(\mathrm{LN})$ and the Raphe nuclei (RN) can be visualised by TCD. Usually, the LN is only discernable when hyperintense, and this increase in echointensity of the LN might differentiate between IPD and APS, such as MSA and PSP. ${ }^{7,8} A$ decrease in the echointensity of the Raphe nuclei (RN) is reported to be associated with depression in patients with or without parkinsonism. ${ }^{8,9}$ For detailed technical aspects of TCD see appendix C.

Numerous studies on the diagnostic accuracy of TCD in parkinsonian syndromes have already been published and several research groups are currently studying TCD. To get a clear overview of the results so far we performed a systematic review. We found 35 eligible studies. Of the 1534 patients with IPD $200(13 \%)$ had an inconclusive SN-TCD since the investigators experienced difficulties judging the SN-TCD, either because of an inappropriate temporal bone window or an atypical form of the hyperechointensity. An increased echointensity of the SN was seen in 1167 $(87 \%)$ of the 1334 patients with IPD. In comparison, an abnormal SN-TCD was only found in $12 \%$ of the healthy controls, $12 \%$ of the patients with ET, $20 \%$ of the patients with VP, $0 \%$ of the patients with DIP and $30 \%$ of the patients with APS. On the contrary, a significantly increased LN echointensity was found in 
$79 \%$ of the patients with APS, in $23 \%$ of the patients with IPD and in $6 \%$ of the healthy controls. A decreased echointensity of the RN was found in $46 \%$ of depressed and in $16 \%$ of the non-depressed patients with IPD.

The conclusion of our systematic review was that SN-TCD accurately differentiates between patients with IPD and healthy controls, or patients with ET, DIP and VP, but not between patients with IPD and those with APS. Also TCD of the LN solely will not allow for the discrimination between IPD and APS in an individual patient. The diagnostic value of RN-TCD to diagnose depression in patients with IPD was low. Unfortunately the SN-TCD was inconclusive in more than $10 \%$ of the patients. In addition, approximately 1 out of 10 apparently healthy individuals appear to have an increased SN echointensity. Long-term follow-up studies are currently underway to assess whether this finding on TCD indicates an increased susceptibility for IPD.

Although TCD is used since 1995, its use is mainly limited to research settings and as a diagnostic tool in parkinsonian patients TCD is not widely employed yet. One of the possible explanations is that there are several methodological issues: lack of standardised TCD techniques, normal values and scoring systems, and the high percentage of subjects with an inconclusive TCD.

Currently, the inter-observer and intra-observer variability of SN-TCD is studied by German and Taiwanese research groups. They report excellent agreement values in their diagnostic studies, although the methods behind these interobserver sub-analyses are not elaborated on. Before implementation of TCD in daily clinical practice its methodological aspects should be investigated more in detail.

Therefore, in chapter 5 we determined the inter-observer and intra-observer reliability of "on-line" and "off-line" assessment of the echointensity of the SN and RN. The echointensity of the SN was judged qualitatively and quantitatively and the RN only qualitatively. Each patient was assessed four times by two independent experienced sonographers using two different transducers. In the "off-line" assessment a third independent experienced sonographer reassessed the stored images.

Concerning the qualitative SN-TCD judgement we found a moderate agreement for the "on-line" inter-observer, "on-line" intra-observer and the "offline" inter-observer agreement. By example, kappa values of 0.23-0.39 were obtained for "on-line" inter-observer agreement, $0.53-0.67$ for the "on-line" intraobserver agreement and $0.32-0.67$ for "off-line" inter-observer variability. The results of the quantitative $\mathrm{SN}$ judgement were comparable to those of the qualitative SN judgement. The kappa values for judging the RN-TCD were low. We concluded that the "on-line" as well as the "off-line" inter-observer agreement of the SN-TCD evaluation is moderately reliable and of the RN-TCD 
it is relatively low. Quantitative judgement of the SN-TCD was not more accurate than qualitative judgement. The results of the "off-line" assessment were in line with those of the "on-line" assessments. For the intra-observer agreement of both the SN-TCD and the RN-TCD we found mediocre accordance.

Previously, considerably higher values for the inter-observer agreement evaluating the SN quantitatively have been reported: kappa values of 0.80 0.98 were obtained. ${ }^{10-14}$ Those investigators, however, studied already diagnosed patients. In contrast, we investigated a mixed population in order to decrease the 'a priori chance' of a positive finding. Furthermore, our sonographers were completely blinded for the clinical diagnoses. Additionally, our sonographers had had their training at different institutions and did never work together before. The relatively mediocre agreement in our study might be partly explained by a lack of generally accepted criteria for the evaluation of the echointensity of the SN and the RN. Possibly, a standardised quantitative measurement of the echointensity of the $\mathrm{SN}$ and the surrounding tissue might aid in improving the uniformity of the results. Additionally, standard settings for the ultrasound system used are required.

Similar to the diagnostic studies using SPECT scans, most of the diagnostic studies using TCD included late-stage, well-diagnosed patients. Therefore, we assessed in chapter 6 the diagnostic accuracy of SN-TCD in unclear parkinsonism, and compared it with presynaptic and postsynaptic SPECT examinations being already part of our workup protocol. We studied 82 patients with an unclassified parkinsonian syndrome. The clinical diagnosis after followup determined by an independent neurologist specialised in movement disorders was used as gold standard.

Firstly, we investigated the diagnostic accuracy to differentiate between patients with IPD and patients without nigrostriatal degeneration like ET, VP, DIP. For SN-TCD we found a sensitivity of $50 \%$, a specificity of $82 \%$, a positive predictive value (PPV) of $89 \%$ and a negative predictive value (NPV) of $35 \%$. For presynaptic SPECT scans these values were $97 \%, 100 \%, 100 \%$ and $92 \%$, respectively.

Secondly, we studied the accuracy to differentiate patients with IPD from patients with APS. For SN-TCD the sensitivity was $50 \%$, the specificity $43 \%$, the PPV $86 \%$ and the NPV $10 \%$ and for postsynaptic SPECT scans $75 \%, 81 \%$, $43 \%$ and $94 \%$, respectively. The PPV of an abnormal SN-TCD for an abnormal presynaptic SPECT scan was $88 \%$.

We concluded that the diagnostic accuracy of presynaptic SPECT scan for the clinical diagnosis is higher than the accuracy of TCD. However, since an abnormal SN-TCD is highly predictive for an abnormal presynaptic SPECT 
scan, SN-TCD can be used as screening tool before ordering a presynaptic SPECT scan.

In chapter 7 we describe the protocol of the prospective diagnostic study we started in August 2006. In this study we enrolled 250 consecutive patients, who were referred to neurology outpatient clinics of two teaching hospitals, for analysis of clinically parkinsonism of unclear origin. All patients underwent TCD, presynaptic SPECT imaging, cognitive tests, motor tests and a smell test. As gold standard we use the clinical diagnosis as agreed upon by two independent, blinded neurologists specialised in movement disorders after a follow-up period of two years. In August 2008 inclusion was finished and we started re-examining the patients. In the coming years, we will continue with the follow-up of the 250 patients in our prospective trial. We expect the final results of this trial to be published by the end of 2010 .

In conclusion, diagnosing IPD can be difficult, especially in the early stages of the disease. Therefore, finding a reliable diagnostic test will have a positive effect on clinical patient care. As yet, there is no perfect test to diagnose Parkinson's disease. Only the presynaptic SPECT scan is sufficiently studied and deemed reliable to use it in clinical diagnostic workup. Using the presynaptic SPECT scan, patients with IPD can be distinguished from healthy controls and from patients with VP and ET. Unfortunately, both post- and presynaptic SPECT scans are not suitable to differentiate patients with IPD from those with APS. Likewise, TCD is also not accurate in the differentiation between patients with IPD and those with APS. Nevertheless, SN-TCD seems to be a good alternative diagnostic tool, since an abnormal SN-TCD is an accurate predictor for the diagnosis of IPD. Although in our studies TCD is less reliable than SPECT scans, the PPV of an abnormal SN-TCD for IPD is very high. The fact that SN-TCD is less costly and less invasive for the patient in comparison with SPECT, makes it very worthwhile to study its true potential further.

Although SN-TCD and SPECT can be helpful in the diagnostic process, they can never replace careful neurological examination since false positives do exist: the diagnosis of parkinsonian disorders continues to be based primarily on the demonstration of the characteristic neurological features.

In our view the future role of SN-TCD is mainly being a screening instrument in two ways. Firstly, in daily clinical practice in selected patients with unclear parkinsonism a TCD can be ordered before a SPECT scan. In case of an abnormal SN-TCD a presynaptic SPECT scan can be considered unnecessary. Secondly, as soon as predictive or curative drugs are available SN-TCD may be an ideal tool for screening large populations to help identify subpopulations at risk. 


\section{References}

1. Rajput AH, Rozdilsky B, Rajput A. Accuracy of clinical diagnosis in parkinsonism--a prospective study. Can J Neurol Sci 1991;18:275-8.

2. Litvan I, Agid Y, Jankovic J, Goetz C, Brandel JP, Lai EC, Wenning G, D'Olhaberriague L, Verny M, Chaudhuri KR, McKee A, Jellinger K, Bartko JJ, Mangone CA, Pearce RK. Accuracy of clinical criteria for the diagnosis of progressive supranuclear palsy (SteeleRichardson-Olszewski syndrome). Neurology 1996;46:922-30.

3. Verny M, Jellinger KA, Hauw JJ, Bancher C, Litvan I, Agid Y. Progressive supranuclear palsy: a clinicopathological study of 21 cases. Acta Neuropathol (Berl) 1996;91:427-31.

4. Hughes AJ, Daniel SE, Ben-Shlomo Y, Lees AJ. The accuracy of diagnosis of parkinsonian syndromes in a specialist movement disorder service. Brain 2002;125:861-70.

5. Watanabe H, Saito Y, Terao S, Ando T, Kachi T, Mukai E, Aiba I, Abe Y, Tamakoshi A, Doyu M, Hirayama M, Sobue G. Progression and prognosis in multiple system atrophy: an analysis of 230 Japanese patients. Brain 2002;125:1070-83.

6. Becker G, Seufert J, Bogdahn U, Reichmann H, Reiners K. Degeneration of substantia nigra in chronic Parkinson's disease visualized by transcranial color-coded real-time sonography. Neurology 1995;45:182-4.

7. Behnke S, Berg D, Naumann M, Becker G. Differentiation of Parkinson's disease and atypical parkinsonian syndromes by transcranial ultrasound. J Neurol Neurosurg Psychiatry 2005; 76:423-5.

8. Walter U, Behnke S, Eyding J, Niehaus L, Postert T, Seidel G, Berg D. Transcranial brain parenchyma sonogrpahy in movement disorders: state of the art. Ultrasound Med Biol 2007; 33:15-25.

9. Becker G, Becker T, Struck M, Lindner A, Burzer K, Retz W, Bogdahn U, Beckmann H. Reduced echogenicity of brainstem raphe specific to unipolar depression: a transcranial color-coded real-time sonography study. Biol Psychiatry 1995;38:180-4.

10. Berg D, Becker G, Zeiler B, Tucha O, Hofmann E, Preier M, Benz P, Jost W, Reiners K, Lange KW. Vulnerability of the nigrostriatal system as detected by transcranial ultrasound. Neurology 1999;53:1026-31.

11. Berg D, Siefker C, Becker G. Echogenicity of the substantia nigra in Parkinson's disease and its relation to clinical findings. J Neurol 2001;248:684-9.

12. Godau J, Schweitzer KJ, Liepelt I, Gerloff C, Berg D. Substantia nigra hypoechogenicity: definition and findings in restless legs syndrome. Mov Disord 2007;22:187-92.

13. Huang YW, Jeng JS, Tsai CF, Chen LL, Wu RM. Transcranial imaging of substantia nigra hyperechogenicity in a Taiwanese cohort of Parkinson's disease. Mov Disord 2007;22:550-5.

14. Tsai CF, Wu RM, Huang YW, Chen LL, Yip PK, Jeng JS. Transcranial color-coded sonography helps differentiation between idiopathic Parkinson's disease and vascular parkinsonism. J Neurol 2007;254:501-7. 
${ }_{142} \mid$ 
Appendix A

Clinical criteria

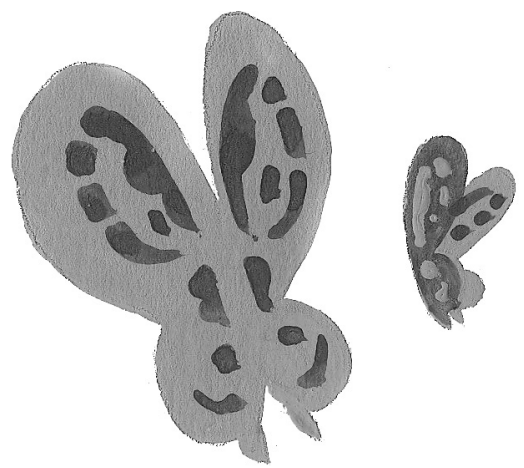




\section{A. Idiopathic Parkinson's Disease}

Hughes AJ, Daniel SE, Kilford L, Lees AJ. Accuracy of clinical diagnosis of idiopathic Parkinson's disease: a clinico-pathological study of 100 cases. J Neurol Neurosurg Psychiatry 1992;55:181-4.

\section{Diagnosis of Parkinsonian syndrome}

- bradykinesia (slowness of initiation of voluntary movement with progressive reduction in speed and amplitude of repetitive actions)

- and at least one of the following: a) muscular rigidity, b) 4-6 Hz tremor, c) postural instability not caused by primary visual, vestibular, cerebellar or proprioceptive dysfunction.

\section{Exclusion criteria for Parkinson's disease}

- history of repeated strokes with stepwise progression of parkinsonian features

- history of repeated head injury

- history of definite encephalitis

- oculogyric crises

- neuroleptic treatment at onset of symptoms

- more than one affected relative

- sustained remission

- strictly unilateral features after 3 years

- supranuclear gaze palsy

- cerebellar signs

- early severe autonomic involvement

- early severe dementia with disturbances of memory, language or praxis

- Babinski sign

- presence of cerebral tumour or communicating hydrocephalus on CT scan

- negative response to large doses of Levodopa (if malabsorption excluded)

- MPTP exposure

\section{Supportive prospective positive criteria for Parkinson's disease}

(> 3 required for diagnosis of definite Parkinson's disease)

- unilateral onset

- rest tremor present

- progressive disorder

- persistent asymmetry affecting side of onset most

- excellent response (70-100\%) to Levodopa 
- severe Levodopa induced chorea

- Levodopa response for 5 years of more

- clinical course of 10 years of more

\section{B. Diagnostic Criteria for Multiple System Atrophy (MSA)}

Gilman S, Low PA, Quinn N, Albanese A, Ben-Shlomo $Y$, Fowler CJ, Kaufmann H, Klockgether T, Lang AE, Lantos PL, Litvan I, Mathias CJ, Oliver $E$, Robertson D, Schatz I, Wenning GK. Consensus statement on the diagnosis of multiple system atrophy. J Neurol Sci 1999;163:94-8.

\section{Clinical domains, features, and criteria used in the diagnosis of MSA}

Feature $(A)$ is a characteristic of the disease

Criterion (B) is a defining feature or composite of features required for diagnosis

\section{Autonomic and urinary dysfunction}

A. Autonomic and urinary features:

1. orthostatic hypotension (by $20 \mathrm{mmHg}$ systolic or $10 \mathrm{mmHg}$ diastolic)

2. urinary incontinence or incomplete bladder emptying

B. Criterion for autonomic failure or urinary dysfunction in MSA:

Orthostatic fall in blood pressure (by $30 \mathrm{mmHg}$ systolic or $15 \mathrm{mmHg}$ diastolic) or urinary incontinence (persistent, involuntary partial or total bladder emptying, accompanied by erectile dysfunction in men) or both

\section{// Parkinsonism}

A. Parkinsonian features:

1. bradykinesia (slowness of voluntary movement with progressive reduction in speed and amplitude during repetitive actions)

2. rigidity

3. postural instability (not caused by primary visual, vestibular, cerebellar, or proprioceptive dysfunction)

4. tremor (postural, resting or both)

B. Criterion for parkinsonism in MSA:

Bradykinesia plus at least 1 of items 2 to 4 


\section{Cerebellar dysfunction}

A. Cerebellar features:

1. gait ataxia (wide based stance with steps of irregular length and direction)

2. atactic dysarthria

3. limb ataxia

4. sustained gaze-evoked nystagmus

B. Criterion for cerebellar dysfunction in MSA: gait ataxia plus at least 1 of items 2 to 4

\section{Corticospinal tract dysfunction}

A. Corticospinal tract features:

Extensor plantar responses with hyperreflexia

B. Corticospinal tract dysfunction in MSA:

No corticospinal tract features are used in defining the diagnosis of MSA

\section{Exclusion criteria for the diagnosis of MSA}

I. History:

- symptomatic onset under 30 years of age

- family history of a similar disorder- systemic diseases or other identifiable causes for clinical features- hallucinations unrelated to medication

II. Physical examination:

- DSM criteria for dementia

- prominent slowing of vertical saccades or vertical supranuclear gaze palsy*

- evidence of focal cortical dysfunction such as aphasia, alien limb syndrome, and parietal dysfunction

III. Laboratory investigation:

- metabolic, molecular genetic, and imaging evidence of an alternative cause of clinical features

*mild limitation of upward gaze alone is non-specific, whereas a prominent $(>50 \%)$ limitation of upward gaze or any limitation of downward gaze suggests progressive supranuclear palsy 


\section{Diagnostic categories of MSA}

\section{Possible MSA}

1 criterion plus 2 features from separate domains

When the criterion is parkinsonism, a poor Levodopa response qualifies as 1 feature (hence only 1 additional feature is required)

\section{Probable MSA}

Criterion for autonomic failure/urinary dysfunction plus poor Levodoparesponsive parkinsonism or cerebellar dysfunction

\section{Definite MSA}

Pathologically confirmed by the presence of a high density of glial cytoplasmic inclusions in association with a combination of degenerative changes in the nigrostriatal and olivopontocerebellar pathways

\section{C Diagnostic Criteria for Progressive Supranuclear palsy (PSP)}

National Institute of Neurological Disorders and Stroke (NINDS)/Society for PSP (NINDS-SPSP); Neurology 1996; 47(1):1-9

\section{Possible PSP}

- gradually progressive disorder

- onset at age 40 or later

- either vertical supranuclear palsy or both slowing of vertical saccades and prominent postural instability with falls in the first year of disease onset

- no evidence of other diseases that could explain the foregoing features, as indicated by mandatory exclusion criteria

\section{Probable PSP}

- gradually progressive disorder

- onset at age 40 or later

- vertical (upward or downward gaze) supranuclear palsy and prominent postural instability with falls in the first year of disease onset

- no evidence of other diseases that could explain the foregoing features, as indicated by mandatory exclusion criteria 


\section{Definite}

- clinically probable or possible PSP and histopathologic evidence of typical PSP

\section{Exclusion criteria}

- recent history of encephalitis

- alien limb syndrome, cortical sensory deficits, focal frontal or temporoparietal atrophy

- hallucinations or delusions unrelated to dopaminergic therapy

- cortical dementia of Alzheimer type (severe amnesia or aphasia or agnosia, according to NINCDS-ADRA criteria)

- prominent early cerebellar symptoms or prominent, early, unexplained dysautonomia (marked hypotension and urinary disturbances)

- severe asymmetric parkinsonian signs (i.e. bradykinesia)

- neuroradiologic evidence of relevant structural abnormality (i.e. basal ganglia or brainstem infarcts, lobar atrophy)

- whipple's disease, confirmed by PCR, if indicated

\section{Supportive criteria}

- symmetric akinesia or rigidity, proximal more than distal

- abnormal neck posture, especially retrocollis

- poor or absent response of parkinsonism to levodopa therapy

- early dysphagia and dysarthria

- early onset of cognitive impairment including at least two if the following: apathy, impairment in abstract thought, decreased verbal fluency, utilisation or imitation behaviour, frontal release signs

NB. Upward gaze is considered abnormal when pursuit or voluntary gaze, or both, have a restriction of at least $50 \%$ of the normal range 


\section{D (Revised) Diagnostic Criteria for Dementia with Lewy Bodies (DLB)}

McKeith IG, Galasko D, Kosaka K, Perry EK, Dickson DW, Hansen LA et al. Consensus guidelines for the clinical and pathologic diagnosis of dementia with Lewy bodies (DLB): report of the consortium on DLB international workshop. Neurology 1996, 47:1113-24.

\section{Central features}

\section{(Essential for a diagnosis of possible or probable DLB)}

- dementia defined as progressive cognitive decline of sufficient magnitude to interfere with normal social or occupational function

- prominent or persistent memory impairment may not necessarily occur in the early stages but is usually evident with progression

- deficits on tests of attention, executive function, and visuospatial ability may be especially prominent

\section{Core features}

(2 core features are sufficient for a diagnosis of probable DLB, 1 for possible DLB)

- fluctuating cognition with pronounced variations in attention and alertness

- recurrent visual hallucinations that are typically well formed and detailed

- spontaneous features of parkinsonism

\section{Suggestive features}

(If one or more of these is present in the presence of one or more core features, a diagnosis of probable DLB can be made. In the absence of any core features, one or more suggestive features is sufficient for possible DLB)

- REM sleep behaviour disorder

- severe neuroleptic sensitivity

- low dopamine transporter uptake in basal ganglia demonstrated by SPECT or PET imaging 


\section{Supportive features}

(commonly present but not proven to have diagnostic specificity)

- repeated falls and syncope

- transient unexplained loss of consciousness

- severe autonomic dysfunction, e.g. orthostatic hypotension, urinary incontinence

- hallucinations in other modalities

- systematized delusions

- relatively preservation of medial temporal lobe structures on CT/MRI

- generalized low uptake on SPECT/PET perfusion scan with reduced occipital activity

- abnormal (low uptake) MIBG myocardial scintigraphy

- prominent slow wave activity on EEG with temporal lobe transient sharp waves

\section{A diagnosis of DLB is less likely}

- in the presence of cerebrovascular disease evident as focal neurologic signs or on brain imaging

- in the presence of any other physical illness or brain disorder sufficient to account in part or in total for the clinical picture

- if parkinsonism only appears for the first time at a stage of severe dementia

\section{Temporal sequence of symptoms}

DLB should be diagnosed when dementia occurs before or concurrently with parkinsonism (if it is present). The term Parkinson disease dementia (PDD) should be used to describe dementia that occurs in the context of well-established Parkinson's disease. In a practice setting the term that is most appropriate to the clinical situation should be used and generic terms such as LB disease are often helpful. In research studies in which distinction needs to be made between DLB and PDD, the existing 1-year rule between the onset of dementia and parkinsonism DLB continues to be recommended. 


\section{$1 \mathrm{E}$ Corticobasal degeneration}

Boeve BF, Lang AE, Litvan I. Corticobasal degeneration and its relationship to progressive supranuclear palsy and frontotemporal dementia. Ann Neurol 2003;54 Supp/ 5:S15-9.

\section{Core features}

1) ilnsidious onset and progressive course

2) no identifiable cause

3) cortical dysfunction as reflected by at least one of the following:

- focal or asymmetric ideomotor apraxia

- alien limb phenomenon

- cortical sensory loss

- visual or sensory hemi-neglect

- constructional apraxia

- focal or asymmetric myoclonus

- apraxia of speech/ nonfluent aphasia

4) extrapyramidal dysfunction as reflected by at least one of the following:

- focal or asymmetric appendicular rigidity lacking prominent and sunstained L-dopa response

- focal or asymmetric appendicular dystonia

\section{Supportive investigations}

1) variable degrees of focal or lateralized cognitive dysfunction, with relative preservation of learning and memory, on neuropsychometric testing

2) focal or asymmetric atrophy

3) focal or asymmetric hypoperfusion on SPECT and hypometabolism on PET, typically maximal in parietofrontal cortex $+/$ - basal ganglia $+/$ - thalamus 


\section{F Vascular parkinsonism}

Zijlmans JC, Daniel SE, Hughes AJ, Revesz T, Lees AJ: Clinicopathological investigation of vascular parkinsonism, including clinical criteria for diagnosis. Movement Disorders 2004;19:630-40.

\section{Parkinsonism}

A. Bradykinesia (slowness of initiation of voluntary movement with progressive reduction in speed and amplitude of repetitive actions in either upper limb or lower limb, including the presence of reduced step length)

B. At least one of the following: rest tremor, muscular rigidity, or postural instability not caused by primary visual, vestibular, cerebellar or proprioceptive dysfunction.

\section{Cerebrovascular disease}

Definition: evidence of relevant cerebrovascular disease by brain imaging (CT or MRI) or the presence of focal signs or symptoms that are consistent with stroke.

\section{A relationship between the above two disorders.}

A. An acute or delayed progressive onset with infarcts in or near areas that can increase the basal ganglia motor output (external globus pallidus or substantia nigra pars compacta) or decrease the thalamocortical drive directly (ventral lateral nucleus of the thalamus, large frontal lobe infarct). The parkinsonism at onset consists of a contralateral bradykinetic rigid syndrome or shuffling gait, within one year after a stroke.

B. An insidious onset of parkinsonism with extensive subcortical white matter lesions, bilateral symptoms at onset, and the presence of early shuffling gait or early cognitive dysfunction.

\section{Exclusion criteria:}

- history of repeated head injury

- definite encephalitis

- neuroleptic treatment at onset of symptoms

- presence of cerebral tumor or communicating hydrocephalus on CT or MRI scan

- other alternative explanation for parkinsonism 


\section{$1 \mathrm{G}$ Essential tremor}

Deuschl G, Bain PG, Brin M, and an Ad Hoc Scientific Committee. Consensus statement of the Movement Disorder Society on tremor. Movement Disorders 1998;13:2-23

The following clinical criteria are used to make the diagnosis of classical essential tremor:

\section{Inclusion criteria:}

- the presence of bilateral, largely symmetrical postural or kinetic tremor involving hands and forearms that is visible and persistent

- additional or isolated tremor of the head may occur but in the absence of abnormal posturing

\section{Exclusion criteria:}

- other abnormal signs, especially dystonia

- the presence of known causes of enhanced physiological tremor, including current or recent exposure to tremorgenic drugs or a drug withdrawal state

- historic or clinical evidence for a psychogenic origin of tremor

- convincing evidence of sudden onset or evidence of stepwise deterioration of tremor

- primary orthostatic tremor

- isolated voice tremor

- isolated position specific or task specific tremors, including occupational tremors and primary writing tremor

- isolated tongue or chin tremor

- isolated leg tremor 
Appendix B

Clinimetric scales

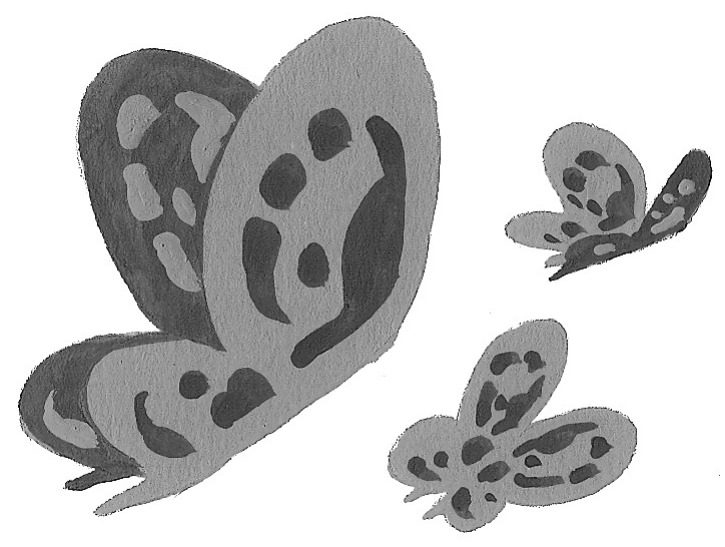


${ }_{1856} \mid$ 


\section{Gestandaardiseerde Parkinsonschaal (UPDRS)}

Fahn S, Elton RL. The Unified Parkinson's Disease Rating Scale. In: Recent developments in Parkinson's disease. Edited by M Goldstein. pp. 153-64. Florham Park, NJ: Marcmillan Health Care Information. 1987:153-64.

\section{Geestestoestand, gedrag en stemming}

1. Cognitieve stoornis

$0=$ Geen.

$1=$ Licht. Constante vergeetachtigheid met gedeeltelijke herinnering van gebeurtenissen zonder andere moeilijkheden.

2 = Matig geheugenverlies met desoriëntatie en matige moeite met complexe probleemhantering. Lichte maar duidelijke functiezwakte in geval van incidenteel op te roepen herinneringen in de thuissituatie.

$3=$ Ernstig geheugenverlies met desoriënatie in tijd en vaak in plaats. Ernstige zwakte in probleemhantering.

$4=$ Ernstig geheugenverlies met enkel oriëntatie in persoon. Niet in staat inschattingen te maken of probleemoplossend te denken. Grote hulpbehoefte bij persoonlijke verzorging. Kan geenszins alleen gelaten worden.

2. Denkstoornis (t.g.v. dementie of geneesmiddelintoxicatie)

$0=$ Geen.

$1=$ Levendige dromen, nachtmerries.

$2=$ Pseudohallucinaties met ziekte-inzicht.

3 = Incidenteel tot frequent hallucinaties of waanideeën; zonder ziekte-inzicht; mogelijk belemmerend voor dagelijkse activiteiten.

$4=$ Persisterende hallucinaties, waanideeën of ernstige psychose. Niet in staat voor zichzelf te zorgen.

3. Depressie

$0=$ Niet aanwezig.

$1=$ Perioden van somberheid of schuldgevoel meer dan normaal, nooit dagen of weken aanhoudend.

2 = Aanhoudende depressie (één week of langer).

$3=$ Aanhoudende depressie met vitale symptomen (slapeloosheid, gebrek aan eetlust, gewichtsverlies, interesseverlies).

$4=$ Aanhoudende depressie met vitale symptomen en zelfmoordgedachten of neigingen.

4. Motivatie/ondernemingszin

$0=$ Normaal.

$1=$ Minder assertief dan normaal; passiever.

$2=$ Verlies van ondernemingszin of desinteresse in voorkeursactiviteiten (niet routinematig).

$3=$ Verlies van van ondernemingszin of desinteresse in dagelijkse activiteiten (routinematige).

$4=$ Teruggetrokken, volledig verlies van motivatie.

\section{Activiteiten dagelijks leven}

\section{Spraak}

$0=$ Normaal.

$1=$ Licht aangedaan. Geen moeilijkheden ondervindend.

2 = Matig aangedaan. Soms gevraagd uitspraken te herhalen.

$3=$ Ernstig aangedaan. Regelmatig gevraagd uitspraken te herhalen.

$4=$ Meestal onverstaanbaar. 
6. Speekselvloed

$0=$ Normaal.

$1=$ Onbeduidende maar duidelijke overmaat aan speeksel in de mond; mogelijk nachtelijk kwijlen.

$2=$ Matige overmaat aan speeksel; mogelijk overdag minimaal kwijlen.

$3=$ Uitgesproken overmaat aan speeksel met enig kwijlen.

$4=$ Uitgesproken kwijlen, constant een zakdoek nodig.

7. Slikken

$0=$ Normaal.

$1=$ Zelden verslikkend.

$2=$ Incidenteel verslikkend

$3=$ Zacht voedsel noodzakelijk.

$4=$ (PEG-) of sondevoeding noodzakelijk.

8. Handschrift

$0=$ Normaal.

$1=$ lets traag of klein.

$2=$ Matig traag of klein; alle woorden zijn leesbaar.

$3=$ Ernstig aangedaan; niet alle woorden zijn leesbaar.

$4=$ De meerderheid van de woorden zijn niet leesbaar.

9. Snijden van voedsel en gebruik van werktuigen

$0=$ Normaal.

$1=$ letwat traag en onhandig, maar geen hulp nodig.

2 = Kan het meeste voedsel snijden, echter onhandig en traag; enige hulp nodig.

$3=$ Voedsel moet door iemand gesneden worden, maar kan nog altijd traag eten.

$4=$ Moet gevoerd worden.

10. Aankleden

$0=$ Normaal.

$1=$ letwat traag, maar geen hulp nodig.

$2=$ Incidenteel hulp nodig bij dichtknopen en armen in mouwen steken.

$3=$ Aanzienlijke hulp nodig, maar kan enkele dingen zelf.

$4=$ Geheel afhankelijk.

11. Hygiène

$0=$ Normaal.

$1=$ letwat traag, maar geen hulp nodig.

$2=$ Hulp nodig bij douchen of baden; of erg traag in hygiënische verzorging.

$3=$ Hulp vereist bij wassen, tandenpoetsen, haar kammen en toiletbezoek.

$4=$ Cathether of andere mechanische hulpmiddelen.

12. Omdraaien in bed en rechttrekken beddegoed

$0=$ Normaal.

$1=$ letwat traag en onhandig, maar geen hulp nodig.

$2=$ Kan zelfstandig draaien of lakens rechttrekken, maar met grote moeite.

$3=$ Kan het intiatief nemen, maar niet zelfstandig omdraaien of de lakens rechttrekken.

$4=$ Geheel afhankelijk.

13. Vallen (Niet gerelateerd aan blokkeren)

$0=$ Niet.

$1=$ Valt zelden.

$2=$ Valt soms, minder dan één keer per dag.

$3=$ Valt gemiddeld één keer per dag.

$4=$ Valt vaker dan één keer per dag.

14. Blokkeren bij lopen

$0=$ Niet.

1 = Zelden blokkeren bij lopen; mogelijk 'startproblemen'.

2 = Soms blokkeren bij lopen.

$3=$ Regelmatig blokkeren. Valt soms t.g.v. blokkeren.

$4=$ Valt frequent t.g.v. blokkeren. 
15. Lopen

$0=$ Normaal.

$1=$ Lichte moeite. Mogelijk afwezige armzwaai of neiging tot sloffen.

$2=$ Matige moeite, maar weinig tot geen hulp vereist.

$3=$ Ernstige loopstoornis, hulp vereist.

$4=$ Kan in het geheel niet lopen, zelfs niet met hulp.

16. Tremor (Symptomatische klachten van tremor in een willekeurig deel van het lichaam.)

$0=$ Afwezig.

$1=$ Onbeduidend en onregelmatig aanwezig.

2 = Matig; hinderlijk voor de patiënt.

$3=$ Ernstig; belemmerend voor veel activiteiten .

4 = Uitgesproken; belemmerend voor de meeste activiteiten.

17. Gevoelsklachten gerelateerd aan parkinson.

$0=$ Geen.

$1=$ Incidenteel last van doof gevoel, tintelingen of lichte pijn.

$2=$ Regelmatig last van doof gevoel, tintelingen of pijn; niet kwellend.

$3=$ Vaak pijnlijke sensaties.

$4=$ Ondraaglijke pijn.

\section{Motorisch onderzoek}

18. Spraak

$0=$ Normaal.

$1=$ Onbeduidend verlies van uitdrukkingskracht, articulatie en/of volume.

$2=$ Monotoon en mompelend, maar begrijpelijk; matig gestoord.

$3=$ Uitgesproken gestoord, moeilijk te begrijpen.

$4=$ Onbegrijpelijk.

19. Gezichtsuitdrukking

$0=$ Normaal.

$1=$ Minimaal verminderde mimiek, zou een normaal 'poker face' kunnen zijn.

$2=$ Lichte, maar duidelijk abnormale vermindering van mimiek.

3 = Matig verminderde mimiek; af en toe open mond.

$4=$ Maskergelaat met ernstig of volledig verlies van mimiek; mond meer dan een halve centimeter open.

20. Rusttremor

$0=$ Afwezig.

$1=$ Onbeduidend en onregelmatig aanwezig.

$2=$ Kleine amplitude en persisterend. Of matige amplitude, maar intermitterend.

$3=$ Matige amplitude en meestal aanwezig.

$4=$ Grote amplitude en meestal aanwezig.

21. Actietremor van de handen

$0=$ Afwezig.

1 = Onbeduidend; aanwezig bij actie.

2 = Matige amplitude, aanwezig bij actie.

3 = Matige amplitude, zowel bij statische houding als bij intentie.

$4=$ Grote amplitude; belemmerend bij eten.

22. Rigiditeit (Beoordeeld bij passief bewegen grote gewrichten terwijl de patiënt ontspannen zit; niet verwarren met tandradfenomeen.)

$0=$ Afwezig.

1 = Onbeduidend of enkel waarneembaar indien geactiveerd door 'mirror movements' of andere bewegingen.

$2=$ Licht tot matig

$3=$ Uitgesproken, maar volledige bewegingsuitslagen worden gemakkelijk bereikt.

$4=$ Ernstig, bewegingsuitslagen worden moeizaam bereikt. 
23. Vingertikken (Patiënt tikt duim en wijsvinger snel opeenvolgend met de grootst mogelijke amplitude, elke hand afzonderlijk.)

$0=$ Normaal.

$1=$ Lichte vertraging en/of verminderde amplitude.

$2=$ Matig gestoord. Duidelijk en snel vermoeid. Eventueel incidentele onderbreking van de beweging.

$3=$ Ernstig gestoord. Frequente aarzeling in het initiëren van bewegingen of onderbreking van herhaalde beweging.

$4=$ Kan de taak nauwelijks uitvoeren.

24. Handbewegingen (Patiënt opent en sluit de hand snel opeenvolgend met de grootst mogelijke amplitude, elke hand afzonderlijk.)

$0=$ Normaal.

$1=$ Lichte vertraging en/of verminderde amplitude.

$2=$ Matig gestoord. Duidelijk en snel vermoeid. Eventueel incidentele onderbreking van de beweging.

$3=$ Ernstig gestoord. Frequente aarzeling in het initiëren van bewegingen of onderbreking van een herhaalde beweging.

$4=$ Kan de taak nauwelijks uitvoeren.

25. Snel alternerende handbewegingen (Pro-/ supinatiebewegingen van de hand, vertikaal en horizontaal, met de grootst mogelijke amplitude, elke hand afzonderlijk.)

$0=$ Normaal.

$1=$ Lichte vertraging en/of verminderde amplitude.

2 = Matig gestoord. Duidelijk en snel vermoeid. Eventueel incidentele onderbreking van de beweging.

$3=$ Ernstig gestoord. Frequente aarzeling in het initiëren van bewegingen of onderbreking van een herhaalde beweging.

$4=$ Kan de taak nauwelijks uitvoeren.

26. Beweeglijkheid van de benen (Patiënt tikt de hiel snel opeenvolgend tegen de grond, het hele been optillend. Amplitude ca. $7,5 \mathrm{~cm}$.)

$0=$ Normaal.

$1=$ Lichte vertraging en/of verminderde amplitude.

2 = Matig gestoord. Duidelijk en snel vermoeid. Mogelijk incidentele onderbreking van de beweging.

$3=$ Ernstig gestoord. Frequente aarzeling in het initieren van bewegingen of onderbreking van een herhaalde beweging.

$4=$ Kan de taak nauwelijks uitvoeren.

27. Opstaan uit stoel (Patiënt tracht op te staan uit een houten of metalen stoel met rechte rugleuning, met de armen gekruist voor de borst.)

$0=$ Normaal.

$1=$ Traag; of heeft meer dan één poging nodig.

$2=$ Duwt zichzelf op vanuit de armleuning.

$3=$ Neigt terug te vallen in de stoel en moet mogelijk meer dan één keer proberen, maar kan opkomen zonder hulp.

$4=$ Niet in staat zonder hulp op te staan.

28. Houding

$0=$ Normaal rechtop.

$1=$ Niet volledig rechtop, enigszins gebogen houding; zou normaal kunnen zijn voor een ouder iemand.

2 = Matig gebogen houding, duidelijk afwijkend; mogelijk iets naar één kant neigend.

$3=$ Ernstig gebogen houding met een kyfose; mogelijk matig naar één kant neigend.

$4=$ Uitgesproken flexie met extreme houdingsafwijking. 
29. Gang

$0=$ Normaal.

$1=$ Loopt traag, mogelijk schuifelend met korte pasjes, maar geen festinatie (snelle pasjes) of propulsie.

$2=$ Moeite met lopen, maar weinig tot geen hulp nodig; mogelijk enige festinatie, korte pasjes of propulsie.

$3=$ Ernstige gangstoornis, hulp vereist.

$4=$ Totaal niet in staat te lopen, zelfs niet met hulp.

30. Houdingsstabiliteit (Reactie op plotselinge, krachtige achterwaartse verplaatsing veroorzaakt door een ruk aan de schouders terwijl de patiënt rechtop staat met geopende ogen en de benen iets gespreid. De patiënt is voorbereid en heeft mogelijk wat oefenpogingen gehad.)

$0=$ Normaal.

$1=$ Retropulsie, maar herstelt zich zonder hulp.

2 = Afwezigheid van de houdingsreflex; zou vallen indien niet opgevangen door de onderzoeker.

$3=$ Erg instabiel, neigt spontaan het evenwicht te verliezen.

$4=$ Niet in staat te staan zonder hulp.

31. Algehele brady- en hypokinesie (Traagheid, aarzeling, afgenomen armzwaai, kleine bewegingsuitslagen en bewegingsarmoede in het algemeen.)

$0=$ Geen.

$1=$ Minimale traagheid, wat het bewegen een bedachtzaam karakter geeft; zou voor sommige personen normaal kunnen zijn. Mogelijk afgenomen bewegingsuitslagen.

$2=$ Lichte mate van traagheid en duidelijke bewegingsarmoede. Ofwel wat afgenomen bewegingsuitslagen.

$3=$ Matige traagheid, bewegingsarmoede of kleine bewegingsuitslagen.

$4=$ Uitgesproken traagheid, bewegingsarmoede of kleine bewegingsuitslagen.

\section{Complicaties van de therapie (In de voorgaande week.)}

\section{A Dyskinesieën}

32. Duur: welk percentage van de dag zijn dyskinesieën aanwezig? [Anamnestisch.]

$0=$ Niet.

$1=1-25 \%$ van de dag.

$2=26-50 \%$ van de dag.

$3=51-75 \%$ van de dag.

$4=76-100 \%$ van de dag.

33. Handicap: in welke mate vormen de dyskinesieën een handicap?

$0=$ Niet invaliderend.

$1=$ Licht invaliderend.

$2=$ Matig invaliderend.

$3=$ Ernstig invaliderend

$4=$ Volledig invaliderend.

34. Pijnlijke dyskinesieën: hoe pijnlijk zijn de dyskinesieën?

$0=$ Geen pijnlijke dyskinesieën.

$1=$ Licht.

$2=$ Matig.

$3=$ Ernstig.

$4=$ Zeer ernstig. 
35. Aanwezigheid van ochtendkramp

$0=$ Nee.

$1=\mathrm{Ja}$.

B. Klinische schommelingen

36. Zijn er voorspelbare 'off'-perioden, samenhangend met tijdstip van medicatie-inname? $0=$ Nee.

$1=\mathrm{Ja}$.

37. Zijn er onvoorspelbare 'off'-perioden, dus niet samenhangend met het tijdstip na medicatie-inname?

$0=$ Nee.

$1=\mathrm{Ja}$.

38. Komen de 'off'-perioden plotseling op, bijvoorbeeld na een paar seconden?

$0=$ Nee.

$1=\mathrm{Ja}$.

39. Welk percentage van de dag is de patiënt gemiddeld 'off'?

$0=$ Geen.

$1=1-25 \%$ van de dag.

$2=26-50 \%$ van de dag.

$3=51-75 \%$ van de dag.

$4=76-100 \%$ van de dag.

C. Andere complicaties

40. Heeft de patiënt last van gebrek aan eetlust, misselijkheid of braken?

$0=$ Nee.

$1=\mathrm{Ja}$.

41. Heeft de patiënt last van slaapstoornissen, bijvoorbeeld slapeloosheid of overmatige slaperigheid?

$0=$ Nee.

$1=\mathrm{Ja}$.

42. Heeft de patiënt last van symptomatische bloeddrukdaling?

$0=$ Nee.

$1=\mathrm{Ja}$. 


\section{Hoehn and Yahr Scale for Parkinson's disease}

Brandt T, Caplan LR, Dichgans J, Diener C, Kennard C. Neurological disorders. Course and treatment. In. San Diego, California: Academic press; 1996.

\begin{tabular}{ll}
\hline Stage & \\
\hline 1 & unilateral disease \\
1.5 & unilateral plus axial involvement \\
2 & bilateral disease without impairment of balance \\
2.5 & mild bilateral disease, with recovery on pull test \\
3 & mild to moderate bilateral disease, some postural instability, physically \\
& independent \\
4 & severe disability, still able to walk or to stand unassisted \\
5 & wheelchair bound or bedridden unless aided \\
\hline
\end{tabular}




\section{Hamilton Rating Scale for Depression}

Hamilton M. A rating scale for depression. J Neurol Neurosurg Psychiatry 1960, 23:56-62.

De HDRS is een vragenlijst met 17 items. Optelling van de eerste 17 items geeft een maat voor de ernst van een al vastgestelde depressie. Score van de eerste 17 items: mild $=10-13$; mild tot matig $=14-17 ;>17=$ matig tot ernstig.

1. Depressieve stemming

Heeft betrekking op de verbale en non-verbale uitingen van een depressieve stemming, gekarakteriseerd door verschijnselen als: neerslachtigheid, bedroefdheid, moedeloosheid, hopeloosheid, hulpeloosheid en pessimisme.

$0=$ afwezig

$1=$ twijfelachtig (patiënt vertelt alleen als er naar gevraagd wordt)

$2=$ duidelijk (patiënt vertelt er spontaan over)

$3=$ non-verbale tekenen van depressie en/ of soms er door overweldigd

$4=$ niet er van af te leiden, uitgesproken non-verbale tekenen van depressie

2. Zelfverwijt

Inhoudelijke denkstoornissen met als thema's: zelfverwijt, schuldgevoel, falen, verminderd zelfrespect et cetera.

$0=$ afwezig

$1=$ twijfelachtig (alleen m.b.t. familie en collega's)

2 = duidelijk (kleine tekortkomingen, falen, verzaken plicht et cetera)

3 = ernstig (waandenkbeelden zoals de huidige ziekte is een soort straf)

4 = stemmingscongruente wanen

3. Suïcidaliteit

$0=$ afwezig

$1=$ het leven is niet de moeite waard, maar geen doodswens

2 = geen zelfmoordplannen, maar wel doodswens

$3=$ overweegt zich te suïcideren

4 = zelfmoordpoging, opgenomen en gevaar voor eigen leven

4. Inslaapstoornissen

$0=$ afwezig

1 = afgelopen 3 nachten duurde inslapen 1 à 2 maal langer dan $1 \frac{1}{2}$ uur

2 = afgelopen 3 nachten duurde inslapen elke nacht langer dan $1 \frac{1}{2}$ uur

5. Doorslaapstoornissen

$0=$ afwezig

1 = afgelopen 3 nachten één à twee maal (onrustige nacht, lichte slaap)

2 = afgelopen 3 nachten elke nacht tenminste eenmaal (lang) wakker

6. Vroeg (voortijdig) ontwaken

$0=$ afwezig

$1=$ afgelopen 3 nachten minder dan een uur, kan weer inslapen

2 = afgelopen 3 nachten constant (meer dan een uur, kan niet meer inslapen)

7. Werk en belangstelling

Heeft betrekking op verrichte werkzaamheden, motivatie.

$0=$ normaal

$1=$ moeite met dagelijkse werkzaamheden, wordt wel gedaan

$2=$ uitgesproken tekortschieten, gereduceerd niveau en tempo

$3=$ werkt hooguit 3 à 4 uur per dag

$4=$ inactief, doet vrijwel niets

8. Retardatie (vertraging, remming)

Heeft op betrekking op de psychomotoriek (onder andere mimiek) en formele denkstoornissen (aandacht, concentratie,denkremming, besluiteloosheid, geheugenstoornissen)

$0=$ afwezig

$1=$ twijfelachtig, licht vertraagd

$2=$ duidelijk vertraagd

3 = gesprek zeer moeizaam, uitermate trage bewegingen

4 = stupor (bewegingloosheid), spraakarmoede, zegt vrijwel niets meer 


\section{9. $\quad$ Agitatie (opwinding)}

Heeft op betrekking op de psychomotoriek.

$0=$ afwezig

$1=$ twijfelachtige of lichte opwinding, onrust en gejaagdheid

$2=$ duidelijke onrust (handen wringen, voortdurend veranderen houding)

$3=$ kan niet blijven zitten, steeds opstaan om te lopen

$4=$ voortdurend heen en weer lopen, haren plukken

10. Angst

Heeft betrekking op het gevoel, omvat gespannenheid, prikkelbaarheid, tobben, onveiligheid, angst tot paniek

$0=$ afwezig

$1=$ twijfelachtig of licht gespannen, prikkelbaar

2 = duidelijk angstig, prikkelbaar, maar zonder invloed op dagelijks leven

3 = paniek, (soms interfererend met dagelijks leven) en anticipatie-angst

4 = vaak angst en paniek, interfereert duidelijk met dagelijks leven

11. Angst (lichamelijke)

Omvat alle fysiologische (lichamelijke) begeleidende symptomen van angst zoals: droge mond, diaree, krampen, misselijk, hartkloppingen, pijn op de borst, versnelde hartactie,

duizelig, wazig zien, ademnood, hyperventilatie, transpireren, trillen

$0=$ afwezig

$1=$ twijfelachtig of lichte verschijnselen

2 = duidelijk verschijnselen, maar zonder invloed op dagelijks leven

$3=$ uitgesproken, soms zorgwekkend, soms invloed op het dagelijks leven

$4=$ veel, hardnekkige verschijnselen, ernstige invloed op dagelijks leven

12. Gastro-intestinaal (maag-darm)

Gebrek aan eetlust, droge mond, obstipatie et cetera

$0=$ afwezig

$1=$ eten smaakt niet, verlies eetlust, eet wel vrijwel normaal

2 = eet duidelijk minder, meestal duidelijke obstipatie

13. Lichamelijk (algemeen)

Moe, geen energie, initiatiefverlies, krachteloos, vage spierpijnen, et cetera

$0=$ afwezig

$1=$ twijfelachtig of vage klachten van vermoeidheid in spieren et cetera

$2=$ duidelijk of constant vermoeid en uitgeput en spierpijnen

14. Seksuele stoornissen

$0=$ normaal

$1=$ twijfelachtig of licht verminderde seksuele belangstelling

2 = duidelijk verlies seksuele belangstelling, vaak impotentie klachten

15. Hypochondrie

Preoccupatie met lichamelijke verschijnselen en functies

$0=$ afwezig

1 = lichte of twijfelachtige bezorgdheid

2 = duidelijk bezorgd omtrent lichamelijke gezondheid

$3=$ preoccupatie met angst of overtuiging ernstige lichamelijke ziekte te hebben

$4=$ hypochondrische wanen

16. Gewichtsverlies

$0=$ afwezig

$1=1-1 \frac{1}{2} \mathrm{~kg} /$ week

$2=3 \mathrm{~kg} /$ week of meer

17. Ziekte-inzicht

$0=$ erkent depressief te zijn

$1=$ erkent depressief te zijn, wijdt het aan andere omstandigheden, bijv. klimaat, werk

$2=$ ontkent ziek te zijn 


\section{SCOPA-COG}

Marinus J, Visser M, Verwey NA, Verhey FRJ, Middelkoop HAM, Stiggelbout AM, van Hilten JJ. Assessment of cognition in Parkinson's disease. Neurology 2003;61:1222-1228.

The mean SCOPA-COG for controls ( $n=75$ ) in this study was 30.7 (standard deviation 5.6). Lower scores indicate more severe impairment.

\section{Geheugen en leren}

\section{1. woordherinneringstaak}

(N.B. elk woord staat gedrukt op een los vel. De 10 woorden worden steeds minimaal 4 seconden aangeboden; hardop door de patiënt laten voorlezen, geen tijdslimiet aan het herinneren)

Instructie:"Lees de woorden hardop. Het zijn tien woorden, waarvan u er zoveel

mogelijk moet proberen te onthouden! Na het oplezen van alle woorden, probeert $\mathrm{u}$ er zoveel op te noemen".

$(10$ goed $=5,8-9$ goed $=4,6-7$ goed $=3,5$ goed $=2,4$ goed $=1,3$ goed $=0)$

groenteboer prikkeldraad boter koffie gordijn hand krant mond trein muur

aantal woorden goed: $\quad / 10$

score: $\quad / 5$

\section{2. spanne achterwaarts}

(NB: patiënt vragen de cijfers in omgekeerde volgorde te herhalen; cijfers worden afzonderlijk opgelezen, 1 seconde per cijfer; indien niet correct wordt herhaald, het alternatief in de $2 \mathrm{e}$ kolom aanbieden; doorgaan totdat tweemaal hetzelfde aantal digits is gemist; noteer hoogste reeks die tenminste 1 x correct werd herhaald; geef voorbeeld: "Als ik zeg 2-7 - 3, dan zegt u $3-7$ - 2")

achterwaarts score:

$\begin{array}{lll}2-4 & 5-8 & =1 \\ 6-2-9 & 4-1-5 & =2 \\ 3-2-7-9 & 4-9-6-8 & =3 \\ 1-5-2-8-6 & 6-1-8-4-3 & =4 \\ 5-3-9-4-1-8 & 7-2-4-8-5-6 & =5 \\ 8-1-2-9-3-6-5 & 4-7-3-9-1-2-8 & =6 \\ 9-4-3-7-6-2-5-8 & 7-2-8-1-9-6-5-3 & =7\end{array}$

score: .$/ 7$

3. blokjes aanwijzen (vier blokjes staan in een rij naast elkaar afgebeeld)

(NB: blokjes in aangegeven volgorde aanwijzen; patiënt dient dit te herhalen; langzaam uitvoeren; patiënt bepaalt zelf met welke hand dit gedaan wordt)
a. $1-2-4-2$
b. $1-2-3-4-3$
c. $3-4-2-1-4$
d. $1-4-2-3-4-1$
e. $1-4-2-3$

aantal goed:....../5

Aandacht 


\section{Aandacht}

\section{4. terugtellen ( 30 naar 0$)$}

(NB: fout kan óf de volgorde, óf het overslaan / niet weten van het getal, óf het niet afmaken van de reeks betreffen)

Instructie: "Wilt u van de 30 drie aftrekken, dan van de uitkomst weer 3 aftrekken en daarmee doorgaan tot 0 ?"

( 0 fout $=2,1$ fout $=1,2$ of meer fouten $=0$ )

aantal goed: $\quad / 10$

score: $\quad / 2$

\section{5. maanden achterwaarts}

(NB: fout kan óf de volgorde, óf het overslaan / niet weten van maanden, óf het niet afmaken van de reeks betreffen)

Instructie: "Noem de maanden van het jaar in omgekeerde volgorde op, beginnend bij de laatste maand van het jaar"

(dec - nov - okt - sept - aug - juli - juni - mei - april - maart - febr - jan)

( 0 fout $=2,1$ fout $=1,2$ of meer fouten $=0$ )

aantal goed: $\quad / 12$

score: $\quad / 2$

\section{Executieve functies}

\section{6. fist-edge-palm}

(NB: 1.vuist met ulnaire zijde naar beneden, 2. gestrekte vingers, ulnaire zijde beneden, 3 . gestrekte vingers, palm naar beneden); eerst 5 series oefenen met verbale ondersteuning, bv door VUIST-STREK-PALM; noteer aantal goede triades uit totaal van 10; patiënt kiest welke hand gebruikt wordt)

$(10$ goed $=3,9$ goed $=2,8$ goed $=1,7$ of minder goed $=0)$

aantal fout aantal goed:

110

score:

\section{7. semantic fluency}

(NB: 1 minuut; geen woordherhalingen of woordvariaties, zoals aap-apin, beer-berin etc.; ook categorieën zijn toegestaan, zo zijn 'vogel' en 'merel' beiden goed; noteer zowel het aantal goede dieren als de namen van alle genoemde dieren)

$(25$ goed $=6,20-24=5,15-19=4,10-14=3,5-9=2,1-4=1,0=0)$

aantal dieren goed:

score:... .6

\section{8. dobbelstenen}

(NB: gebruik 2 kaartjes, een met JA = EVEN, NEE = ONEVEN; een met JA = HOGER, NEE = LAGER. Leg het correcte plaatje bij de uitleg van de test neer en zorg dat het andere, niet relevante plaatje, niet zichtbaar is.

De patient krijgt een aantal bladzijden te zien met dobbelstenen.

De eerste testreeks (conditie 1) wordt niet gescoord. Verbeter de patiënt als deze een fout maakt).

Conditie 1: JA = EVEN 
Instructie: "Zeg JA tegen een even aantal ogen op de dobbelsteen en NEE tegen een oneven aantal ogen".

Hierna wordt de patiënt gevraagd te antwoorden volgens het principe JA $=$ HOGER, NEE = LAGER. Het gaat hierbij steeds om de eerste respons. Corrigeren is in conditie 2 niet toegestaan.

Conditie 2: JA = HOGER

Instructie: Zeg JA indien het aantal ogen op de dobbelsteen hoger is dan op de vorige en NEE als dit aantal lager is.

1234556789910

$(10$ goed $=3,9$ goed $=2,8$ goed $=1,7$ of minder goed $=0$ )

aantal goed: ..../10

score:............../3

\section{Visuospatiële functies}

\section{9. figuren completeren}

NB: patiënt krijgt 5 incomplete figuren te zien en moet steeds 2 of 3 vormen uit 4 of 5 mogelijke alternatieven kiezen om het figuur te completeren. Eerst 2 oefen voorbeelden
a. b.
c.
d.
e.
aantal goed: .15

\section{Geheugen}

\section{0. delayed recall}

Instructie: "Kunt u de 10 woorden die $u$ in het begin uit uw hoofd hebt moeten leren nog een proberen op te noemen?"

$(10$ goed $=5,8-9$ goed $=4,6-7$ goed $=3,5$ goed $=2,4$ goed $=1,3$ goed $=0)$ groenteboer prikkeldraad boter koffie gordijn hand krant mond trein muur

aantal woorden goed: $\quad / 10$

score: $\quad / 5$

Totale COG score: 


\section{Sniffin Smell tests}

Kobal G, Hummel T, Sekinger B, Barz S, Roscher S, Wolf S. "Sniffin' sticks": screening of olfactory performance. Rhinology 1996, 34:222-6.

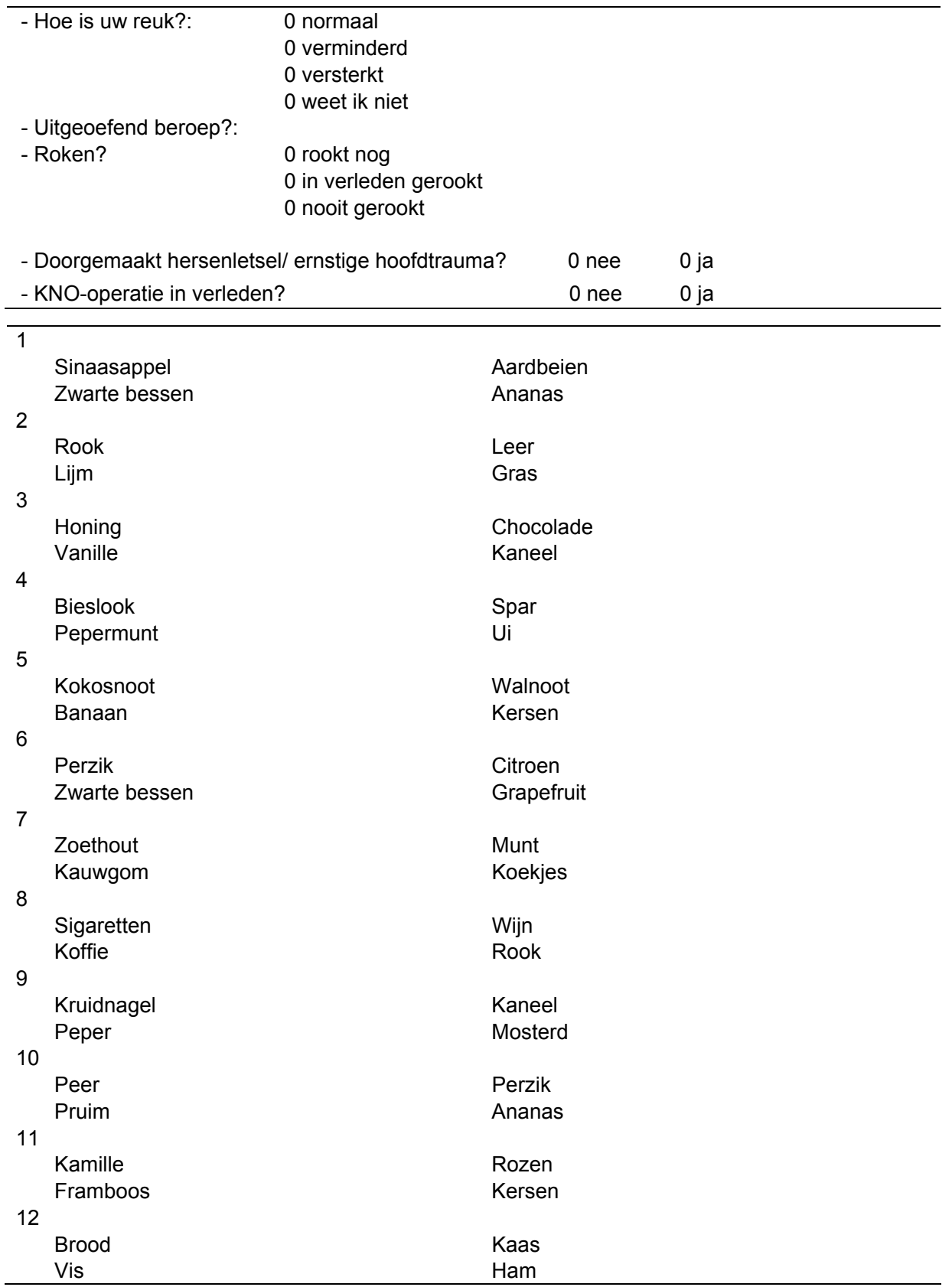




\section{Appendix C}

Practical guideline transcranial duplex scanning

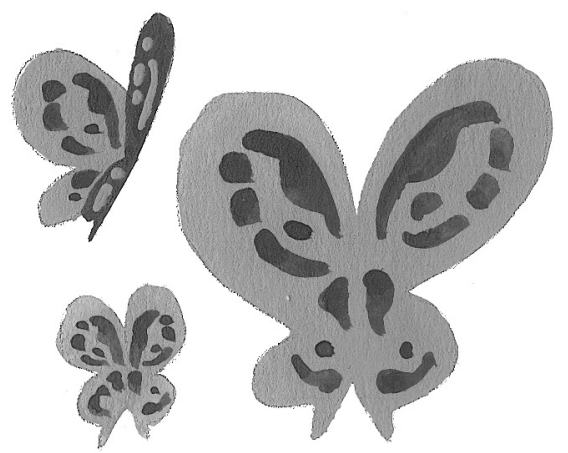




\section{Praktische handleiding transcraniële echografie}

\section{Inleiding}

Sedert ruim 10 jaar wordt transcraniële duplex (TCD) in het kader van wetenschappelijk onderzoek gebruikt bij patiënten met een parkinsonistische aandoening. ${ }^{1}$ Met behulp van deze techniek kunnen veranderingen in de echointensiteit van hersenstructuren gevisualiseerd worden. Veranderingen in echointensiteit worden veroorzaakt door veranderingen in weefsel impedantie ten gevolge van gliale reactie, verandering in celdichtheid en het gehalte aan metalen zoals ijzer en koper. ${ }^{2}$

Inmiddels zijn circa 70 studies verricht naar de diagnostische waarde van TCD bij parkinsonistische aandoeningen en steeds meer onderzoeksgroepen zijn de techniek gaan gebruiken. Voor het implementeren van de techniek als diagnosticum in de klinische praktijk is het allereerst van belang om ervaring op te doen bij patiënten met verschillende aandoeningen. Hierbij kan deze praktische handleiding als een soort leidraad gebruikt worden.

In deze handleiding worden namelijk de technische aspecten met betrekking tot het benaderen van de te onderzoeken structuren met behulp van TCD beschreven, alsmede een overzicht van de betekenis van afwijkende TCD bevindingen bij de ziekte van Parkinson (ZvP) en overige extrapiramidale aandoeningen. ${ }^{3}$

\section{Technische aspecten}

TCD is een elegante, niet-invasieve, goedkope en snelle techniek welke gebruikt kan worden voor verscheidene onderzoeksdoeleinden waaronder het afbeelden van de intracraniële vaten. Sinds 1995 wordt TCD ook gebruikt om de substantia nigra (SN) en verschillende andere hersenstructuren in beeld te brengen. ${ }^{1}$ De techniek is eenvoudig te leren mits men TCD ervaring heeft. Wel is, om een goed oordeel te kunnen geven of de te onderzoeken hersenstructuur een normaal of afwijkend aspect heeft, specifieke ervaring van enkele maanden nodig.

TCD wordt over het algemeen verricht bij een patiënt in rugligging. De onderzoeker zit bij het hoofdeind en plaatst een ultrageluid transducer voor het oor op het os temporale (Figuur 1). Bij de meeste mensen (circa 85\%) is dit botvenster toegankelijk genoeg om zo een tweedimensionaal beeld van de intracraniële structuren te verkrijgen. ${ }^{4,5}$ Daarvoor wordt een laagfrequente transducer gebruikt (1-4 MHz). De diepte range wordt ingesteld op 12 tot 16 $\mathrm{cm}$, zodat de contralaterale zijde van de schedel in beeld komt. In een latere instantie wordt verder ingezoomd. 


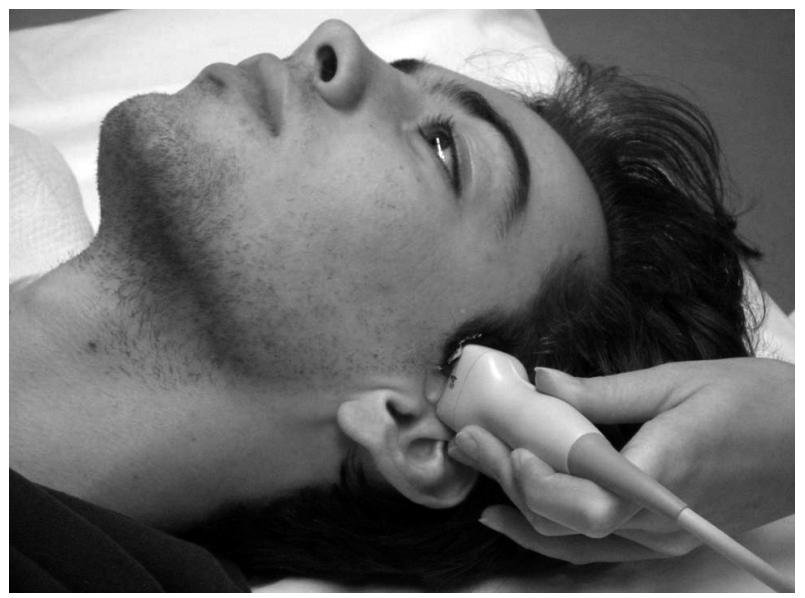

Figuur 1 Plaatsing van de ultrageluid transducer over het transtemporale schedelvenster.

\section{Substantia nigra (SN)}

De rechter en linker SN gelegen in het mesencephalon worden tegelijk in beeld gebracht door te scannen in het axiale vlak dat parallel loopt aan de zogenaamde orbitomeatale lijn (Figuur $2 \mathrm{~A}$ en $2 \mathrm{~B}$ ). Het mesencephalon is zichtbaar als een echo-arme, vlindervormige structuur, omringd door de basale cisternen die een hogere echo-intensiteit hebben (Figuur 3).

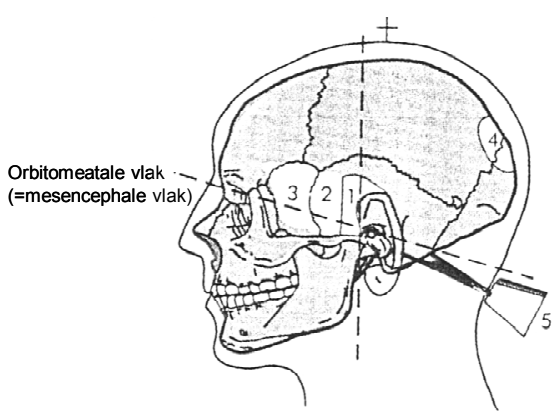

1-3 temporaal venster

4 occipitaal venster

5 nuchaal venster

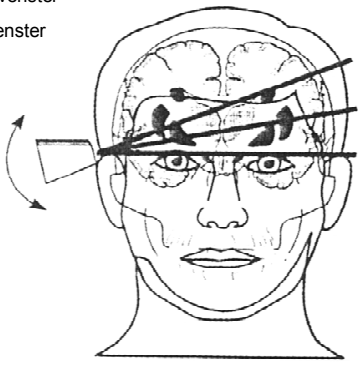

Cellamedia vlak

Derdeventrikel vlak

Mesencephale vlak

Figuur 2A Schematisch overzicht van de axiale TCD sneden die gebruikt kunnen worden bij bewegingsstoornissen. 1 = mesencephale vlak (orbitomeatale vlak) , $2=$ derde ventrikel-vlak (nadat de transducer vanuit het orbitomeatale vlak circa $10 \%$ naar craniaal gekanteld is) 

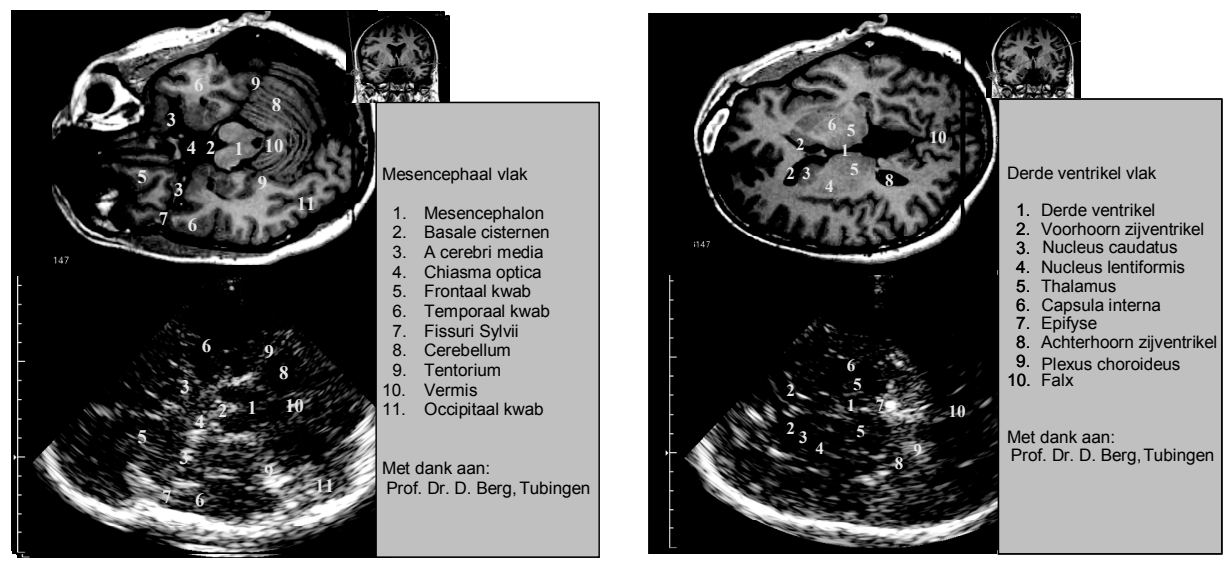

Figuur 2B Structuren zichtbaar in het mesencephale vlak en derde ventrikel vlak

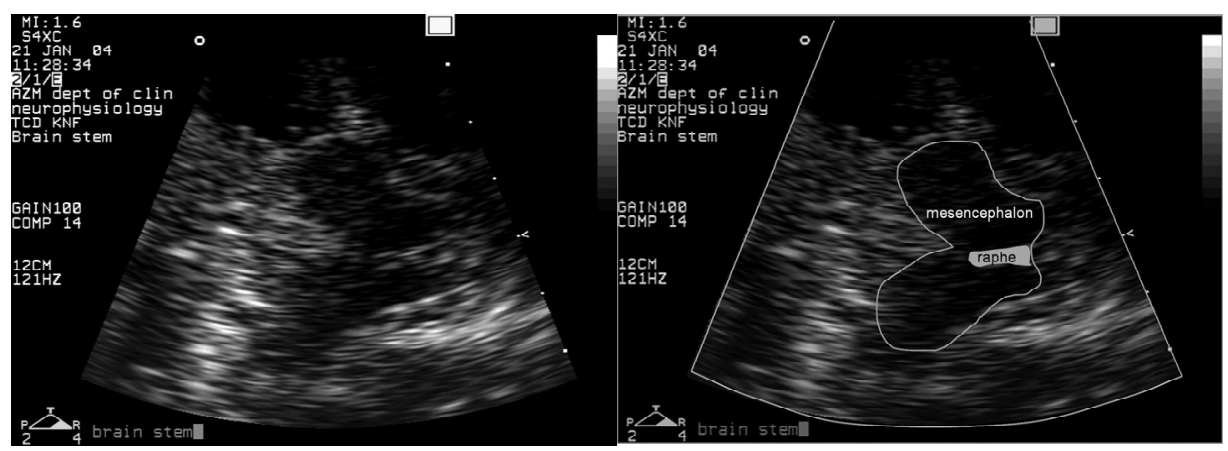

Figuur 3 Een normale hersenstam toont zich in het axiale vlak als een homogeen echoarme en vlindervormige structuur. De substantia nigra (SN) is niet tot nauwelijks zichtbaar. De raphe kernen (RN) daarentegen imponeren als relatief echorijke structuur in de middellijn. Een SN-TCD wordt als normaal beschouwd als de echo-intensiteit van beide SN normaal (hypo-echogeen) zijn. Een RN-TCD wordt normaal beschouwd als de $\mathrm{RN}$ vanuit een of beide zijde normaal (hyper-echogeen) zijn. ${ }^{3}$

Normaal gesproken is het mesencephalon vrij homogeen. In veel gevallen kan wel een aanduiding van de SN gezien worden in het mediale gebied. Van een afwijkende $\mathrm{SN}$ wordt gesproken als er een grote duidelijke hyperechogene zone zichtbaar is op de plaats van de SN (Figuur 4). Deze hyperechogene zone kan streepvormig zijn (overeenkomstig met de anatomie van de substantia nigra) maar ook meer bolvormig, dus buiten de normale grenzen. 


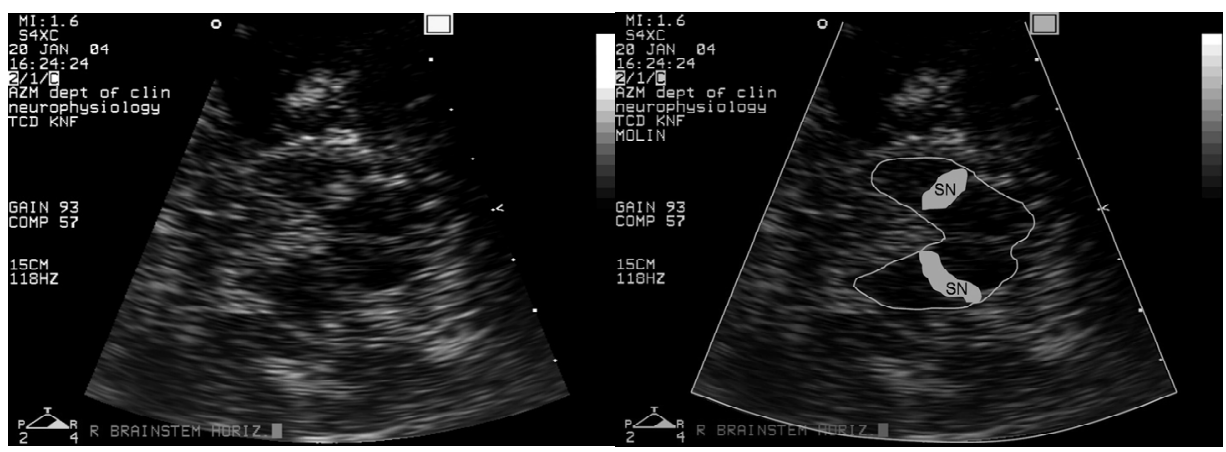

Figuur $4 \quad$ Bij een patiënt met de ziekte van Parkinson kan ter plaatse van de substantia nigra (SN) een gebied met verhoogde echo-intensiteit herkend worden. Als aan één zijde of beide zijden ter plaatse van de SN een hyperecho-intensiteit zichtbaar is wordt de SNTCD als afwijkend beschouwd. ${ }^{3}$

De SN wordt beoordeeld vanuit de ipsilaterale zijde.

De hyperecho-intensiteit kan op twee manieren beoordeeld worden (Tabel 1):

- Visuele (kwalitatieve) methode. Hierbij wordt een 2-, 3- of 4-deling toegepast, van een afwezige of twijfelachtige tot een duidelijk afgetekende hyperechogene zone.

- Semi-kwantitatieve methode. Hierbij wordt de hyperechogene zone ter plaatse van de SN handmatig omcirkeld, zodat de oppervlakte berekend kan worden (Figuur 5). Gebruikmakend van deze laatste methode werd bij de meeste vergelijkende onderzoeken tussen gezonde vrijwilligers en patiënten met de ZvP gevonden dat een oppervlakte van $<0.2 \mathrm{~cm}^{2}$ als normaal, $0.2-0.25 \mathrm{~cm}^{2}$ als licht afwijkend en $>0.25 \mathrm{~cm}^{2}$ als fors afwijkend kan worden beschouwd. ${ }^{4}$

Tabel 1 Beoordeling van de substantia nigra en Raphe nuclei.

\begin{tabular}{|c|c|}
\hline substantia nigra & $\begin{array}{l}\text { - beoordelen vanuit ipsilaterale zijde } \\
\text { - kwalitatief (visuele) beoordeling of semi-kwantitatief (inzoomen en het } \\
\text { gebied omcirkelen voor oppervlakte meting ( }>0.2 \mathrm{~cm} 2 \text { passend bij een } \\
\text { hyper-echointensiteit) }\end{array}$ \\
\hline Raphe nuclei & $\begin{array}{l}\text { - beoordelen vanuit beide zijden } \\
\text { - kwalitatieve beoordeling; afwijkend indien vanuit beide zijden niet zichtbaar } \\
\text { of onderbroken (hypo-echointens) }\end{array}$ \\
\hline derde ventrikel & $\begin{array}{l}\text { - diameter beoordelen vanuit één of beide zijden; } \\
\text { - normaal: <60 jaar tot } 7 \mathrm{~mm},>60 \text { jaar tot } 10 \mathrm{~mm}\end{array}$ \\
\hline $\begin{array}{l}\text { thalamus, } \\
\text { n. caudatus en } \\
\text { n. lentiformis }\end{array}$ & $\begin{array}{l}\text { - het beste te beoordelen vanuit contralaterale zijde } \\
\text { - normaal niet te onderscheiden, afwijkend indien zichtbaar (hyper-echo- } \\
\text { intens) }\end{array}$ \\
\hline
\end{tabular}




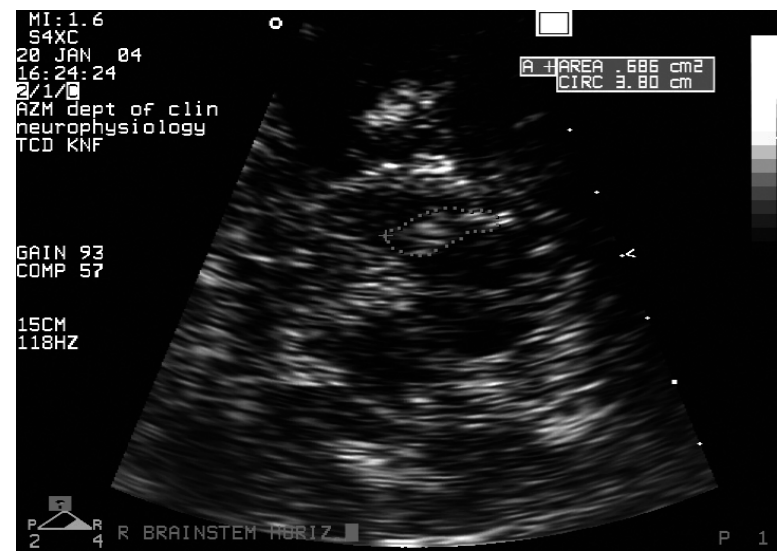

Figuur 5 Door het gebied met verhoogde echo-intensiteit te omcirkelen (gestippelde lijn) kan de oppervlakte kwantitatief bepaald worden (in $\mathrm{cm} 2$ ). ${ }^{3}$

Idealiter moeten voor elk transducer type de normaalwaarden afzonderlijk bepaald worden, aangezien de mogelijkheden om de basale kernen af te beelden per type aanzienlijk verschillen. Zelf gebruiken wij de kwalitatieve indeling (normaal, afwijkend, inconclusief, niet te beoordelen) in combinatie met de semi-kwantitatieve methode.

De echo-intensiteit ter plaatse van de $\mathrm{SN}$ is niet altijd eenvoudig te beoordelen. Soms is de echo-intensiteit slechts licht verhoogd of heeft de hyperechointensiteit een atypische vorm. Bij twijfel scoren wij de SN-TCD inconclusief (Figuur 6). Indien de beeldkwaliteit onvoldoende is scoren wij de SN-TCD als niet te beoordelen (Figuur 7).

Om achteraf ook nog een goede beoordeling van de structuur te kunnen laten plaatsvinden, is het raadzaam een serie images op te slaan waarbij de transducer langzaam van craniaal naar caudaal wordt gedraaid. Voor de uiteindelijke beoordeling van de $\mathrm{SN}$ wordt de image genomen waarop het gebied met een verhoogde echo-intensiteit het grootst en het duidelijkst is. 


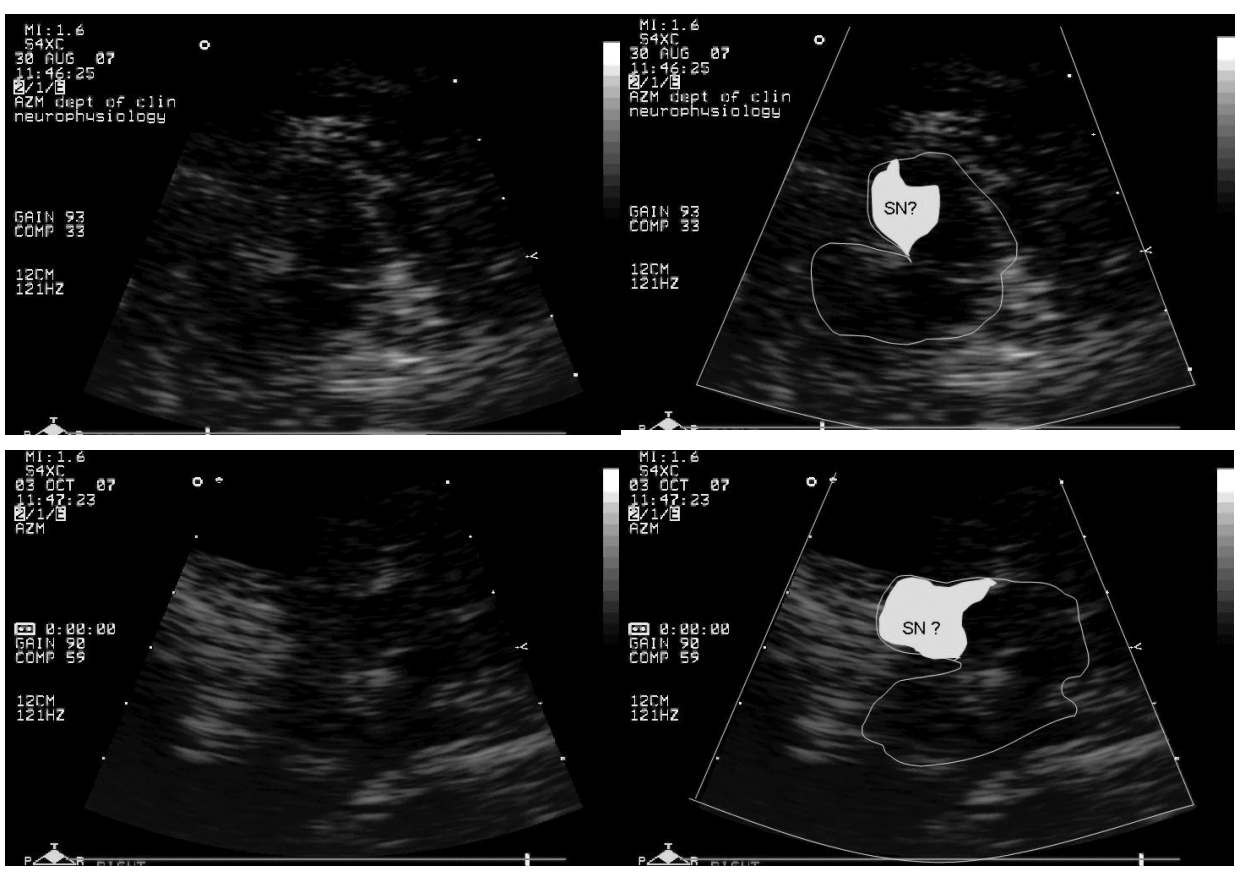

Figuur 6 Bij deze twee personen is de beeldkwaliteit vanuit rechts slechts matig. In het gebied van de rechter substantia nigra $(\mathrm{SN})$ is bij beide personen een relatief groot gebied van slechts een licht toegenomen echo-intensiteit zichtbaar met een niet typische configuratie. In een dergelijk geval van twijfel scoren we de SN inconclusief (voor de klinische praktijk negatief). Als de contralaterale SN wel betrouwbaar te beoordelen is nemen we deze zijde als resultaat voor de SN-TCD.

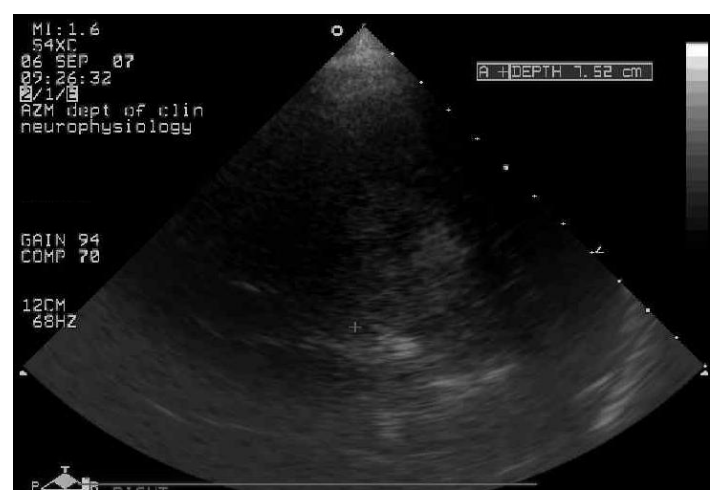

Figuur $7 \quad$ Bij deze patiënt is het temporale botvenster niet voldoende om de echo-intensiteit van de substantia nigra en andere hersenstructuren te beoordelen gezien het mesencephalon en de omgevende structuren (epifyse, basale cisternen) niet geïdentificeerd kunnen worden. 


\section{Raphe kernen}

De Raphe nuclei (RN) bevinden zich in hetzelfde axiale vlak als de SN, maar in de midline van het mesencephalon en dienen vanaf beide zijden kwalitatief te worden beoordeeld. Gewoonlijk zijn de RN zichtbaar als een zeer hyperechogene lijn (als het ware als het lijfje van de vlinder; zie figuur 3 ). Als deze lijn niet zichtbaar is, dat wil zeggen dezelfde echo-intensiteit heeft als het omringende mesencephale weefsel, of als deze lijn onderbroken is, wordt deze als afwijkend beschouwd (Tabel 1).

Pas als de echo-intensiteit van de RN verminderd is vanuit beide zijden wordt de TCD van de RN als afwijkend beschouwd. ${ }^{4}$

\section{Derde ventrikel}

Vanuit het voornoemde vlak waarin het mesencephalon goed te beoordelen is, wordt de ultrageluid transducer zodanig van positie veranderd (gekanteld) dat het insonatie vlak een hoek van $10^{\circ}$ naar boven maakt (Figuur 2 ). In dit vlak komt het typische patroon van twee parallelle hyperechogene lijnen van de derde ventrikel à vue en kan de grootste diameter van de $3 e$ ventrikel goed worden gemeten. Deze diameter wordt bepaald door de afstand vanaf de ipsilaterale tot de contralaterale binnenste laag van het hyperechogene ependym te meten (Figuur 8). Deze diameter is in de leeftijdsgroep van 20-60 jaar $<7 \mathrm{~mm}$ en voor 60 jaar of ouder $<10 \mathrm{~mm}$.

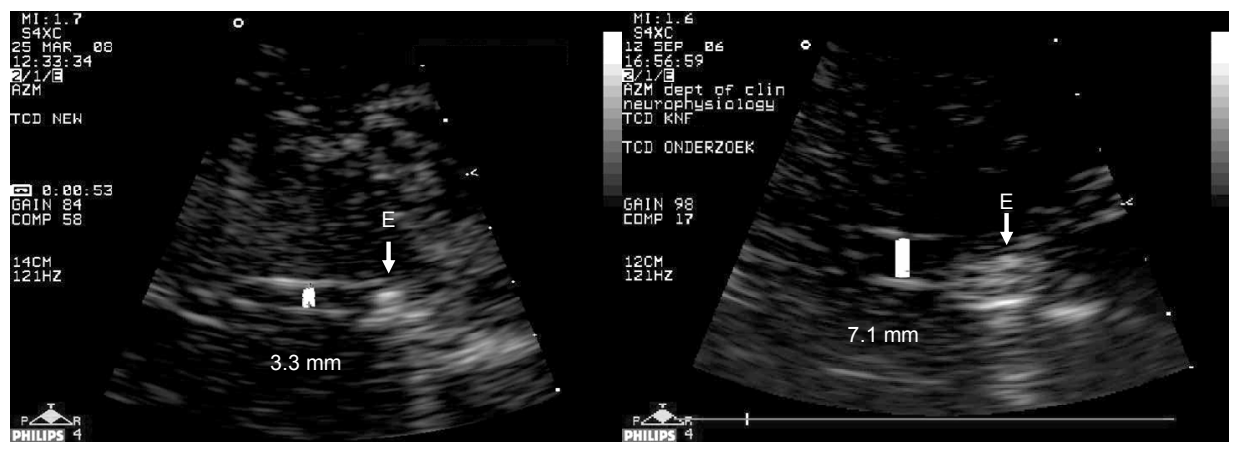

Figuur 8 Diameterbepaling van de derde ventrikel.

De diameter wordt bepaald door de afstand tussen de binnenste lagen te meten (wit balkje). Links is een normale bevinding weergegeven, rechts een relatief wijde derde ventrikel, waarbij de gemeten waarde grensnormaal is. (E) is de epifyse, zichtbaar als een hyperechogene structuur. ${ }^{3}$ 


\section{Thalamus, nucleus lentiformis en nucleus caudatus}

In hetzelfde insonatie vlak als de derde ventrikel kan de echo-intensiteit van de contralaterale thalamus, nucleus lentiformis (NL) en/of nucleus caudatus worden beoordeeld. Normaal gesproken zijn deze structuren niet te onderscheiden omdat zij iso-echogeen zijn aan het omliggende hersenparenchym. Een matige of forse hyperecho-intensiteit van deze structuren wordt als afwijkend beschouwd (Figuur 9).

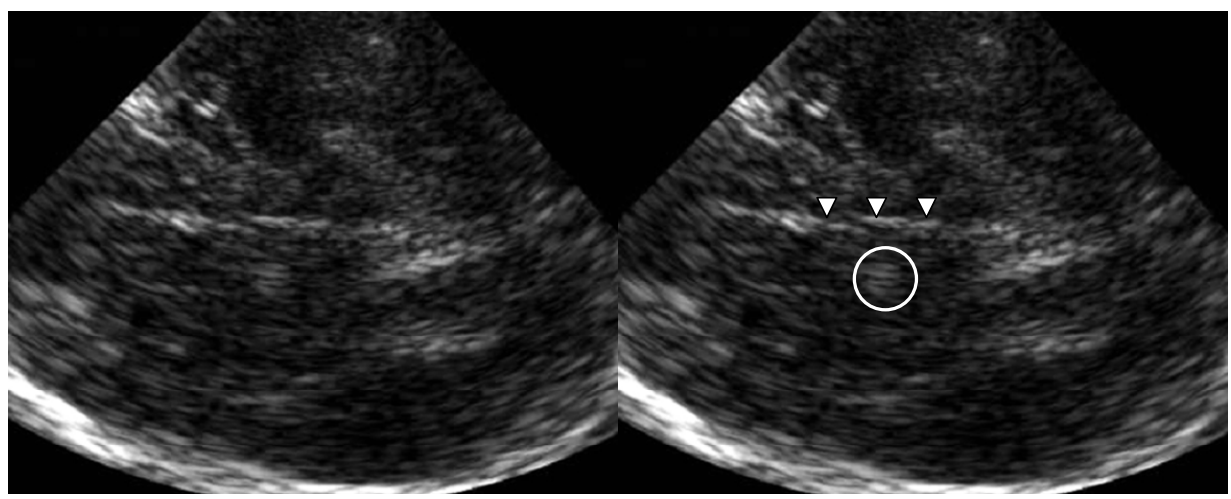

Figuur 9 De ipsilaterale wand van de derde ventrikel is als hyperintense lijn zichtbaar (witte pijlpunten). Contralateraal van de zijde van insonatie is in het gebied van de nucleus lentiformis een groot echorijk gebied aanwijsbaar (witte cirkel).

Deze figuur werd door Prof.dr. D. Berg uit Tübingen ter beschikking gesteld.

\section{Betekenis van afwijkende bevindingen in het kader van de differentiële diagnostiek van parkinsonisme}

In Tabel 2 vindt $u$ de percentages van de afwijkende TCD bevindingen van de substantia nigra (SN) en de nucleus lentiformis (NL) bij patiënten met verschillende parkinsonistische aandoeningen, patiënten met een essentiële tremor en bij gezonde controles. Achter de percentages staan het aantal personen waarop het percentage gebaseerd is. Uit de tabel blijkt dat een afwijkende SN-TCD heel sensitief is voor de ZvP. Echter een abnormale SNTCD wordt niet exclusief bij de ZvP gezien, en eveneens sluit een normale SNTCD de ZvP niet uit. Hetzelfde geldt voor de voorspellende waarde van een abnormale NL-TCD voor atypische parkinsonistische syndromen.

In de laatste kolom is de diagnostische bijdrage van de wijdte van de derde ventrikel te vinden. Een verwijde derde ventrikel schijnt specifiek (en sensitief) 
voor progressieve supranucleaire paralyse te zijn. ${ }^{4,6}$ Echter naar de diagnostische betrouwbaarheid is nog maar zeer weinig onderzoek verricht.

Tabel 2 Percentage van afwijkingen ter plaatse van de substantia nigra, de nucleus lentiformis en de derde ventrikel voor gezonde controles, patiënten met een essentiële tremor of een parkinsonistische aandoening. Achter het percentage staat het patiëntenaantal waarop het percentage berust. ${ }^{4,5,6}$

\begin{tabular}{|c|c|c|c|}
\hline & $\begin{array}{l}\text { Percentage } \\
\text { afwijkende } \\
\text { substantia nigra }\end{array}$ & $\begin{array}{l}\text { Percentage } \\
\text { afwijkende } \\
\text { nucleus lentiformis }\end{array}$ & $\begin{array}{l}\text { Percentage } \\
\text { verwijding } \\
\text { derde ventrikel }\end{array}$ \\
\hline Ziekte van Parkinson & $87 \%(n=1334)$ & $23 \%(n=493)$ & laag? \\
\hline Atypische parkinsonistische & $30 \%(n=138)$ & $79 \%(n=150)$ & variahel \\
\hline - MSA & $17 \%$ & $\begin{array}{l}\text { frequent? } \\
\text { fro }(n=150)\end{array}$ & sporadisch? \\
\hline - PSP & $30 \%$ & frequent? & frequent? \\
\hline - CBD & $88 \%$ & frequent? & sporadisch? \\
\hline - DLBD & $100 \%$ & frequent? & sporadisch? \\
\hline Vasculair parkinsonisme & $20 \%(n=30)$ & middelmatig? & sporadisch? \\
\hline $\begin{array}{l}\text { Medicatie geïnduceerd } \\
\text { parkinsonisme }\end{array}$ & $0 \%(n=3)$ & sporadisch? & sporadisch? \\
\hline Essentiële tremor & $11 \%(n=112)$ & sporadisch? & sporadisch? \\
\hline Gezonde controles & $12 \%(n=2340)$ & $6 \%(n=94)$ & sporadisch? \\
\hline
\end{tabular}

$\mathrm{n}$ : aantal personen, MSA: multipele systeem atrofie, PSP: progressieve supranucleaire paralyse, CBD: corticobasale degeneratie, DLBD: diffuse Lewy body dementie

Een aantal onderzoeksgroepen bereikten een hogere sensitiviteit en specificiteit door het maken van subgroepen. Bijvoorbeeld door een hyperechointensiteit ter plaatse van de $\mathrm{SN}$ in te delen in een matig en zeer duidelijk verhoogde echo-intensiteit. Ook wordt een hogere betrouwbaarheid gehaald door het combineren van de bevindingen van de $\mathrm{SN}, \mathrm{NL}$ en de derde ventrikel. ${ }^{4,6}$

Zoals eerder genoemd is het visualiseren afhankelijk van de ervaring en de gebruikte apparatuur. In onze kliniek meten we standaard de echo-intensiteit van de SN en de RN en de wijdte van de derde ventrikel. Echter onze ervaringen met het betrouwbaar visualiseren van de $\mathrm{NL}$, thalamus en de nucleus caudatus vallen enigszins tegen. 


\section{Referenties}

1. Becker G, Seufert J, Bogdahn U, Reichmann H, Reiners K. Degeneration of substantia nigra in chronic Parkinson's disease visualized by transcranial color-coded real-time sonography. Neurology 1995;45:182-4.

2. Berg D. Disturbance of iron metabolism as a contributing factor to $\mathrm{SN}$ hyperechogenicity in Parkinson's disease: implications for idiopathic and monogenetic forms. Neurochem Res 2007;32:1646-54.

3. Tromp SC, Mess WH. Transcraniele echografie bij extrapiramidale aandoeningen. (www.nvknf.nl/onderwijs/nascholing/knfdagen/2008)

4. Walter U, Behnke S, Eyding J, Niehaus L, Postert T, Seidel G, Berg D. Transcranial brain parenchyma sonography in movement disorders: state of the art. Ultrasound Med Biol 2007; 33:15-25.

5. Vlaar AMM, Bouwmans A, Mess WH, Tromp SC, Weber WEJ. Transcranial duplex in the differential diagnosis of parkinsonian syndromes: a systematic review. Journal of Neurology 2009;256:530-8.

6. Berg $\mathrm{D}, \mathrm{U}$ Walter $\mathrm{U}$. Transcranial sonography in movement disorders. Lancet neurology 2008;7:1044-55. 
Appendix D

Additional files chapter 2

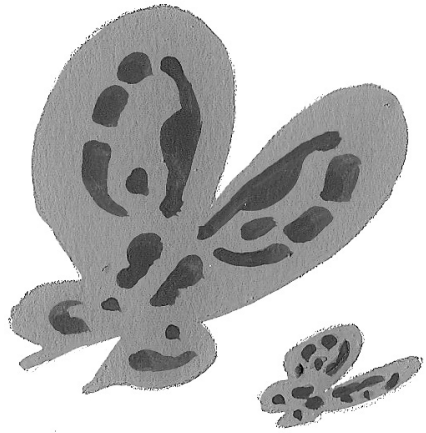




\title{
Meta-analysis of the literature on diagnostic accuracy of SPECT in parkinsonian syndromes:
}

\author{
Excluded trials ${ }^{[1-153]}$
}

1. Parkinson Study Group. Pramipexole vs levodopa as initial treatment for Parkinson disease: A randomized controlled trial. JAMA 2000;284:1931-8.

2. Parkinson Study Group. A randomized controlled trial comparing pramipexole with levodopa in early Parkinson's disease: design and methods of the CALM-PD Study. Clin Neuropharmacol 2000;23:34-44.

3. Parkinson Study Group. Dopamine transporter brain imaging to assess the effects of pramipexole vs levodopa on Parkinson disease progression. JAMA 2002;287:1653-61.

4. Abi-Dargham A, Innis RB, Wisniewski G, Baldwin RM, Neumeyer JL, Seibyl JP. Human biodistribution and dosimetry of iodine-123-fluoroalkyl analogs of beta-CIT. Eur J Nucl Med 1997;24:1422-5.

5. Ahlskog JE, Maraganore DM, Uitti RL, Uhl GR. Brain imaging to assess the effects of dopamine agonists on progression of Parkinson disease. JAMA 2002;288:311; author reply 312-3.

6. Ahlskog JE, Uitti RJ, O'Connor MK, Maraganore DM, Matsumoto JY, Stark KF, Turk MF, Burnett OL. The effect of dopamine agonist therapy on dopamine transporter imaging in Parkinson's disease. Mov Disord 1999;14:940-6.

7. Antonini A, Benti R, De Notaris R, Tesei S, Zecchinelli A, Sacilotto G, Meucci N, Canesi M, Mariani C, Pezzoli G, Gerundini P. 123I-loflupane/SPECT binding to striatal dopamine transporter (DAT) uptake in patients with Parkinson's disease, multiple system atrophy, and progressive supranuclear palsy. Neurol Sci 2003;24:149-50.

8. Antonini A, Landi A, Benti R, Mariani C, De Notaris R, Marotta G, Pezzoli G, Gaini SM, Gerundini P. Functional neuroimaging (PET and SPECT) in the selection and assessment of patients with Parkinson's disease undergoing deep brain stimulation. J Neurosurg Sci 2003; 47:40-6.

9. Arnold G, Tatsch K, Oertel WH, Vogl T, Schwarz J, Kraft E, Kirsch CM. Clinical progressive supranuclear palsy: differential diagnosis by IBZM-SPECT and MRI. J Neural Transm Suppl 1994;42:111-8.

10. Asenbaum S, Brucke T, Pirker W, Podreka I, Angelberger P, Wenger S, Wober C, Muller C, Deecke L. Imaging of dopamine transporters with iodine-123-beta-CIT and SPECT in Parkinson's disease. J Nucl Med 1997;38:1-6.

11. Barthel H, Muller U, Wachter T, Slomka P, Dannenberg C, Murai T, Kahn T, Georgi P. Multimodal SPECT and MRT imaging data analysis for an improvement in the diagnosis of idiopathic Parkinson's syndrome. Radiologe 2000;40:863-9.

12. Baulieu JL, Ribeiro MJ, Levilion-Prunier C, Tranquart F, Chartier JR, Guilloteau D, Cottier JP, Besnard JC, Pourcelot L, Autret A. Effects of the method of drawing regions of interest on the differential diagnosis of extrapyramidal syndromes using 123I-iodolisuride SPET. Nucl Med Commun 1999;20:77-84.

13. Benamer HT, Oertel WH, Patterson J, Hadley DM, Pogarell O, Hoffken H, Gerstner A, Grosset DG. Prospective study of presynaptic dopaminergic imaging in patients with mild parkinsonism and tremor disorders: part 1. Baseline and 3-month observations. Mov Disord 2003;18:977-84.

14. Benamer HT, Patterson J, Wyper DJ, Hadley DM, Macphee GJ, Grosset DG. Correlation of Parkinson's disease severity and duration with 123I-FP-CIT SPECT striatal uptake. Mov Disord 2000;15:692-8. 
15. Berding G, Brucke T, Odin P, Brooks DJ, Kolbe H, Gielow P, Harke H, Knoop BO, Dengler R, Knapp WH. [123l]beta-CIT SPECT imaging of dopamine and serotonin transporters in Parkinson's disease and multiple system atrophy. Nuklearmedizin 2003;42:31-8.

16. Berding G, Gratz KF, Kolbe H, Meyer GJ, Dengler R, Knoop BO, Hundeshagen H. 123I-IBZM SPECT. reconstruction methodology and results in parkinsonism and dystonia. Nuklearmedizin 1994;33:194-9.

17. Berendse HW, Booij J, Francot CM, Bergmans PL, Hijman R, Stoof JC, Wolters EC. Subclinical dopaminergic dysfunction in asymptomatic Parkinson's disease patients' relatives with a decreased sense of smell. Ann Neurol 2001;50:34-41.

18. Bettin S, Kampfer I, Seese A, Schafer A, Reuter M, Lossner J, Dietrich J, Wagner A, Knapp $\mathrm{WH}$. Striatal uptake of I-123-beta-CIT and I-123-IBZM in patients with extrapyramidal symptoms. Nuklearmedizin 1997;36:167-72.

19. Bokobza B, Ruberg M, Scatton B, Javoy-Agid F, Agid Y. [3H]spiperone binding, dopamine and HVA concentrations in Parkinson's disease and supranuclear palsy. Eur $\mathrm{J}$ Pharmacol 1984;99:167-75.

20. Booij J, Tissingh G, Boer GJ, Speelman JD, Stoof JC, Janssen AG, Wolters EC, Royen van EA. [123I]FP-CIT SPECT shows a pronounced decline of striatal dopamine transporter labelling in early and advanced Parkinson's disease. J Neurol Neurosurg Psychiatry 1997; 62:133-40.

21. Booij J, Tissingh G, Winogrodzka A, Boer GJ, Stoof JC, Wolters EC, Royen van EA. Practical benefit of [123I]FP-CIT SPET in the demonstration of the dopaminergic deficit in Parkinson's disease. Eur J Nucl Med 1997;24:68-71.

22. Bosman T, Laere van K, Santens P. Anatomically standardised 99mTc-ECD brain perfusion SPET allows accurate differentiation between healthy volunteers, multiple system atrophy and idiopathic Parkinson's disease. Eur J Nucl Med Mol Imaging 2003;30:16-24.

23. Brucke T, Asenbaum S, Pirker W, Djamshidian S, Wenger S, Wober C, Muller C, Podreka I. Measurement of the dopaminergic degeneration in Parkinson's disease with [123l] beta-CIT and SPECT. Correlation with clinical findings and comparison with multiple system atrophy and progressive supranuclear palsy. J Neural Transm Suppl 1997;50:9-24.

24. Brucke T, Djamshidian S, Bencsits G, Pirker W, Asenbaum S, Podreka I. SPECT and PET imaging of the dopaminergic system in Parkinson's disease. J Neurol 2000;247 Suppl 4: $\mathrm{IV} / 2-7$.

25. Brucke T, Podreka I, Angelberger P, Wenger S, Topitz A, Kufferle B, Muller C, Deecke L. Dopamine D2 receptor imaging with SPECT: studies in different neuropsychiatric disorders. J Cereb Blood Flow Metab 1991;11:220-8.

26. Catafau AM, Tolosa E. Impact of dopamine transporter SPECT using 123I-loflupane on diagnosis and management of patients with clinically uncertain Parkinsonian syndromes. Mov Disord 2004;9:1175-82.

27. Ceravolo R, Volterrani D, Gambaccini G, Bernardini S, Rossi C, Logi C, Tognoni G, Manca G, Mariani G, Bonuccelli U, Murri L. Presynaptic nigro-striatal function in a group of Alzheimer's disease patients with parkinsonism: evidence from a dopamine transporter imaging study. $\mathrm{J}$ Neural Transm 2004, 111:1065-73.

28. Chou KL, Hurtig HI, Stern MB, Colcher A, Ravina B, Newberg A, Mozley PD, Siderowf S. Diagnostic accuracy of [99mTc]TRODAT-1 SPECT imaging in early Parkinson's disease. Parkinsonism Relat Disord 2004;10:375-9.

29. Chouker M, Tatsch K, Linke R, Pogarell O, Hahn K, Schwarz J. Striatal dopamine transporter binding in early to moderately advanced Parkinson's disease: monitoring of disease progression over 2 years. Nucl Med Commun 2001;22:721-5.

30. Colloby SJ, O'Brien JT, Fenwick JD, Firbank MJ, Burn DJ, McKeith IG, Williams ED. The application of statistical parametric mapping to 123I-FP-CIT SPECT in dementia with Lewy bodies, Alzheimer's disease and Parkinson's disease. Neuroimage 2004;23:956-66.

31. Contin M, Martinelli P, Mochi M, Albani F, Riva R, Scaglione C, Dondi M, Fanti C, Pettinato C, Baruzzi A. Dopamine transporter gene polymorphism, spect imaging, and levodopa response in patients with Parkinson disease. Clin Neuropharmacol 2004;27:111-5. 
32. Contin M, Martinelli P, Riva R, Dondi M, Fanti S, Pettinato C, Scaglione C, Albani F, Baruzzi A. Assessing dopaminergic function in Parkinson's disease: levodopa kinetic-dynamic modeling and SPECT. J Neurol 2003;250:1475-81.

33. Cordes M, Henkes H, Laudahn D, Brau H, Kramp W, Girke W, Hierholzer J, Eichstadt H, Felix R. Initial experience with SPECT examinations using [123I]IBZM as a D2-dopamine receptor antagonist in Parkinson's disease. Eur J Radiol 1991;12:182-6.

34. Cordes M, Hierholzer J, Schelosky L, Poewe W, Cordes I, Horowski R, Eichstaedt H, Schmidt D, Felix R. IBZM-SPECT imaging in Parkinson's disease. Quantification of binding ratios from sequential SPECT measurements in patients and controls. Adv Neurol 1993;60:525-8.

35. Cordes M, Hierholzer J, Schelosky L, Schrag A, Richter WS, Eichstadt H, Schulze PE, Poewe W, Felix R. lodine-123-iodo-lisuride SPECT in Parkinson's disease. J Nucl Med 1996;37:22-5.

36. Druschky A, Hilz MJ, Platsch G, Radespiel-Troger M, Druschky K, Kuwert T, Neundorfer B. Differentiation of Parkinson's disease and multiple system atrophy in early disease stages by means of I-123-MIBG-SPECT. J Neurol Sci 2000;175:3-12.

37. Easterford K, Clough P, Kellett M, Fallon K, Duncan S. Reversible parkinsonism with normal beta-CIT-SPECT in patients exposed to sodium valproate. Neurology 2004;62:1435-7.

38. Eisensehr I, Linke R, Noachtar S, Schwarz J, Gildehaus FJ, Tatsch K. Reduced striatal dopamine transporters in idiopathic rapid eye movement sleep behaviour disorder. Comparison with Parkinson's disease and controls. Brain 2000;123 ( Pt 6):1155-60.

39. Eising EG, Muller TH, Freudenberg L, Muller SP, Dutschka K, Sonnenschein W, Przuntek H, Bockisch A. SPECT imaging with [123l]-beta-CIT in Parkinsonism: comparison of SPECT images obtained by a single-headed and a three-headed gamma camera. Nucl Med Commun 2001;22:145-50.

40. Eising EG, Muller TT, Zander C, Kuhn W, Farahati J, Reiners C, Coenen HH. SPECTevaluation of the monoamine uptake site ligand [123I](1R)-2-beta-carbomethoxy-3-beta-(4iodophenyl)-tropane ([123I]beta-CIT) in untreated patients with suspicion of Parkinson disease. J Investig Med 1997;45:448-52.

41. Fahn S, Oakes D, Shoulson I, Kieburtz K, Rudolph A, Lang A, Olanow CW, Tanner C, Marek K. Levodopa and the progression of Parkinson's disease. N Engl J Med 2004, 351:2498-508.

42. Fall PA, Ekberg S, Granerus AK, Granerus G. ECT in Parkinson's disease-dopamine transporter visualised by [123I]-beta-CIT SPECT. J Neural Transm 2000;107:997-1008.

43. Feigin A, Antonini A, Fukuda M, De Notaris R, Benti R, Pezzoli G, Mentis MJ, Moeller JR, Eidelberg D. Tc-99m ethylene cysteinate dimer SPECT in the differential diagnosis of parkinsonism. Mov Disord 2002;17:1265-70.

44. Fischman AJ, Bonab AA, Babich JW, Palmer EP, Alpert NM, Elmaleh DR, Callahan RJ, Barrow SA, Graham W, Meltzer PC, Hanson RN, Madras BK. Rapid detection of Parkinson's disease by SPECT with altropane: a selective ligand for dopamine transporters. Synapse 1998;29:128-41.

45. Frey KA, Koeppe RA, Kilbourn MR, Vander Borght TM, Albin RL, Gilman S, Kuhl DE. Presynaptic monoaminergic vesicles in Parkinson's disease and normal aging. Ann Neurol 1996;40:873-84.

46. Garcia Vicente AM, Vaamonde Cano J, Poblete Garcia VM, Rodado Marina S, Cortes Romera M, Ruiz Solis S, Ibanez Alonso R, Soriano Castrejon A. Utility of dopamine transporter imaging (123-I loflupane SPECT) in the assessment of movement disorders. Rev Esp Med Nucl 2004;23:245-52.

47. Geng Y, Shi GH, Jiang Y, Xu LX, Hu XY, Shao YQ. Investigating the role of 99mTc-TRODAT1 SPECT imaging in idiopathic Parkinson's disease. J Zhejiang Univ Sci B 2005;6:22-7.

48. Giobbe D, Castellano GC, Podio V. Dopamine D2 receptor imaging with SPECT using IBZM in 16 patients with Parkinson disease. Ital J Neurol Sci 1993;14:165-9.

49. Guttman M, Stewart D, Hussey D, Wilson A, Houle S, Kish S. Influence of L-dopa and pramipexole on striatal dopamine transporter in early PD. Neurology 2001;56:1559-64.

50. Hamano T, Tsuchida T, Hirayama M, Fujiyama J, Mutoh T, Yonekura Y, Kuriyama M. Dopamine transporter SPECT in patients with Parkinson's disease. Kaku Igaku 2000;37: 125-9. 
51. Hauser RA, Koller WC, Hubble JP, Malapira T, Busenbark K, Olanow CW. Time course of loss of clinical benefit following withdrawal of levodopa/carbidopa and bromocriptine in early Parkinson' s disease. Mov Disord 2000;15:485-9.

52. Hertel A, Weppner M, Baas H, Schreiner M, Maul FD, Baum RP, Fischer PA, Hor G. Quantification of IBZM dopamine receptor SPET in de novo Parkinson patients before and during therapy. Nucl Med Commun 1997;18:811-22.

53. Hierholzer J, Castelli L, Cordes M, Schelosky L, Poewe W, Felix R. Cerebral SPECT with iodine-123 IBZM in patients with extrapyramidal system disorders: the evaluation of its sensitivity in therapy with dopaminergic drugs. Radiol Med (Torino) 1996;91:207-10.

54. Hierholzer J, Cordes M, Schelosky L, Barzen G, Poewe W, Henkes H, Keske U, Horowski R, Felix R. The determination of cerebral dopamine (D2) receptor density by using 123I-IBZMSPECT in Parkinson disease patients. Rofo 1992;157:390-8.

55. Hierholzer J, Cordes M, Schelosky L, Richter W, Schrag A, Poewe W, Schulze PE, Semmler W, Eichstadt H, Felix R. Brain SPECT with 123I-lisuride in patients with Parkinson's disease and controls. Nuklearmedizin 1995;34:141-5.

56. Hierholzer J, Cordes M, Schelosky L, Sander B, Bock JC, David I, Horowski R, Poewe W. The differential diagnosis of Parkinson diseases--123I-IBZM-SPECT vs. the apomorphine test. Rofo 1993;159:86-90.

57. Hierholzer J, Cordes M, Venz S, Schelosky L, Harisch C, Richter W, Keske U, Hosten N, Maurer J, Poewe W, Felix R. Loss of dopamine-D2 receptor binding sites in Parkinsonian plus syndromes. J Nucl Med 1998;39:954-60.

58. Huang WS, Chiang YH, Lin JC, Chou YH, Cheng CY, Liu RS. Crossover study of (99m)TcTRODAT-1 SPECT and (18)F-FDOPA PET in Parkinson's disease patients. J Nucl Med 2003;44:999-1005.

59. Ichise M, Ballinger JR. SPECT imaging of dopamine receptors. J Nucl Med 1996;37:1591-5.

60. Ichise M, Ballinger JR, Vines D, Tsai S, Kung HF. Simplified quantification and reproducibility studies of dopamine D2-receptor binding with iodine-123-IBF SPECT in healthy subjects. J Nucl Med 1997;38:31-7.

61. Ichise M, Kim YJ, Ballinger JR, Vines D, Erami SS, Tanaka F, Lang AE. SPECT imaging of pre- and postsynaptic dopaminergic alterations in L-dopa-untreated PD. Neurology 1999; 52:1206-14.

62. Ichise M, Kim YJ, Erami SS, Ballinger JR, Vines D, Tanaka F, Lang AE. Functional morphometry of the striatum in Parkinson's disease on three-dimensional surface display of 123I-beta-CIT SPECT data. J Nucl Med 1999;40:530-8.

63. Imon $\mathrm{Y}$, Matsuda $\mathrm{H}$, Ogawa $\mathrm{M}$, Kogure $\mathrm{D}$, Sunohara $\mathrm{N}$. SPECT image analysis using statistical parametric mapping in patients with Parkinson's disease. J Nucl Med 1999; 40:1583-9.

64. Innis R, Baldwin R, Sybirska E, Zea Y, Laruelle M, al-Tikriti M, Charney D, Zoghbi S, Smith E, Wisniewski G, et al. Single photon emission computed tomography imaging of monoamine reuptake sites in primate brain with [123I]CIT. Eur J Pharmacol 1991;200:369-70.

65. Innis RB, Marek KL, Sheff K, Zoghbi S, Castronuovo J, Feigin A, Seibyl JP. Effect of treatment with L-dopa/carbidopa or L-selegiline on striatal dopamine transporter SPECT imaging with [123I]beta-CIT. Mov Disord 1999;14:436-42.

66. Innis RB, Seibyl JP, Scanley BE, Laruelle M, Abi-Dargham A, Wallace E, Baldwin RM, ZeaPonce $\mathrm{Y}$, Zoghbi S, Wang S, et al. Single photon emission computed tomographic imaging demonstrates loss of striatal dopamine transporters in Parkinson disease. Proc Natl Acad Sci U S A 1993;90:11965-9.

67. Ishikawa T, Dhawan V, Kazumata K, Chaly T, Mandel F, Neumeyer J, Margouleff C, Babchyck B, Zanzi I, Eidelberg D. Comparative nigrostriatal dopaminergic imaging with iodine-123-beta CIT-FP/SPECT and fluorine-18-FDOPA/PET. J Nucl Med 1996;37:1760-5.

68. J Jankovic, AH Rajput, MP McDermott, DP Perl. The evolution of diagnosis in early Parkinson disease. Parkinson Study Group. Arch Neurol 2000;57:369-72.

69. Jennings DL, Seibyl JP, Oakes D, Eberly S, Murphy J, Marek K. (123I) beta-CIT and singlephoton emission computed tomographic imaging vs clinical evaluation in Parkinsonian syndrome: unmasking an early diagnosis. Arch Neurol 2004;61:1224-9. 
70. Kageyama H, Kikuchi S, Tashiro K. Analysis of Parkinson's disease and related syndromes using 123I-IMP-SPECT with the ARG method. Nippon Rinsho 1997;55:238-42.

71. Kao PF, Tzen KY, Yen TC, Lu CS, Weng YH, Wey SP, Ting G. The optimal imaging time for [99Tcm]TRODAT-1/SPET in normal subjects and patients with Parkinson's disease. Nucl Med Commun 2001;22:151-4.

72. Katzenschlager R, Costa D, Gerschlager W, O'Sullivan J, Zijlmans J, Gacinovic S, Pirker W, Wills A, Bhatia K, Lees AJ, Brown P. [123I]-FP-CIT-SPECT demonstrates dopaminergic deficit in orthostatic tremor. Ann Neurol 2003;53:489-96.

73. Kegeles LS, Zea-Ponce $\mathrm{Y}$, Abi-Dargham A, Rodenhiser J, Wang T, Weiss R, Heertum van RL, Mann JJ, Laruelle M. Stability of [123I]IBZM SPECT measurement of amphetamineinduced striatal dopamine release in humans. Synapse 1999;31:302-8.

74. Kim GM, Kim SE, Lee WY. Preclinical impairment of the striatal dopamine transporter system in sporadic olivopontocerebellar atrophy: studied with [(123)!]beta-CIT and SPECT. Eur Neurol 2000;43:23-9.

75. Kim HJ, Im JH, Yang SO, Moon DH, Ryu JS, Bong JK, Nam KP, Cheon JH, Lee MC, Lee HK. Imaging and quantitation of dopamine transporters with iodine-123-IPT in normal and Parkinson's disease subjects. J Nucl Med 1997;38:1703-11.

76. Kim SE, Choi JY, Choe YS, Choi Y, Lee WY. Serotonin transporters in the midbrain of Parkinson's disease patients: a study with 123I-beta-CIT SPECT. J Nucl Med 2003;44:870-6.

77. Kim SE, Lee WY, Choe YS, Kim JH. SPECT measurement of iodine-123-beta-CIT binding to dopamine and serotonin transporters in Parkinson's disease: correlation with symptom severity. Neurol Res 1999;21:255-61.

78. Knable MB, Jones DW, Coppola R, Hyde TM, Lee KS, Gorey J, Weinberger DR. Lateralized differences in iodine-123-IBZM uptake in the basal ganglia in asymmetric Parkinson's disease. J Nucl Med 1995;36:1216-25.

79. Knudsen GM, Karlsborg M, Thomsen G, Krabbe K, Regeur L, Nygaard T, Videbaek C, Werdelin L. Imaging of dopamine transporters and D2 receptors in patients with Parkinson's disease and multiple system atrophy. Eur J Nucl Med Mol Imaging 2004;31:1631-8.

80. Landwehrmeyer B, Palacios JM. Alterations of neurotransmitter receptors and neurotransmitter transporters in progressive supranuclear palsy. J Neural Transm Suppl 1994;42:229-46.

81. Larisch R, Meyer W, Klimke A, Kehren F, Vosberg H, Muller-Gartner HW. Left-right asymmetry of striatal dopamine D2 receptors. Nucl Med Commun 1998;19:781-7.

82. Laulumaa V, Kuikka JT, Soininen H, Bergstrom K, Lansimies E, Riekkinen P. Imaging of D2 dopamine receptors of patients with Parkinson's disease using single photon emission computed tomography and iodobenzamide I 123. Arch Neurol 1993;50:509-12.

83. Lavalaye J, Booij J, Reneman L, Habraken JB, Royen van EA. Effect of age and gender on dopamine transporter imaging with [123I]FP-CIT SPET in healthy volunteers. Eur J Nucl Med 2000;27:867-9.

84. Lorberboym M, Djaldetti R, Melamed E, Sadeh M, Lampl Y. 123I-FP-CIT SPECT imaging of dopamine transporters in patients with cerebrovascular disease and clinical diagnosis of vascular parkinsonism. J Nucl Med 2004;45:1688-93.

85. Maloteaux JM, Vanisberg MA, Laterre C, Javoy-Agid F, Agid Y, Laduron PM. [3H]GBR 12935 binding to dopamine uptake sites: subcellular localization and reduction in Parkinson's disease and progressive supranuclear palsy. Eur J Pharmacol 1988;156:331-40.

86. Marek K, Innis R, Dyck van C, Fussell B, Early M, Eberly S, Oakes D, Seibyl S. [123I]betaCIT SPECT imaging assessment of the rate of Parkinson's disease progression. Neurology 2001;57:2089-94.

87. Marek K, Jennings D, Seibyl J. Single-photon emission tomography and dopamine transporter imaging in Parkinson's disease. Adv Neurol 2003;91:183-91.

88. Marek K, Jennings $\mathrm{D}$, Seibyl J. Dopamine agonists and Parkinson's disease progression: what can we learn from neuroimaging studies. Ann Neurol 2003;53 Suppl 3:S160-6; discussion S166-9. 
89. Marek KL, Seibyl JP, Zoghbi SS, Zea-Ponce Y, Baldwin RM, Fussell B, Charney DS, Dyck van C, Hoffer PB, Innis RP. [123I] beta-CIT/SPECT imaging demonstrates bilateral loss of dopamine transporters in hemi-Parkinson's disease. Neurology 1996;46:231-7.

90. Mozley PD, Schneider JS, Acton PD, PlossI K, Stern MD, Siderowf A, Leopold NA, Li PY, Alavi A, Kung HF. Binding of [99mTc]TRODAT-1 to dopamine transporters in patients with Parkinson's disease and in healthy volunteers. J Nucl Med 2000;41:584-9.

91. Muller T, Eising EG, Reiners C, Przuntek H, Jacob M, Kuhn W. 2-[123I]-iodolisuride SPET visualizes dopaminergic loss in de-novo parkinsonian patients: is it a marker of striatal presynaptic degeneration? Nucl Med Commun 1997;18:1115-21.

92. Murai T, Muller U, Werheid K, Sorger D, Reuter M, Becker T, von Cramon DY, Barthel H. In vivo evidence for differential association of striatal dopamine and midbrain serotonin systems with neuropsychiatric symptoms in Parkinson's disease. J Neuropsychiatry Clin Neurosci 2001;13:222-8.

93. Nadeau SE, Couch MW, Devane CL, Shukla SS. Regional analysis of D2 dopamine receptors in Parkinson's disease using SPECT and iodine-123-iodobenzamide. J Nucl Med 1995;36:384-93.

94. O'Brien JT, Colloby S, Fenwick J, Williams ED, Firbank M, Burn D, Aarsland D, McKeith IG. Dopamine transporter loss visualized with FP-CIT SPECT in the differential diagnosis of dementia with Lewy bodies. Arch Neurol 2004;61:919-25.

95. Parkinson Study Group. A multicenter assessment of dopamine transporter imaging with DOPASCAN/SPECT in parkinsonism. Neurology 2000;55:1540-7.

96. Pavics L, Dibo G, Ambrus E, Sera T, Vecsei L, Csernay L. Initial experiences with 123-lodineIBZM neuroreceptor scintigraphy in extrapyramidal disorders. Orv Hetil 2000;141:1073-7.

97. Pierot L, Desnos C, Blin J, Raisman R, Scherman D, Javoy-Agid F, Ruberg M, Agid Y. D1 and D2-type dopamine receptors in patients with Parkinson's disease and progressive supranuclear palsy. J Neurol Sci 1988;86:291-306.

98. Piggott MA, Marshall EF, Thomas N, Lloyd S, Court JA, Jaros E, Burn D, Johnson M, Perry RH, McKeith IG, Ballard C, Perry EK. Striatal dopaminergic markers in dementia with Lewy bodies, Alzheimer's and Parkinson's diseases: rostrocaudal distribution. Brain 1999, 122 ( Pt 8): $1449-68$.

99. Pirker W. Correlation of dopamine transporter imaging with parkinsonian motor handicap: how close is it? Mov Disord 2003;18 Suppl 7:S43-51.

100. Pirker W, Asenbaum S, Hauk M, Kandlhofer S, Tauscher J, Willeit M, Neumeister A, Praschak-Rieder N, Angelberger P, Brucke T. Imaging serotonin and dopamine transporters with 123I-beta-CIT SPECT: binding kinetics and effects of normal aging. J Nucl Med 2000; 41:36-44.

101. Pirker W, Holler I, Gerschlager W, Asenbaum S, Zettinig G, Brucke T. Measuring the rate of progression of Parkinson's disease over a 5-year period with beta-CIT SPECT. Mov Disord 2003, 18:1266-72.

102. Pizzolato G, Cagnin A, Rossato A, Chierichetti F, Fabbri M, Dam M, Ferlin G, Battistin L. Striatal dopamine D2 receptor alterations and response to L-DOPA in Parkinson's disease. A [123I]IBZM SPET study. Adv Neurol 1996;69:467-73.

103. Pizzolato G, Chierichetti F, Rossato A, Briani C, Dam M, Borsato N, Saitta B, Zanco P, Ferlin G, Battistin L. Dopamine receptor SPET imaging in Parkinson's disease: a [123I]-IBZM and [99mTc]-HM-PAO study. Eur Neurol 1993;33:143-8.

104. Pizzolato G, Chierichetti F, Rossato A, Cagnin A, Fabbri M, Dam M, Ferlin G, Battistin L. Alterations of striatal dopamine D2 receptors contribute to deteriorated response to L-dopa in Parkinson's disease: a [123I]-IBZM SPET study. J Neural Transm Suppl 1995;45:113-22.

105. Plotkin M, Amthauer H, Quill S, Marzinzik F, Klostermann F, Klaffke S, Kivi A, Gutberlet M, Felix R, Kupsch A. Imaging of dopamine transporters and D2 receptors in vascular parkinsonism: a report of four cases. J Neural Transm 2005;112(10):1355-61.

106. Popperl G, Radau P, Linke R, Hahn K, Tatsch K. Diagnostic performance of a 3-D automated quantification method of dopamine D2 receptor SPECT studies in the differential diagnosis of parkinsonism. Nucl Med Commun 2005;26:39-43. 
107. Popperl G, Tatsch K, Ruzicka E, Storch A, Gasser T, Schwarz J. Comparison of alphadihydroergocryptine and levodopa monotherapy in Parkinson's disease: assessment of changes in DAT binding with [123I]IPT SPECT. J Neural Transm 2004;111:1041-52.

108. Prunier C, Tranquart F, Cottier JP, Giraudeau B, Chalon S, Guilloteau D, De Toffol B, Chossat F, Autret A, Besnard JC, Baulieu JL. Quantitative analysis of striatal dopamine D2 receptors with 123 I-iodolisuride SPECT in degenerative extrapyramidal diseases. Nucl Med Commun 2001;22:1207-14.

109. Quinn N. A multicenter assessment of dopamine transporter imaging with DOPASCAN/ SPECT in parkinsonism. Neurology 2001;57:746-7.

110. Radau PE, Linke R, Slomka PJ, Tatsch K. Optimization of automated quantification of 123IIBZM uptake in the striatum applied to parkinsonism. J Nucl Med 2000;41:220-7.

111. Ransmayr G, Seppi K, Donnemiller E, Luginger E, Marksteiner J, Riccabona G, Poewe W, Wenning GK. Striatal dopamine transporter function in dementia with Lewy bodies and Parkinson's disease. Eur J Nucl Med 2001;28:1523-8.

112. Reiche W, Grundmann M, Huber G. [Dopamine (D2) receptor SPECT with 123Iiodobenzamide (IBZM) in diagnosis of Parkinson syndrome]. Radiologe 1995;35:838-43.

113. T Sasaki, T Amano, J Hashimoto, $Y$ Itoh, K Muramatsu, A Kubo, $Y$ Fukuuchi. [SPECT imaging using [123I]beta-CIT and [123I]IBF in extrapyramidal diseases]. No To Shinkei 2003; 55:57-64.

114. HB Saur, P Bartenstein, O Schober, C Oberwittler, H Lerch, H Masur. Comparison of D2 receptor scintigraphy (123I-IBZM) with cerebral perfusion (99m-Tc-HMPAO) in extrapyramidal disorders. Nuklearmedizin 1994;33:184-8.

115. Scherfler C, Seppi K, Donnemiller E, Goebel G, Brenneis C, Virgolini I, Wenning GK, Poewe W. Voxel-wise analysis of [123I]\{beta\}-CIT SPECT differentiates the Parkinson variant of multiple system atrophy from idiopathic Parkinson's disease. Brain 2005;128:1605-12.

116. Schulz JB, Klockgether T, Petersen D, Jauch M, Muller-Schauenburg W, Spieker S, Voigt K, Dichgans J. Multiple system atrophy: natural history, MRI morphology, and dopamine receptor imaging with 123IBZM-SPECT. J Neurol Neurosurg Psychiatry 1994;57:1047-56.

117. Schwarz J, Oertel WH, Tatsch K. lodine-123-iodobenzamide binding in parkinsonism: reduction by dopamine agonists but not L-Dopa. J Nucl Med 1996;37:1112-5.

118. Schwarz J, Storch A, Koch W, Pogarell O, Radau PE, Tatsch K. Loss of dopamine transporter binding in Parkinson's disease follows a single exponential rather than linear decline. J Nucl Med 2004;45:1694-7.

119. Schwarz J, Tatsch K, Arnold G, Gasser T, Trenkwalder C, Kirsch CM, Oertel WH. 123Iiodobenzamide-SPECT predicts dopaminergic responsiveness in patients with de novo parkinsonism. Neurology 1992;42:556-61.

120. Seibyl J, Jennings D, Tabamo R, Marek K. Neuroimaging trials of Parkinson's disease progression. J Neurol 2004;251 Suppl 7:vll9-13.

121. Seibyl JP, Laruelle M, van Dyck CH, Wallace E, Baldwin RM, Zoghbi S, Zea-Ponce Y, Neumeyer JL, Charney DS, Hoffer PB, Innis RB. Reproducibility of iodine-123-beta-CIT SPECT brain measurement of dopamine transporters. J Nucl Med 1996;37:222-8.

122. Seibyl JP, Marek K, Sheff K, Baldwin RM, Zoghbi S, Zea-Ponce Y, Charney DS, Dyck van $\mathrm{CH}$, Hoffer PB, Innis RB. Test/retest reproducibility of iodine-123-betaCIT SPECT brain measurement of dopamine transporters in Parkinson's patients. J Nucl Med 1997;38:1453-9.

123. Seibyl JP, Marek K, Sheff K, Zoghbi S, Baldwin RM, Charney DS, Dyck van CH, Innis RB. lodine-123-beta-CIT and iodine-123-FPCIT SPECT measurement of dopamine transporters in healthy subjects and Parkinson's patients. J Nucl Med 1998;39:1500-8.

124. Seibyl JP, Marek KL, Quinlan D, Sheff K, Zoghbi S, Zea-Ponce Y, Baldwin RM, Fussell B, Smith EO, Charney DS, et al. Decreased single-photon emission computed tomographic [123I]beta-CIT striatal uptake correlates with symptom severity in Parkinson's disease. Ann Neurol 1995;38:589-98.

125. Sjoholm H, Mellgren SI, Sundsfjord J. Nigro-striatal degeneration demonstrated in parkinsonian patients with iodine-123-beta-CIT SPECT: methods of quantitation. Acta Neurol Scand 1997;96:91-6. 
126. Sohmiya M, Tanaka M, Aihara Y, Okamoto K. Structural changes in the midbrain with aging and Parkinson's disease: an MRI study. Neurobiol Aging 2004;25:449-53.

127. Sommer U, Hummel T, Cormann K, Mueller A, Frasnelli J, Kropp J, Reichmann H. Detection of presymptomatic Parkinson's disease: combining smell tests, transcranial sonography, and SPECT. Mov Disord 2004;19:1196-202.

128. Staffen W, Hondl N, Trinka E, Zenzmaier R, Ladurner G. SPET investigations in extrapyramidal diseases using specific ligands. Nucl Med Commun 1997;18:159-63.

129. Staffen W, Mair A, Unterrainer J, Trinka E, Bsteh C, Ladurner G. [123I] beta-CIT binding and SPET compared with clinical diagnosis in parkinsonism. Nucl Med Commun 2000;21:417-24.

130. Staffen W, Mair A, Unterrainer J, Trinka E, Ladurner G. Measuring the progression of idiopathic Parkinson's disease with [123I] beta-CIT SPECT. J Neural Transm 2000;107: 543-52.

131. Staley JK, Krishnan-Sarin S, Zoghbi S, Tamagnan G, Fujita M, Seibyl JP, Maciejewski PK, O'Malley S, Innis TB. Sex differences in [123I]beta-CIT SPECT measures of dopamine and serotonin transporter availability in healthy smokers and nonsmokers. Synapse 2001;41: $275-84$

132. Stockbridge HL, Lewis D, Eisenberg B, Lee M, Schacher S, Belle van G, Keifer M, Brodkin CA, Buchwald D. Brain SPECT: a controlled, blinded assessment of intra-reader and interreader agreement. Nucl Med Commun 2002;23:537-44.

133. Swanson RL, Newberg AB, Acton PD, Siderowf A, Wintering N, Alavi A, Mozley PD, Plossl K, Udeshi $M$, Hurtig $H$. Differences in [99mTc]TRODAT-1 SPECT binding to dopamine transporters in patients with multiple system atrophy and Parkinson's disease. Eur $\mathrm{J} \mathrm{Nucl}$ Med Mol Imaging 2005;32:302-7.

134. Tatsch K, Schwarz J, Mozley PD, Linke R, Pogarell O, Oertel WH, Fieber RS, Hahn K, Kung HF. Relationship between clinical features of Parkinson's disease and presynaptic dopamine transporter binding assessed with [123I]IPT and single-photon emission tomography. Eur J Nucl Med 1997;24:415-21.

135. Terashi H, Nagata K, Hirata $Y$, Hatazawa J, Utsumi U. Study on dopamine D2 binding capacity in vascular parkinsonism. Rinsho Shinkeigaku 2001;41:659-64.

136. Thobois S, Jahanshahi M, Pinto S, Frackowiak R, Limousin-Dowsey P. PET and SPECT functional imaging studies in Parkinsonian syndromes: from the lesion to its consequences. Neuroimage 2004;23:1-16.

137. Tissingh G, Bergmans P, Booij J, Winogrodzka A, Stoof JC, Wolters EC, Royen van EA. [123I]beta-CIT single-photon emission tomography in Parkinson's disease reveals a smaller decline in dopamine transporters with age than in controls. Eur J Nucl Med 1997;24:1171-4.

138. Tissingh G, Bergmans P, Booij J, Winogrodzka A, Royen van EA, Stoof JC, Wolters EC. Drug-naive patients with Parkinson's disease in Hoehn and Yahr stages I and II show a bilateral decrease in striatal dopamine transporters as revealed by [123I]beta-CIT SPECT. J Neurol 1998;245:14-20.

139. Tissingh G, Booij J, Bergmans P, Winogrodzka A, Janssen AG, Royen van EA, Stoof JC, Wolters EC. lodine-123-N-omega-fluoropropyl-2beta-carbomethoxy-3beta-(4-iod ophenyl) tropane SPECT in healthy controls and early-stage, drug-naive Parkinson's disease. J Nucl Med 1998;39:1143-8.

140. Torizuka K, Mizuno Y, Kubo A, Konishi J, Yonekura Y, Hatazawa J, Momose T, Murata M, Amano T, Fukuyama H, Kuwabara Y. Phase 2 clinical study of 123I-IBF, a dopamine D2 receptor imaging agent, to evaluate clinical efficacy and safety in Parkinson's disease and Parkinson syndromes]. Kaku Igaku 1999;36:845-64.

141. Tranquart F, Le Bras FH, Toffol de B, Autret A, Guilloteau D, Baulieu JL. Progressive supranuclear paralysis. Quantification of dopamine D2 receptors using radionuclide tomography. Presse Med 1994;23:1299-300.

142. Tsuchida T, Ballinger JR, Vines D, Kim YJ, Utsunomiya K, Lang AE, Ichise M. Reproducibility of dopamine transporter density measured with 123I-FPCIT SPECT in normal control and Parkinson's disease patients. Ann Nucl Med 2004;18:609-16.

143. Tzen KY, CS Lu CS, Yen TC, Wey SP, Ting G. Differential diagnosis of Parkinson's disease and vascular parkinsonism by (99m)Tc-TRODAT-1. J Nucl Med 2001;42:408-13. 
144. Vaamonde J, Ibanez R, Garcia AM, Poblete V. Study of the pre and post-synaptic dopaminergic system by DaTSCAN/IBZM SPECT in the differential diagnosis of parkinsonism in 75 patients. Neurologia 2004;19:292-300.

145. Dyck van $\mathrm{CH}$, Seibyl JP, Malison RT, Laruelle M, Zoghbi SS, Baldwin RM, Innis RB. Agerelated decline in dopamine transporters: analysis of striatal subregions, nonlinear effects, and hemispheric asymmetries. Am J Geriatr Psychiatry 2002;10:36-43.

146. Laere van K, Santens P, Bosman T, Reuck de J, Mortelmans L, Dierckx R. Statistical parametric mapping of $(99 \mathrm{~m}) \mathrm{TC}-\mathrm{ECD}$ SPECT in idiopathic Parkinson's disease and multiple system atrophy with predominant parkinsonian features: correlation with clinical parameters. J Nucl Med 2004;45:933-42.

147. Varrone A, Marek KL, Jennings D, Innis RB, Seibyl JP. [(123)I]beta-CIT SPECT imaging demonstrates reduced density of striatal dopamine transporters in Parkinson's disease and multiple system atrophy. Mov Disord 2001;16:1023-32.

148. Verhoeff NP, Kapucu O, Sokole-Busemann E, Royen van EA, Janssen AG. Estimation of dopamine D2 receptor binding potential in the striatum with iodine-123-IBZM SPECT: technical and interobserver variability. J Nucl Med 1993;34:2076-84.

149. Vermeulen, Wolters EC, Tissingh G, J Booij J, Janssen AG, Habraken J, Sokole-Busemann E, Stoof JC, Royen van EA: Evaluation of [123I] beta-CIT binding with SPECT in controls, early and late Parkinson's disease. Nucl Med Biol 1995;22:985-91.

150. Weng YH, Yen TC, Chen MC, Kao PF, Tzen KY, Chen RS, Wey SP, Ting G, Lu CS. Sensitivity and specificity of 99mTc-TRODAT-1 SPECT imaging in differentiating patients with idiopathic Parkinson's disease from healthy subjects. J Nucl Med 2004;45:393-401.

151. Wenning GK, Donnemiller E, Granata R, Riccabona G, Poewe W. 123I-beta-CIT and 123IIBZM-SPECT scanning in levodopa-naive Parkinson's disease. Mov Disord 1998;13:438-45.

152. Winogrodzka A, Bergmans P, Booij J, Royen van EA, Janssen AG, Wolters EC. [123I]FPCIT SPECT is a useful method to monitor the rate of dopaminergic degeneration in earlystage Parkinson's disease. J Neural Transm 2001;108:1011-9.

153. Winogrodzka A, Bergmans P, Booij J, Royen van EA, Stoof JC, Wolters EC. [(123)!]beta-CIT SPECT is a useful method for monitoring dopaminergic degeneration in early stage Parkinson's disease. J Neurol Neurosurg Psychiatry 2003;74:294-8.

\section{Included trials ${ }^{[1-32]}$}

1. Asenbaum S, Pirker W, Angelberger P, Bencsits G, Pruckmayer M, Brucke T. [123I]beta-CIT and SPECT in essential tremor and Parkinson's disease. J Neural Transm 1998;105:1213-28.

2. Benamer TS, Patterson J, Grosset DG, Booij J, de Bruin K, van Royen E, Speelman JD, Horstink MH, Sips HJ, Dierckx RA, Versijpt J, Decoo D, Van Der Linden C, Hadley DM, Doder M, Lees AJ, Costa DC, Gacinovic S, Oertel WH, Pogarell O, Hoeffken H, Joseph K, Tatsch K, Schwarz J, Ries V. Accurate differentiation of parkinsonism and essential tremor using visual assessment of [123I]-FP-CIT SPECT imaging: the [123I]-FP-CIT study group. Mov Disord 2000;15:503-10.

3. Booij J, Speelman JD, Horstink MW, Wolters EC. The clinical benefit of imaging striatal dopamine transporters with [123I]FP-CIT SPET in differentiating patients with presynaptic parkinsonism from those with other forms of parkinsonism. Eur J Nucl Med 2001;28:266-72.

4. Buck A, Westera G, Sutter M, Albani C, Kung HF, vonSchulthess GK. lodine-123-IBF SPECT evaluation of extrapyramidal diseases. J Nucl Med 1995;36:1196-200.

5. Eerola J, Tienari PJ, Kaakkola S, Nikkinen P, Launes J. How useful is [123l]beta-CIT SPECT in clinical practice? J Neurol Neurosurg Psychiatry 2005;76:1211-6.

6. Gerschlager W, Bencsits G, Pirker W, Bloem BR, Asenbaum S, Prayer D, Zijlmans JC, Hoffmann M, Brucke T. [123I]beta-CIT SPECT distinguishes vascular parkinsonism from Parkinson's disease. Mov Disord 2002;17:518-23. 
7. Haapaniemi TH, Ahonen A, Torniainen P, Sotaniemi KA, Myllyla VV. [123l]beta-CIT SPECT demonstrates decreased brain dopamine and serotonin transporter levels in untreated parkinsonian patients. Mov Disord 2001;16:124-30.

8. Huang WS, Lin SZ, Lin JC, Wey SP, Ting G, Liu RS. Evaluation of early-stage Parkinson's disease with 99mTc-TRODAT-1 imaging. J Nucl Med 2001;42:1303-8.

9. Kim YJ, Ichise M, Ballinger JR, Vines D, Erami SS, Tatschida T, Lang AE. Combination of dopamine transporter and D2 receptor SPECT in the diagnostic evaluation of PD, MSA, and PSP. Mov Disord 2002;17:303-12.

10. Lee MS, Kim YD, Im JH, Kim HJ, Rinne JO, Bhatia KP. 123I-IPT brain SPECT study in essential tremor and Parkinson's disease. Neurology 1999;52:1422-6.

11. Lokkegaard A, Werdelin LM, Friberg L. Clinical impact of diagnostic SPET investigations with a dopamine re-uptake ligand. Eur J Nucl Med Mol Imaging 2002;29:1623-9.

12. Lu CS, Weng YH, Chen MC, Chen RS, Tzen KY, Wey SP, G Ting G, Chang HC, Yen TC. 99mTc-TRODAT-1 imaging of multiple system atrophy. J Nucl Med 2004;45:49-55.

13. Messa C, Volonté MA, Fazio F, Zito F, Carpinelli A, d'Amico A, Rizzo G, Moresco RM, Paulesu E, Franceschi M, Lucignani G Differential distribution of striatal [123l]beta-CIT in Parkinson's disease and progressive supranuclear palsy, evaluated with single-photon emission tomography. Eur J Nucl Med 1998;25:1270-6.

14. Muller T, Farahati J, Kuhn W, Eising EG, Przuntek H, Reiners C, Coenen HH. [123l]beta-CIT SPECT visualizes dopamine transporter loss in de novo parkinsonian patients. Eur Neurol 1998;39:44-8.

15. Oertel WH, Schwarz J, Tatsch K, Arnold G, Gasser T, Kirsch CM. IBZM-SPECT as predictor for dopamimetic responsiveness of patients with de novo parkinsonian syndrome. Adv Neurol 1993;60:519-24.

16. Oyanagi C, Katsumi Y, Hanakawa T, Hayashi T, Thuy DD, Hashikawa K, Nagahama Y, Fukuyama H, Shibasaki H. Comparison of striatal dopamine D2 receptors in Parkinson's disease and progressive supranuclear palsy patients using [123l] iodobenzofuran singlephoton emission computed tomography. J Neuroimaging 2002;12:316-24.

17. W Pirker, S Asenbaum, G Bencsits, D Prayer, W Gerschlager, L Deecke, T Brucke. [123I]beta-CIT SPECT in multiple system atrophy, progressive supranuclear palsy, and corticobasal degeneration. Mov Disord 2000;15:1158-67.

18. Pirker W, Asenbaum S, Wenger S, Kornhuber J, Angelberger P, Deecke L, Podreka I, Brucke T. lodine-123-epidepride-SPECT: studies in Parkinson's disease, multiple system atrophy and Huntington's disease. J Nucl Med 1997;38:1711-7.

19. Pirker W, Djamshidian S, Asenbaum S, Gerschlager W, Tribl G, Hoffmann M, Brucke T. Progression of dopaminergic degeneration in Parkinson's disease and atypical parkinsonism: a longitudinal beta-CIT SPECT study. Mov Disord 2002;17:45-53.

20. Plotkin M, Amthauer H, Klaffke S, Kuhn A, Ludemann L, Arnold G, Wernecke KD, Kupsch A, Felix R, Venz S. Combined (123)I-FP-CIT and (123)I-IBZM SPECT for the diagnosis of parkinsonian syndromes: study on 72 patients. J Neural Transm 2005;112:677-92.

21. Schelosky L, Hierholzer J, Wissel J, Cordes M, Poewe W. Correlation of clinical response in apomorphine test with D2-receptor status as demonstrated by 123I IBZM-SPECT. Mov Disord 1993;8:453-8.

22. Schwarz J, Antonini A, Tatsch K, Kirsch CM, Oertel WH, Leenders KL. Comparison of 123IIBZM SPECT and 11C-raclopride PET findings in patients with parkinsonism. Nucl Med Commun 1994;15:806-13.

23. Schwarz J, Linke R, Kerner M, Mozley PD, Trenkwalder C, Gasser T, Tatsch K. Striatal dopamine transporter binding assessed by [I-123]IPT and single photon emission computed tomography in patients with early Parkinson's disease: implications for a preclinical diagnosis. Arch Neurol 2000, 57:205-8.

24. Schwarz J, Tatsch K, Arnold G, Ott M, Trenkwalder C, Kirsch CM, Oertel WH. 123Iiodobenzamide-SPECT in 83 patients with de novo parkinsonism. Neurology 1993;43: S17-20. 
25. Schwarz J, Tatsch K, Gasser T, Arnold G, Oertel WH. [123]IBZM binding predicts dopaminergic responsiveness in patients with parkinsonism and previous dopaminomimetic therapy. Mov Disord 1997;12:898-902.

26. Schwarz J, Tatsch K, Gasser T, Arnold G, Pogarell O, Kunig G, Oertel WH. 123I-IBZM binding compared with long-term clinical follow up in patients with de novo parkinsonism. Mov Disord 1998;13:16-9.

27. Seppi K, Schocke MF, Donnemiller E, Esterhammer R, Kremser C, Scherfler C, Diem A, Jaschke W, Wenning GK, Poewe W. Comparison of diffusion-weighted imaging and [123I]IBZM-SPECT for the differentiation of patients with the Parkinson variant of multiple system atrophy from those with Parkinson's disease. Mov Disord 2004;19:1438-45.

28. Stoffers D, Booij J, Bosscher L, Winogrodzka A, Wolters EC, Berendse HW. Early-stage [(123)!]beta-CIT SPECT and long-term clinical follow-up in patients with an initial diagnosis of Parkinson's disease. Eur J Nucl Med Mol Imaging 2005;32(6):689-95.

29. Tatsch K, Schwarz J, Oertel WH, Kirsch CM: SPECT imaging of dopamine D2 receptors with 123I-IBZM: initial experience in controls and patients with Parkinson's syndrome and Wilson's disease. Nucl Med Commun 1991;12:699-707.

30. Laere $v$ K, Ceuninck de L, Dom R, Eynden vd J, Vanbilloen $\mathrm{H}$, Cleynhens J, Dupont $\mathrm{P}$, Bormans G, Verbruggen A, Mortelmans L. Dopamine transporter SPECT using fast kinetic ligands: 123I-FP-beta-CIT versus 99mTc-TRODAT-1. Eur J Nucl Med Mol Imaging 2004; 31:1119-27.

31. Royen v E, Verhoeff NF, Speelman JD, Wolters EC, Kuiper MA, Janssen AG. Multiple system atrophy and progressive supranuclear palsy. Diminished striatal D2 dopamine receptor activity demonstrated by 123I-IBZM single photon emission computed tomography. Arch Neurol 1993;50:513-6.

32. Vlaar AMM, Kessels AGH, Nijs de T, Kessels AGH, Vreeling FW, Winogrodzka A, Mess WH, Tromp SC, Kroonenburgh v MJPG, Weber WEJ. Diagnostic value of FP-CIT and IBZM SPECT scans in 28 patients with parkinsonian syndromes. European Neurology 2008;59:258-66. 
${ }_{198} 6$ 
Appendix E

Additional file chapter 7

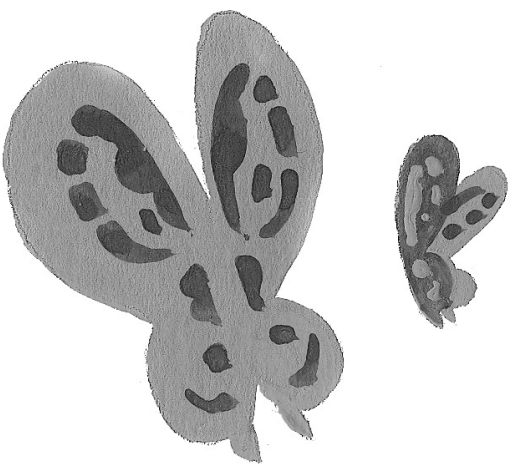




\section{STANDARD FORM PROSPECTIVE TRIAL}

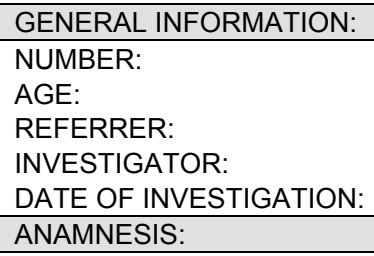




\section{Samenvatting}

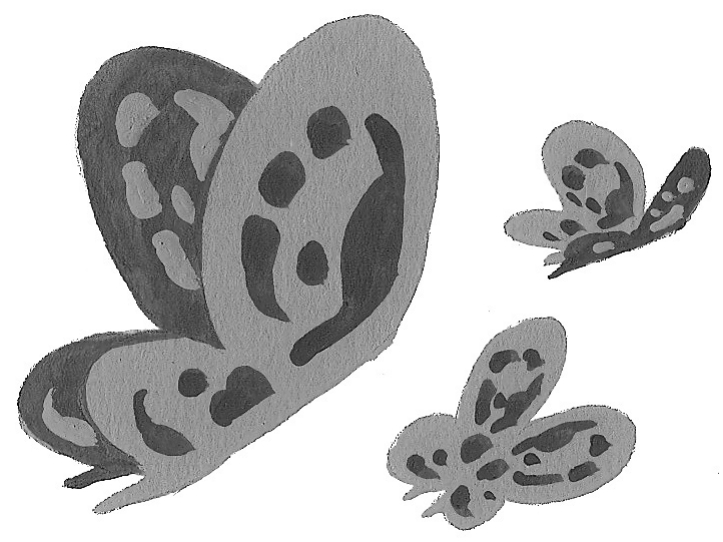




\section{Samenvatting}

De ziekte van Parkinson (ZvP) is na de ziekte van Alzheimer de meest voorkomende neurodegeneratieve aandoening. Aangezien er geen betrouwbare test bestaat, die de aanwezigheid van de ziekte bevestigt, is de diagnose gebaseerd op klinische criteria. Indien de hoofdsymptomen, zoals bradykinesie, rigiditeit en tremor aanwezig zijn, is de diagnose vaak eenvoudig te stellen. Echter, in het beginstadium, wanneer de symptomen nog mild en aspecifiek zijn, is het niet altijd mogelijk onderscheid te maken tussen de ZvP en andere parkinsonistische syndromen. Aandoeningen, die in een vroeg stadium op de ZvP kunnen lijken, zijn: atypische parkinson syndromen (APS, bijv. multiple systeem atrofie [MSA], progressieve supranucleaire paralyse [PSP]) of secundair parkinsonisme (vasculair parkinsonisme [VP], medicamenteus geïnduceerd parkinsonisme [DIP]) en essentiële tremor. Met behulp van de klinische criteria kan de ZvP alleen als "waarschijnlijke" diagnose gesteld worden. Een "zekere" ZvP vereist een neuropathologische diagnose na obductie. Neuropathologische studies tonen aan, dat zelfs in het eindstadium van de ziekte de diagnostische betrouwbaarheid voor de ZvP op basis van klinische symptomen varieert tussen de $75-90 \% .^{1-5}$

Het stellen van een vroege en juiste diagnose is van belang, omdat de prognose en behandeling verschillen tussen de verschillende parkinsonistische aandoeningen. Het ontwikkelen van aanvullende diagnostische technieken, die de diagnose in een vroeger stadium en betrouwbaarder kunnen stellen, is dan ook een belangrijk onderzoeksdoel. Voorbeelden van technieken, die veel gebruikt worden, maar niet zijn opgenomen in de reguliere diagnostiek, zijn: single photon emmission computer tomography (SPECT), positron emission tomography (PET), magnetic resonance imaging (MRI), transcraniële echografie (TCD), reuktesten, neuropsychologische testen en genetisch onderzoek.

De SPECT scan is momenteel de meest toegepaste aanvullende onderzoekstechniek bij patiënten, bij wie onduidelijkheid bestaat over de aard van hun parkinsonistische aandoening. De SPECT scan kan worden gebruikt om de integriteit van het dopaminerge systeem te visualiseren. Verscheidene radioactieve isotopen zijn verkrijgbaar om verschillende delen van het dopaminerge systeem af te beelden. Uit eerder onderzoek blijkt dat een afwijkende SPECT scan met isotopen, die binden aan de presynaptische dopamine transporters, een goede voorspeller is voor een onderliggend degeneratief lijden, zoals bijvoorbeeld de ZvP en APS. De meest gebruikte presynaptische isotopen zijn ${ }^{123}$ I-ioflupane and 99mCT-TRODAT-1. 
Een SPECT scan met radioactieve isotopen, die binden aan de postsynaptische dopamine receptors, geeft informatie over het postsynaptische deel van het nigro-striatale circuit. Postsynaptische SPECT scans worden met name gebruikt om te differentiëren tussen de ZvP en APS. De meest gebruikte postsynaptische isotoop is ${ }^{123}$ I-iodobenzamide. Ondanks veel onderzoek is er nog steeds discussie over de precieze diagnostische bijdrage van presynaptische en postsynaptische SPECT scans bij de differentiatie tussen verschillende parkinsonistische syndromen.

Een relatief nieuwe onderzoekstechniek bij patiënten met een parkinsonistische aandoeningen is $\operatorname{TCD}^{6}$ Deze techniek verschilt van de SPECT in die zin, dat TCD structurele afwijkingen visualiseert en SPECT veranderingen in de functie van een bepaald systeem. TCD kan een verhoogde echo-intensiteit ter plaatse van de substantia nigra (SN) laten zien. Tot nu toe wordt deze techniek voor deze indicatie alleen gebruikt in het kader van onderzoek, maar het feit, dat het een elegante, niet-invasieve, relatief goedkope en snelle onderzoeksmethode is, maakt TCD tot een veelbelovende techniek. Voordat TCD in de dagelijkse klinische praktijk toegepast kan worden, moet de betrouwbaarheid en toegevoegde diagnostische waarde ten opzichte van de reeds bestaande technieken goed onderzocht zijn.

In dit proefschrift hebben we allereerst de diagnostische waarde van SPECT scans bij patiënten met een parkinsonistisch beeld onder de loep genomen. Verder hebben we de diagnostische waarde van TCD in de differentiaal diagnose van de ZvP onderzocht. Tenslotte hebben we de combinatie van beide technieken in de diagnostiek van patiënten met een nog niet gediagnosticeerd parkinsonistisch beeld onderzocht.

In Hoofdstuk 2 wordt een meta-analyse gepresenteerd van de klinische studies, waarin de betrouwbaarheid van de presynaptische en postsynaptische SPECT scans in het differentiëren van de verschillende parkinsonistische aandoeningen onderzocht werd. Relevante studies zijn gezocht in Medline, EMBASE en de Cochrane databases, waarbij de referentielijsten van de geschikte artikelen handmatig zijn nagezocht. De zoektocht leverde 185 artikelen op, waarvan er 32 geschikt waren voor de analyse. Uit deze studies herberekenden we de diagnostische odds ratio (OR) met een 95\% betrouwbaarheids interval. Voor de presynaptische SPECT was de diagnostische waarde om patiënten met de ZvP in een vroeg stadium te differentiëren van gezonde controles hoog (OR 60 [13-277], evenals voor het onderscheid tussen patiënten met de ZvP en een essentiële tremor (210 [78-563] en voor het onderscheid tussen patiënten met de ZvP en VP (OR 105 [32-382]. De betrouwbaarheid om patiënten met de ZvP en APS van elkaar te 
onderscheiden was laag, zowel voor de presynaptische scan (OR 2 [1-4]) als voor de postsynaptische SPECT scan (OR 19 [10-36]).

Uit deze meta-analyse kan geconcludeerd worden, dat de SPECT scan met presynaptische radioactieve isotopen nauwkeurig is in het differentiëren tussen patiënten met de ZvP in een vroeg stadium en gezonde controles, danwel patiënten met een ET of VP. Het blijkt niet mogelijk betrouwbaar onderscheid te maken tussen patiënten met de ZvP en patiënten met APS. Dit geldt voor zowel de presynaptische als de postsynaptische SPECT .

Tot op heden werden in de meeste studies alleen reeds gediagnosticeerde patiënten geïncludeerd. Deze groep patiënten is echter geen goede representatie van de klinische praktijk, waarbij men een patiënt met een parkinsonistisch beeld vaak in een vroeg stadium probeert te diagnosticeren.

In Hoofdstuk 3 beschrijven we de diagnostische waarde van de presynaptische en postsynaptische SPECT scan in ons eigen ziekenhuis. Deze retrospectieve studie bevatte gegevens van 248 patiënten, die in de periode 2000-2006 een SPECT scan ondergingen vanwege onduidelijkheid over de origine van hun parkinsonisme. Als gouden standaard werd de klinische diagnose na follow-up gebruikt. De diagnostische OR voor de presynaptische SPECT scans was relatief hoog voor de differentiatie tussen patiënten met de ZvP en patiënten met een ET (OR 82 [11-674]). Ook het onderscheiden van patiënten met de ZvP en patiënten met VP (OR 61 [8-490]) of patiënten met DIP (OR 33 [2-697]) was goed mogelijk middels een presynaptische SPECT scan. Daarentegen was de nauwkeurigheid om patiënten met de ZvP te differentiëren van patiënten met APS relatief laag. Dit gold zowel voor presynaptische (OR 1 [04]) als postsynaptische (OR 7 [2-17] SPECT scans.

De conclusies van dit hoofdstuk komen overeen met de eerder genoemde resultaten van de meta-analyse in hoofdstuk 2.

In Hoofdstuk 4 beschrijven we onze literatuurstudie over het gebruik van TCD bij parkinsonistische aandoeningen. Deze patiëntvriendelijke techniek is beschikbaar in veel klinieken en kan tegenwoordig zelfs aan het bed van de patiënt uitgevoerd worden. Door de transducer op het temporale botvenster te plaatsen kunnen meerdere hersenstructuren, waaronder de substantia nigra (SN), gevisualiseerd worden. Voor een gedetailleerde beschrijving van de TCD techniek zie appendix $\mathrm{C}$.

Normaal gesproken is het mesencephalon een vrij homogene echo-arme vlindervormige structuur. Bij de meeste patiënten met de ZvP is de SN duidelijk zichtbaar als een grote echo-intense zone. De verhoogde echo-intensiteit berust waarschijnlijk op een toegenomen ijzergehalte. Ook andere hersenstructuren zoals de nucleus lentiformis (NL) en Raphe nuclei (RN) zijn af te beelden met behulp van TCD. De NL is bij gezonde personen niet te 
onderscheiden. Het vinden van een NL en dus een verhoogde echo-intensiteit van de kern is mogelijk van belang bij het differentiëren tussen patiënten met de ZvP en patiënten met APS. ${ }^{7,8}$

Een afname van de echo-intensiteit van de RN wordt geassocieerd met een depressie bij zowel patiënten met als zonder de ZvP.,

Omdat er inmiddels vele studies zijn verschenen over de diagnostische waarde van TCD bij parkinsonistische aandoeningen, hebben wij een systematisch literatuuronderzoek verricht. In totaal waren 35 studies volgens onze criteria geschikt om op te nemen in het onderzoek.

De resultaten van dit onderzoek kunnen als volgt worden samengevat: van de 1534 patiënten met de ZvP hadden 200 patiënten (13\%) een inconclusieve SNTCD, omdat men moeite had de SN-TCD te beoordelen, vanwege een ontoegankelijk botvenster of een atypische vorm van de hyperecho-intensiteit. Een verhoogde echo-intensiteit ter plaatse van de SN werd gevonden bij 1167 (87\%) van de 1334 patiënten met de ZvP. Diezelfde verhoogde echo-intensiteit werd ook aangetoond bij $12 \%$ van de gezonde controles, $12 \%$ van de patiënten met een $\mathrm{ET}, 20 \%$ van de patiënten met $\mathrm{VP}, 30 \%$ van de patiënten met een APS, maar bij geen van de patiënten met DIP.

Daarentegen hadden $79 \%$ van de patiënten met APS, slechts $23 \%$ van de patiënten met de ZvP en $6 \%$ van de gezonde controles een verhoogde echointensiteit ter plaatse van de NL. Een verlaagde echo-intensiteit van de RN was aanwezig bij $46 \%$ van de patiënten met de ZvP en een depressie en bij $16 \%$ van de patiënten met de ZvP zonder depressie.

De conclusie van dit literatuuroverzicht is, dat de SN-TCD nauwkeurig kan differentiëren tussen patiënten met de ZvP en patiënten met ET, DIP of VP en gezonde controles, maar niet tussen patiënten met de ZvP en APS.

Ook de NL-TCD alleen kan in een individuele patiënt niet differentiëren tussen de ZvP en APS. De diagnostische waarde van de RN-TCD om een depressie in patiënten met de ZvP aan te tonen is laag. Helaas was de SN-TCD in meer dan $10 \%$ van de onderzochte patiënten inconclusief. Verder heeft bij benadering 1 op de 10 ogenschijnlijk gezonde individuen een verhoogde echointensiteit ter plaatse van de SN. Momenteel lopen er vervolgstudies met een langdurige follow-up om uit te zoeken of deze bevinding een teken is voor een toegenomen vatbaarheid voor de ZvP.

Ondanks een hoge mate van patiëntvriendelijkheid en - voor zover op basis van de bestaande literatuur te beoordelen - betrouwbaarheid wordt TCD momenteel klinisch niet op brede schaal toegepast. Eén van de mogelijke verklaringen is, dat er meerdere methodologische onduidelijkheden zijn: het ontbreken van een gestandaardiseerde TCD techniek, scoringssysteem en 
normaalwaardes, en het hoge percentage van personen met een inconclusieve TCD.

Tot op heden is de inter-observer en intra-observer betrouwbaarheid van de SN-TCD alleen bestudeerd door Duitse en Taiwanese onderzoeksgroepen. ${ }^{10-14}$ Zij rapporteren hiervoor uitstekende waardes in hun diagnostische studies. Helaas is niet gepubliceerd, welke methoden zijn gebruikt voor het bepalen van deze inter-observer subanalyses. Voordat de TCD techniek geïmplementeerd kan worden in de klinische praktijk, moeten de methologische aspecten uitgebreider bestudeerd worden.

In Hoofdstuk 5 wordt een studie beschreven, waarin de inter-observer en intertransducer betrouwbaarheid van TCD wordt onderzocht. De echo-intensiteit van de SN is zowel kwalitatief als kwantitatief beoordeeld, de echo-intensiteit van de RN enkel kwalitatief. Elke patiënt werd viermaal onderzocht door twee onafhankelijke ervaren onderzoekers, die twee verschillende echosystemen gebruikten. In de "off-line" beoordeling scoorde een derde onafhankelijke ervaren echografist de opgeslagen beelden.

De resultaten waren als volgt: wij vonden een matige overeenstemming voor de kwalitatieve SN-TCD beoordeling; dit geldt zowel voor de "on-line" interobserver, de "on-line" intra-observer en de "off-line" inter-observer overeenstemming. Zo werden kappa-waardes van 0.23-0.39 voor de "on-line" inter-observer, 0.53-0.67 voor de "on-line" intra-observer en 0.32-0.67 voor de "off-line" inter-observer overeenstemming berekend. De resultaten voor de kwantitatieve SN beoordeling waren vergelijkbaar en niet wezenlijk verschillend van de kwalitatieve SN beoordeling. De kappa-waardes voor de RN-TCD waren laag.

De conclusie van deze studie is, dat de betrouwbaarheid van zowel de "on-line" als "off-line" inter-observer overeenstemming van de SN-TCD evaluatie matig is en die van de RN-TCD relatief laag. De intra-observer overeenstemming van zowel de SN-TCD als de RN-TCD was matig. De kwantitatieve beoordeling van de SN-TCD was even nauwkeurig als de kwalitatieve. Verder stemmen de resultaten, die "off-line" verkregen waren overeen met die van de "on-line" beoordelingen.

Andere onderzoeksgroepen rapporteerden met kappa-waardes van $0.80-0.98$ een aanzienlijk grotere inter-observer overeenstemming van de kwantitatieve SN-TCD beoordeling. ${ }^{10-14}$ Deze onderzoekers includeerden echter patiënten met een reeds bekende diagnose. Daarentegen kozen wij voor een gemengde populatie, om de a priori kans op een positieve bevinding te verkleinen. Ook waren onze echografisten geheel geblindeerd voor de klinische diagnoses. Tenslotte hadden onze echografisten hun training in een ander ziekenhuis 
genoten en nooit eerder samengewerkt. De relatief matige overeenstemming in onze studie kan deels verklaard worden door het ontbreken van criteria voor de evaluatie voor de echo-intensiteit van de SN en de RN. Mogelijk kan een gestandaardiseerde kwantitatieve beoordeling van de echo-intensiteit van de $\mathrm{SN}$ en het omliggende weefsel bijdragen aan uniformiteit van de resultaten. Verder zijn standaard instellingen voor het echosysteem vereist.

Net als bij de diagnostische SPECT studies zijn de meeste studies over TCD gedaan bij patiënten met een reeds bekende diagnose. Daarom hebben wij in Hoofdstuk 6 verder onderzoek verricht naar de betrouwbaarheid van TCD bij 82 patiënten met nog onduidelijkheid over de oorzaak van hun parkinsonisme. De betrouwbaarheid van de SN-TCD hebben we vergeleken met die van presynaptische en postsynaptische SPECT scans. De klinische diagnose na follow-up diende daarbij als gouden standaard; deze diagnose werd gesteld door een onafhankelijke neuroloog gespecialiseerd in bewegingsstoornissen.

Allereerst onderzochten we de diagnostische betrouwbaarheid van TCD om patiënten met de ZvP te onderscheiden van patiënten zonder nigrostriatale degeneratie (oa. ET, VP, DIP). SN-TCD bereikte hiervoor een sensitiviteit van $50 \%$, een specificiteit van $82 \%$, een positief voorspellende waarde (PPV) van $89 \%$ en een negatief voorspellende waarde (NPV) van $35 \%$. Voor de presynaptische SPECT scan daarentegen vonden we waardes van respectievelijk $97 \%, 100 \%, 100 \%$ en $92 \%$.

Vervolgens onderzochten we de betrouwbaarheid van TCD om patiënten met de ZvP te onderscheiden van patiënten met APS. SN-TCD bereikte hiervoor een sensitiviteit van $50 \%$, een specificiteit van $43 \%$, een PPV van $86 \%$ en een NPV van $10 \%$ en voor de postsynaptische SPECT scan waren deze waarden respectievelijk $75 \%, 81 \%, 43 \%$ en $94 \%$. De PPV van een afwijkende SN-TCD voor een afwijkende presynaptische SPECT was $88 \%$.

Wij concludeerden, dat de voorspellende waarde van de SPECT uitslag voor de klinische diagnose evident hoger is dan die van de SN-TCD. Omdat een afwijkende SN-TCD een hoge voorspellende waarde heeft voor een afwijkende presynaptische SPECT scan, kan de SN-TCD gebruikt worden als instrument voor screening, voordat een presynaptische SPECT scan wordt aangevraagd.

In Hoofdstuk 7 wordt het onderzoeksprotocol beschreven van de prospectieve trial, die in augustus 2006 van start is gegaan. In deze prospectieve trial worden 250 patiënten geïncludeerd, die vanwege onduidelijkheid over de origine van hun parkinsonistisch beeld verwezen zijn naar de polikliniek neurologie van de twee betrokken ziekenhuizen.

Bij alle patiënten werd een TCD, een presynaptische SPECT scan, cognitieve testen, motorische testen en een reuktest verricht. De gouden standaard is de klinische diagnose na een follow-up van 2 jaar. Deze diagnose wordt 
vastgesteld op basis van de consensus, die bereikt wordt tussen twee onafhankelijke, geblindeerde neurologen gespecialiseerd in bewegingsstoornissen.

Deze studie is essentieel, omdat het een prospectieve opzet heeft en plaats vindt in zowel een academische als een perifere kliniek. In augustus 2008 beëindigden we de inclusie en is een start gemaakt met de klinische herbeoordelingen. Wij verwachten, dat de resultaten van deze prospectieve studie eind 2010 bekend gemaakt kunnen worden.

\section{Conclusie}

Het diagnosticeren van de ZvP kan met name in een vroeg stadium van de ziekte vrij lastig zijn, gezien de overlap met symptomen van andere aandoeningen. Een betrouwbare diagnostische test zal daarom een positief effect hebben op de klinische zorg. Tot op heden bestaat de perfecte test voor de ZvP nog niet.

Wij zijn van mening, dat enkel de presynaptische SPECT scan voldoende onderzocht en betrouwbaar is om als regulier diagnostisch onderzoek gebruikt te worden. Met de presynaptische SPECT scan is betrouwbaar onderscheid mogelijk tussen patiënten met de ZvP enerzijds en gezonde controles, patiënten met VP of een ET anderzijds. Het differentiëren tussen patiënten met de ZvP en APS is noch met een presynaptische noch met een postsynaptische SPECT scan mogelijk.

SN-TCD is mogelijk een goed alternatief om de ZvP te diagnosticeren, aangezien een afwijkende SN-TCD een marker is voor de diagnose ZvP. Hoewel in onze onderzoeken de SN-TCD minder betrouwbaar is dan de SPECT scan, is het gezien de hoge positief voorspellende waarde zinvol de mogelijkheden van de SN-TCD verder te onderzoeken. Daarnaast biedt de SN-TCD ook voordelen boven de SPECT ten aanzien van kosten en belastbaarheid voor de patiënt. Evenals de SPECT scan lijkt TCD vooralsnog niet geschikt om patiënten met de ZvP te onderscheiden van die met APS.

Hoewel de SN-TCD en SPECT zeker kunnen bijdragen in het uitwerken van de differentiaal diagnose, kunnen deze onderzoeken nooit een nauwkeurige anamnese en neurologisch onderzoek vervangen, aangezien fout positieve bevindingen altijd kunnen voorkomen. De diagnose ZvP blijt tot op heden primair gebaseerd op het aantonen van enkele karakteristieke neurologische kenmerken.

Naar onze mening kan SN-TCD in de toekomst op twee manieren een rol spelen als screeningsinstrument. Ten eerste kan in de dagelijkse klinische praktijk bij patiënten met onduidelijkheid over de diagnose allereerst een TCD verricht worden. Afhankelijk van de TCD bevindingen kan daarna alsnog een 
presynaptische SPECT scan worden uitgevoerd. In het geval van een afwijkende SN-TCD kan een presynaptische SPECT scan als overbodig gezien worden. Dit kan een kostenbesparing van de gezondheidszorg opleveren. Ten tweede is de SN-TCD een ideale techniek voor het screenen van grote groepen mensen met een verhoogd risico op de ZvP. Dit wordt vooral belangrijk op het moment, dat er preventieve of curatieve medicijnen beschikbaar komen voor de ZvP. 


\section{References}

1. Rajput AH, Rozdilsky B, Rajput A: Accuracy of clinical diagnosis in parkinsonism--a prospective study. Can J Neurol Sci 1991;18:275-8.

2. Litvan I, Agid Y, Jankovic J, Goetz C, Brandel JP, Lai EC, Wenning G, D'Olhaberriague L, Verny M, Chaudhuri KR, et al: Accuracy of clinical criteria for the diagnosis of progressive supranuclear palsy (Steele-Richardson-Olszewski syndrome). Neurology 1996;46:922-30.

3. Verny M, Jellinger KA, Hauw JJ, Bancher C, Litvan I, Agid Y: Progressive supranuclear palsy: a clinicopathological study of 21 cases. Acta Neuropathol (Berl) 1996;91:427-31.

4. Hughes AJ, Daniel SE, Ben-Shlomo Y, Lees AJ: The accuracy of diagnosis of parkinsonian syndromes in a specialist movement disorder service. Brain 2002;125:861-70.

5. Watanabe H, Saito Y, Terao S, Ando T, Kachi T, Mukai E, Aiba I, Abe Y, Tamakoshi A, Doyu $\mathrm{M}$, et al: Progression and prognosis in multiple system atrophy: an analysis of 230 Japanese patients. Brain 2002;125:1070-83.

6. Becker G, Seufert J, Bogdahn U, Reichmann H, Reiners K: Degeneration of substantia nigra in chronic Parkinson's disease visualized by transcranial color-coded real-time sonography. Neurology 1995;45:182-4.

7. Behnke S, Berg D, Naumann M, Becker G: Differentiation of Parkinson's disease and atypical parkinsonian syndromes by transcranial ultrasound. J Neurol Neurosurg Psychiatry 2005; 76:423-5.

8. Walter U, Behnke S, Eyding J, Niehaus L, Postert T, Seidel G, Berg D: Transcranial brain parenchyma sonogrpahy in movement disorders: state of the art. Ultrasound Med Biol 2007; 33:15-25.

9. Becker G, Becker T, Struck M, Lindner A, Burzer K, Retz W, Bogdahn U, Beckmann H: Reduced echogenicity of brainstem raphe specific to unipolar depression: a transcranial color-coded real-time sonography study. Biol Psychiatry 1995;38:180-4.

10. Berg D, Becker G, Zeiler B, Tucha O, Hofmann E, Preier M, Benz P, Jost W, Reiners K, Lange KW: Vulnerability of the nigrostriatal system as detected by transcranial ultrasound. Neurology 1999;53:1026-31.

11. Berg D, Siefker C, Becker G: Echogenicity of the substantia nigra in Parkinson's disease and its relation to clinical findings. J Neurol 2001;248:684-9.

12. Godau J, Schweitzer KJ, Liepelt I, Gerloff C, Berg D: Substantia nigra hypoechogenicity: definition and findings in restless legs syndrome. Mov Disord 2007;22:187-92.

13. Huang YW, Jeng JS, Tsai CF, Chen LL, Wu RM: Transcranial imaging of substantia nigra hyperechogenicity in a Taiwanese cohort of Parkinson's disease. Mov Disord 2007;22:550-5.

14. Tsai CF, Wu RM, Huang YW, Chen LL, Yip PK, Jeng JS: Transcranial color-coded sonography helps differentiation between idiopathic Parkinson's disease and vascular parkinsonism. J Neurol 2007;254:501-7. 


\section{List of publications}

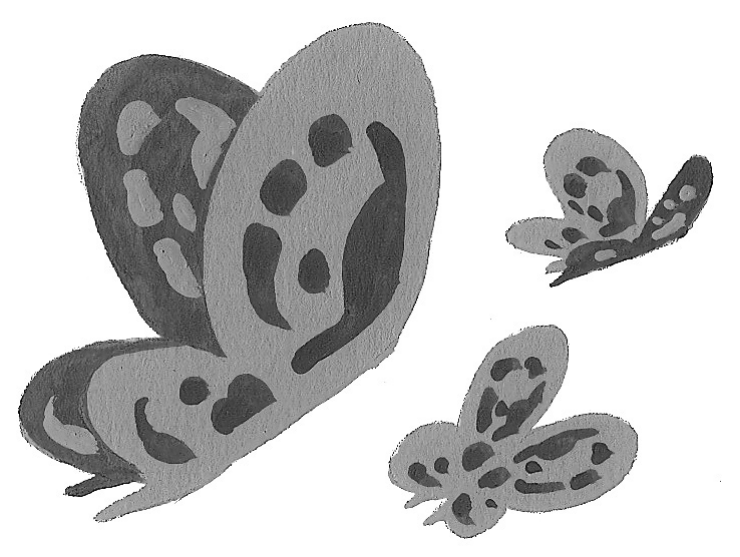




\section{List of publications}

Vlaar AMM, Wade DT. The Adult Memory and Information Processing Battery (AMIPB) test of information- processing speed: a study of its reliability and feasibility in patients with multiple sclerosis. Clinical Rehabilitation. 2003;17:386-93.

Vlaar AMM, Wade DT. Verbal fluency assessment of patients with multiple sclerosis: test-retest and inter-observer reliability. Clinical Rehabilitation. 2003;17:756-64.

Vlaar AMM, De Jong G. The clinical pharmacology of anti-platelet agents used in the secondary prevention ischemic stroke. Neurologie actueel. Jaargang $7 \mathrm{nr} 4$ maart 2004.

Vlaar AMM, Twijnstra A. Case report neuro-imaging: gliomatosis cerebri. Tijdschrift voor neurologie en neurochirurgie Jan 2005, p37.

Vlaar AMM, Transcraniële echografie in de diagnostiek van parkinsonistische syndromen. Nederlands tijdschrift voor neurologie en neurochirurgie. Vol 107, $\mathrm{Nr}$ 4, 2006

Vlaar AMM, Bouwmans AE, van Kroonenburgh MJ, Mess WH, Tromp SC, Wuisman PG, Kessels AG, Winogrodzka A, Weber WE. Protocol of a prospective study on the diagnostic value of transcranial duplex scanning in parkinsonian patients. BMC Neurology 2007;7:28.

Vlaar AMM, van Kroonenburgh MJ, Kessels AG, Weber WE. Meta-analysis of the literature on diagnostic accuracy of SPECT in parkinsonian syndromes. BMC Neurology 2007;7:27.

Vlaar AMM, de Nijs T, Kessels AG, Vreeling FW, Winogrodzka A, Mess WH, Tromp SC, van Kroonenburgh MJ, Weber WE. Diagnostic value of 123I loflupane and 123I Idobenzamide SPECT scans in 248 patients with Parkinsonian syndromes. European Neurology 2008:59:258-66.

Vlaar AMM, de Nijs T, van Kroonenburgh MJ, Mess WH, Winogrodzka A, Tromp SC, Weber WE. The predictive value of transcranial duplex sonography for the clinical diagnosis in undiagnosed parkinsonian syndromes: comparison with SPECT scans. BMC Neurology 2008;8:42.

Weber WE, Vlaar AMM. Role of DAT-SPECT in diagnostic work-up of parkinsonism. Movement disorders 2008;23:774.

Vlaar AMM, Bouwmans A, Mess WH, Tromp SC, Weber WE. Transcranial duplex in the differential diagnosis of parkinsonian syndromes: a systematic review. Journal of Neurology 2009; 256:530-8. 


\section{Dankwoord}

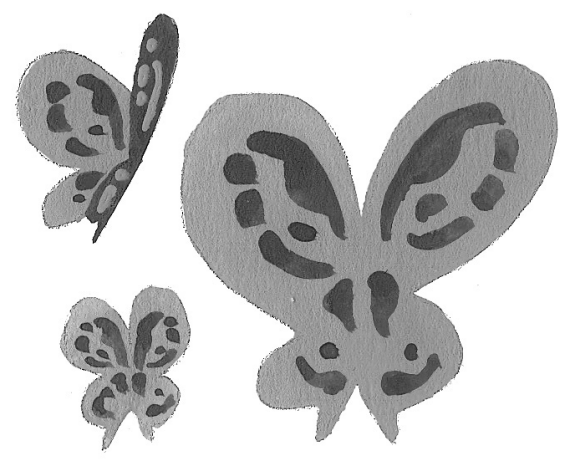




\section{Dankwoord}

De afgelopen jaren heb ik met veel plezier gewerkt aan dit proefschrift. Dit onderzoek had niet kunnen slagen zonder de inzet en inbreng van anderen.

Mijn promotie team. Prof. dr. Mess, beste Werner, ik wil je bedanken voor de mogelijkheid, die je mij hebt gegeven om binnen jouw groep een promotieonderzoek te doen. En natuurlijk voor de 250 echo's die je deels in je lunchpauze maakte.

Dr. Weber, beste Wim, dank voor de plezierige samenwerking en de vele uren die je met me hebt doorgebracht om het onderzoek en de artikelen vorm te geven.

Dr. van Kroonenburgh, beste Marinus, jou wil ik graag bedanken voor de inspiratie en steun, die je me in de loop der jaren getoond en gegeven hebt.

Dr. Tromp, beste Selma, het kritisch lezen van een manuscript is een hele klus. Door jouw inzet is het mooi geworden. Wellicht is dit het enige hoofdstuk dat aan je scherpe blik is ontkomen.

Dr. Winogrodzka, dr. Weber, dr. Vreeling en dr. Anten, jullie maken de voortzetting van het onderzoek mogelijk door de klinische herbeoordeling van de 250 patiënten voor jullie rekening te nemen. Een grote klus, waarvoor ik veel waardering heb.

De Sittardse neurologen, drs. Rooyer, drs. Morré, drs. Triebels, dr. Anten en dr. Ter Berg wil ik bedanken voor hun ondersteuning bij de inclusie van de onderzoekspatiënten. In het bijzonder drs. Wuisman en Rosie Hubens-Hustinx voor het maken van de echo's in Sittard.

Drs. ir. Kessels, beste Fons, hartelijk dank voor de ondersteuning bij de statistiek.

De leden van de leescommissie, prof. dr. Vles, prof. dr. Steinbusch, prof. dr. Verhey, prof. dr. Berg en prof. dr. van Laere. Ik wil u bedanken voor het kritisch lezen van mijn proefschrift en het plaatsnemen in de leescommissie.

Mede onderzoekers. Tjerk en Jan-Dirk, hartelijk dank voor jullie hulp bij het doornemen van statussen en het invallen bij het scoren van patiënten. Angela erg fijn, dat jij het onderzoek vol gedrevenheid hebt overgenomen.

Secretaressen en laboranten op de afdeling KNF en nucleaire geneeskunde in Maastricht en Sittard. Het was passen en meten om alle patiënten hun onderzoeken te geven, maar het is gelukt! Ik heb waardering voor jullie vriendelijke hulp en betrokkenheid. 
Tiny, je hulp in de slotfase van dit proefschrift is onmisbaar geweest. Door jouw inzet is het een afgerond geheel geworden.

Een speciaal woord van dank gaat uit naar mijn paranimfen. Marjanke, jouw enthousiasme heeft me over veel strepen getrokken, ook over die van het doen van onderzoek. Monique (en Patrick), jullie zijn fantastisch. Samen hebben we veel beleefd en hier gaan we mee door. Fijn dat jullie mijn paranimf willen zijn.

Zowel binnen als buiten het werk een goede band met je collega's hebben, is waar de neurologie in Maastricht voor staat. Alle assistenten neurologie en neurologen wil ik dan ook via deze weg bedanken. Hilde, Yvonne, Nienke, Manuela en Monique onze wekelijkse eetafspraakjes zijn bijna een reden om in het zuiden te blijven.

Jorrit, fijn dat je het promoveren hebt ondersteund. Straks meer laptop-vrije tijd samen. Ouders, broers, schoonzussen, Sebastiaan en Isabelle, met jullie sluit ik mijn dankwoord af. Door jullie steun en vertrouwen, heb ik me kunnen ontwikkelen tot de persoon, die ik nu ben en dat is meer dan een gepromoveerd aanstaand neuroloog, want ach.... zo'n titel is maar bijzaak. Bedankt! 
Curriculum Vitae

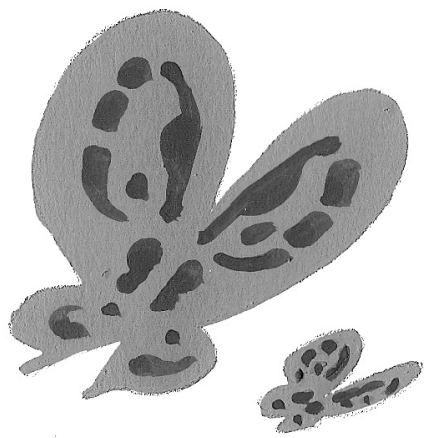




\section{Curriculum Vitae}

Annemarie Vlaar is op 26 december 1978 geboren te Amsterdam.

$\mathrm{Na}$ het VWO aan het Pius X college in Almelo studeerde zij geneeskunde aan de Rijksuniversiteit in Groningen. Naast haar studie verrichtte zij onder leiding van prof. dr. B. Meyboom-de Jong wetenschappelijk onderzoek naar zelfzorg bij patiënten, die een herseninfarct hadden doorgemaakt.

Voor haar doctoraal scriptie deed zij onderzoek bij prof. dr. D.T. Wade in het Rivermead Revalidatiecentrum in Oxford, UK, naar de betrouwbaarheid van bestaande cognitieve en motorische testen bij patiënten met multiple sclerose.

$\mathrm{Na}$ het doctoraal examen volgde zij haar coschappen in het Medisch Spectrum Twente in Enschede. Tussentijds liep zij aanvullende klinische stages in Estland, Malta, India en China. Het keuzecoschap neurologie deed zij bij dr. G. de Jong in het ziekenhuis De Weezenlanden te Zwolle.

Vanaf december 2003 is Annemarie in opleiding tot neuroloog in het Maastricht Universitair Medisch Centrum met als opleiders prof. dr. M. Limburg en dr. M.C.T.F.M. de Krom. Tijdens de opleiding werd onder leiding van dr. W.E.J. Weber, dr. S.C. Tromp, dr. M.J.P.G. van Kroonenburgh en prof. dr. W.H. Mess wetenschappelijk onderzoek verricht met dit proefschrift als resultaat.

In het laatste jaar van haar opleiding heeft zij een stage bewegingsstoornissen gevolgd in het Universitair Medisch Centrum Nijmegen onder leiding van prof. dr. B.R. Bloem, dr. B.P. van de Warrenburg en dr. R.A. Esselink.

In december 2009 hoopt Annemarie haar opleiding tot neuroloog af te ronden. 